\title{
Insights into Nurses' Work: Exploring Relationships among Work Attitudes \& Work-related Behaviours
}

by

Tyrone A. Perreira

A thesis submitted in conformity with the requirements

for the degree of Doctor of Philosophy

Institute of Health Policy, Management and Evaluation University of Toronto

(C) Copyright by Tyrone A. Perreira 2016 


\title{
Insights into Nurses' Work: Exploring Relationships among Work Attitudes \& Work-related Behaviours
}

\author{
Tyrone A. Perreira \\ Doctor of Philosophy \\ Institute of Health Policy, Management and Evaluation \\ University of Toronto
}

2016

\section{Abstract}

Work motivation has been associated with work productivity. In health care, low motivation levels are associated with low productivity and linked to poor performance, decreased patient safety, and overall poor quality care. Hence the importance, ascribed in the literature, to clearly identifying the relationships between and among factors associated with work motivation, including work attitudes, and behaviours linked to work performance such as extra-role behaviours. Despite their importance to performance in health care, these relationships are understudied and poorly understood. The purpose of this study is to better understand work attitudes and their relationships to one another and to extra-role behaviours amongst nurses working in hospitals, the community, and long-term care settings in Ontario. This study comprises two stages: first, a scoping review focused on identifying individual-, unit-level, and organization-level characteristics that influence work motivation in health service organizations. The findings from the scoping review, augmented by a more in-depth review of the literature, aided in the development of a conceptual framework that guided the second stage of the study, to examine relationships amongst a specific set of nurses' work attitudes - including perceptions of organizational justice, perceived organizational support, and affective commitment - and extra- 
role behaviours - specifically, organizational citizenship behaviours - in Ontario health care settings. In the second stage of the study, a survey was developed and administered to frontline nurses actively working in hospitals, the community, and long-term care settings in Ontario. Relationships amongst the constructs of interest were examined using structural equation modeling and path analysis. Examining the relationships of these concepts in a single model is novel, and offers insights regarding their complexity. The analyses further suggest that prior studies may be under-nuanced, and approaches to conceptualizing the concepts of perceived organizational justice and affective commitment in particular may have led to erroneous conclusions regarding their associations with perceived organizational support and organizational citizenship behaviours. This study further addresses four significant gaps previously identified in the work motivation and work behaviour literature: (1) how affective commitment relates to behavioural efforts, specifically organizational citizenship behaviours; (2) utilization of reliable and validated instruments to study work motivation; (3) use of a sufficiently large sample to have empirical support for generalizability; and (4) examination of these phenomena, among nurses, across diverse health care settings.

Keywords: work attitudes, organizational justice, perceived organizational support, affective commitment, organizational citizenship behaviours, structural equation modeling, path analysis 


\section{Acknowledgments}

A sincere thanks to my exemplary supervisor Whitney Berta, for her kindness, patience, and guidance. To my committee members Jan Barnsley and Liane Ginsburg, a special thanks for your insightful comments and positive attitude. My thanks to Ann Tourangeau and Rhonda Cockerill for your input and critique. To my external examiner, Greta Cummings, thank you for challenging me. I owe thanks to Irmajean Bajnok and the RNAO for their commitment to this project. Laure Perrier, Jennifer Innis and Monique Herbert, you have become dear friends; thanks for helping to make this an incredible experience. Lynn Christie, Jon Rowan, Romain and Sean Perreira, thank you for believing in me. A heartfelt thanks to my partner and best friend Travis Wingate for his unyielding support, encouragement, and motivation. Without you, this would not have been possible. You believe in me, you inspire me, you keep me grounded. Mom and dad, we did it! 


\section{Table of Contents}

Acknowledgments.................................................................................................................... iv

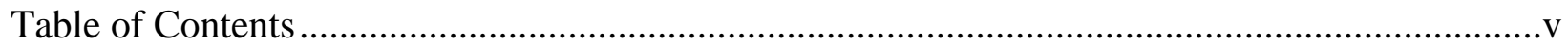

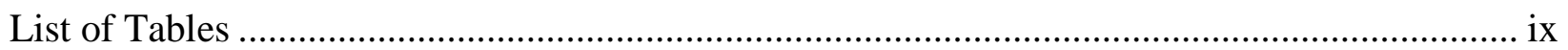

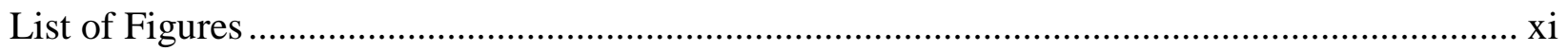

List of Appendices ................................................................................................................ xiiii

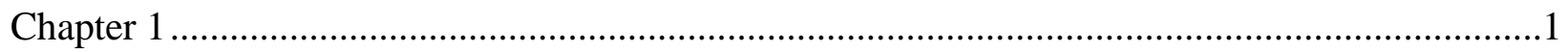

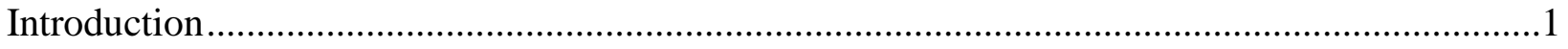

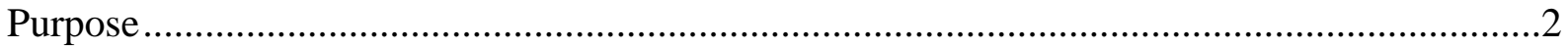

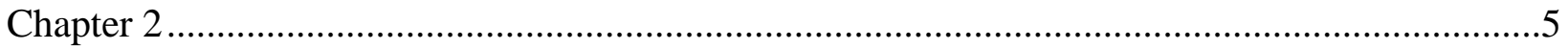

Scoping Review Methods .......................................................................................................

Study Design, Publication Status, Time Period .....................................................................

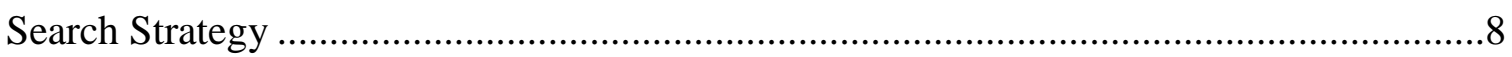

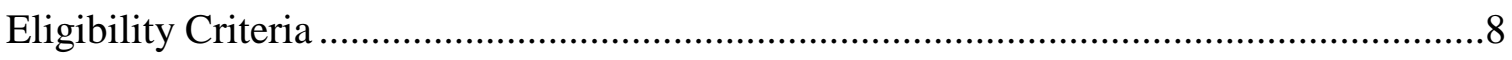

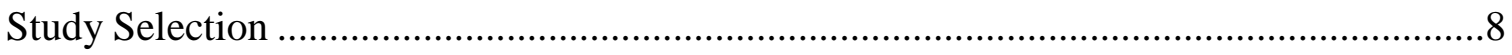

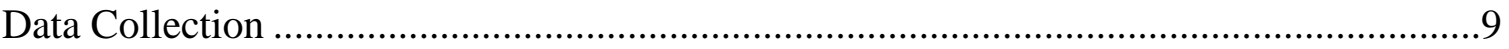

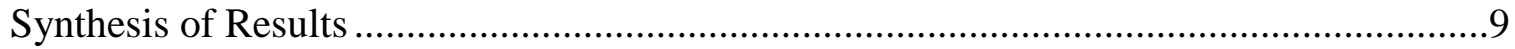

Work Motivation Literature (2005 - present): Results .................................................................

Individual- and Unit- Level Characteristics Influencing Work Motivation .......................10

Gaps in the individual- and unit- level literature..............................................................11

Organization-Level Characteristics Influencing Work Motivation .....................................11

Gaps in Organization-Level Literature ............................................................................12

Gaps in Work Motivation Research Methodology ………...............................................12

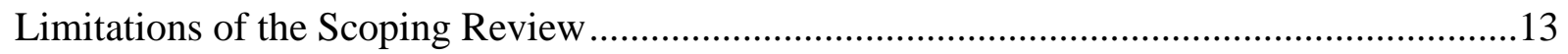

Scoping Review Conclusions...............................................................................................13 


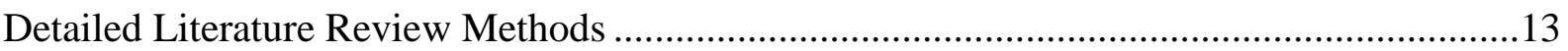

Study Design, Publication Status, Time Period ......................................................................13

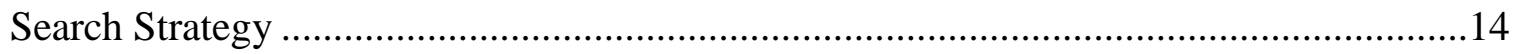

Development of Conceptual Framework \& Propositions ..............................................................14

Extra-Role Organizational Citizenship Behaviours............................................................17

Factors that Influence Extra-Role Organizational Citizenship Behaviours........................19

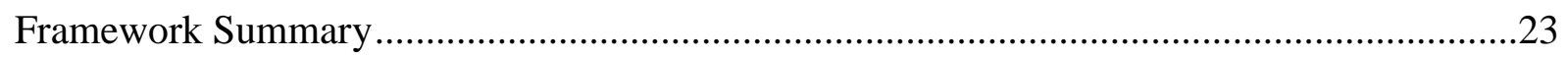

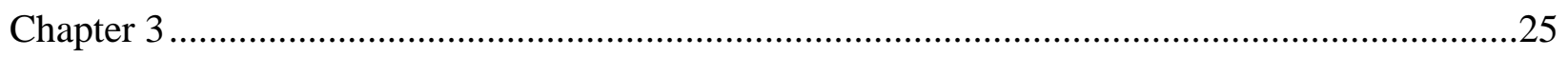

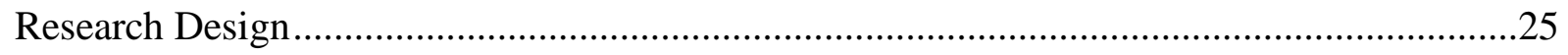

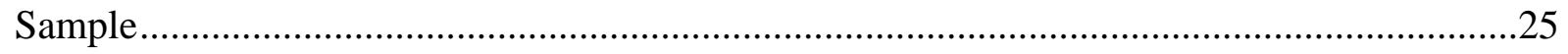

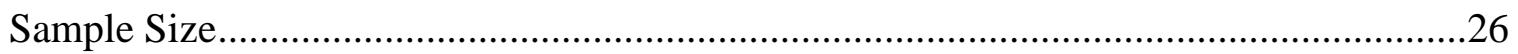

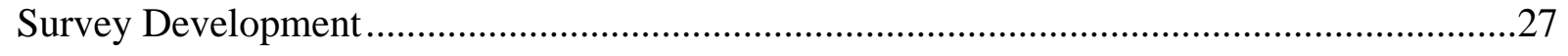

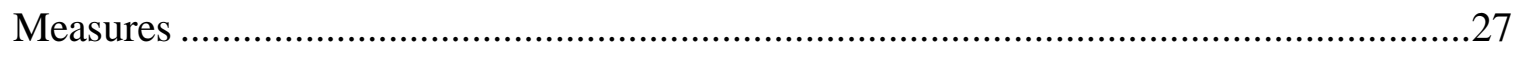

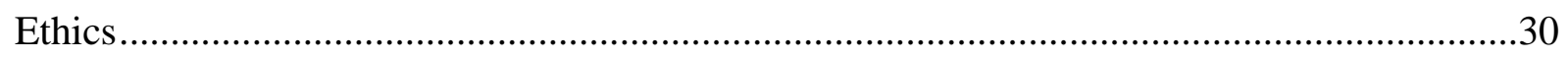

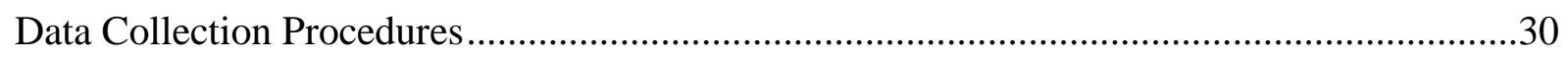

Data Cleaning: Preparation and Screening ...........................................................................

Statistical Assumptions Underlying Structural Equation Modeling...................................33

Confirmatory Factor Analysis...............................................................................................34

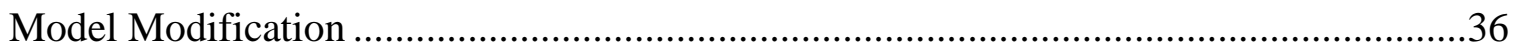

Reliability for Latent Constructs..................................................................................36

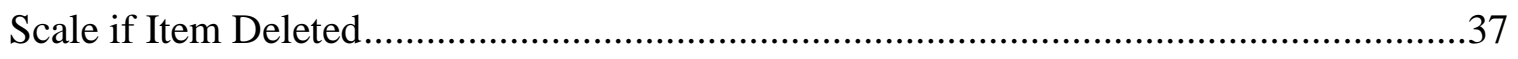

Corrected Item-Total Correlation ..................................................................................37

Cronbach’s Alpha if Item Deleted ..................................................................................

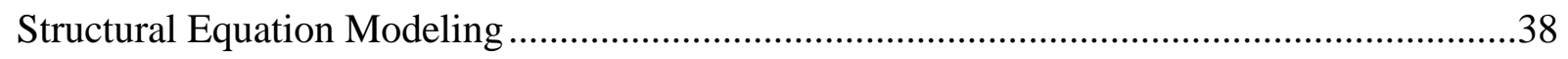

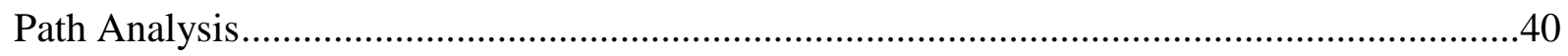


Statistical Assumptions Underlying Path Analysis.

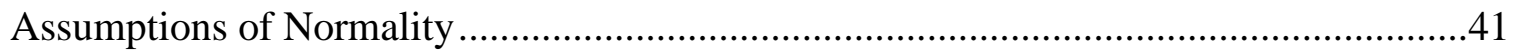

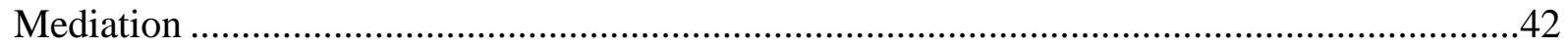

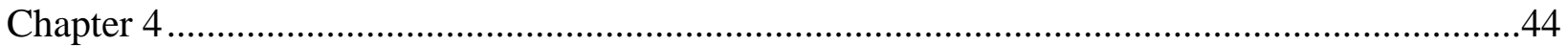

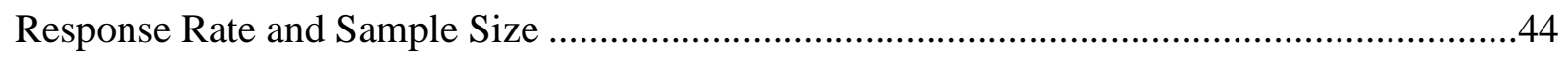

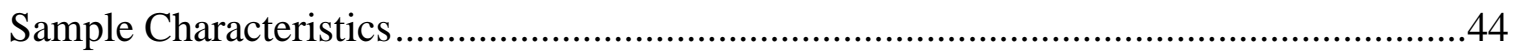

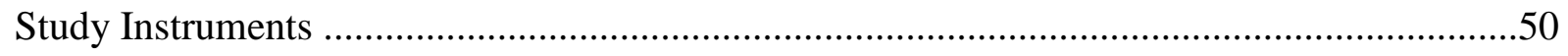

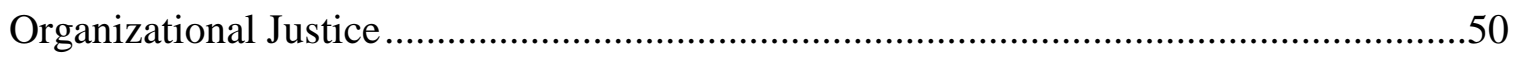

Perceived Organizational Support (POS) ...............................................................53

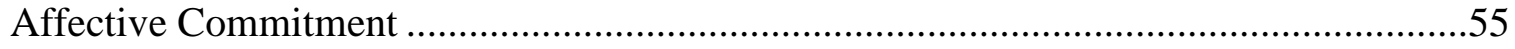

Organizational Citizenship Behaviour (OCB) .......................................................59

Measurement Models and Reliability ........................................................................60

Confirmatory Factor Analysis for Perceived Organizational Justice ............................60

Confirmatory Factor Analysis for Perceived Organizational Support............................66

Confirmatory Factor Analysis for Affective Commitment.........................................68

Confirmatory Factor Analysis for Organizational Citizenship Behaviour ......................74

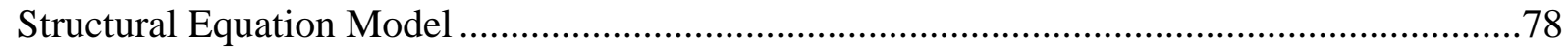

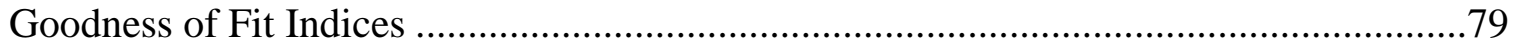

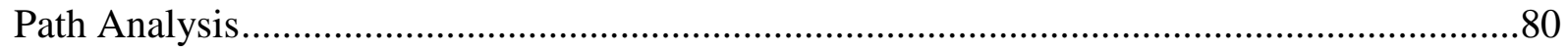

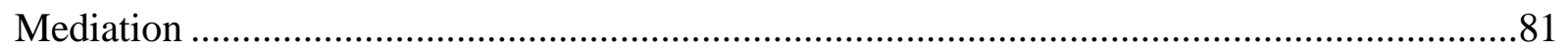

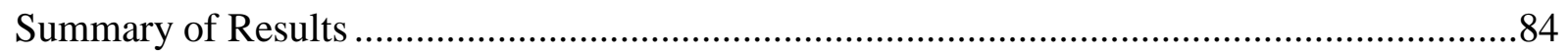

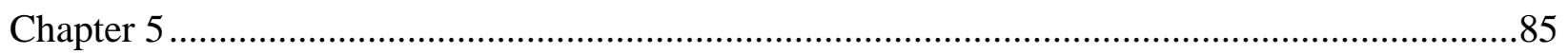

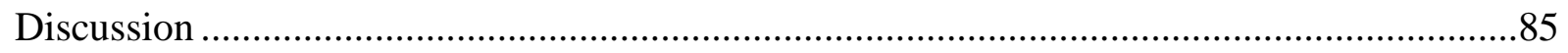

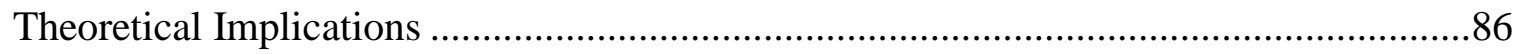

Practical Implications for Nurse Managers and Leadership ......................................97 
Implications for the Definition of Work Motivation ..............................................100

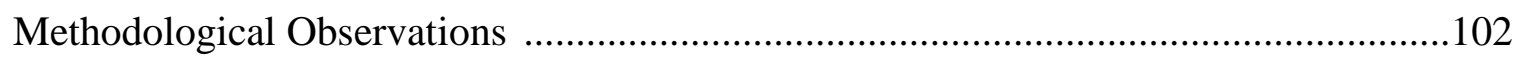

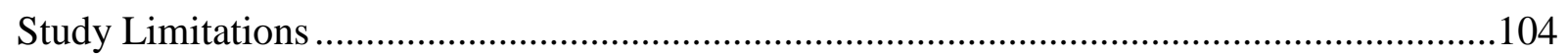

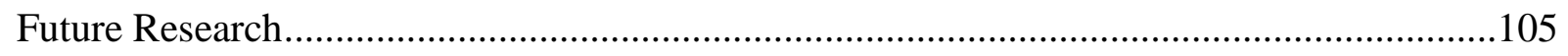

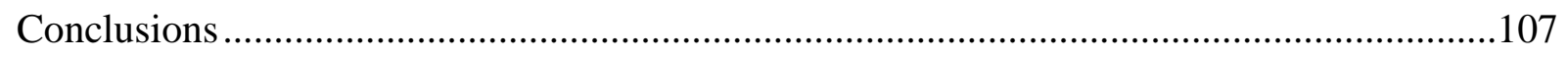

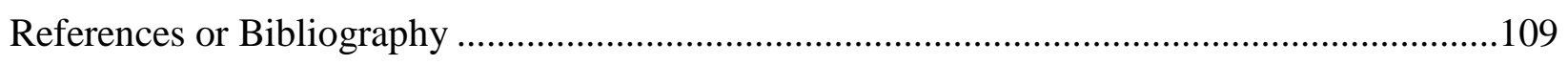

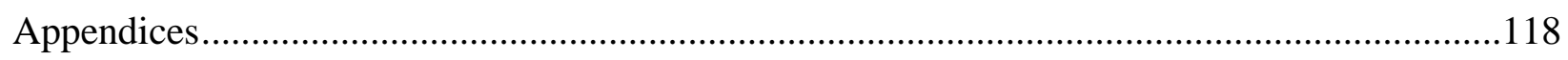

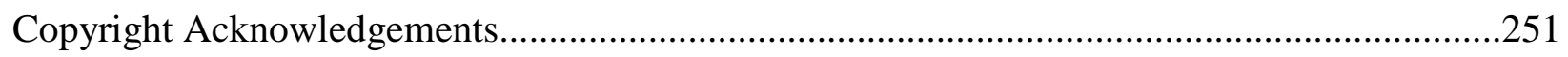




\section{List of Tables}

Table 2.1. Sample of Common Dyadic Relationship ........................................................... 28

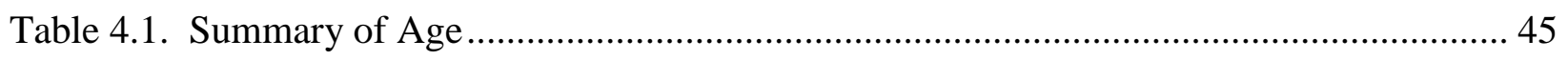

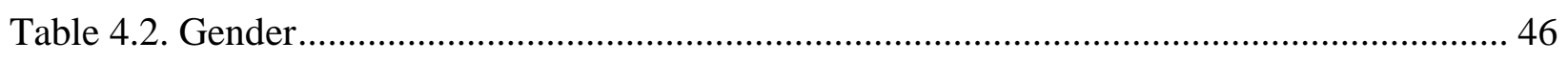

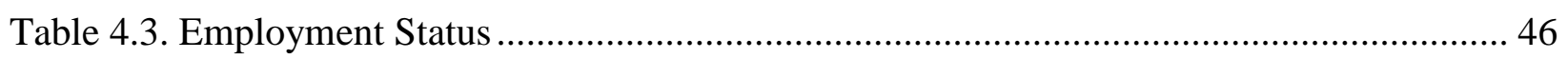

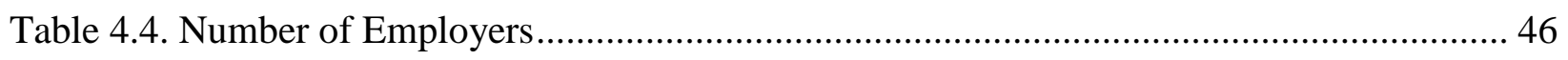

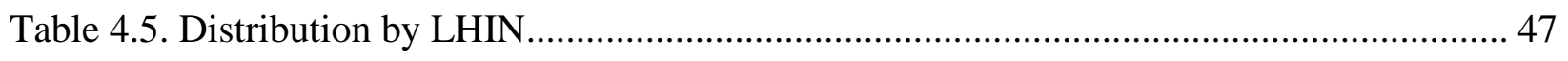

Table 4.6. Additional Respondent Characteristics.............................................................. 48

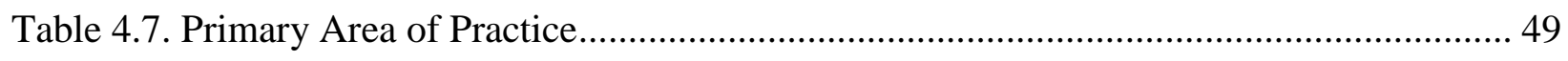

Table 4.8. Years of Experience and Employment Characteristics............................................ 49

Table 4.9. Descriptive Statistics for Instruments .................................................................. 51

Table 4.10. Distributive Justice Frequencies .......................................................................... 51

Table 4.11. Procedural Justice Frequencies ...................................................................... 52

Table 4.12. Interpersonal Justice Frequencies .................................................................... 52

Table 4.13. Informational Justice Frequencies ................................................................... 53

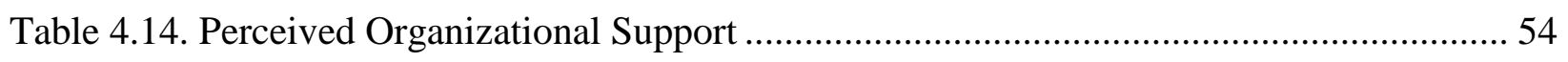

Table 4.15. Frequency Distribution - Affective Commitment to the Organization..................... 55

Table 4.16. Frequency Distribution - Affective Commitment to Supervisor ............................. 56

Table 4.17. Frequency Distribution - Affective Commitment to Co-workers............................ 56

Table 4.18. Frequency Distribution - Affective Commitment to Patients ................................. 57

Table 4.19. Frequency Distribution - Affective Commitment to Profession............................. 57

Table 4.20. Frequency Distribution - Affective Commitment to Work ................................... 58

Table 4.21. Frequency Distribution - Affective Commitment to Tasks .................................... 58

Table 4.22. Frequency Distribution - Affective Commitment to Career.................................... 59

Table 4.23. Organizational Citizenship Behaviours to Individuals (OCBI) .............................. 59

Table 4.24. Organizational Citizenship Behaviours to the Organization (OCBO)..................... 60

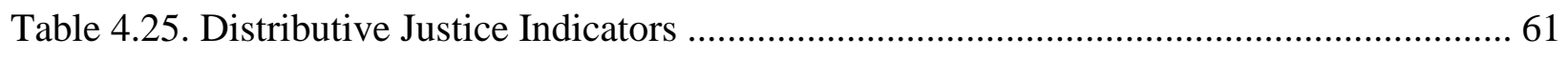

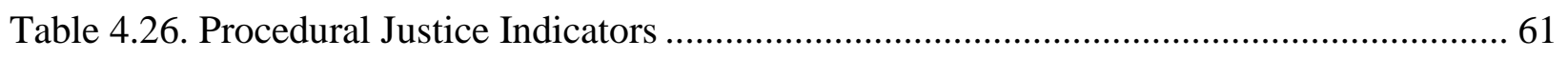

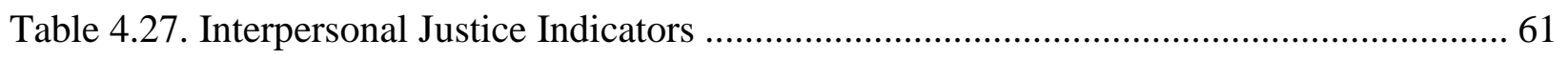

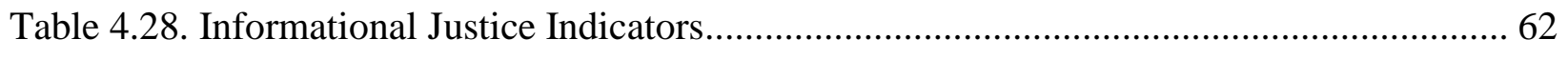

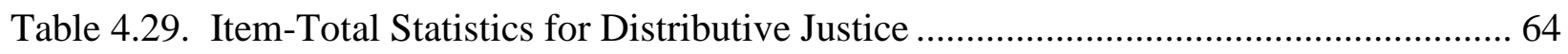

Table 4.30. Item-Total Statistics for Procedural Justice ....................................................... 64 
Table 4.31. Item-Total Statistics for Interpersonal Justice ................................................... 65

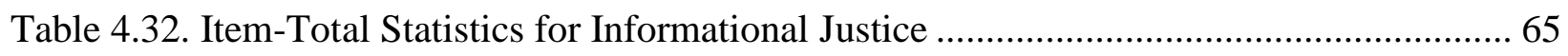

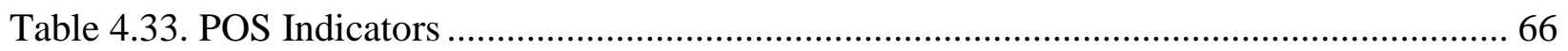

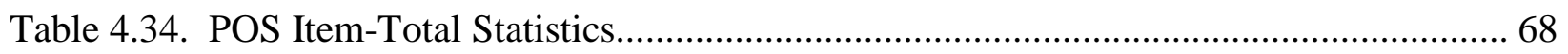

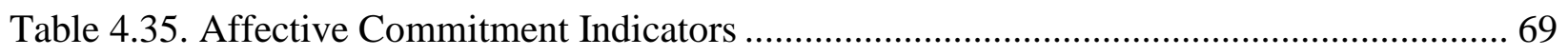

Table 4.36. Item-Total Statistics for Affective Commitment to their Organization.................... 71

Table 4.37. Item-Total Statistics for Affective Commitment to their Supervisor ...................... 71

Table 4.38. Item-Total Statistics for Affective Commitment to their Co-workers...................... 72

Table 4.39. Item-Total Statistics for Affective Commitment to their Patients............................ 72

Table 4.40. Item-Total Statistics for Affective Commitment to their Profession........................ 73

Table 4.41. Item-Total Statistics for Affective Commitment to their Work .............................. 73

Table 4.42. Item-Total Statistics for Affective Commitment to Tasks Performed...................... 73

Table 4.43. Item-Total Statistics for Affective Commitment to their Career............................. 74

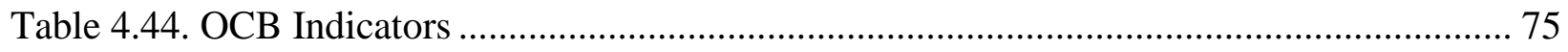

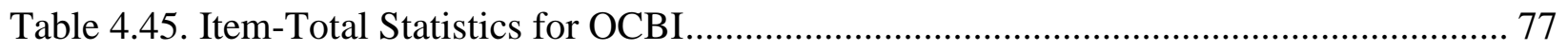

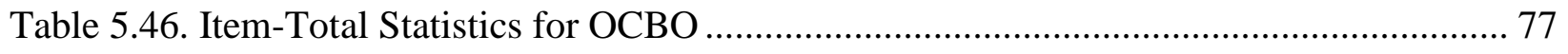

Table 4.47. Summary Goodness of Fit Indices \& Internal Reliability .................................... 78

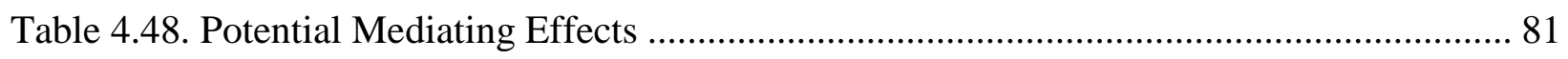

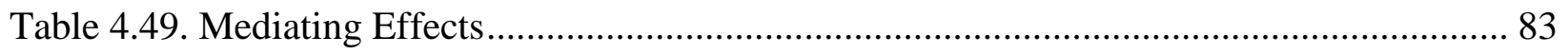




\section{List of Figures}

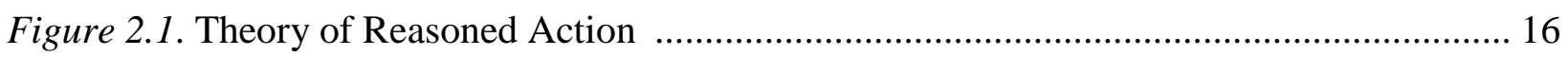

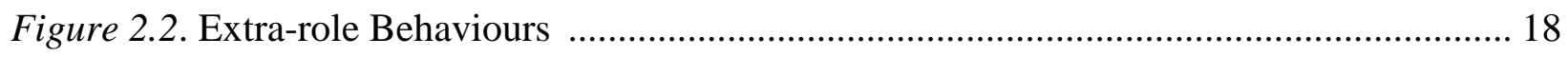

Figure 2.3. Affective Commitment Influences Extra-role Behaviours ........................................ 20

Figure 2.4. Perceived Organizational Support Influences Affective Commitment ...................... 21

Figure 2.5. Organizational Justice Influences Perceived Organizational Support ........................ 23

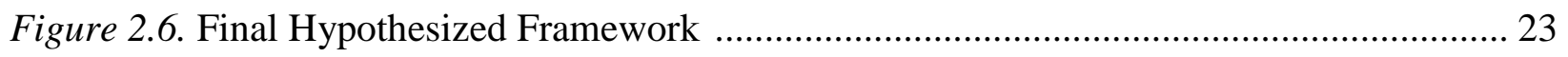

Figure 3.1. Final Hypothesized Framework ................................................................................ 38

Figure 4.1. CFA Path Diagram for Organizational Justice. ……………………………............ 62

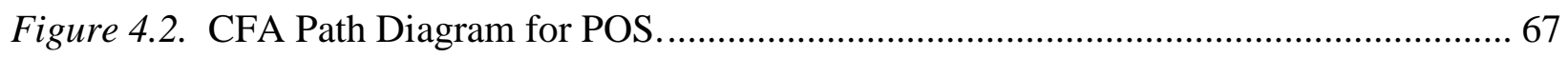

Figure 4.3. CFA Path Diagram for Affective Commitment........................................................ 70

Figure 4.4. CFA Path Diagram for OCB................................................................................... 76

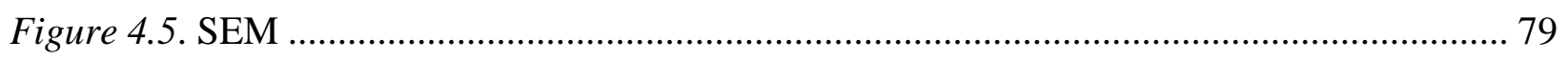

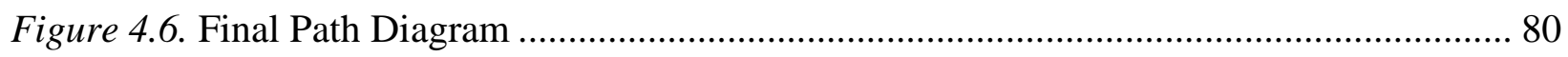

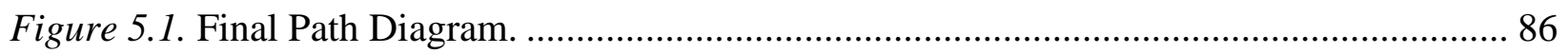

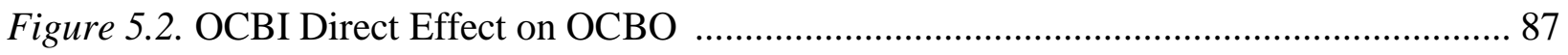

Figure 5.3. Affective Commitment and OCB Relationships........................................................ 89

Figure 5.4. Relationships amongst Affective Commitment Targets ........................................... 91

Figure 5.5. Direct Effect of Justice Constructs on POS _............................................................. 92

Figure 5.6. Direct Effect of POS on Affective Commitment Targets ......................................... 92

Figure 5.7. Direct Effect of Justice on Affective Commitment Targets ..................................... 93

Figure 5.8. Relationships between Justice, POS, and Affective Commitment ........................... 94

Figure 5.9. Relationships amongst Organizational Justice Constructs .......................................... 96 


\section{List of Appendices}

Appendix A. Work Motivation - Chronological Summary and Key Findings up until 2005 .... 119

Appendix B. Electronic Search Strategy - PsychINFO ........................................................ 133

Appendix C. Consort Screening Flow Diagram ............................................................ 134

Appendix D. Data Abstraction Chart.............................................................................. 135

Appendix E. Conceptual Framework - Characteristics Influencing Motivation....................... 153

Appendix F. RNAO Interest Groups Included in Study ................................................... 154

Appendix G. Organizational Behaviour Scale ............................................................... 155

Appendix H. Workplace Affective Commitment Multidimensional Questionnaire (SHORT).... 156

Appendix I. WACMQ - Modifications for Use in Health Care .............................................. 160

Appendix J. Organizational Justice Scale ...................................................................... 162

Appendix K. Perceived Organizational Support Questionnaire ........................................... 163

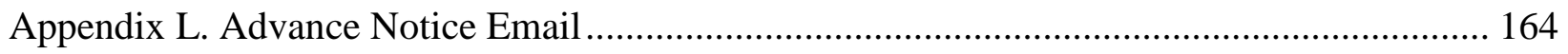

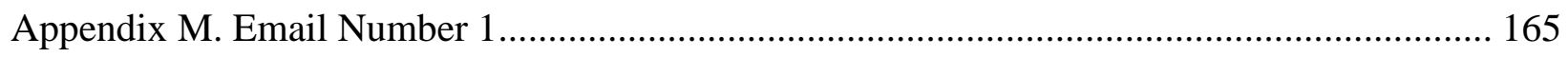

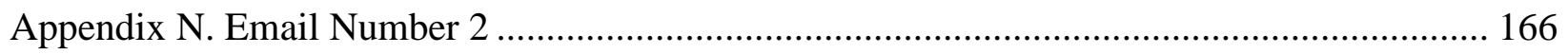

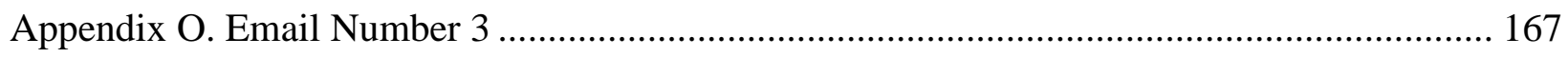

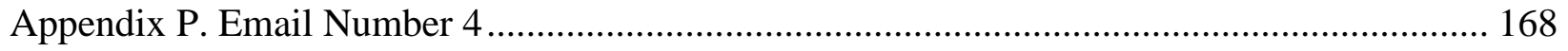

Appendix Q. Model Modification.................................................................................. 169

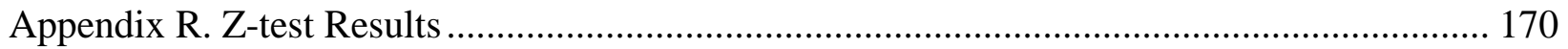

Appendix S. Univariate Summary Statistics.................................................................. 186

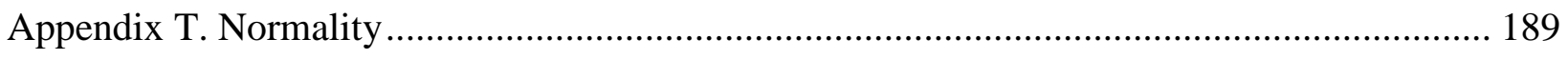

Appendix U. Correlation Matris for Justice Measures ...................................................... 220

Appendix V. Corrlation Matrix for Justic Independent Variables......................................... 221

Appendix W. Model Misspecification for Justice Measures ................................................ 222 
Appendix X. Correlation Matrix for POS Measures …........................................................ 224

Appendix Y. Model Misspecification for POS Measures ..................................................... 225

Appendix Z. Correlation Matrix for Affective Commitment ................................................. 226

Appendix AA. Correlation Matrix for Affective Commitment Independent Variables ............. 227

Appendix BB. Model Misspecification for Affective Commitment ..................................... 228

Appendix CC. Correlation Matrix for OCB .................................................................... 229

Appendix DD. Correlation Matrix for OCB Independen Variables ....................................... 230

Appendix EE. Model Misspecification for OCB ................................................................ 231

Appendix FF. SEM Correlation Matrix …..................................................................... 232

Appendix GG. SEM Measurement Equations ............................................................... 237

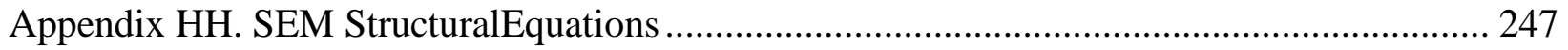

Appendix II. Path Analysis Correlation Matrix .............................................................. 248

Appendix JJ. Path Analysis Structural Equations ............................................................ 249 


\section{Chapter 1}

\section{Introduction}

Recent changes to health care settings in Canada (Alameddine, Baumann, Laporte, \& Deber, 2012) present nurse managers with new challenges including decentralized decision-making, increased demands for accountability, and enlarged spans of control in work environments. Decreasing numbers of practicing nurses and concurrent increased workloads are expected to lead to a shortfall of nurses by 2016 (Wilson, Squires, Widger, Cranley, \& Tourangeau, 2008). The impacts of these work conditions on nurse managers and nursing staff are understudied; however, the literature in organizational behaviour would suggest that these conditions are likely to negatively impact work attitudes and, by association, positive work-related behaviours related to work performance.

Work motivation is defined as a set of energetic forces that originate within and outside of an individual's being, to initiate work-related behaviour, and to determine its form, direction, intensity, and duration (Pinder, 2008). To clarify, work motivation is an overarching concept comprised of energetic forces which can be either internal or external. Internal forces include work attitudes, defined as positive or negative evaluations about aspects of one's work environment, e.g., perceptions of organizational justice or organizational support (O'Reilly, 1991). External forces consist of characteristics of the work environment e.g., the nature of work being performed or the style of leadership (Pinder, 2008). My interests lie in internal forces, specifically work attitudes. A number of studies have shown important linkages between internal forces - work attitudes specifically - and work-related behaviours (Greenberg, 2009; Lavelle et al., 2009; Mathieu \& Zajac, 1990; Moorman, Blakely, \& Niehoff, 1998; Organ, 1988; Solinger, van Olffen, \& Roe, 2008; Suliman \& Kathairi, 2013). In health care settings, work motivation has been shown to be directly related to organization-level performance including productivity, patient safety, and overall quality care (Chandler, Chonya, Mtei, Reyburn, \& Whitty, 2009). Hence, it is important

to clearly identify factors that motivate behaviours and impact behaviour outcomes that are in line with organizational goals. While these linkages have been established in disparate studies, a coherent understanding of the inter-relationships amongst employee work attitudes and work- 
related behaviours in health care settings has yet to be established. Further, there is a paucity of literature evaluating the link between work attitudes and work-related behaviours in nursing practice. With a focus on nurses, I evaluate extra-role work-related behaviours in health care and how they are influenced by work attitudes.

\section{Purpose}

The purpose of this study is to better understand work attitudes and their relationships to one another and to extra-role behaviours amongst nurses working in hospitals, the community, and long-term care settings in Ontario. The focus is on a set of work attitudes and work-related behaviours shown to relate to work motivation in the health services literature (Chu, Lee, Hsu, \& Chen, 2005; Dargahi, Alirezaie, \& Shaham, 2012; Lee \& Allen, 2002) and in the organization studies literature (Greenberg, 2009; Lavelle, 2007; Lavelle et al., 2009; Mathieu \& Zajac, 1990; Morin et al., 2011; Rhoades, Eisenberger, \& Armeli, 2001; Rupp \& Cropanzano, 2002; Solinger et al., 2008). Specifically, I examine the relationships amongst three distinct work attitudes: perceived organizational justice, perceived organizational support, and affective commitment and a form of extra-role work behaviour referred to as organizational citizenship behaviours.

Organizational justice refers to the study of people's perceptions of fairness in organizations (Greenberg, 1987). The importance of an association between a just and fair culture and the role of nurse leaders have been emphasized in safety literature. In health services research, perceived injustice is reportedly associated with poor job performance and lower perceptions of the quality of patient care (Faulkner \& Laschinger, 2008).

Human behaviours - whether constructive or destructive - are directed toward a target (Solinger et al., 2008). In a work setting, the chief target for workers' behaviours is generally assumed to be the organization in which they work (Solinger et al., 2008). Organization scientists refer to this orientation as workers' organizational commitment, or affective commitment - or emotional attachment - to their workplace (Mowday, 1982; Solinger et al., 2008). The process by which commitment develops and manifests as behaviour has not been well researched in any work setting; there is limited understanding of the commitment process (i.e., how commitment builds, 
or declines) and the cognitive, emotional, and behavioural components of the commitment attitude that is expressed as target-directed behaviours (Solinger et al., 2008). Commitment has been found to be positively associated with workplace behaviours which affect organizational effectiveness and performance (Choi, 2007; Organ, 1988; Podsakoff, MacKenzie, Paine, \& Bachrach, 2000).

Perceived organizational support (POS) is defined as an employee's belief that their work organization cares about their well-being and values their contribution (Rhoades \& Eisenberger, 2002). The behaviour literature suggests that POS has been found to play an antecedent role in the commitment process and acts as a mediator between organizational justice and affective commitment (Rhoades et al., 2001).

In this study I focus on a particular form of work behaviour, organizational citizenship behaviours (OCBs). OCBs refer to discretionary, extra-role behaviours that promote the effective functioning of the organization, and are not directly or explicitly recognized by a formal reward system (Organ, 1988). OCBs were selected as they have most consistently and strongly been shown to be associated with work attitudes (Greenberg, 2009; Lavelle et al., 2009; Mathieu \& Zajac, 1990; Moorman et al., 1998; Organ, 1988; Solinger et al., 2008; Suliman \& Kathairi, 2013).

There are numerous studies that establish dyadic relationships amongst (some of) these concepts in the empirical literature (Beugre, 1997; Greenberg, 1994, 2009; Lavelle et al., 2009; Loi, HangYue, \& Foley, 2006; McNabb, 2009; Moorman et al., 1998; Motlagh, Yarmohammadian, \& Yaghoubi, 2012; Organ, 1988, 1990; Rhoades et al., 2001; Solinger et al., 2008; Suliman \& Kathairi, 2013), however the inter-relationships amongst them is poorly understood and underexplored. Our limited understanding of the nuances of these relationships - that is, the subtle ways in which these complex concepts interrelate - limits our ability to develop strategies to positively influence work-related behaviours that in turn can influence work performance.

These concepts are understudied in health care generally, and are poorly understood as they pertain specifically to the nursing workforce. Investigating the work attitudes of nurses and how they relate to work-related behaviours may contribute to understanding about the concept of work 
motivation in nursing, add empirical evidence regarding factors that motivate nurses (Toode, Routasalo, \& Suominen, 2011), and aid in addressing key nursing human resource issues such as enhancing nursing recruitment, retention, satisfaction, and healthy work environments (Cummings et al., 2010; Price \& Mueller, 1986). Based on my review of extant research on work motivation, I developed and tested the inter-relationships among work attitudes and extra-role work-related behaviours in a comprehensive framework. In addition to affording insights into the complex inter-relationships amongst these concepts, this study addresses four significant gaps identified in the work motivation and organizational behaviour literature: (1) it examines how affective commitment is related to behavioural efforts, specifically organizational citizenship behaviours (Boezeman \& Ellemers, 2008); (2) it utilizes reliable and validated instruments (Toode et al., 2011); (3) it comprises a fairly large sample to have empirical support for generalizability (Ayupp \& Kong, 2010); and (4) by using a cross-sector design, it is generalizable to nurses actively working in hospitals, the community, and long-term care settings in Ontario, Canada (Park, 2010). 


\section{Chapter 2 Review of the Literature}

This chapter presents the results of a two-step literature review. A scoping review is first conducted, followed by an more detailed literature review. A scoping review is an approach to reviewing literature that provides a quick way of mapping fields of study where it is difficult to visualize the range of material that might be available (Arksey \& O’Malley, 2005). The purpose

of the scoping review in this study is to determine what is known from the extant literature about individual-, unit-, and organization-level characteristics that can and/or do influence work motivation. The focus of my thesis is on work attitudes and work-related behaviours. To ensure the greatest breadth, my scoping review was therefore conducted on work motivation, defined as a set of energetic forces that originate within and outside of an individual's being, to initiate workrelated behaviour (Pinder, 2008). Internal forces include work attitudes, while the external forces consist of characteristics of the work environment. The scoping review is used to help identify potential work attitudes that I can further examine using a detailed literature review.

\section{Scoping Review}

The concept of work motivation has been around for decades. Researchers have and are expending a lot of energy examining it. Despite its portrayal as a critical element of work and work performance, work motivation is not defined consistently, is not interpreted the same by different authors, and is rarely measured using the same techniques (Toode et al., 2011). Kleinginna \& Kleinginna (1981) reported and categorized over 140 definitions (Kleinginna Jr \& Kleinginna, 1981). Work motivation, for example, can be defined as an individual's degree of willingness to exert and maintain an effort towards organizational goals (p.13) (Franco, Bennett, \& Kanfer, 2002), or as the degree to which an individual wants and chooses to engage in certain specified behaviours (Mitchell, 1982).

Although there are numerous models, framework and theories of work motivation, there is no single absolute doctrine. This is in part because of the diversity of philosophical orientations 
toward the nature of human beings. Some believe behaviour stems from a physiological or subconscious perspective, while others feel it is goal oriented and the result of conscious choice processes. Common to many theories is the concept of intrinsic and extrinsic motivation. To help provide an overview of the vast amount of literature on this topic, a chronological summary of work motivation theories and key findings up until 2005 can be found in Appendix A. One of the most comprehensive definitions of work motivation is provided by Pinder (2008). In his book, he also discusses at length the complexity of the concept of work motivation and one's personally held philosophical beliefs regarding the nature of human beings and behaviour, so it is not surprising that confusion exists.

In an attempt to bring some clarity to the definition, Pinder (2008) defines work motivation as "a set of energetic forces that originate within and outside of an individual's being, to initiate workrelated behaviour, and to determine its form, direction, intensity, and duration” (p.11). It includes the concept of force, which allows for motivation levels to be either weak or strong, to vary between individuals at any particular time, and implies multiplicity of needs, drives, instincts and external factors. The definition implies the notion of movement and both internal (e.g., work attitudes) and external drivers (characteristics of the environment) of behaviour. It does not presume to be a general definition of human motivation, but rather the definition purports to deal with events and phenomena of work (Pinder, 2008). There is also no implication that motivation is the sole source of human or work behaviour. As Pinder points out, most critical is the feature that motivation is an invisible, internal concept, or 'hypothetical concept' representing an assumed physical process that is unobservable directly (p. 13). The definition entails direction toward which motivated force is focused, and incorporates intensity, defined as the momentary magnitude of actual motivational arousal (Pinder, 2008). The definition also takes into account behaviour patterns such as choice, persistence and continuing motivation. Finally, Pinder's definition incorporates duration, implying that goal attainment may be a possible outcome of behaviour.

Shared goals, linking employee goals and company goals, has been shown to reinforce work motivation (Ayupp \& Kong, 2010), where pursuing set goals reduces the negative effects of high demands (Tadic, Bakker, \& Oerlemans, 2013). High demands refer to jobs that are onerous, over- 
challenging, or require an unreasonable amount of effort. Negative effects of high demands can include stress, disengagement, and displeasure. As a result of the association made between work motivation and work performance, health services researchers suggest that investigating the factors that contribute to work motivation amongst nurses may provide valuable insights into the challenges facing health care institutions (Gaki, Kontodimopoulos, \& Niakas, 2013). I completed a scoping review to examine the extent, range, and nature of research activity in this area. This method of review is selected as it permits a rigorous and transparent method for mapping areas of research for a wide range of research designs and methodologies, and identification of specific research gaps in the existing literature (Arksey \& O’Malley, 2005).

The purpose of this scoping review is to determine what is known from the existing literature (theoretical and empirical) about work motivation in health service organizations. The specific objectives are to: (1) conduct a systematic search of the work motivation literature (organization and health services literature); (2) identify key individual- and unit-level characteristics, organization-level characteristics, and processes that influence an individual's work motivation; (3) identify gaps in the evidence base for research in health care (Arksey \& O'Malley, 2005); and (4) utilize both theoretical and empirical findings to develop a conceptual framework and inform a research study design that will address significant gaps within the work motivation and behaviour literature.

\section{Scoping Review Methods}

\section{Study Design, Publication Status, Time Period}

Articles published in English are included regardless of publication status, study design, and duration of trial. Articles are included if they were published between January 1, 2005 to March 28, 2014. This interval was chosen as prior literature was summarized in a review article by Latham and Pinder published in 2005 discussing the evolution of work motivation since a seminal article by Korman, Greenhaus, and Badin published in 1977 (Korman, Greenhaus, \& Badin, 1977; Latham \& Pinder, 2005). Refer to Appendix A for a chronological summary of work motivation theories and key findings up until 2005. 


\section{Search Strategy}

The following electronic databases were searched: Business Source Premiere, ProQuest, PsycINFO, MEDLINE, and CINAHL. These databases were searched on March 28, 2014 and retrieved $8,13,15,63$, and 81 studies respectively. No restrictions were placed on the search. The following search terms were used: work motivation. Appropriate wildcards were used in searches to account for plurals and variations in spelling. Additional articles were identified through reference lists and discussions with experts. Three experienced librarians (LP, DK, HI) were consulted regarding the search. An example of the literature search can be found in Appendix B. Searches used a combination of medical sub-headings (MeSH) and free text terms, with modifications as necessary for the other databases.

\section{Eligibility Criteria}

A study was included if it involved work motivation and included individual- and unit-level characteristics, organization-level characteristics and/or processes that influence work motivation. Only articles published in peer-reviewed journals are included. Grey literature was excluded. No restrictions are applied with respect to age, sex, race, educational status, specific population characteristics, government or private, status (casual, part-time, full-time, permanent, or contract), or country of origin.

\section{Study Selection}

Two reviewers (JI, TP) independently screened the results of the literature search. Prior to commencing the screening process, a calibration exercise was conducted to ensure reliability in correctly selecting articles for inclusion. This entailed independently screening a random sample of $5 \%$ of the included citations. Each citation, (title and abstract) generated by the literature search was screened by both reviewers independently using our pre-established eligibility criteria. The article needed to involve work motivation and individual- and unit-level characteristics, organization-level characteristics and/or processes that influence work motivation. Conflicts were resolved by discussion $(n=6)$. In the event that agreement could not be reached, the involvement 
of a third reviewer (WB) was sought $(n=34) .138$ full-text articles were reviewed, of which 96 were included in the study. The consort diagram is located in Appendix C.

\section{Data Collection}

A data abstraction form was tested independently by two reviewers on a random sample of 10 articles and revised iteratively, as needed. The data items, see Appendix D, included study and participant characteristics, e.g., first author, year of publication, country of origin, industry, major theory, population examined, sample size, whether it was theoretical or empirical, the methodology, and main findings. Major publications are sorted from companion reports (or duplicate publications).

\section{Synthesis of Results}

The results of the scoping review are synthesized descriptively to identify individual-, unit-, and organization-level characteristics associated with individual work motivation. The review also led to the identification of gaps in the evidence base and topic areas for future research. Analysis of the data, gleaned from the review, involved qualitative analysis.

\section{Work Motivation Literature (2005 - present): Results}

The literature is global, with authors from Europe, Asia, Africa, North and South America. Most of the studies are set in Europe or the United States, with a range of industries covered (i.e., pharmaceutical, health care, business, education, recreation, food, military, technology, manufacturing, retail, energy, policing, hospitality and tourism, organization and management, public, private and non-profit sectors). The predominant industries are health care and education. The majority of the studies were cross-sectional and consisted of self-reported questionnaires/surveys. Attitude surveys made generalizations to other organizations difficult as they are for the most part tailored to specific institutions. This data can be found in Appendix D, under the columns: Major Theories/Focus Area, Country of Origin, Industry, and Methodology. 


\section{Individual- and Unit- Level Characteristics Influencing Work Motivation}

A number of individual- and unit-level characteristics, or factors, have been shown to influence work motivation. Individual-level characteristics are endogenous. Examples of endogenous characteristics are work attitudes, defined as positive or negative evaluations about aspects of one's work environment (O'Reilly, 1991). Unit-level characteristics are exogenous to individual workers and are characteristics of the unit-level work environment that influence work motivation.

The most common individual- and unit- level characteristics identified in the scoping review that influence work motivation are organizational justice - feeling respected and valued (Dickin, Dollahite, \& Habicht, 2011; Greenberg, 2009; Kuvaas, 2006; Latham, 2005; Organ, 1988; Purohit, 2014; Sahoo, 2011; Suliman \& Kathairi, 2013) and affective commitment - the importance of (emotional attachment to) autonomy and/or supportive relationships (Dickin et al., 2011; Lavelle et al., 2009; Mathieu \& Zajac, 1990; Organ, 1988, 1990; Solinger et al., 2008). Additional characteristics identified include the need for acknowledgement (Tolli \& Schmidt, 2008); intrinsic rewards, a meaningful job, observing impacts (Dickin et al., 2011), security (Sahoo, Sahoo, \& Das, 2011), and preference for certain job characteristics (Bipp \& Kleinbeck, 2011). Other important motivators identified are: satisfied needs and values (Toode et al., 2011), and perceived behavioural control (Hinsz, Nickell, \& Park, 2007). Multi-industry studies from Africa, Asia, Europe, North and South America found motivation can be increased with task significance (Grant, 2008); variety, learning, skill acquisition, and working with preferred populations (Toode et al., 2011); job assignment where employees feel competent (Nafziger, 2011); and finally both income and job security (Haagh, 2011; Purohit \& Bandyopadhyay, 2014). Finally, work motivation is impacted by leadership characteristics, whether leaders are benevolent, moral, and/or charismatic (Jung \& Sosik, 2006; Niu, Wang, \& Cheng, 2009), affective commitment to one’s unit (Bard Kuvaas, 2006), clearly understood, important, achievable yet challenging tasks (Gaki et al., 2013), collaboration, co-worker and supervisor support, and salary (Chandler et al., 2009; Toode et al., 2011; Tsai, Chen, \& Liu, 2007). 
Gaps in the individual- and unit- level literature. A number of gaps are identified in the literature. Future research in work motivation, it is suggested, should focus on investigating: emotional bonds and personal attributes (Jung \& Sosik, 2006); individual characteristics, teams and effectiveness (Tremblay, Blanchard, Taylor, Pelletier, \& Villeneuve, 2010); measuring 'feelings' (Toode et al., 2011); moods and task performance (Tsai et al., 2007); perceptions versus reality (Von Bonsdorff, 2011); emotions and psychological empowerment (Wegge et al., 2010); health care worker motivation and incentives (Chandler et al., 2009); task design, emotional labour, and well-being; (Bhat \& Shah, 2010); matching job and personal resources (de Jonge, Le Blanc, Peeters, \& Noordam, 2008); targeted sampling; non-financial reward preferences; management practices; reward preferences; and subjective components of security (Sahoo et al., 2011). Several of the features identified in this section are once again captured by the concept of affective commitment, relating to moods, feeling, attitudes, and emotional attachment to a target - a person, object, place or thing selected as the aim.

\section{Organization-Level Characteristics Influencing Work Motivation}

Organization-level characteristics, or organization-level factors, also influence work motivation. The most common organization-level characteristic identified in this review is organizational support (Boezeman \& Ellemers, 2008; Dickin, Dollahite, \& Habicht, 2011; Gillet, Huart, Colombat, \& Fouquereau, 2013; Jakobsen \& Andersen, 2013; Wei Ting, Kou Hsien, Yi Ching, Chia Huei, \& Hui Chin, 2013). European and American studies (multi-industry) find work motivation is also enhanced by compatibility with others and teamwork (Gallie, Zhou, Felstead, \& Green, 2012); an organization’s mission (Wright, 2007); social networks (van Beek, Wagner, Frijters, Ribbe, \& Groenewegen, 2013), contact with beneficiaries (Grant et al., 2007); and training opportunities (Dysvik \& Kuvaas, 2008). Canadian, European, Indian and American studies (multiindustry) highlight contextual features that influence work motivation including: feedback (Bedny \& Karwowski, 2006); merit pay (Sung Min, 2010); performance linkage with rewards, remuneration and promotions (Dwivedula \& Bredillet, 2010); high emotional support (de Jonge et al., 2008); and job resources allowing basic psychological needs to be met (Fernet, Austin, \& Vallerand, 2012). Lower motivation levels are associated with shiftwork, rotations that include 
nights, and exhaustion (Toode et al., 2011). Workplace bullying, a form of workplace violence, also decreases performance and increases error (Yildirim, 2009). Many of these features are captured by the work-attitude concept of perceived organizational support (POS) which entails an employee's belief that their work organization cares about their well-being and values their contribution (Rhoades \& Eisenberger, 2002). POS has been identified as playing an antecedent role in the commitment process and acts as a mediator between organizational justice and affective commitment (Rhoades et al., 2001).

Gaps in the organization-level literature. Opportunities for further research include organizational commitment, culture, union status, effect of individual motivation on groups, and whether individual or group needs take priority (Lewis, 2011); varied work settings and cultures (Lewis, 2011); organizational identification; more organizational variables (Bhat \& Shah, 2010); team work (Gallie et al., 2012); beneficiaries (Grant et al., 2007); private versus public sector (Negussie, 2012); motivators across sectors (Sung Min \& Word, 2012); and the development of hierarchical models of motivation (Wei Ting, Kou Hsien, Yi Ching, Chia Huei, \& Hui Chin, 2013). Additional research on organizational commitment is required as recent work by Morin et al. (2011) disputes the former conceptualization of organizational commitment as an aggregate construct representing the sum of one's commitment to all possible 'constituencies' of an organization (Hunt \& Morgan, 1994; Morin et al., 2011).

Although only key individual-, unit- and organization-level characteristics are cited in this section, the sum of the results from the scoping review can be found in Appendix E.

\section{Gaps in Work Motivation Research Methodology}

With respect to the research conducted to date in this area, the most common concern identified is its lack of generalizability. Researchers underscore the importance, in future research, of: the use of larger samples, cross-national and cross-cultural testing (Jung \& Sosik, 2006; Park \& Rainey, 2012); empirical research testing generalizability (Gillet et al., 2013); social and religious components; more rigorous comparative and experimental designs, field, laboratory, situated experiments, mixed methods (Brewer \& Brewer, 2011; Fernet, Gagne, \& Austin, 2010); 
longitudinal studies (Von Bonsdorff, 2011); research from the organization's or employee's perspective (Buchner, 2007); and the use of validated instruments (Toode et al., 2011).

\section{Limitations of the Scoping Review}

The original literature search initially revealed more articles of supposed relevance than anticipated: over 7000 articles. Information specialists helped ensure the scope was appropriately technically described, and manageable. Only if the term 'work motivation' was utilized by authors, was the article identified. Due to the volume of literature, and varying writing styles, it was challenging to sometimes accurately categorize methods, theories, findings, and effect sizes, however best attempts were made to interpret, abstract and summarize findings.

\section{Scoping Review Conclusions}

The most common work attitudes identified in the scoping review, the internal forces of work motivation, are perceived organizational justice, perceived organizational support and affective commitment. In the next chapter, I augment the results of this scoping review with an in-depth review of organizational behaviour and health sciences literature to develop a comprehensive framework, by which to examine the relationships among perceived organizational justice, perceived organizational support, and affective commitment to different targets. Further, I address some of the identified gaps in methodology through my use of a large cross-sectoral sample, and reliable and validated survey instruments.

\section{Detailed Literature Review Methods}

\section{Study Design, Publication Status, Time Period}

Articles published in English are included regardless of publication status, study design, and duration of trial. Articles are included if they were published between January 1, 2005 to March 28, 2014, to coincide with the scoping review. 


\section{Search Strategy}

The following electronic databases were searched: Business Source Premiere, ProQuest, PsycINFO, MEDLINE, and CINAHL. These databases were searched on June 26, 2014 . No restrictions were placed on the search. The following search terms were used: organizational justice, perceptions of organizational support, affective commitment, organizational citizenship behaviour, extra-role behaviour. Appropriate wildcards were used in searches to account for plurals and variations in spelling. Additional articles were identified through reference lists and discussions with experts. Searches used a combination of medical sub-headings (MeSH) and free text terms, with modifications as necessary for the other databases.

\section{Development of Conceptual Framework \& Propositions}

Recall that the overarching aim of this study is to better understand work attitudes and their relationships to extra-role work-related behaviours amongst nurses working in hospitals, the community, and long-term care settings in Ontario.

The scoping review helped to identify three common work attitudes which influence work motivation (i.e. organizational justice, perceived organizational support, and affective commitment). A more in-depth review of the literature revealed common recurring dyadic relationships involving these three work attitudes and a common behaviour outcome, extra-role organizational citizenship behaviours, see Table 2.1. This more in-depth review also exposed a dearth of comprehensive theories that explain the relationships among work attitudes and their linkages to work-related behaviours. The theory of reasoned action (TRA) theory, depicted in Figure 2.1, is one theory that has been used in the organizational behaviour literature to predict work-related behaviours (Muse \& Stamper, 2007; Teh \& Yong, 2011; Williams \& Shiaw, 1999). This theory suggests that there are competing interests at play that must be taken into consideration when understanding factors which motivate behavioural intention - although work motivation is not made explicit in the theoretical framework. According to the TRA, attitudes and norms are the main predictors of behavioural intention. The TRA separates behavioural intention from behaviour, allowing for the explanation of attitudinal influence (Ajzen \& Fishbein, 1980). However, while reference is made to "attitudes”, these refer to attitudes about specific behaviours 
in TRA, not the more generalized feelings about work, or "work attitudes", discussed in prior chapters. For example, TRA would explore an individual's attitude about a specific behaviour (whether their attitude is positive or negative) and the norms that the individual perceives (i.e., based on their co-workers reactions and attitudes) about whether or not this behaviour would be a desirable thing to perform. In addition, the TRA is criticized for neglecting the importance of social factors (Werner, 2004), environmental influences which surround the individual (Ajzen, 1991).

\section{Table 2.1. Sample of Common Dyadic Relationship}

\begin{tabular}{|c|c|}
\hline Author & Sample Dyadic Relationships \\
\hline Organ 1988 & Organizational justice is positively related to Organizational citizenship behaviors (OCBs) \\
\hline Organ 1988 & Organizational commitment is positively related to OCBs \\
\hline Organ 1990 & Affective commitment is positively related to OCBs \\
\hline Greenberg 1994 & High levels interactional justice mitigate negative reactions to distributive justice \\
\hline Beugre 1997 & Organizational justice is positively related to affective organizational commitment \\
\hline Moorman 1998 & Procedural justice is an antecedent to POS \\
\hline Rhoades 2001 & Perceived organizational support (POS) leads to affective organizational commitment \\
\hline Rhoades 2001 & POS related and contributes to affective organizational commitment \\
\hline Loi 2006 & Procedural justice contributes to the development of POS \\
\hline Loi 2006 & Distributive justice contributes to the development of POS \\
\hline McNabb 2009 & Organizational justice is positively related to affective organizational commitment \\
\hline Greenberg 2009 & OCBs are related to perceptions of organizational justice \\
\hline Greenberg 2009 & Procedural justice enhances OCBs \\
\hline Greenberg 2009 & Procedural justice strongly predicts organizational commitment \\
\hline Greenberg 2009 & Procedural justice strongly predicts OCBs \\
\hline Solinger 2008 & low levels of commitment are likely associated with destructive and deviant behaviours \\
\hline Solinger 2008 & Organizational commitment is positively, significantly related to OCBs \\
\hline Lavelle 2009 & affective commitment is a strong predictor of extra-role OCBs \\
\hline Motlagh 2012 & Perceived organizational justice is related to work commitment \\
\hline Suliman 2013 & Interactional and procedural justice are strong independent predictors of OCBs \\
\hline Suliman 2013 & Interactional and procedural justice are strongly associated with affective commitment, \\
\hline
\end{tabular}




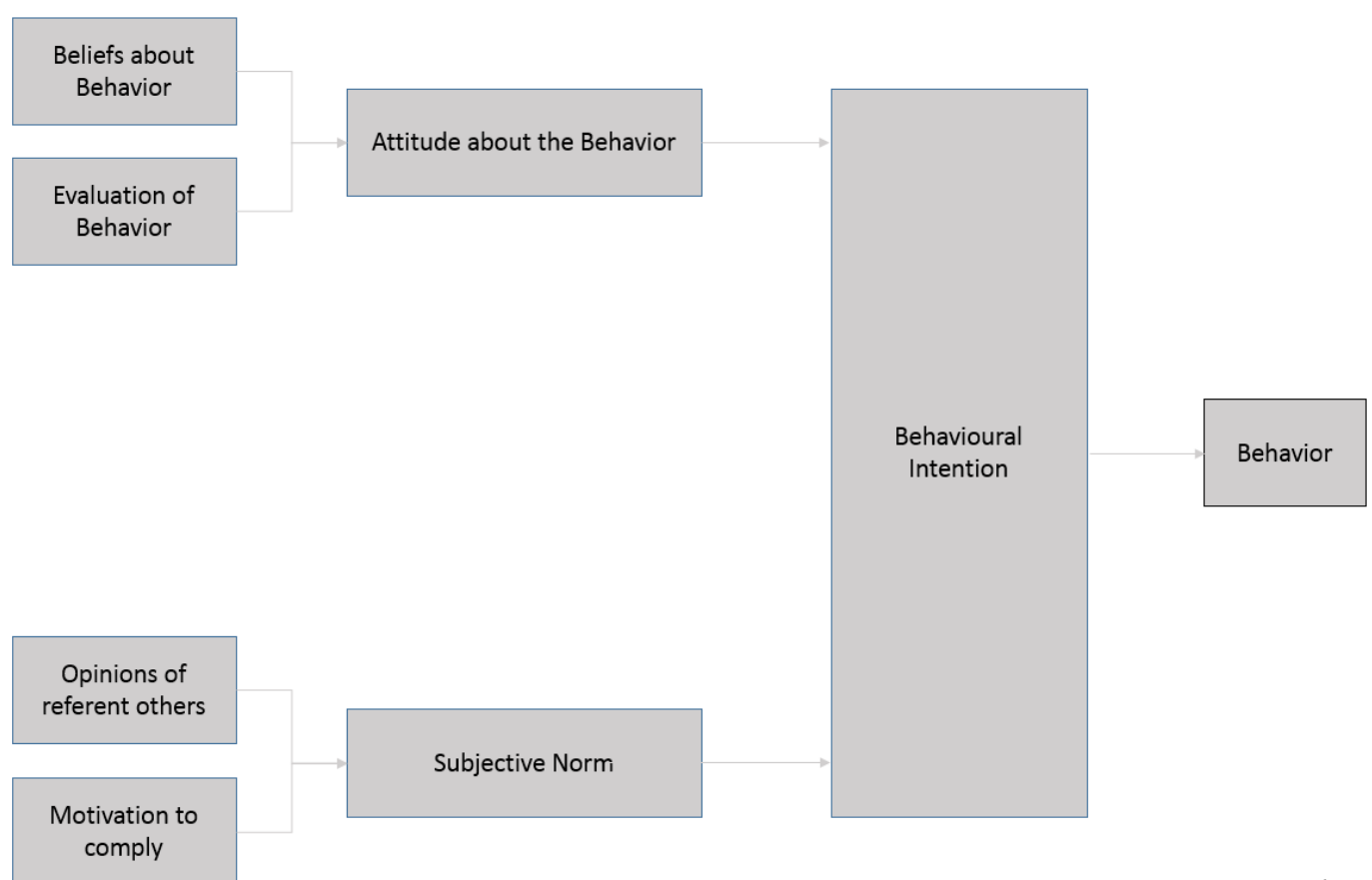

(Ajzen \& Fishbein, 1980)

Figure 2.1. Theory of Reasoned Action

While I considered TRA as a theory with which to frame my research, the shortcomings I discuss above ultimately led me to proceed with the development of my own conceptual framework that takes into account general work attitudes and the influence of social factors such as organizational justice and organizational support. I was also interested in actual behaviours, as opposed to intended behaviors, and wished to include behaviours that benefited both individuals and organizations. Thus, I created a conceptual framework based on my review of additional articles, suggested by my scoping review that focussed on work attitudes and work-related extra-role behaviours. Hence, both the scoping review and this additional review informed the model. I developed propositions predicated on what the research evidence suggests regarding factors relevant to work attitudes and behaviours in the nursing context, such as the relationships between organizational justice, perceived organizational support, affective commitment and extra-role work-related behaviours. 


\section{Extra-Role Organizational Citizenship Behaviours}

Other literature in organizational behaviour which affords insights (albeit not well integrated) into the linkages between work attitudes and work-related behaviours, is drawn upon to discuss and elaborate upon a specific form of 'behaviour,' extra-role behaviours (ERBs). These behaviours are of critical importance to health care organizations because they contribute to the efficient use of scarce resources, and increase organizational and effectiveness (Chu et al., 2005; Organ, 1988). ERBs are defined as behaviours that attempt to benefit the organization, extending beyond existing role expectations (Organ, Podsakoff, \& MacKenzie, 2006).

Organizational citizenship behaviours (OCBs) are examples of ERBs, empirically linked to organizational effectiveness (Organ, 1988). OCBs are discretionary behaviours that are not directly or explicitly recognized by a formal reward system, and in the aggregate promote the effective functioning of the organization (Organ, 1988). OCB's are 'targeted' behaviours that can benefit the organization (OCB-O) or the individual (OCB-I) (Podsakoff, MacKenzie, Paine, \& Bachrach, 2000). An example of an OCB-O would be giving advanced notice when unable to come to work. Helping someone who has been absent would be an example of an OCB-I. Both OCB-O and OCB-I will be measured in this study.

OCBs have been observed in health care. A 2002 study by Lee and Allen consisting of 149 RNs from Ontario Canada, with over 70 percent working in a general hospital, found that job affect (feelings about work) was associated more strongly than are job cognitions (thoughts about work such as fairness, recognition) with OCBs directed at individuals, whereas job cognitions correlated more strongly than did job affect with OCBs directed at the organization (Lee \& Allen, 2002). A cross-sectional, descriptive and analytical study by Dargahi, Alirezaie, and Shaham (2012) conducted amongst 510 nurses working in 15 teaching hospitals in Tehran, Iran, confirmed the existence of OCBs amongst nurses with frequent demonstration of sportsmanship, civil virtue, conscientiousness, and altruism behaviours (Dargahi et al., 2012).

OCBs are important to hospitals. Health care delivery is changing with a shift from acute inpatient delivery of care to a more dispersed (i.e. to home and community) delivery system (Chu et al., 
2005). With the increase of expenditure caps and cutbacks, hospitals need to facilitate the provision of services, on the part of health care professionals, at that point in the continuum of care where the greatest efficiency is achieved (Chu et al., 2005). OCBs are of critical importance to organizations because they contribute to the efficient use of scarce resources and increase organizational productivity. In addition, the quality of health care has become a major concern in all health-care systems. The assurance of quality is heavily dependent on experience, expertise, and interaction amongst different health care professions. OCBs are deemed indispensable due to their importance in promoting positive relationships amongst employees and involving employees in the organization's activities (Chu et al., 2005). In acute care settings, for example, there are not always dedicated individuals to perform discharge planning, and this is often done on an as needed basis by the health care professional who is at hand upon discharge, which, if not done well, could have serious repercussions for patients and organizational outcomes such as readmissions. Figure 2.2 depicts the extra-role workplace behaviours OCBIs and OCBOs. .

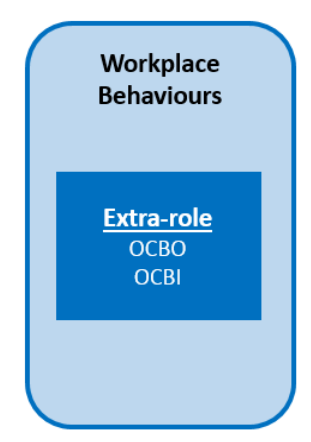

Figure 2.2. Extra-role behaviours.

\section{Factors that Influence Extra-Role Organizational Citizenship Behaviours}

The scoping review together with a more in-depth review of the literature, revealed that the most common work attitudes (i.e. affective commitment, perceived organizational support, and organizational justice) were frequently shown to be related to extra-role work-related behaviours. 
Affective Commitment. The term 'commitment' refers to an individual's emotional affective attachment to a target; 'affective’ relates to moods, feelings and attitudes; organizational commitment refers to a worker's affective commitment to their organization (Mowday, 1982; Solinger et al., 2008). Thus for the purpose of this paper, affective commitment simply means an emotional attachment to a target - a person, object, place or thing selected as the aim. Morin, Madore, Morizot, Boudrias, and Tremblay (2009) demonstrated that employees (analysts, research specialists, insurance agents, account managers, technicians, call center, and customer services) from three Canadian organizations can be affectively committed towards at least eight workrelated targets: organization, career, co-workers, supervisor, tasks, profession, customers, and work. In health care, amongst nurses, it is feasible to think of targets for nurses' affective commitment as similarly comprising the hospital, their careers, their co-workers, their manager, the tasks they perform, their profession, their patients, and their work. Hence, predictions of behaviours can be improved by considering commitment to other targets, not solely the organization (Meyer, Allen, \& Smith, 1993).

Research suggests that individuals will only engage in behaviours that may benefit those constituencies to which they feel committed (Lavelle, 2007; Morin et al., 2011; Rupp \& Cropanzano, 2002). High levels of affective commitment are known to be positively, significantly related to a wide range of extra-role work-related behaviours (Lavelle et al., 2009; Mathieu \& Zajac, 1990; Solinger et al., 2008). Solinger et al. (2008) suggest that high levels of commitment can inspire people to go to great lengths, sacrificing their own personal well-being for a greater good that they identify with, whether it be a unit, a team, or a community (Solinger et al., 2008).

Understanding how commitment is formed, and what is targeted, is highly relevant to understanding work attitudes and work-related behaviours since commitment (the attitude) has been shown to lead directly to behavioural intention (the conscious plan to carry out a behaviour) (Solinger et al., 2008). The relationships discussed here amongst affective commitment, behavioural intention and extra-role work-related behaviours are reflected in Proposition 1, and illustrated in Figure 2.3. Employees can be affectively committed towards eight work-related 
targets. Affective commitment influences extra-role work-related Organizational Citizenship Behaviours that can benefit the organization (OCBO) and/or individuals (OCBI).

Proposition 1: Affective commitment experienced by nurses will influence their demonstration of extra-role organizational citizenship behaviours.

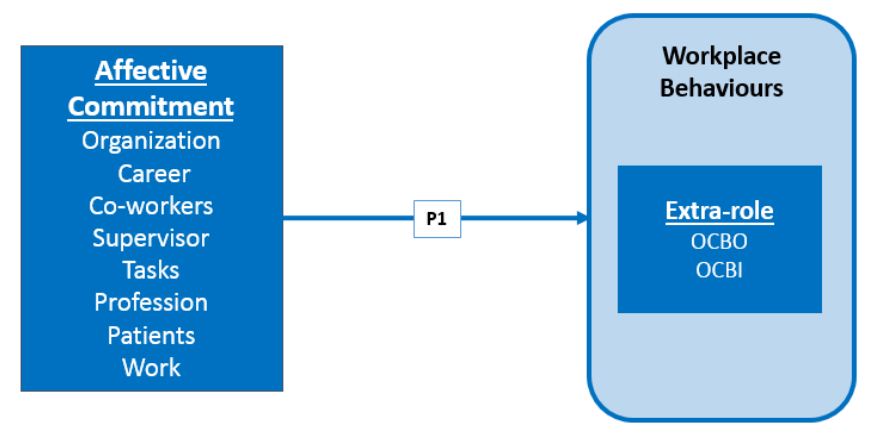

Figure 2.3. Employees can be affectively committed towards eight work-related targets. Affective commitment influences extra-role work-related Organizational Citizenship Behaviours that can benefit the organization (OCBO) and/or individuals (OCBI).

Perceived Organizational Support (POS). POS is defined as an employee's belief that their work organization cares about their well-being and values their contribution (Rhoades \& Eisenberger, 2002). POS has been associated with affective commitment, where Rhoades, Eisenberger, and Armeli (2001) identified a direct, positive relationship between POS and AC in a study involving 333 employees in one sample and a second sample of 226 employees of a large electronics and appliance sales organization located in the Northeastern U.S. (Rhoades et al., 2001). In another study, the authors identified in a study involving 367 employees from variety of organizations, that POS plays an antecedent role in the commitment process (Rhoades et al., 2001). Finally, a third study by the authors, involving 1124 retail employees and 262 retail, poultry, and feed processing employees, found that POS related and contributes to affective organizational commitment, with POS playing an antecedent role in the commitment process (Rhoades et al., 2001). 
This discussion is described in Proposition 2. Figure 2.4 depicts the influence of POS on affective commitment.

Proposition 2: Perceived organizational support experienced by nurses will influence their affective commitment to various targets.

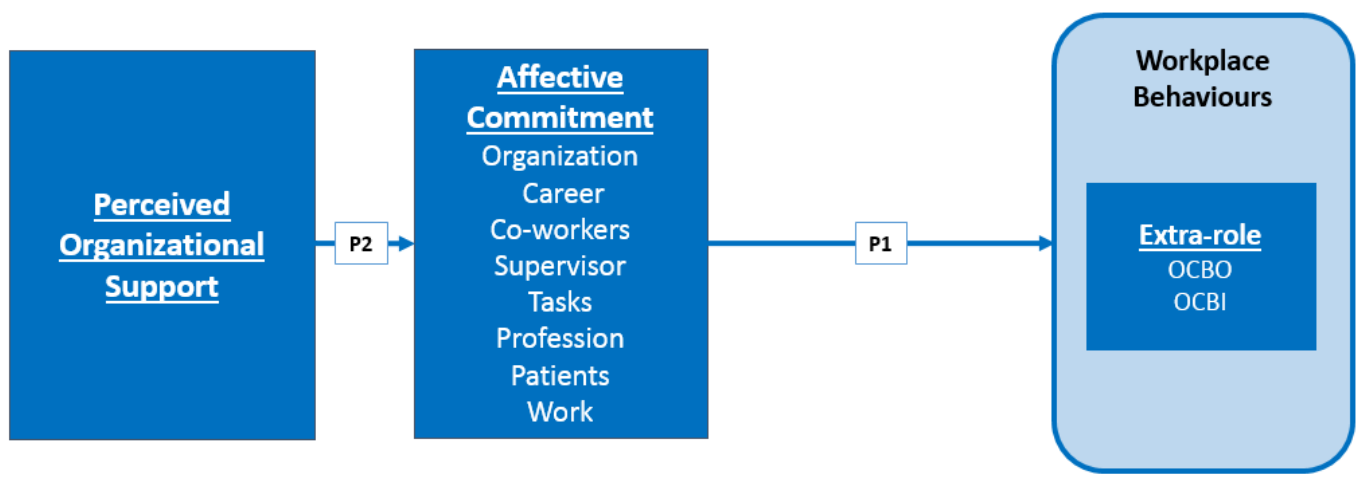

Figure 2.4. Perceived organizational support by an employee influences their affective commitment.

Organizational justice. Organizational justice refers to the study of people's perceptions of fairness in organizations (Greenberg, 1987), and has been shown to be related to other work attitudes and work-related behaviours. There are three primary distinct forms of organizational justice: distributive, procedural, and interactional justice. Distributive justice refers to the perceived fairness of how outcomes are distributed (Greenberg, 2009). Procedural justice refers to the perceived fairness of the procedures or manner in which outcomes are determined (Greenberg, 2009). Interactional justice has two components: informational justice - the manner in which outcomes and procedures are communicated, and interpersonal justice - the expectation that things be explained in an adequate and respectful manner (Bies \& Moag, 1986). Research 
suggests that fair procedures and communication processes can enhance both individual and organizational outcomes (Greenberg, 2009).

\section{Research findings regarding the relationship between affective commitment, perceived} organizational support, organizational justice, and extra-role organizational citizenship behaviours. The three dimensions of organizational justice are known to work together. High levels of interactional justice mitigate negative reactions to distributive and/or procedural injustices (Greenberg, 1994) and adverse reactions to procedural injustice are exacerbated when combined with interactional injustice (Greenberg, 2009).

A study from Hong Kong, involving 514 practicing solicitors, suggests that procedural and distributive justice contributed to the development of POS (Loi et al., 2006). An additional study involving 255 civilian subordinate and supervisors from a large military hospital in the Midwest USA, found that procedural justice is an antecedent to POS (Moorman et al., 1998).

High levels of extra-role behaviours are observed even in unjust environments. Qualitative studies on commitment reveal that it is present when a person continues in a behaviour even under circumstances that would otherwise have caused him/her to change that behaviour (such as an unjust environment or one which lacks organizational support); inspiring individuals to go to great lengths, even sacrificing their own personal well-being for a greater good (Adler \& Adler, 1988; Shamir, 1991; Solinger et al., 2008). This suggests that commitment 'trumps' injustice. This tends to occur when there are extremely high levels of commitment to a particular target (Adler \& Adler, 1988). For example, nurses or allied health professionals who perceive that they are unfairly treated, may provide superlative care for their patients, regardless of their perceptions of fairness, because their targeted commitment is to their patients. Similarly, employees may perceive that they are not supported by their organization or perhaps that their hard work is not being recognized by their supervisor, however they continue to go above and beyond to assist co-workers in spite of the situation, because their targeted commitment is to their co-workers. Individuals working in health care likely have more than one 'target' for affective commitment at a time, resulting in different behaviours. 
This discussion is reflected in Figure 2.5 and in the third and final proposition.

Proposition 3: Distributive, procedural, and interactional justice experienced by nurses directly impact their perceived organizational support.

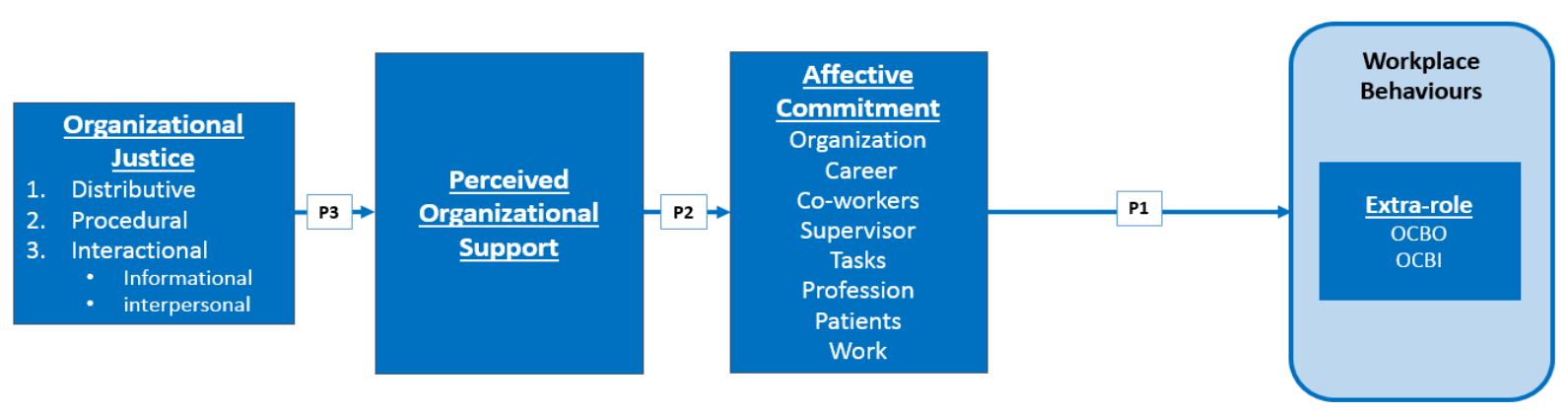

Figure 2.5. Employee perceptions of organizational justice impacts their perception of organizational support, which directly impacts affective commitment.

\section{Framework Summary}

In the interests of developing a more fulsome understanding of the complex inter-relationships amongst work attitudes and work-related behaviours amongst nurses working in health care contexts, a conceptual framework was created with concepts from the extensive literatures on work attitudes and work motivation. The framework depicts the relationships between organizational justice, perceived organizational support, affective commitment and extra-role organizational citizenship behaviours as suggested by extant literature. The final hypothesized framework that is tested in this study is depicted in Figure 2.6. 


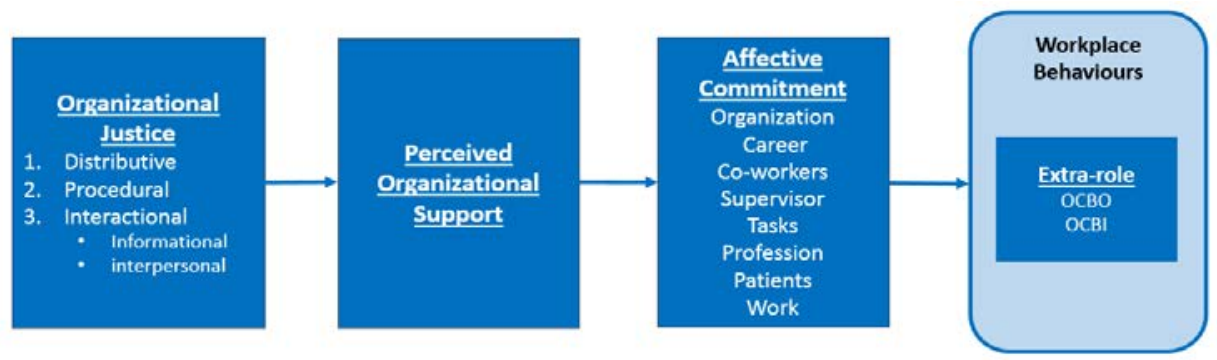

Figure 2.6. Final Hypothesized Framework. 


\section{Chapter 3 \\ Methods and Procedures}

This chapter describes the methodology and procedures used in the study. Outlined are the research design, sample, survey design, data collection, data management, analyses, instruments used, ethics approval, risks and benefits.

\section{Research Design}

The study design is cross-sectional. The method of data collection was an electronic survey. Participants received an information email containing a link to an online survey. An online survey was used as it was an inexpensive method that allowed for rapid surveying of a large, geographically distributed sample across the Province of Ontario, Canada (Dillman, Smyth, \& Christian, 2014) My underlying aim of this study is to examine relationships among nurses' work attitudes - specifically perceived organizational justice, perceived organizational support, and affective commitment - and their relationships to extra-role behaviours, specifically organizational citizenship behaviours. My sample is multi-sectoral, including nurses working in hospitals, the community, and long-term care settings in Ontario. Cross-sectional studies are carried out at one point in time, over a short period of time (Dillman et al., 2014). This design was selected as it enabled me to obtain a subgroup within a population at a given time to find the prevalence of my outcome measures.

\section{Sample}

The College of Nurses of Ontario (CNO) is the governing body for registered nurses (RNs), registered practical nurses (RPNs) and nurse practitioners (NPs) in Ontario, Canada (CNO, 2015). Therefore, the CNO have data representing all RNs in Ontario, the population of interest. The unit of analysis in this study is the individual front-line registered nurse working in Ontario. Unfortunately, I was not able to work and collaborate with the CNO. Instead, I accessed my survey respondents via the Registered Nurses’ Association of Ontario (RNAO). All participants in this study were members of the Registered Nurses’ Association of Ontario (RNAO). The RNAO is a 
professional association representing approximately 41, 000 registered nurses, nurse practitioners and nursing students in Ontario. The RNAO advocates for healthy public policy, promotes excellence in nursing practice, increases nurses' contribution to shaping the health-care system, and helps influence decisions that affect nurses and the public they serve (RNAO, 2015). Membership is voluntary and satisfies the CNO's professional liability protection (PLP) requirement. This is important as it is a convenient way for all Ontario nurses to meet this requirement. Hence, of the 104, 298 general class RNs registered with the CNO, 41, 000 are members of the RNAO (CNO, 2015). Representativeness of my sample is discussed in the demographics section of the Results chapter.

The survey was distributed to all 25 RNAO “interest groups.” For a complete list of interest groups included in the study, see Appendix F. These interest groups were identified by RNAO because collectively they represent the unique specialties or populations within the nursing spectrum, the diversity of the profession, and consist mainly of front-line staff. In total, there are 7,375 RNAO members in the selected interest groups, representing approximately $18 \%$ of all RNAO registrants. Although data were not available from the RNAO to verify how representative these $18 \%$ were of the entire RNAO registrant population, I am able to verify in the Results chapter, that the sample is representative of the CNO population, the population of interest. The inclusion criteria for potential participants were that they be a front-line, registered nurse, actively working in Ontario. Because it was not possible to contact only front-line staff, invitational emails containing the survey link were sent out to all nurses registered with the RNAO whom were active members of the 25 interest groups listed in Appendix F. Nurses who responded to the survey were asked to indicate their role so that front-line staff responses could be distinguished from the responses of nurses in other roles (e.g., leadership).

\section{Sample Size}

Data analysis uses Structural Equation Modeling (SEM) analytic techniques. SEM is appropriate for my study as it allows me to confirm my developed framework, it assesses and corrects for measurement error, and can incorporate both unobserved (i.e. latent) and observed variables (Byrne, 2014). Sample size requirements when using SEM are somewhat dependent on model 
complexity, the estimation method used, the distributional characteristics of observed variables, and the amount of missing data (Kline, 2011), although guidelines regarding sample size for SEM are conflicting and not well established (Weston, Gore, Chan, \& Catalano, 2008). Bentler (1989) suggest a ratio of sample size to number of free parameters as low as 5:1, whereas Weston et al. (2008) suggest between 10 and 20 participants per observed variable (Bentler, 1995; Weston et al., 2008). Having 34 observed variables, the more conservative number was opted for to reduce the likelihood of insufficient statistical power. The target sample size, 680, was achieved; once exclusions, survey non-response and duplicates were accounted for.

\section{Survey Development}

\section{Measures}

\section{Behaviours.}

Organizational citizenship behaviours. Organizational Citizenship Behaviours (OCBs) were measured using a 16-item self-report scale previously adapted by Lee and Allen (2002) (Lee \& Allen, 2002), see Appendix G. This measure distinguishes OCBs directed towards the organization (OCBO: 8 items) from that directed towards fellow employees/individuals (OCBI: 8 items). Lee and Allen confirmed construct validity; an empirical distinction between OCBI and OCBO (Lee \& Allen, 2002). The significance of this distinction is established in the literature (McNeely \& Meglino, 1994; Williams \& Anderson, 1991). An example of scale items for OCBI is "help others who have been absent" and an example of an OCBO scale items is "express loyalty towards the organization.” Responses to these items were made on a 5-point scale ( 1 = Never, 5 = Always) (Dunlop \& Lee, 2004). This scale has been utilized in health care settings, with good reliabilities of $\alpha=.83$ (OCBI) and $\alpha=.88$ (OCBO) (Lee \& Allen, 2002).

\section{Work Attitudes.}

Affective Commitment. The Workplace Affective Commitment Multidimensional Questionnaire (WACMQ) is the only questionnaire designed to measure affective commitment towards eight work-related targets identified in the literature (organization, career, co-workers, 
supervisor, tasks, profession, customers, and work) (Morin, Madore, Morizot, Boudrias, \& Tremblay, 2009). The original WACMQ is comprised of 49 items (Morin et al., 2009). Following further psychometric work, a short version of this instrument containing 24 items, was developed by Morin and colleagues (Morin et al., 2009). Sample statements for each of the eight targets of commitment are as follows: organization (e.g., "I am proud to say that I work for this organization"), supervisor (e.g., "I like the values my immediate supervisor conveys"), co-workers (e.g., "I’m happy to work with my coworkers"), work itself (e.g., "Work is a priority in my life"), tasks (e.g., "I find the tasks I perform in my current position stimulating"), career (e.g., "It is important for me to move up through the ranks or obtain promotions"), customers (e.g., "Delivering quality products and/or services to customers is a major source of satisfaction for me"), and profession (e.g., "I am proud to say this is my profession”).

This new 24-item short version of the instrument was used in this study. This instrument, see Appendix $\mathrm{H}$, has not been utilized in acute care settings, but has been used in long-term care facilities with alpha reliabilities ranging from 0.70 - 0.87 (Morin, Vandenberghe, Turmel, Madore, \& Maïano, 2013). Morin et al. (2009) reported evidence of factorial validity and measurement invariance across gender and language. Responses to these items were made on a 5-point scale (1 = Totally Disagree, 5 = Totally Agree). The multi-target conceptualization of affective commitment has applicability to complex health care contexts where providers of care may develop commitment toward a multiplicity of targets.

Nursing industry experts with extensive nursing experience, with whom I have collaborated and worked with for many years, identified that the care models, organizational and reporting structures can be quite diverse hospital acute care and emergency departments. As a result, they suggested that I ensure that the WACMQ was applicable and worded appropriately for acute care and emergency department of hospitals in Ontario. Since the WACMQ had not been used in hospital acute care or emergency department settings, two focus groups were convened in order to undertake linguistic validation through cognitive debriefing. The groups were representative of the intended survey target population, and consisted of nurses working in acute care and emergency departments in hospitals in Ontario. Cognitive debriefing is the dominant mode for 
testing questionnaire items (Dillman \& Groves, 2011). In this study, cognitive debriefing entailed exposing the participants to each item (a total of 24), then asking them to "brainstorm" on the meaning they ascribed to each item, in response to the question "explain what you think the item means in your own words.” This made apparent the participants' understanding of the item, and congruence - or lack of it - with the meaning intended by the original item. Participants were then asked to offer suggestions for alternative wording (for each item) ("how the wording could be improved to make the meaning more clear for their respective health care departments?”), if they felt this was needed.

The final wording for items, as a consequence of this work, is summarized in Appendix I. As a consequence of the cognitive debriefing exercise, minor changes to the instrument were effected to reflect the health care context, e.g., instead of 'supervisor' or 'coworkers,' items were re-worded to explicitly reference 'the authority figure who conducts performance appraisals,' and ‘interprofessional co-workers’, respectively.

Organizational Justice. Organizational justice refers to the study of people's perceptions of fairness in organizations (Greenberg, 1987). Colquitt (2001) developed a unique scale for measuring all dimensions of organizational justice perception, see Appendix J. This instrument was used in this study. The scale has been utilized in health care settings (Sulu, Ceylan, \& Kaynak, 2010), is both valid and reliable (distributive, $\alpha=.93$; procedural, $\alpha=.93$; informational, $\alpha=.90$; interpersonal, $\alpha=.92$ ), and has 20 items with response options ranging from 1 (to a very small extent) to 5 (to a very large extent) (Colquitt, 2001). Colquitt (2001) established good construct validity, establishing some degree of generalizability for the justice measure. Respondents were asked to think about their supervisor as they responded to each item. Examples of items from each scale are as follows: 'Have those procedures been free of bias?' (Procedural), 'Is your outcome justified given your performance?' (Distributive), 'Has he/she treated you in a polite manner?' (Interpersonal), 'Has he/she communicated details in a timely manner?' (Informational). Although organizational justice is considered an external force, I am measuring one’s internal perception of organizational justice. 
Perceived Organizational Support. Perceived organizational support (POS) refers to the extent to which employer organizations value employee contributions and care about their wellbeing (Eisenberger, Huntington, Hutchinson, \& Sowa, 1986; Rhoades \& Eisenberger, 2002). A short 8-item instrument was used in this study to assess POS, see Appendix K (Rhoades et al., 2001). The scale consists of eight items rated on a 7-point Likert scale, ranging from 1 (strongly disagree) to 7 (strongly agree). An example of an item is 'The organization really cares about my well-being.' This scale has been used in health care with reliability coefficients ranging from $\alpha=$ 0.89 - 0.94 (Rhoades \& Eisenberger, 2002; Tourangeau, Cranley, Spence Laschinger, \& Pachis, 2010; H. Wong, Wong, Wong, \& Lee, 2010). The scale has been found to be unidimensional with good discriminant validity (Rhoades \& Eisenberger, 2002). Similarly to organizational justice, although organizational support is an external force, I am measuring one's internal perception of organizational support.

\section{Demographic Information}

Demographic data collected via the e-survey included: age, education, number of organizations employed by, employment status, geographic location, union status, involvement in academia, primary area of practice, years of nursing experience, years working with current organization, years working in current department, years working with current supervisor, and years remaining before retirement. These demographics are important for determining sample representativeness compared to data available from the Canadian Nurses of Ontario (CNO) database (see below).

\section{Ethics}

Ethical approval for this study was received from the Ethics Review Office at the University of Toronto.

\section{Data Collection Procedures}

The opportunity to complete the online survey was communicated to nurses by the Membership and Services Department Registered Nurses' Association of Ontario (RNAO) via an email prepared by the researcher containing a link to the online survey. The Dillman internet 
methodology was used (Dillman et al., 2014). The steps included an advanced notice email; then one week later, a cover-email with instructions and the link to the survey; one week after that, a follow up email was distributed. Two weeks after the initial survey invitation a new cover email containing the link was distributed again; and finally, a termination email was distributed one week later (4 weeks after the initial pre-notification email), to notify all that the survey was closing in one week. Instructions on the survey explained that the questions related to respondents' perceptions, and that there were no "right" or "wrong” answers. All questions on the survey were mandatory (not optional) meaning that participants were unable to proceed to a new page of questions on the electronic survey before responding to all questions on the previous page. Upon completion of the survey, all participants were offered the opportunity to provide their name and contact information for a draw to win one of three \$100 prepaid VISA gift cards. Participants’ names and contact information were not connected to their survey responses in order to assure anonymity of responses. For the communications relating to survey distribution, see Appendix L to Appendix P.

The survey was administered through FluidSurveys. Once participants clicked on the link, they were directed to an introduction page which explicitly stated "By completing and submitting your survey, you are consenting to participate in this study.” If respondents identified in the demographic section that they were in a leadership position, were unemployed or a student, then they were immediately directed to the final draw at the end of the survey and were not invited to complete the main body of the survey.

\section{Data Preparation: Cleaning and Screening}

The purpose of data screening is to ensure that the data are an accurate representation of what was measured and that the underlying assumptions of analytic procedures are met (Meyers, Gamst, \& Guarino, 2013). Data were imported from FluidSurveys into Excel. Each case was reviewed independently to ensure that there were no coding errors, no missing data, and that the survey logic performed correctly (e.g., if one worked outside of Ontario, the participant was not asked to which Ontario LHIN they belonged). The data were then sorted in Excel to ensure only cases meeting the inclusion criteria were retained (e.g., the inclusion of only frontline RNs actively working in 
Ontario), and cases meeting exclusion criteria were removed (e.g., students, unemployed, or RNs working outside of Ontario).

Data from the Excel spreadsheet were then imported directly into SPSS IBM Statistics version 22. All data are categorical. Some researchers have argued that categorical variables should be treated as continuous variables, but Byrne (2014) identifies several risks with this approach: (i) Pearson correlation coefficients are higher when computed between two continuous variables than when computed between the same two variables restructured with an ordered categorical scale; (ii) greatest attenuation occurs with variables having fewer than five categories and those with a high degree of skewness; (iii) when categorical variables approximate a normal distribution, the number of categories has little effect on the chi-squared likelihood ratio test of model fit, although increasing skewness and differential skewness can lead to inflated chi-squared values; (iv) factor loadings and factor correlations are modestly underestimated, which becomes critical when there are fewer than three categories, skewness and differential skewness; (v) error variance estimates are sensitive, and (iv) standard error estimates for all parameters tend to be low. Due to these risks, the decision was made to treat the categorical data as categorical, not continuous.

Descriptive analyses were performed to generate frequency distributions for each variable. Z-tests were performed between the study sample and data from the CNO, to identify any statistical differences between the study sample and the population of Ontario nurses. P-values were calculated for two-tailed comparisons using the following website: http://epitools.ausvet.com.au/content.php?page=z-test-2. P-values of $\geq .05$ indicate that there are no significant differences, the null hypothesis should be accepted, and sample proportions are equal. P-values of $\leq .05$ indicate that there are significant differences, in which case Cohen's $d$ was then calculated to determine the effect size of the difference using the following website: http://www.campbellcollaboration.org/escalc/html/EffectSizeCalculator-SMD10.php. An effect size of 0.2 constitutes a small effect; 0.5 constitutes a medium effects size; and 0.8 constitutes a large effect size. The study sample appears representative of the Ontario nursing population. Although discussed in detail in the Results chapter, the few categories with statistical differences were only found to have small effect sizes. 
In preparation for import into LISREL and for Confirmatory Factor Analysis (CFA), negative survey items were reverse coded and included as new variables in the data set. Next, a correlation/covariance matrix was generated. The nature of the observed data, in this case categorical, dictated the most appropriate type of correlation matrix. Joreskog and Sorbom (1989) recommend polychoric correlations when the observed variables are all categorical (Jöreskog \& Sörbom, 1989). These correlations are regarded as theoretical correlations and are estimated from the observed pairwise contingency tables of the ordinal variables (Byrne, 2014).

With correlation matrices, the variables must be inter-correlated, but they should not correlate too highly (extreme multicollinearity and singularity) as this would cause difficulties in determining the unique contribution of the variables to a factor (Field, 2014). To avoid or correct multicollinearity, Field (2014) suggests reviewing the correlation matrix for variables very highly correlated ( $r>.8$ ) and consider eliminating one or more of these variables. Although this would seem like a simple approach, as Field describes, the effect of two variables that correlate with $\mathrm{r}=$ .9 for example, might be less than the effect of say three variables that all correlate at $r=.6$.

\section{Statistical Assumptions Underlying Structural Equation Modeling.}

SEM requires that certain underlying assumptions be satisfied to ensure accurate inferences. These assumptions include multivariate normality, completely random missing data, sufficiently large sample size, and the assumption of exogeneity (Kaplan, 2009). The most common approach to parameter estimation in SEM is maximum likelihood (ML) (Cortina, Chen, \& Dunlap, 2001). ML estimation is the default setting in LISREL and was used for analysis of measurement models, as it identified estimates with the greatest chance of reproducing the observed data (Kline, 2005). Although there are alternatives to ML, there is considerable evidence that ML is robust with respect to many types of violation of the multivariate normality assumption, and is superior in terms of bias in parameter estimates, Type 1 error, and power (Cortina et al., 2001).

The testing of assumptions is embedded in the LISREL analysis. The diagnostic tests include univariate distributions for ordinal variables, correlations and test statistics (e.g., tests for bivariate normality), means, standard deviations, and the correlation matrix. Multivariate normality is 
assessed via skewness and kurtosis for each item and 'Relative Multivariate Kurtosis,' produced in the LISREL output. The Relative Multivariate Kurtosis measure is the Mardia-based kappa, rescaled to have a mean of 1 . It should be close to 1 in value if the distribution is multivariate normal (Jöreskog \& Sörbom, 2002). As reported in the results section below, this value is considered relatively small and collectively the multivariate distribution is reasonably normal. The variables and included relationships are suitable and satisfied the assumptions, and no fatal errors are obtained. In addition, normality was also tested in SPSS so that histograms, P-P and QQ plots could also be viewed.

\section{Confirmatory Factor Analysis}

Confirmatory Factor Analysis (CFA) was performed for each of the latent constructs. For OJ, CFA was performed for both a four factor and a three factor model, since both are present in the literature, to determine which model was best suited for inclusion into the SEM. CFA was then conducted for a one factor POS model and eight factor affective commitment model, again reflective of the extant literature. Finally CFA was performed for both a two factor and one factor OCB model, since both are present in the literature, to determine which factor structure was best suited for inclusion into the SEM.

The goodness-of-fit for each construct was evaluated by reviewing the fit statistics and program warnings. One test of model fit (chi-square $\left[\chi^{2}\right]$ ), and five goodness of fit indices were assessed: root mean square error of approximation (RMSEA); standardized root mean square residual (SRMR); goodness-of-fit indices (GFI); comparative fit index (CFI); and normed fit index (NFI). These indices were selected as they tend to be the most accurate reflection of model fit (Kline, 2005). Rather than making determination of goodness-of-fit using only one of the indices, a more rigorous approach was applied. Each of the model fit indices were calculated differently (Schumacker \& Lomax, 2004) and indicate different aspects of fit, hence determination of goodness of fit in this study is based on the accumulation of evidence across five of the statistics/indices. 
Absolute fit measures indicate how well the proposed interrelationships between the variables match the interrelationships between the actual or observed interrelationships (e.g., chi-square, GFI, RMSEA and SRMR). The chi-square statistic is used to test the difference between the predicted and observed relationships. A non-significant chi-square is preferred, however, this test is sample size sensitive, affected by the size of correlations in the model, and often too powerful for most research studies (Meyers et al., 2013). Chi-square is an adequate measure of fit for models with a small number of cases (75-200) (Kenny, 2012; Meyers et al., 2013). For models with more cases, chi-square is often statistically significant as the size of the calculated chi-square is directly proportional to the size of the sample (Meyers et al., 2013). Since chi-square is sensitive to sample size, and is affected by the size of the correlations in the model, some authors (Joreskog and Sorbom, 1996; Bentler, 1990) advise against the exclusive use of chi-square in judging the overall fit of the model. RMSEA is the average of the residuals between the observed correlation/covariance from the sample and the expected model estimated for the population (Meyers et al., 2013). SRMR is the difference between the observed correlation and the predicted correlation. GFI is a measure of the proportion of variance in the sample correlation/covariance accounted for by the predicted model. Less conservative approaches suggest that adequate fit is indicated by cut-off values of .08 (or .06 for a more conservative approach) for RMSEA, .08 for SRMR, and .90 for GFI (Byrne, 2014; Hancock \& Mueller, 2015; Meyers et al., 2013). Since this is the first time all of the constructs are being combined in one framework, I opted to use this less conservative approach.

Relative fit measures, or comparison with baseline measures, are measures of fit relative to the independence model, which assumes that there are no relationships in the data (a poor fit) and the saturated model, which assumes a perfect fit (Meyers et al., 2013). CFI analyzes a model's relative fit by examining the discrepancy between the data and the hypothesized model. NFI is the discrepancy between the chi-squared value of the hypothesized model and the chi-squared value of the null model. A value of $>.90$ for both NFI and CFI indicates acceptable fit to the data (Bentler, 1992; Byrne, 2014). Meyers et al. (2006) recommend a more conservative value of .95 (Hancock \& Mueller, 2015; Meyers et al., 2013). Ultimately, there is a range of opinion about what is considered acceptable fit. For instance, in contrast to cut-offs noted above, Hu \& Bentler 
(1999) suggest a two-index strategy where models with SRMR values $<0.08$ and CFI values > 0.95 or RMSEA values $<0.06$ indicate good model fit. For the purpose of this study, to simply understand the relationships between constructs, the more liberal parameters are applied. In addition, it is suggested that when an initial model fits well, it is unwise to modify it to achieve even better fit, as modifications may be fitting small idiosyncratic characteristics of the sample (Byrne, 2014; MacCallum, Roznowski, \& Necowitz, 1992).

\section{Model Modification}

Model modification is not performed in this analysis as I do not have a cross-validation sample. The initial results are sufficient for the purpose of this study, which is to understand the relationship between constructs. More about model modification and modification indices can be found in Appendix Q.

\section{Reliability for Latent Constructs}

After CFA was performed, internal consistency coefficients (Cronbach's alpha) were calculated in SPSS. The most common measure of scale reliability is Cronbach's alpha $(\alpha)$. Reliability refers to the ability of a measure to produce consistent results when the same entities are measured under different conditions (Field, 2014). A reliable measure should consistently reflect the construct it is measuring. In other words, if a questionnaire is reliable, all else being equal, one should obtain the same score if completed at two different time points (Field, 2014). Survey questions in this study were all selected because they have all demonstrated good reliability in the literature.

There is debate in the literature regarding what constitutes an acceptable value for Cronbach's $\alpha$. Kline (2013) states that although the generally accepted value of .8 is appropriate for intelligence tests, for ability tests, a cut-off point of .7 is more suitable. For psychological constructs, values below .7 can be expected (Kline, 2013). Furthermore, in the early stages of research when measures/items are being developed, values as low as .5 will suffice (Field, 2014). Field (2014) identifies the following ranges: $>.9=$ excellent, .7 to $.9=$ good, acceptable $=.6$ to.7.

The value of $\alpha$ depends on the number of items on a scale. As the number of items on a scale increases, so will the $\alpha$. This is important as one can obtain a large value of $\alpha$ simply due to having 
many items, not because the scale is reliable. Secondly, if a questionnaire has subscales, $\alpha$ should be applied separately to each of the subscales (Field, 2014).

The following are outputs obtained from SPSS that can be beneficial in helping to evaluate internal consistency reliability:

\section{Scale if Item Deleted}

This value indicates what the value of $\alpha$ would be if each item were to be deleted. A reliable questionnaire is one in which the deletion of one item would not greatly affect the overall reliability, hence no item should cause a substantial decrease in $\alpha$, if it does, one should consider dropping that item to improve reliability (Field, 2014).

\section{Corrected Item-Total Correlation}

This value indicates the correlations between each item and the total score from the questionnaire. In a reliable scale, all items should correlate with the total. Any values less than .3 indicate that the item does not correlate well with the scale overall. Items with low correlations may have to be dropped (Field, 2014).

\section{Cronbach's Alpha if Item Deleted}

These are the values of overall $\alpha$ if the item was not included in the calculation. Values of $\alpha$ should be around the same value of the overall $\alpha$. Any values of $\alpha$ greater than the overall $\alpha$ are identified, as deletion of these items would improve reliability. Having none of the items increase reliability if they were to be deleted, indicates that all items are positively contributing to the overall reliability.

\section{Structural Equation Modeling}

A two-step approach to Structural Equation Modeling (SEM) was used. First the measurement models were tested (confirmatory factor analyses), then the structural model. Structural Equation Modeling (SEM) was used to test the hypothesized conceptual framework. 


\section{Model Specification}

Model specification involves specifying the relationships among the latent variables and determining how the latent variables will be measured. Extant literature was used to specify the model (Norman \& Streiner, 2003). Generally dyadic relationships existed. This was the first time all concepts had been used together in one model. The conceptual framework (see Figure 3.1), hypothesized a pattern of relationships amongst latent constructs, with measured variables that functioned as indicators. The latent factors instead of average scores were used to test the relationship described in Figure 3.1.

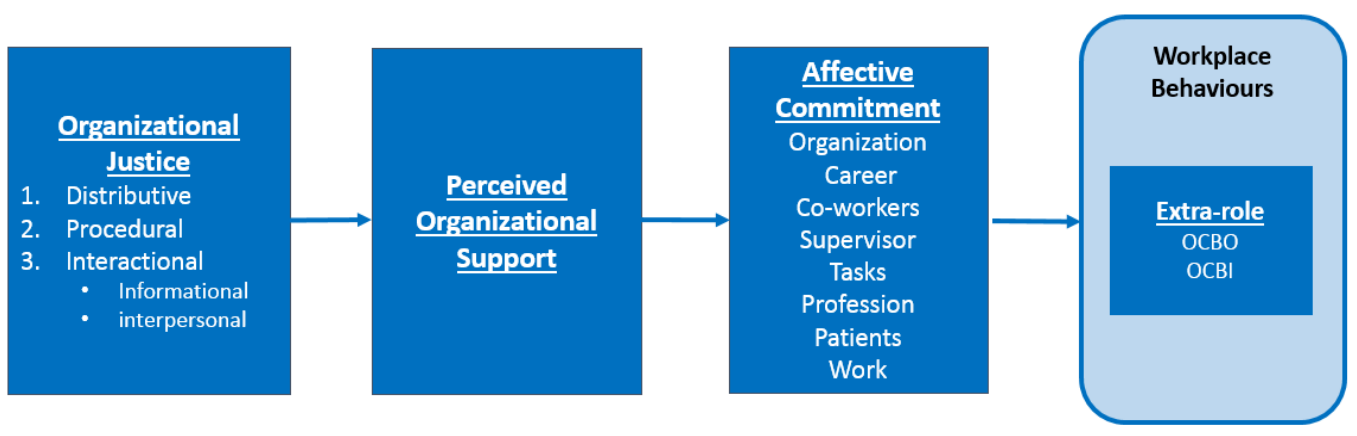

Figure 3.1. Hypothesized Model - Relationships between Perceived Organizational Justice, Perceived Organizational Support, Affective Commitment and Organizational Citizenship Behaviours.

SEM is not a single statistical technique, but rather a set of analytic tools that utilize covariance matrices to address hypotheses about models. There are two important aspects to structural equation modeling: (i) the causal process under study are represented by a series of structural (e.g., regression) equations, and (ii) these structural relations can be modelled pictorially to allow for a clearer conceptualization of the theory being studied (Byrne, 2014). SEM takes a confirmatory approach, rather than exploratory, to data analysis; it provides explicit estimates for measurement error; and it uses a matrix of variances and covariances amongst observed variables to estimate hidden variables (Byrne, 2014; Valluzzi, Larson, \& Miller, 2003). 
Adding all items into the SEM caused the statistical program to cease, disrupting internal mathematical operations. This can sometimes be the result of extensive multicollinearity amongst variables (Meyers et al., 2013). To address this, each latent construct was added into the SEM, one construct at time, from left to right (see Figure 4.1). I started with the (only) exogenous construct, perceived organizational justice. First, the four factor model for organizational justice and the one factor model for POS was added, followed by all 8 targets of affective commitment, concluding with both OCBI and OCBO. Each time a new latent construct was added, the LISREL output was reviewed (e.g., measurement equations, structural equations, goodness-of-fit statistics, standardized residuals, and suggested modification indices). Once again, determination of goodness of fit was based on the accumulation of evidence across all the statistics.

After combining the justice constructs and POS, a warning appeared indicating that there was multicollinearity within the model. Importantly, this is the first time all of these constructs have been combined in a single model. Niemelä-Nyrhinen \& Leskinen (2014) point out the misconception that SEM is robust enough to deal with multicollinearity (Niemelä-Nyrhinen \& Leskinen, 2014). This, however, is inaccurate: multicollinearity can distort the interpretation of multiple regression results. As Meyers et al. (2013) explain, if two or more variables are highly correlated, they are largely confounded with one another, essentially measuring the same characteristic, and making it impossible to determine which of the variables is more relevant (Meyers et al, 2013). In addition, the values of the standardized regression coefficients of the highly correlated independent variables are distorted, exceeding the expected range of \pm 1 . Another problem with multicollinearity is that the standard errors of the regression weights of those multicollinear predictors can be inflated, increasing confidence intervals (sometimes including zero). When this occurs, one cannot determine if an increase in the predictor is associated with an increase or decrease in the criterion variable.

Two methods for addressing multicollinearity in the structural model are to either utilize a model comparison approach and restrain paths as per Marsh, Dowson, Pietsch, and Walker (2004), or to remove several of the highly correlated variables (Field, 2014; Marsh, Dowson, Pietsch, \& Walker, 2004). Unfortunately the model comparison approach and restraining paths did not change results. 
The second option, removing several of the highly correlated variables, would have meant deletion of many of the variables and would most likely have altered the factor structure.

Additional diagnostic investigation to assess specification of SEM was performed as per Hayduk (2014). There were no problems with the data (i.e., missing data, use of incorrect variables, or recoding errors). There were no problems with the modelling process (i.e., syntax, program defaults, inappropriate estimators, or fixed values). Finally, regarding theory, all relationships were based on the extant literature. Group level causes were considered (i.e., gender, roles, primary area of practice), however a larger sample size would have been required.

As a result, to further investigate the relationships, the decision was made to conduct a path

analysis using average scores for each of the constructs to see if multicollinearity would still be an issue. Since path analysis does not include the correlations between each of the observed measures, this method mitigated the issue of multicollinearity.

Since path analysis was used to further investigate the relationships between the observed measures, the latent variables are not included in the analysis that follows, nor are measurement errors accounted for. The full implications of these necessary exclusions are discussed in a later chapter.

\section{Path Analysis}

Path analysis is the simplest case of SEM, where latent variables are not included in the model. Because there are no latent variables included in a path analysis, there is no measurement model to assess. A mean response score over all items in each scale was computed in SPSS for the path analysis. Prior to conducting the path analysis, however, statistical assumptions underlying path analysis, and assumptions regarding normality, were assessed in order to ensure that path analysis was an appropriate approach.

\section{Statistical Assumptions Underlying Path Analysis}

The assumptions for path analysis are the same as those for multiple regression: linear relationship, multivariate normality, variables are measured without error, and homoscedasticity. There are five 
additional assumptions underlying path analysis when multiple regression is used (Kline, 2011; Meyers et al. 2013): (1) Relations between variables in the model are linear; (2) The errors associated with endogenous variables are not correlated with the variables that are predicting that variable; (3) There is only a one-way causal flow in the model, called a recursive model; (4) The variables are measured on at least an interval or near-interval scale; and (5) The variables are measured without error, hence the reliability of the measured variables is perfect. All were assessed to ensure that the statistical assumptions were met in order to proceed with path analysis.

\section{Assumptions of Normality}

Next, assumptions of normality were then assessed. Recall, that due to the categorical nature of the data, normality checks in SPSS were not initially performed as the data are ordinal. Special matrices are created within LISREL, checking for bivariate normality. Since, however, a mean response score for all items in each scale was computed for the path analysis, assumptions of normality were then performed in SPSS.

Probability-probability plots (P-P plots) plot the cumulative probability of a variable against the cumulative probability of a particular distribution, or normal distribution. Data are ranked and sorted, then for each rank, the corresponding z-score is calculated, creating an 'expected value' that the score should have in a normal distribution. The actual z-score is plotted against the expected z-score. If the data are normally distributed, the actual z-score will be the same as the expected z-score, resulting in a straight diagonal line. Kurtosis measures the degree to which scores cluster in the tails of a frequency distribution, and skew is a measure of the symmetry of a frequency distribution (Field, 2014).

A distribution can deviate from normality by lack of symmetry, skew, or by pointiness, kurtosis. If there is a positive skew, the tall bars, or frequent scores, are clustered at the lower end and the tail points to the higher/more positive scores. When there is a negative skew, the frequent scores are clustered at the higher end, and the tail points to the lower/more negative scores (Field, 2014). Kurtosis refers to whether the data are peaked or flat relative to a normal distribution. Positive kurtosis is pointy and has many scores in the tails, also referred to as a leptokurtic distribution. 
Negative kurtosis tends to be flatter and relatively thin in the tails, known as platykurtic. In a normal distribution, values of skewness and kurtosis are 0 (Field, 2014).

Normal quantile-quantile (Q-Q) plots plot the quantiles (values that split a data set into equal portions) of the data. Detrended P-P and Q-Q plots depict the actual deviations of the data points from the straight horizontal line at zero. No specific pattern in a detrended plot indicates normality of the variable.

Kolmogorov-Smirnov test and Shapiro-Wilk test also helps to determine if the distribution of scores deviates from a comparable normal distribution. It compares the scores in the sample to a normally distributed set of scores with the same mean and standard deviation. If the test is nonsignificant $(\mathrm{p}>.05)$, it means that the distribution of the sample is not significantly different from a normal distribution, in other words, it is most likely normal. A significant test $(p<.05)$ indicates that the distribution is significantly different from a normal distribution. However, in large samples, the test can be significant even for small and unimportant effects, and in small samples they lack power to detect violations of assumptions.

Since only mild skewness was observed (see Results chapter), path analysis was conducted.

\section{Mediation}

Mediation refers to a situation when the relationship between a predictor variable and an outcome variable can be explained by their relationship to a third intervening variable, the mediator (Field, 2014). ${ }^{1}$ If the strength of relationship between the predictor and outcome is reduced by including the mediator, then mediation is said to occur. 'Perfect mediation' occurs when the relationship between a predictor variable and an outcome variable can be completely explained by a third variable. Only one mediation effect is identified in the literature. ${ }^{2}$ Since this was the first time all

\footnotetext{
${ }^{1}$ No moderating effects are identified in the literature.

2 The only indirect effect identified in the literature was POS mediation of the relationship between procedural justice and affective organizational commitment in a study involving 367 employees from variety of organizations (Rhoades et al., 2001).
} 
of the constructs were considered in a single model, (a four factor justice model, a one factor POS model, an eight factor affective commitment model, and a two factor OCB model), the path model was reviewed to identify any potential mediating effects. In total, 18 potential mediation or indirect effects were identified in the final path model.

All of the assumptions for regression were also considered for mediation analysis. Hence all assumptions are the same as those previously discussed. Although mediation can be tested using path analysis, it is more complex and requires multiple steps as one would need to first test the model without the mediator, and then again with the mediator (Field, 2014). For the purposes of this study, 18 potential mediation effects in the final model were tested by conducting a one-step regression analysis in SPSS using Hayes' PROCESS download tool for SPSS (http://www.afhayes.com).

By default PROCESS uses 1000 bootstrap samples. Bootstrapping is a technique from which the sampling distribution is estimated by taking repeated samples from the dataset (Field, 2014). Bootstrapping is a robust method by which sample data are treated as a population from which smaller samples are taken, putting each score back prior to a new one being drawn. The mean for each sample is calculated. This permitted a quick method for determining whether mediation occurred in the final model.

Mediator effect sizes are also reported. A small effect $\left(\mathrm{k}^{2}=.01\right)$ suggests that the effect explains $1 \%$ of the total variance; a medium effects size $\left(\mathrm{k}^{2}=.09\right)$ suggests the effect accounts for $9 \%$ of the total variance; and a large effect size $\left(\mathrm{k}^{2}=.25\right)$ suggests that the effect accounts for $25 \%$ of the variance (Field, 2014; Preacher \& Kelley, 2011). 


\section{Chapter 4}

\section{Results}

In this chapter, the results of my analysis are reported. Response rates and sample characteristics are first discussed, followed by findings of the measurement models and structural model.

\section{Response Rate and Sample Size}

Of the 7,364 emails distributed containing a link to the survey, five emails were undelivered/bounced. 1,309 email recipients completed the survey, for a response rate of 18\%. Since the study focuses on frontline RNs, 633 are not eligible for inclusion in the study: 579 held positions of leadership, 25 are Nurse Practitioners, and seven are Registered Practical Nurses. These positions are excluded as, compared to RNs, these groups have significantly different roles, tasks, responsibilities and reporting structures. These differences result in different interactions. In addition, five individuals are excluded as they emailed the researcher, indicating that they are unable to properly complete the survey; four had never received an evaluation and one considered herself both leadership and frontline. Having a performance appraisal was important as several of the questions on the survey refer to 'the authority figure who conducts their performance evaluation.' Finally 13 duplicates are also removed, identified by IP address, date and time of survey completion. The final sample consisted of 676 eligible/usable complete cases with no missing data for analysis.

\section{Sample Characteristics}

What follows is a series of tables and explanatory prose to report results. Descriptive analyses are completed to summarize characteristics about the respondents including: age, education, number of organizations employed by, employment status, geographic location, union status, involvement in academia, primary area of practice, years of nursing experience, years working with current organization, years working in current department, years working with current supervisor, and years remaining before retirement. 
Z-tests are performed to determine if there are any statistical differences between the study sample distribution and the CNO data representing all Ontario nurses. P-values are calculated for twotailed comparisons of age, gender, employment status, number of employers and Local Health Integration Network (LHIN), see Appendix R. The far-right columns in Table 4.1 through Table 4.5, are marked with an “*” to indicate the presence of a significant difference between the study sample and the population of Ontario nurses. Recall that an effect size of 0.2 constitutes a small effect; 0.5 constitutes a medium effects size; and 0.8 constitutes a large effect size. The few categories that have statistical differences only have small effect sizes, with the exception of the “Hamilton Niagara Haldimand Brant” LHIN which has a small to medium effect size. Based on these findings, the study sample appears to be representative of the Ontario nursing population.

The majority of respondents (59.6\%) are above the age of 45 . Only 5.0\% are under the age of 25. The sample data reflects the 2014 CNO membership statistics, which is representative of all Ontario RNs. All RNs in Ontario are required to register with the CNO in order to practice. Of study respondents, $4.1 \%$ of the sample are male. This too is in keeping with all Ontario RNs as per the College of Nurses of Ontario data, which identifies $6.1 \%$ of their RN membership as male (CNO, 2015). These data are summarized in Table 4.1 and Table 4.2.

Table 4.1. Summary of Age

\begin{tabular}{|c|c|c|c|c|}
\hline \multirow[t]{2}{*}{ Characteristic } & & $\begin{array}{c}\text { This Study } \\
\text { (RNAO) } \\
\mathrm{N}=676\end{array}$ & $\begin{array}{c}\text { All Ontario RNs (CNO } \\
\text { data, 2014) } \\
\mathrm{N}=104,298\end{array}$ & \multirow[t]{2}{*}{$\begin{array}{l}\text { Significant Difference } \\
\text { b/w groups (Cohen's } d \text { ) }\end{array}$} \\
\hline & & (\%) & (\%) & \\
\hline \multirow[t]{11}{*}{ Age } & & & & \\
\hline & $18-24$ & 5.0 & 4.1 & \\
\hline & $25-29$ & 10.5 & 10.0 & \\
\hline & $30-34$ & 9.3 & 9.5 & \\
\hline & $35-39$ & 7.1 & 9.7 & $* 0.1877$ \\
\hline & $40-44$ & 8.4 & 12.2 & $* 0.2291$ \\
\hline & $45-49$ & 12.6 & 13.7 & \\
\hline & $50-54$ & 15.7 & 14.0 & \\
\hline & $55-59$ & 16.1 & 13.0 & *0.1379 \\
\hline & $60-64$ & 11.2 & 9.2 & \\
\hline & $>=65$ & 4.0 & 4.6 & \\
\hline
\end{tabular}

*Note: results may not add to 100 due to rounding 
Table 4.2. Gender

\begin{tabular}{|c|c|c|c|}
\hline Characteristic & $\begin{array}{l}\text { This Study } \\
\text { (RNAO) } \\
\mathrm{N}=676\end{array}$ & $\begin{array}{l}\text { All Ontario RNs } \\
\text { (CNO data, 2014) } \\
\text { N = 104, } 298\end{array}$ & $\begin{array}{c}\text { Significant Difference b/w } \\
\text { groups }\left({ }^{*}\right)\end{array}$ \\
\hline & $(\%)$ & $(\%)$ & \\
\hline \multicolumn{4}{|l|}{ Gender } \\
\hline Male & 4.1 & 6.1 & $* 0.2307$ \\
\hline Female & 95.9 & 93.9 & *0.2307 \\
\hline
\end{tabular}

A large portion of the respondents (67.9\%) work full time. Part-time workers account for 26.3\% of the sample, and the remainder are casual employees (5.8\%). $79.4 \%$ work for one organization, $18.2 \%$ work for two organizations, and 2.3\% work for three or more organizations. Once again, these findings are very similar to the population of RNs in Ontario. The results are presented in Table 4.3 and Table 4.4 .

Table 4.3. Employment Status

\begin{tabular}{|lccl|}
\hline Employment & $\begin{array}{c}\text { This Study } \\
\text { (RNAO) } \\
\mathrm{N}=676\end{array}$ & $\begin{array}{c}\text { All Ontario RNs } \\
\text { (CNO data, 2014) } \\
\mathrm{N}=104,298\end{array}$ & $\begin{array}{c}\text { Significant Difference } \\
\text { b/w groups }(*)\end{array}$ \\
\hline FT & $(\%)$ & $(\%)$ & \\
PT & 67.9 & 66.5 & \\
Casual & 26.3 & 26.2 & \\
\hline
\end{tabular}

Table 4.4. Number of Employers

\begin{tabular}{|lccc|}
\hline \# Employers & $\begin{array}{c}\text { This Study } \\
\text { (RNAO) } \\
\mathrm{N}=676\end{array}$ & $\begin{array}{c}\text { All Ontario RNs } \\
(\mathrm{CNO} \text { data, 2014) } \\
\mathrm{N}=104,298\end{array}$ & Significant Difference b/w groups (*) \\
& $(\%)$ & $(\%)$ & $* 0.1786$ \\
1 & 79.4 & 84.2 & $* 0.1815$ \\
$3+$ & 18.2 & 13.8 & \\
\hline
\end{tabular}

The highest percentage of respondents work in the Toronto Central LHIN (17.6\%), Champlain LHIN (12.0\%), and South West LHIN (10.9\%). The fewest respondents work- in North West 
(4.0\%), Central West (3.8\%), North Simcoe Muskoka (3.3\%) and Erie St. Claire (2.8\%). These results are in keeping with the College of Nurses of Ontario membership statistics by LHIN (CNO, 2015). As mentioned above, the few categories that have statistical differences only have small effect sizes, with the exception of the "Hamilton Niagara Haldimand Brant” LHIN, which only has a small to medium effect size. The study sample appears representative of the Ontario nursing population. These data are presented in Table 4.5.

Table 4.5. Distribution by LHIN

\begin{tabular}{|c|c|c|c|}
\hline \multirow{2}{*}{ Characteristic } & $\begin{array}{l}\text { This Study } \\
\text { (RNAO) }\end{array}$ & $\begin{array}{l}\text { All Ontario RNs } \\
\text { (CNO data, 2014) }\end{array}$ & \multirow{2}{*}{$\begin{array}{c}\text { Significant } \\
\text { Difference b/w } \\
\text { groups (*) }\end{array}$} \\
\hline & $\begin{array}{c}N=676 \\
(\%)\end{array}$ & $\begin{array}{c}\mathrm{N}=104,298 \\
(\%)\end{array}$ & \\
\hline \multicolumn{4}{|l|}{ LHIN } \\
\hline Central & 8.1 & 8.6 & \\
\hline Central East & 8.9 & 8.4 & \\
\hline Central West & 3.8 & 3.3 & \\
\hline Champlain & 12.0 & 10.6 & \\
\hline Erie St Clair & 2.8 & 4.6 & $* 0.284$ \\
\hline Hamilton Niagara Haldimand & 6.2 & 10.8 & *0.3337 \\
\hline Mississauga Halton & 7.2 & 6.8 & \\
\hline North East & 5.0 & 5.4 & \\
\hline North Simcoe Muskoka & 3.3 & 3.4 & \\
\hline North West & 4.0 & 2.6 & \\
\hline South East & 5.0 & 4.6 & \\
\hline South West & 10.9 & 8.7 & *0.1377 \\
\hline Toronto Central & 17.6 & 17.5 & \\
\hline Waterloo Wellington & 5.0 & 4.6 & \\
\hline
\end{tabular}

*Note: results may not add to 100 due to rounding

Based on the above demographics, the sample is a fair representation of the RN population of Ontario, the population of interest in this study. Unable to compare these data with the CNO, the following are additional respondent characteristics. The majority of respondents are unionized (62.4\%), with a few individuals unsure (0.6\%). A high proportion work in urban settings, defined as a major city or town (79.6\%). A large portion of the sample hold undergraduate degrees (50.7\%) or college diplomas (35.2\%). Fourteen percent hold a graduate degree report being 
involved in academia (e.g., regularly participate in research, education, and scholarship). Community (45\%) and hospitals (41.3\%) account for the largest percentage of nursing employers. 4.5\% work in Long Term Care, and 9.3\% report 'other' for care setting. These data are presented in Table 4.6.

\section{Table 4.6. Additional Respondent Characteristics}

\begin{tabular}{|c|c|}
\hline Characteristic & $\%$ \\
\hline \multicolumn{2}{|l|}{ Unionized } \\
\hline Yes & 62.4 \\
\hline No & 37.0 \\
\hline Unsure & 0.6 \\
\hline \multicolumn{2}{|l|}{ Organization Location } \\
\hline Urban & 79.6 \\
\hline Rural & 20.4 \\
\hline \multicolumn{2}{|l|}{ Nursing Employer } \\
\hline Hospital & 41.3 \\
\hline Community & 45.0 \\
\hline LTC & 4.4 \\
\hline Other & 9.3 \\
\hline \multicolumn{2}{|l|}{ Education } \\
\hline College Diploma & 35.2 \\
\hline University Undergraduate & 50.7 \\
\hline Graduate Degree & 14.1 \\
\hline \multicolumn{2}{|l|}{ Academia } \\
\hline Yes & 29.6 \\
\hline No & 70.4 \\
\hline
\end{tabular}

*Note: $\mathrm{N}=676$, \% results may not add to 100 due to rounding

Regarding primary area of practice, respondents had the option of specifying 'Other.' The highest percentage of respondents selected 'Other' (57.3\%), with just over a quarter of the sample (27.2\%) identifying as primary care workers. Examples of 'Other' areas of practice included pediatrics, professional practice, endoscopy, ambulatory care, and clinical informatics to name a few. See Table 4.7 for primary areas of practice. 
Table 4.7. Primary Area of Practice

\begin{tabular}{|cl|}
\hline Characteristic & \\
\hline Primary Area of Practice & $\%$ \\
Primary care & 26.6 \\
Cardiac & 0.7 \\
Critical & 4.3 \\
Emergency & 3.6 \\
medicine, surgery, or combined & 8.1 \\
Other & 56.7 \\
\hline
\end{tabular}

*Note: $\mathrm{N}=676, \%$ results may not add to 100 due to rounding

Amongst the respondents, the lowest percentage of respondents (3.1\%) have less than one year of experience, and the highest percentage of respondents (13.3\%) have 1-4 years of experience. The highest percentage of respondents are fairly new to their organizations, having worked with their organization 1-4 years (28.2\%) and 5-10 years (25.8\%). Similarly, approximately one third of respondents have worked in their current department for 1-4 years (33\%) and 5-10 years (28.1\%). Over half of the sample have worked with their current supervisor for 1-4 years (53.7\%) and almost a quarter (23.8\%) for less than a year. Over half of the sample (56.1\%) will be retiring in the next 15 years. For a summary of years of experience and employment characteristics, see Table 4.8.

Table 4.8. Years of Experience and Employment Characteristics

\begin{tabular}{|rcccccccccc|}
\hline Characteristic & $<1$ & $1-4$ & $5-10$ & $11-15$ & $16-20$ & $21-25$ & $26-30$ & $31-35$ & $36-40$ & $>=41$ \\
\hline \# Years & $\%$ & $\%$ & $\%$ & $\%$ & $\%$ & $\%$ & $\%$ & $\%$ & $\%$ & $\%$ \\
$\begin{array}{r}\text { Nursing } \\
\text { experience: }\end{array}$ & 3.1 & 13.3 & 11.1 & 8.4 & 11.2 & 12.1 & 12.6 & 11.2 & 8.9 & 8.0 \\
$\begin{array}{r}\text { With current } \\
\text { organization: }\end{array}$ & 8.3 & 28.4 & 25.6 & 16.4 & 5.9 & 4.6 & 6.8 & 2.7 & 0.9 & 0.4 \\
$\begin{array}{r}\text { In current } \\
\text { department: }\end{array}$ & 11.7 & 33.1 & 28.0 & 15.8 & 4.0 & 4.3 & 2.1 & 0.6 & 0.3 & 0.1 \\
$\begin{array}{r}\text { Under current } \\
\text { supervisor: }\end{array}$ & 24.3 & 53.4 & 16.6 & 3.3 & 1.6 & 0.7 & 0.1 & 0.0 & 0.0 & 0.0 \\
$\begin{array}{r}\text { Remaining before } \\
\text { retirement: }\end{array}$ & 3.4 & 17.8 & 20.1 & 13.6 & 9.0 & 9.6 & 7.0 & 7.1 & 4.3 & 7.2 \\
\hline
\end{tabular}

*Note: $\mathrm{N}=676$, \% results may not add to 100 due to rounding 


\section{Study Instruments}

The frequencies, means, and standard deviations of responses for each of the study variables were calculated in SPSS and are reported below. There is no missing data and a sufficiently large sample. LISREL was used to produce Univariate Normality statistics, see Appendix S. With the exception of a few items that have mild skew and kurtosis, the items are relatively normally distributed. Multivariate normality is assessed via 'Relative Multivariate Kurtosis,' the Mardiabased kappa, rescaled to have a mean of 1. The Relative Multivariate Kurtosis for this sample is 1.122. Since this value is close to 1 , the distribution is multivariate normal (Jöreskog \& Sörbom, 2002). The variables and included relationships are suitable and satisfy the assumptions, and no fatal errors were obtained in LISREL. All five assumptions underlying path analysis are met: (1) The relations between variables in the model are linear; (2) The errors associated with endogenous variables are not correlated with the variables that are predicting that variable; (3) There is only a one-way causal flow in the model; (4) The variables are measured on at least an interval or nearinterval scale; and (5) The variables are measured without error. In addition, normality of the scales are also tested in SPSS so that histograms, P-P and Q-Q plots could also be viewed. The scales met normality, with the exception of a few that are slightly skewed, and one (Affective Commitment to Patients) which had more severe kurtosis. The histograms, P-P and Q-Q plots can be found in Appendix T.

\section{Organizational Justice}

Organizational justice items use a Likert scale ranging from 1 (Very Small Extent) to 5 (Very Large Extent). $\quad$ Table 4.9 shows the mean score for each scale: $M_{\text {procedural justice }}=3.02, S D=0.99$; $M_{\text {distributive justice }}=3.09, S D=1.03 ; M_{\text {interpersonal justice }}=3.88, S D=1.11$; and $M_{\text {informational justice }}=3.35$, $S D=1.11$. Table 4.10 to Table 4.15 display the frequency distributions for the items in these scales. 
Table 4.9. Descriptive Statistics for Instruments

\begin{tabular}{|c|c|c|c|c|c|c|c|c|c|}
\hline & \multicolumn{9}{|c|}{ Std. } \\
\hline & \multirow[b]{3}{*}{ Statistic } & \multirow{3}{*}{$\begin{array}{l}\text { Minimum } \\
\text { Statistic }\end{array}$} & \multirow{3}{*}{$\begin{array}{l}\text { Maximum } \\
\text { Statistic }\end{array}$} & \multirow{3}{*}{$\begin{array}{l}\text { Mean } \\
\text { Statistic }\end{array}$} & \multirow{3}{*}{$\begin{array}{l}\text { Deviation } \\
\text { Statistic }\end{array}$} & \multicolumn{2}{|c|}{ Skewness } & \multicolumn{2}{|c|}{ Kurtosis } \\
\hline & & & & & & & Std. & & Std. \\
\hline & & & & & & Statistic & Error & Statistic & Error \\
\hline GMJD & 676 & 1.00 & 5.00 & 3.0884 & 1.02670 & $\begin{array}{l}-.358 \\
\end{array}$ & .094 & -.532 & .188 \\
\hline GMJP & 676 & 1.00 & 5.00 & 3.0224 & .98502 & -.254 & .094 & -.419 & .188 \\
\hline GMJInper & 676 & 1.00 & 5.00 & 3.8772 & 1.10801 & -.898 & .094 & .029 & .188 \\
\hline GMJInfo & 676 & 1.00 & 5.00 & 3.3503 & 1.11130 & -.419 & .094 & -.594 & .188 \\
\hline GMPOS & 676 & 1.00 & 7.00 & 4.0906 & 1.54069 & .002 & .094 & -.682 & .188 \\
\hline GMACorg & 676 & 1.00 & 5.00 & 3.8772 & 1.01067 & -.814 & .094 & .004 & .188 \\
\hline GMACsup & 676 & 1.00 & 5.00 & 3.3969 & 1.22916 & -.413 & .094 & -.807 & .188 \\
\hline GMACco & 676 & 1.00 & 5.00 & 4.1627 & .91902 & -1.249 & .094 & 1.105 & .188 \\
\hline GMACpt & 676 & 1.00 & 5.00 & 4.6548 & .52449 & -2.024 & .094 & 5.559 & .188 \\
\hline GMACprof & 676 & 1.00 & 5.00 & 4.2771 & .82540 & -1.356 & .094 & 1.615 & .188 \\
\hline GMACwrk & 676 & 1.00 & 5.00 & 3.6558 & .84418 & -.577 & .094 & -.038 & .188 \\
\hline GMACtsk & 676 & 1.00 & 5.00 & 4.0385 & .86800 & -1.094 & .094 & 1.223 & .188 \\
\hline GMACcar & 676 & 1.00 & 5.00 & 3.7855 & .84416 & -.463 & .094 & -.316 & .188 \\
\hline GMOCBI & 676 & 1.00 & 5.00 & 4.0292 & .57303 & -.608 & .094 & 1.331 & .188 \\
\hline GMOCBO & 676 & 1.00 & 5.00 & 3.6104 & .68529 & -.391 & .094 & .208 & .188 \\
\hline $\begin{array}{l}\text { Valid N } \\
\text { (listwise) }\end{array}$ & 676 & & & & & & & & \\
\hline
\end{tabular}

Table 4.10. Distributive Justice Frequencies

\begin{tabular}{|c|c|c|c|c|c|c|}
\hline & & $\begin{array}{l}\text { Very } \\
\text { Small } \\
\text { Extent } \\
\%\end{array}$ & $\begin{array}{c}\text { Small } \\
\text { Extent } \\
\%\end{array}$ & $\begin{array}{l}\text { Moderate } \\
\text { Extent } \\
\text { \% }\end{array}$ & $\begin{array}{c}\text { Large } \\
\text { Extent } \\
\%\end{array}$ & $\begin{array}{c}\text { Very } \\
\text { Large } \\
\text { Extent } \\
\%\end{array}$ \\
\hline JD1 & $\begin{array}{l}\text { The following items refer to your } \\
\text { performance evaluation. To what extent: } \\
\text { Does your performance evaluation reflect } \\
\text { the effort you have put into your work? }\end{array}$ & 10.5 & 15.7 & 32.5 & $32.7 \%$ & 8.6 \\
\hline JD2 & $\begin{array}{l}\text { Is your performance evaluation appropriate } \\
\text { for the work you have completed? }\end{array}$ & 9.8 & 18.5 & 30.2 & 34.8 & 6.8 \\
\hline JD3 & $\begin{array}{l}\text { Does your performance evaluation reflect } \\
\text { what you have contributed to the } \\
\text { organization? }\end{array}$ & 13.0 & 21.4 & 32.0 & 27.4 & 6.2 \\
\hline JD4 & $\begin{array}{l}\text { Is your performance evaluation justified, } \\
\text { given your performance? }\end{array}$ & 10.4 & 13.6 & 30.3 & 37.6 & 8.1 \\
\hline
\end{tabular}

*Note: results may not add to 100 due to rounding 
Table 4.11. Procedural Justice Frequencies

\begin{tabular}{|c|c|c|c|c|c|c|}
\hline & & $\begin{array}{c}\text { Very } \\
\text { Small } \\
\text { Extent } \\
\%\end{array}$ & $\begin{array}{c}\text { Small } \\
\text { Extent } \\
\%\end{array}$ & $\begin{array}{l}\text { Moderate } \\
\text { Extent } \\
\%\end{array}$ & $\begin{array}{c}\text { Large } \\
\text { Extent } \\
\%\end{array}$ & $\begin{array}{c}\text { Very } \\
\text { Large } \\
\text { Extent } \\
\%\end{array}$ \\
\hline & $\begin{array}{l}\text { The following items refer to the } \\
\text { procedures used to arrive at your } \\
\text { performance evaluation. In other } \\
\text { words, it refers to the procedures or } \\
\text { processes used to evaluate you. To } \\
\text { what extent: }\end{array}$ & & & & & \\
\hline JP1 & $\begin{array}{l}\text { Have you been able to express your } \\
\text { views and feelings during the process? }\end{array}$ & 10.9 & 15.5 & 29.4 & 29.9 & 14.2 \\
\hline JP2 & $\begin{array}{l}\text { Have you had influence over the } \\
\text { outcome of your performance } \\
\text { appraisal? }\end{array}$ & 13.9 & 19.8 & 33.4 & 26.6 & 6.2 \\
\hline JP3 & $\begin{array}{l}\text { Have those procedures been applied } \\
\text { consistently? }\end{array}$ & 14.3 & 17.5 & 35.2 & 25.9 & 7.1 \\
\hline JP4 & $\begin{array}{l}\text { Have those procedures been free of } \\
\text { bias? }\end{array}$ & 13.5 & 17.9 & 32.1 & 29.0 & 7.5 \\
\hline JP5 & $\begin{array}{l}\text { Have those procedures been based on } \\
\text { accurate information? }\end{array}$ & 11.1 & 14.2 & 34.5 & 32.7 & 7.5 \\
\hline JP6 & $\begin{array}{l}\text { Have you been able to appeal the } \\
\text { outcome of your performance } \\
\text { appraisal? }\end{array}$ & 21.7 & 16.9 & 31.1 & 24.3 & 6.1 \\
\hline JP7 & $\begin{array}{l}\text { Have those procedures upheld ethical } \\
\text { and moral standards? }\end{array}$ & 11.2 & 11.7 & 32.4 & 32.4 & 12.3 \\
\hline
\end{tabular}

*Note: results may not add to 100 due to rounding

Table 4.12. Interpersonal Justice Frequencies

\begin{tabular}{|llccccc|}
\hline & & $\begin{array}{c}\text { Very } \\
\text { Small } \\
\text { Extent } \\
\%\end{array}$ & $\begin{array}{c}\text { Small } \\
\text { Extent }\end{array}$ & $\begin{array}{c}\text { Moderate } \\
\text { Extent }\end{array}$ & $\begin{array}{c}\text { Large } \\
\text { Extent } \\
\%\end{array}$ & $\begin{array}{c}\text { Very } \\
\text { Large } \\
\text { Extent } \\
\%\end{array}$ \\
\hline & $\begin{array}{l}\text { The following items refer to the } \\
\text { AUTHORITY FIGURE who conducts } \\
\text { your performance evaluation. To what }\end{array}$ & & & & & \\
& extent: & & & & & \\
JInper1 & Has she/he treated you in a polite manner? & 4.1 & 6.8 & 15.7 & 35.5 & 37.9 \\
JInper2 & Has she/he treated you with dignity? & 5.6 & 7.4 & 17.3 & 33.6 & 36.1 \\
JInper3 & Has she/he treated you with respect? & 6.1 & 8.7 & 17.3 & 31.7 & 36.2 \\
JInper4 & Has she/he refrained from improper remarks & 7.1 & 7.8 & 16.9 & 30.0 & 38.2 \\
& or comments? & & & & & \\
\hline
\end{tabular}

*Note: results may not add to 100 due to rounding 
Table 4.13. Informational Justice Frequencies

\begin{tabular}{|c|c|c|c|c|c|c|}
\hline & & $\begin{array}{c}\text { Very } \\
\text { Small } \\
\text { Extent } \\
\%\end{array}$ & $\begin{array}{c}\text { Small } \\
\text { Extent } \\
\%\end{array}$ & $\begin{array}{l}\text { Moderate } \\
\text { Extent } \\
\%\end{array}$ & $\begin{array}{c}\text { Large } \\
\text { Extent } \\
\%\end{array}$ & $\begin{array}{c}\text { Very } \\
\text { Large } \\
\text { Extent } \\
\%\end{array}$ \\
\hline JInfo1 & $\begin{array}{l}\text { The following items refer to the } \\
\text { AUTHORITY FIGURE who conducts } \\
\text { your performance evaluation. To } \\
\text { what extent: } \\
\text { Has she/he been candid } \\
\text { (truthful/straightforward) in her/his } \\
\text { communication with you? }\end{array}$ & 6.8 & 8.9 & 22.6 & 37.9 & 23.8 \\
\hline JInfo2 & $\begin{array}{l}\text { Has she/he explained the procedures for } \\
\text { determining your evaluation thoroughly? }\end{array}$ & 11.2 & 12.9 & 24.4 & 33.6 & 17.9 \\
\hline JInfo3 & $\begin{array}{l}\text { Were her/his explanations regarding the } \\
\text { procedures reasonable? }\end{array}$ & 10.9 & 10.1 & 26.0 & 35.1 & 17.9 \\
\hline JInfo4 & $\begin{array}{l}\text { Has she/he communicated pertinent } \\
\text { details in a timely manner? }\end{array}$ & 13.9 & 14.9 & 25.4 & 30.2 & 15.5 \\
\hline JInfo5 & $\begin{array}{l}\text { Has she/he seemed to tailor her/his } \\
\text { communications to individuals' specific } \\
\text { needs? }\end{array}$ & 14.1 & 14.6 & 23.8 & 31.5 & 16.0 \\
\hline
\end{tabular}

*Note: results may not add to 100 due to rounding

\section{Perceived Organizational Support (POS)}

The POS scale is a Likert scale ranging from 1 (Strongly Disagree) to 7 (Strongly Agree). Table 4.9 shows the mean score for POS, $M_{P O S}=4.09, S D=1.54$. Table 4.14 displays the frequency distributions for the items in this scale. Negatively worded items are identified with italics. Negative items have been reverse coded so that in each case agreement indicates the positive response. 
Table 4.14. Perceived Organizational Support

\begin{tabular}{|c|c|c|c|c|c|c|c|c|}
\hline & \multirow[t]{2}{*}{ POS } & 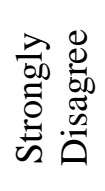 & 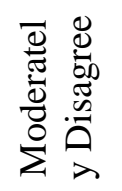 & 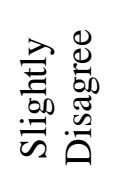 & 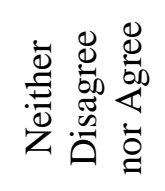 & 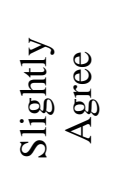 & 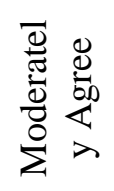 & 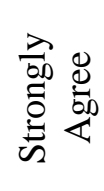 \\
\hline & & $\%$ & $\%$ & $\%$ & $\%$ & $\%$ & $\%$ & $\%$ \\
\hline & $\begin{array}{l}\text { The following statements } \\
\text { represent possible opinions that } \\
\text { YOU may have about working } \\
\text { at your organization. Please } \\
\text { indicate the degree of your } \\
\text { agreement or disagreement with } \\
\text { each statement. }\end{array}$ & & & & & & & \\
\hline POS1 & $\begin{array}{l}\text { The organization values my } \\
\text { contribution to its well-being. }\end{array}$ & 9.8 & 8.4 & 9.9 & 12.6 & 17.6 & 27.5 & 14.2 \\
\hline POS2 & $\begin{array}{l}\text { The organization fails to } \\
\text { appreciate any extra effort from } \\
\text { me }\end{array}$ & 9.8 & 13.8 & 10.2 & 12.4 & 18.0 & 18.2 & 17.6 \\
\hline POS3 & $\begin{array}{l}\text { The organization would ignore } \\
\text { any complaint from me. }\end{array}$ & 13.2 & 19.8 & 17.0 & 12.9 & 14.9 & 14.3 & 7.8 \\
\hline POS4 & $\begin{array}{l}\text { The organization really cares } \\
\text { about my well-being. }\end{array}$ & 13.0 & 14.2 & 11.4 & 14.5 & 17.2 & 19.4 & 10.4 \\
\hline POS5 & $\begin{array}{l}\text { Even if I did the best job } \\
\text { possible, the organization would } \\
\text { fail to notice. }\end{array}$ & 12.1 & 14.6 & 14.1 & 13.8 & 17.3 & 15.5 & 12.6 \\
\hline POS6 & $\begin{array}{l}\text { The organization cares about my } \\
\text { general satisfaction at work. }\end{array}$ & 14.9 & 13.2 & 12.7 & 14.6 & 19.4 & 16.7 & 8.4 \\
\hline POS7 & $\begin{array}{l}\text { The organization shows very } \\
\text { little concern for me. }\end{array}$ & 12.9 & 15.1 & 15.1 & 17.3 & 14.1 & 13.5 & 12.1 \\
\hline POS8 & $\begin{array}{l}\text { The organization takes pride in } \\
\text { my accomplishments at work. }\end{array}$ & 11.1 & 9.9 & 10.7 & 20.4 & 21.4 & 15.1 & 11.4 \\
\hline
\end{tabular}




\section{Affective Commitment}

The affective commitment scales are Likert scales ranging from 1 (Totally Disagree) to 5 (Totally Agree). Table 4.9 shows the mean affective commitment scores for each of the eight targets. The highest mean affective commitment score relates to patients (Mpatients $=4.65, \mathrm{SD}=0.52$ ). This is followed by profession (Mprofession $=4.28, \mathrm{SD}=0.83$ ), co-workers (Mco-workers $=4.16$, $\mathrm{SD}$ $=0.92$ ), tasks (Mtasks $=4.04, \mathrm{SD}=0.87$ ), the organization (Morganization $=3.88, \mathrm{SD}=1.01$ ), one’s career $($ Mcareer $=3.79, \mathrm{SD}=0.84)$ and work $($ Mwork $=3.66, \mathrm{SD}=0.84)$. The lowest mean affective commitment score relates to one's supervisor (Msupervisor $=3.40, \mathrm{SD}=1.23$ ). Table 4.15 through Table 4.22 display the frequency distributions for the items in this scale. Negatively worded items are identified with italics. Negative items have been reverse coded so that in each case agreement indicates the positive response.

Table 4.15. Frequency Distribution - Affective Commitment to the Organization

\begin{tabular}{|c|c|c|c|c|c|c|}
\hline & $\begin{array}{l}\text { Affective Commitment to the } \\
\text { Organization }\end{array}$ & $\begin{array}{c}\text { Totally } \\
\text { Disagree } \\
\%\end{array}$ & $\begin{array}{c}\text { Partly } \\
\text { Disagree } \\
\%\end{array}$ & $\begin{array}{c}\text { Neutral } \\
\%\end{array}$ & $\begin{array}{l}\text { Partly } \\
\text { Agree } \\
\%\end{array}$ & $\begin{array}{l}\text { Totally } \\
\text { Agree } \\
\%\end{array}$ \\
\hline & $\begin{array}{l}\text { The following items express } \\
\text { what YOU may feel about } \\
\text { yourself as a member of your } \\
\text { organization. }\end{array}$ & & & & & \\
\hline ACorg1 & $\begin{array}{l}\text { I am proud to say that I work } \\
\text { for my organization }\end{array}$ & 4.4 & 5.8 & 20.0 & 32.0 & 37.9 \\
\hline ACorg2 & $\begin{array}{l}\text { My organization means a lot to } \\
\text { me }\end{array}$ & 4.3 & 8.0 & 24.7 & 34.5 & 28.6 \\
\hline ACorg3_Rec & $\begin{array}{l}\text { I DON'T like working for my } \\
\text { organization }\end{array}$ & 47.9 & 20.0 & 16.4 & 10.7 & 5.0 \\
\hline
\end{tabular}

*Note: results may not add to 100 due to rounding 
Table 4.16. Frequency Distribution - Affective Commitment to Supervisor

\begin{tabular}{|c|c|c|c|c|c|c|}
\hline & Affective Commitment to Supervisor & $\begin{array}{c}\text { Totally } \\
\text { Disagree } \\
\% \\
\end{array}$ & $\begin{array}{c}\text { Partly } \\
\text { Disagree } \\
\% \\
\end{array}$ & $\begin{array}{c}\text { Neutral } \\
\% \\
\end{array}$ & $\begin{array}{l}\text { Partly } \\
\text { Agree } \\
\% \\
\end{array}$ & $\begin{array}{l}\text { Totally } \\
\text { Agree } \\
\% \\
\end{array}$ \\
\hline ACsup1 & $\begin{array}{l}\text { The following items express what YOU } \\
\text { may feel about yourself as a member of } \\
\text { your organization. } \\
\text { I like the values conveyed by the } \\
\text { authority figure who conducts my } \\
\text { performance evaluation } \\
\text { I feel privileged to work with someone }\end{array}$ & 9.9 & 11.2 & 24.7 & 28.1 & 26.0 \\
\hline ACsup2 & $\begin{array}{l}\text { like the authority figure who conducts my } \\
\text { performance evaluation }\end{array}$ & 13.8 & 12.9 & 25.9 & 23.4 & 24.1 \\
\hline ACsup3 & $\begin{array}{l}\text { When I talk to my friends about the } \\
\text { authority figure who conducts my } \\
\text { performance evaluation, I describe } \\
\text { him/her as a great person to work with }\end{array}$ & 12.4 & 13.0 & 23.8 & 24.9 & 25.9 \\
\hline
\end{tabular}

*Note: results may not add to 100 due to rounding

Table 4.17. Frequency Distribution - Affective Commitment to Co-workers

\begin{tabular}{|c|c|c|c|c|c|c|}
\hline & $\begin{array}{l}\text { Affective Commitment to Co- } \\
\text { workers }\end{array}$ & $\begin{array}{c}\text { Totally } \\
\text { Disagree } \\
\%\end{array}$ & $\begin{array}{c}\text { Partly } \\
\text { Disagree } \\
\%\end{array}$ & $\begin{array}{c}\text { Neutral } \\
\%\end{array}$ & $\begin{array}{l}\text { Partly } \\
\text { Agree } \\
\%\end{array}$ & $\begin{array}{l}\text { Totally } \\
\text { Agree } \\
\%\end{array}$ \\
\hline ACco1 & $\begin{array}{l}\text { The following items express what } \\
\text { YOU may feel about yourself as a } \\
\text { member of your organization. } \\
\text { I'm happy to work with my co- } \\
\text { workers in my unit (includes } \\
\text { interprofessional) }\end{array}$ & 0.7 & 6.7 & 5.9 & 31.4 & 55.3 \\
\hline ACco2 & $\begin{array}{l}\text { My co-workers in my unit } \\
\text { (includes interprofessional) make } \\
\text { me feel like going to work }\end{array}$ & 3.1 & 7.1 & 15.7 & 33.7 & 40.4 \\
\hline ACco3 & $\begin{array}{l}\text { When I talk to my friends about } \\
\text { my co-workers in my unit } \\
\text { (includes interprofessional), I } \\
\text { describe them as great people to } \\
\text { work with }\end{array}$ & 2.5 & 5.9 & 12.6 & 33.3 & 45.7 \\
\hline
\end{tabular}

*Note: results may not add to 100 due to rounding 
Table 4.18. Frequency Distribution - Affective Commitment to Patients

\begin{tabular}{|c|c|c|c|c|c|c|}
\hline & Affective Commitment to Patient & $\begin{array}{c}\text { Totally } \\
\text { Disagree } \\
\%\end{array}$ & $\begin{array}{c}\text { Partly } \\
\text { Disagree } \\
\%\end{array}$ & $\begin{array}{l}\text { Neutral } \\
\text { \% }\end{array}$ & $\begin{array}{l}\text { Partly } \\
\text { Agree } \\
\%\end{array}$ & $\begin{array}{l}\text { Totally } \\
\text { Agree } \\
\%\end{array}$ \\
\hline & $\begin{array}{l}\text { The following items express what } \\
\text { YOU may feel about yourself as a } \\
\text { member of your organization. }\end{array}$ & & & & & \\
\hline ACpt1 & $\begin{array}{l}\text { I really care about the satisfaction of } \\
\text { my organization's patients }\end{array}$ & 0.4 & 0 & 3.0 & 13.2 & 83.4 \\
\hline ACpt2 & $\begin{array}{l}\text { Delivering quality care and/or services } \\
\text { to my organization's patients is a } \\
\text { major source of satisfaction for me }\end{array}$ & 0.4 & 0.6 & 2.8 & 17.0 & 79.1 \\
\hline ACpt3 & $\begin{array}{l}\text { In my opinion, the satisfaction of my } \\
\text { organization's patients is a priority }\end{array}$ & 2.5 & 1.9 & 8.1 & 24.4 & 63.0 \\
\hline
\end{tabular}

*Note: results may not add to 100 due to rounding

Table 4.19. Frequency Distribution - Affective Commitment to Profession

\begin{tabular}{|c|c|c|c|c|c|c|}
\hline & Affective Commitment to Profession & $\begin{array}{c}\text { Totally } \\
\text { Disagree } \\
\%\end{array}$ & $\begin{array}{c}\text { Partly } \\
\text { Disagree } \\
\%\end{array}$ & $\begin{array}{c}\text { Neutral } \\
\text { \% }\end{array}$ & $\begin{array}{l}\text { Partly } \\
\text { Agree } \\
\%\end{array}$ & $\begin{array}{c}\text { Totally } \\
\text { Agree } \\
\%\end{array}$ \\
\hline & $\begin{array}{l}\text { The following items express what } \\
\text { YOU may feel about yourself as a } \\
\text { member of your organization. }\end{array}$ & & & & & \\
\hline ACprof1 & $\begin{array}{l}\text { I'm proud to say this is my } \\
\text { profession }\end{array}$ & 0.9 & 1.3 & 4.7 & 15.8 & 77.2 \\
\hline ACprof2 & $\begin{array}{l}\text { I would be happy to practice this } \\
\text { profession until retirement }\end{array}$ & 3.7 & 4.7 & 11.5 & 20.4 & 59.6 \\
\hline ACprof3 & $\begin{array}{l}\text { I like my profession too much to } \\
\text { think about changing }\end{array}$ & 4.0 & 10.9 & 17.0 & 28.7 & 39.3 \\
\hline
\end{tabular}

*Note: results may not add to 100 due to rounding 
Table 4.20. Frequency Distribution - Affective Commitment to Work

\begin{tabular}{|c|c|c|c|c|c|c|}
\hline & Affective Commitment to Work & $\begin{array}{l}\text { Totally } \\
\text { Disagree } \\
\%\end{array}$ & $\begin{array}{c}\text { Partly } \\
\text { Disagree } \\
\%\end{array}$ & $\begin{array}{c}\text { Neutral } \\
\%\end{array}$ & $\begin{array}{l}\text { Partly } \\
\text { Agree } \\
\quad \%\end{array}$ & $\begin{array}{l}\text { Totally } \\
\text { Agree } \\
\%\end{array}$ \\
\hline & $\begin{array}{l}\text { The following items express what } \\
\text { YOU may feel about yourself as a } \\
\text { member of your organization. }\end{array}$ & & & & & \\
\hline ACwrk1 & Work is a priority in my life & 3.0 & 8.0 & 14.8 & 40.8 & 33.4 \\
\hline ACwrk2 & $\begin{array}{l}\text { One of the most satisfying things in } \\
\text { my life is the fact that I work }\end{array}$ & 2.2 & 9.8 & 13.9 & 41.6 & 32.5 \\
\hline ACwrk3 & $\begin{array}{l}\text { Most of my personal objectives are } \\
\text { focused on work }\end{array}$ & 7.7 & 23.1 & 28.8 & 31.8 & 8.6 \\
\hline
\end{tabular}

*Note: results may not add to 100 due to rounding

Table 4.21. Frequency Distribution - Affective Commitment to Tasks

\begin{tabular}{|c|c|c|c|c|c|c|}
\hline & Affective Commitment to Tasks & $\begin{array}{c}\text { Totally } \\
\text { Disagree } \\
\% \\
\end{array}$ & $\begin{array}{c}\text { Partly } \\
\text { Disagree } \\
\% \\
\end{array}$ & $\begin{array}{c}\text { Neutral } \\
\% \\
\end{array}$ & $\begin{array}{c}\text { Partly } \\
\text { Agree } \\
\% \\
\end{array}$ & $\begin{array}{c}\text { Totally } \\
\text { Agree } \\
\% \\
\end{array}$ \\
\hline ACtsk1 & $\begin{array}{l}\text { The following items express what } \\
\text { YOU may feel about yourself as a } \\
\text { member of your organization. } \\
\text { I find the tasks I perform in my } \\
\text { current position stimulating }\end{array}$ & 2.7 & 6.5 & 11.8 & 41.9 & 37.1 \\
\hline ACtsk2 & $\begin{array}{l}\text { I find the tasks I perform in my } \\
\text { current position rewarding }\end{array}$ & 2.4 & 5.3 & 8.7 & 42.9 & 40.7 \\
\hline ACtsk3_Rec & $\begin{array}{l}\text { I DON'T like the tasks I perform in } \\
\text { my current position }\end{array}$ & 39.2 & 30.9 & 16.3 & 10.9 & 2.7 \\
\hline
\end{tabular}

*Note: results may not add to 100 due to rounding 
Table 4.22. Frequency Distribution - Affective Commitment to Career

\begin{tabular}{|c|c|c|c|c|c|c|}
\hline & Affective Commitment to Career & $\begin{array}{c}\text { Totally } \\
\text { Disagree } \\
\%\end{array}$ & $\begin{array}{c}\text { Partly } \\
\text { Disagree } \\
\%\end{array}$ & $\begin{array}{c}\text { Neutral } \\
\%\end{array}$ & $\begin{array}{c}\text { Partly } \\
\text { Agree } \\
\%\end{array}$ & $\begin{array}{c}\text { Totally } \\
\text { Agree } \\
\%\end{array}$ \\
\hline ACcar1 & $\begin{array}{l}\text { The following items express what } \\
\text { YOU may feel about yourself as a } \\
\text { member of your organization. } \\
\text { I would like to hold increasingly } \\
\text { important positions throughout my } \\
\text { career }\end{array}$ & 5.0 & 6.4 & 24.4 & 26.3 & 37.9 \\
\hline ACcar2 & $\begin{array}{l}\text { It is important for me to move up } \\
\text { the ranks or obtain promotions }\end{array}$ & 12.6 & 13.5 & 29.6 & 26.8 & 17.6 \\
\hline ACcar3 & $\begin{array}{l}\text { I feel it is important to plan one's } \\
\text { career }\end{array}$ & 0.6 & 1.6 & 14.1 & 38.0 & 45.7 \\
\hline
\end{tabular}

*Note: results may not add to 100 due to rounding

\section{Organizational Citizenship Behaviour (OCB).}

The OCB scales are Likert scales ranging from 1 (Never) to 5 (Always). Table 4.9 shows the mean scores for $\mathrm{OCBI}$ and OCBO, $M_{\mathrm{OCBI}}=4.03, S D=0.57$ and $M_{\mathrm{OCBO}}=3.61, S D=0.69$. Table 4.23 and Table 4.24 display the frequency distributions for the items in these scales.

Table 4.23. Organizational Citizenship Behaviours to Individuals (OCBI)

\begin{tabular}{|c|c|c|c|c|c|c|}
\hline & & $\begin{array}{c}\text { Never } \\
\%\end{array}$ & $\begin{array}{c}\text { Rarely } \\
\%\end{array}$ & $\begin{array}{c}\text { Sometimes } \\
\%\end{array}$ & $\begin{array}{c}\text { Often } \\
\%\end{array}$ & $\begin{array}{c}\text { Always } \\
\%\end{array}$ \\
\hline & $\begin{array}{l}\text { To what extent do you agree with the } \\
\text { following statements? }\end{array}$ & & & & & \\
\hline OCBI1 & Help others who have been absent. & 1.2 & 1.9 & 17.5 & 48.2 & 31.2 \\
\hline OCBI2 & $\begin{array}{l}\text { Willingly give your time to help others who } \\
\text { have work-related problems. }\end{array}$ & 0.4 & 0.9 & 18.2 & 46.0 & 34.5 \\
\hline OCBI3 & $\begin{array}{l}\text { Adjust your work schedule to accommodate } \\
\text { other employees' requests for time off. }\end{array}$ & 1.8 & 5.8 & 32.0 & 42.0 & 18.5 \\
\hline OCBI4 & $\begin{array}{l}\text { Go out of the way to make newer employees } \\
\text { feel welcome in the work group. }\end{array}$ & 0.9 & 0.9 & 6.8 & 38.2 & 53.3 \\
\hline OCBI5 & $\begin{array}{l}\text { Show genuine concern and courtesy toward } \\
\text { coworkers, even under the most trying business } \\
\text { or personal situations. }\end{array}$ & 0.3 & 0.3 & 7.2 & 42.2 & 50.0 \\
\hline OCBI6 & $\begin{array}{l}\text { Give up time to help others who have work or } \\
\text { nonwork problems. }\end{array}$ & 1.2 & 2.8 & 25.9 & 42.8 & 27.4 \\
\hline OCBI7 & Assist others with their duties. & 0.6 & 0.1 & 14.5 & 48.2 & 36.5 \\
\hline OCBI8 & $\begin{array}{l}\text { Share personal property with others to help } \\
\text { their work. }\end{array}$ & 7.4 & 14.2 & 29.3 & 30.6 & 18.5 \\
\hline
\end{tabular}

*Note: results may not add to 100 due to rounding 
Table 4.24. Organizational Citizenship Behaviours to the Organization (OCBO)

\begin{tabular}{|c|c|c|c|c|c|c|}
\hline & & $\begin{array}{l}\text { Never } \\
\%\end{array}$ & $\begin{array}{l}\text { Rarely } \\
\%\end{array}$ & $\begin{array}{l}\text { Sometimes } \\
\%\end{array}$ & $\begin{array}{c}\text { Often } \\
\%\end{array}$ & $\begin{array}{l}\text { Always } \\
\%\end{array}$ \\
\hline & $\begin{array}{l}\text { To what extent do you agree with the } \\
\text { following statements? }\end{array}$ & & & & & \\
\hline OCBO1 & $\begin{array}{l}\text { Attend functions that are not required but that } \\
\text { help the organizational image. }\end{array}$ & 8.7 & 21.4 & 39.2 & 25.9 & 4.7 \\
\hline OCBO2 & $\begin{array}{l}\text { Keep up with developments in the } \\
\text { organization. }\end{array}$ & 0.4 & 4.1 & 22.3 & 52.2 & 20.9 \\
\hline OCBO3 & $\begin{array}{l}\text { Defend the organization when other } \\
\text { employees criticize it. }\end{array}$ & 5.3 & 13.6 & 43.0 & 28.6 & 9.5 \\
\hline OCBO4 & $\begin{array}{l}\text { Show pride when representing the } \\
\text { organization in public. }\end{array}$ & 2.1 & 5.2 & 21.9 & 38.6 & 32.2 \\
\hline OCBO5 & $\begin{array}{l}\text { Offer ideas to improve the functioning of the } \\
\text { organization. }\end{array}$ & 1.6 & 8.1 & 33.3 & 39.6 & 17.3 \\
\hline OCBO6 & Express loyalty toward the organization. & 2.1 & 7.2 & 25.0 & 41.7 & 24.0 \\
\hline OCBO7 & $\begin{array}{l}\text { Take action to protect the organization from } \\
\text { potential problems. }\end{array}$ & 2.1 & 7.1 & 28.6 & 37.7 & 24.6 \\
\hline OCBO8 & $\begin{array}{l}\text { Demonstrate concern about the image of the } \\
\text { organization. }\end{array}$ & 2.2 & 8.7 & 29.4 & 36.8 & 22.8 \\
\hline
\end{tabular}

*Note: results may not add to 100 due to rounding

\section{Measurement Models and Reliability}

Before attempting the Structural Equation Model, confirmatory factor analysis (CFA) was performed on each of the constructs as a stand-alone analysis to determine if the relationships between the variables in the hypothesized model resemble the relationships between the variables in the observed data set (Meyers, 2013).

\section{Confirmatory Factor Analysis for Perceived Organizational Justice}

Colquitt's (2001) organizational justice scale measures four constructs of organizational justice: distributive (4 items), procedural (7 items), interpersonal (4 items), and informational (5 items). Item definitions can be found in Table 4.25 through Table 4.28. 
Table 4.25. Distributive Justice Indicators

Survey Item - Distributive

Label

The following items refer to your performance evaluation. To what extent:

Does your performance evaluation reflect the effort you have put into your work?

JD1

Is your performance evaluation appropriate for the work you have completed?

JD2

Does your performance evaluation reflect what you have contributed to the organization? JD3

Is your performance evaluation justified, given your performance?

JD4

Table 4.26. Procedural Justice Indicators

The following items refer to the procedures used to arrive at your performance evaluation. In other words, it refers to the procedures or processes used to Label evaluate you. To what extent:

Have you been able to express your views and feelings during the process?

JP1

Have you had influence over the outcome of your performance appraisal?

Have those procedures been applied consistently?

Have those procedures been free of bias?

Have those procedures been based on accurate information?

JP5

Have you been able to appeal the outcome of your performance appraisal?

Have those procedures upheld ethical and moral standards?

JP7

Table 4.27. Interpersonal Justice Indicators

Survey Item - Interpersonal

Label

The following items refer to the AUTHORITY FIGURE who conducts your

performance evaluation. To what extent:

Has she/he treated you in a polite manner?

JInper1

Has she/he treated you with dignity?

JInper2

Has she/he treated you with respect?

JInper3

Has she/he refrained from improper remarks or comments?

JInper4 
Table 4.28. Informational Justice Indicators

Survey Item - Informational

Label

The following items refer to the AUTHORITY FIGURE who conducts your performance evaluation. To what extent:

Has she/he been candid (truthful/straightforward) in her/his communication with you? JInfo1

Has she/he explained the procedures for determining your evaluation thoroughly? JInfo2

Are her/his explanations regarding the procedures reasonable? JInfo3

Has she/he communicated pertinent details in a timely manner? JInfo4

Has she/he seemed to tailor her/his communications to individuals’ specific needs? JInfo5

All twenty items are included in the CFA. Figure 4.1 depicts the path diagram created. All paths are significant at the 0.000 level. The correlation matrix for each measured item is presented in Appendix U. The correlation matrix for independent variables (the latent constructs) can be found in Appendix V.

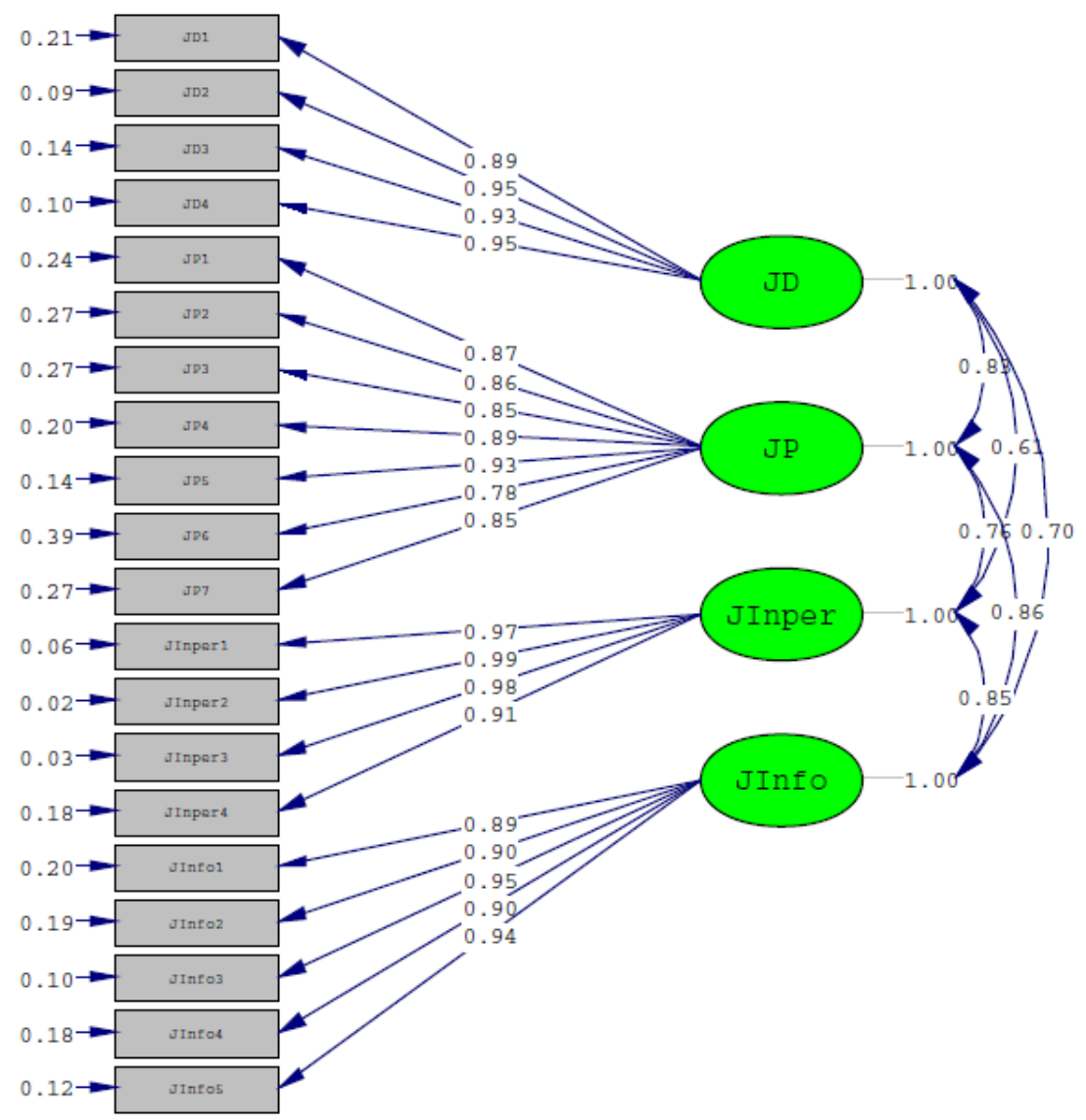

Figure 4.1. CFA Path Diagram for Organizational Justice. 
It is suggested that two variables correlated in the middle .7s or higher, should probably not be used together in a regression or any other multivariate analysis (Meyers, 2013), and one is almost certain to encounter problems if a correlation is above .8 (Allison, 1999). Upon review of the correlation matrices in Appendix U and Appendix V, the high correlations between the observed indicators and the very high correlation between the latent constructs, suggests that multicollinearity is a concern. Recall that multicollinearity can distort results in SEM and potentially cause difficulties in determining the unique contribution of the variables to a factor (Field, 2014). A brief discussion regarding these high correlations and its implications can be found later in this chapter at the end of the SEM section, and a more in depth discussion is located in the Discussion, Chapter 5.

Goodness of fit indices. The CFA for the organizational justice model yields the following goodness of fit indices: $\chi^{2}=1179.989(\mathrm{P}=0.0000)$; $d f=164$; $\mathrm{RMSEA}=0.0957$; $\mathrm{SRMR}=0.0303$; $\mathrm{NFI}=0.981$; CFI $=0.983$; GFI $=0.853$. In this example, the chi-square is significant, suggesting a poor fit; this is not surprising, given the large sample size (several hundred cases) (Meyers, 2013). However, based on the other fit statistics, even though I am using more liberal parameters, one can see that this model fits conservative cut offs of NFI and CFI values above .95, and a SRMR value of less than .06.

Reliability analysis. The overall reliability analysis for the distributive justice measure in this study is .947 (excellent). In Table 4.29, one can see that in the Scale Mean and Scale Variance if Item Deleted columns, the deletion of any one item does not greatly affect the value. There are no corrected item-total correlations less than .3. Finally, in the Cronbach's Alpha if Item Deleted column, there are no values of $\alpha$ greater than the overall $\alpha(.947)$. 
Table 4.29. Item-Total Statistics for Distributive Justice

\begin{tabular}{|lrrrr|}
\hline & $\begin{array}{c}\text { Scale Mean if } \\
\text { Item Deleted }\end{array}$ & $\begin{array}{c}\text { Scale Variance } \\
\text { if Item Deleted }\end{array}$ & $\begin{array}{c}\text { Corrected Item- } \\
\text { Total Correlation }\end{array}$ & $\begin{array}{c}\text { Cronbach's } \\
\text { Alpha if Item } \\
\text { Deleted }\end{array}$ \\
\hline JD1 & 9.22 & 9.734 & .852 & .937 \\
JD2 & 9.25 & 9.569 & .907 & .920 \\
JD3 & 9.43 & 9.635 & .860 & .934 \\
JD4 & 9.16 & 9.680 & .870 & .931 \\
\hline
\end{tabular}

The overall reliability analysis for the procedural justice measure in this study is .939 (excellent). In Table 4.30, one can see that in the Scale Mean and Scale Variance if Item Deleted columns, the deletion of any one item does not greatly affect the value. There are no corrected item-total correlations less than .3. Finally, in the Cronbach's Alpha if Item Deleted column, there are no values of $\alpha$ greater than the overall $\alpha(.939)$.

Table 4.30. Item-Total Statistics for Procedural Justice

\begin{tabular}{|lrrrr|}
\hline & $\begin{array}{c}\text { Scale Mean if } \\
\text { Item Deleted }\end{array}$ & $\begin{array}{c}\text { Scale Variance } \\
\text { if Item Deleted }\end{array}$ & $\begin{array}{c}\text { Corrected Item- } \\
\text { Total Correlation }\end{array}$ & $\begin{array}{c}\text { Cronbach's } \\
\text { Alpha if Item } \\
\text { Deleted }\end{array}$ \\
\hline JP1 & 17.95 & 34.754 & .810 & .928 \\
JP2 & 18.24 & 35.571 & .799 & .929 \\
JP3 & 18.22 & 35.533 & .792 & .930 \\
JP4 & 18.16 & 35.053 & .824 & .927 \\
JP5 & 18.04 & 35.209 & .855 & .925 \\
JP6 & 18.40 & 35.588 & .725 & .936 \\
JP7 & 17.93 & 35.293 & .796 & .930 \\
\hline
\end{tabular}

The overall reliability analysis for the interpersonal justice measure in this study is .968 (excellent). In Table 4.31, one can see that in the Scale Mean and Scale Variance if Item Deleted columns, the deletion of any one item does not greatly affect the value. There are no corrected item-total correlations less than .3. However, based on Cronbach's $\alpha$ if Item Deleted column, if JInper4 was to be deleted, the Cronbach's $\alpha$ would increase to .977 , suggesting that removal of this item would improve reliability. However, this was not done as the value is already considered excellent. 
Table 4.31. Item-Total Statistics for Interpersonal Justice

\begin{tabular}{|lrrrr|}
\hline & $\begin{array}{c}\text { Scale Mean if } \\
\text { Item Deleted }\end{array}$ & $\begin{array}{c}\text { Scale Variance } \\
\text { if Item Deleted }\end{array}$ & $\begin{array}{c}\text { Corrected Item- } \\
\text { Total Correlation }\end{array}$ & $\begin{array}{c}\text { Cronbach's } \\
\text { Alpha if Item } \\
\text { Deleted }\end{array}$ \\
\hline JInper1 & 11.55 & 11.543 & .937 & .953 \\
JInner2 & 11.64 & 11.031 & .955 & .947 \\
JInner3 & 11.68 & 10.889 & .940 & .951 \\
JInper4 & 11.67 & 11.210 & .853 & .977 \\
\hline
\end{tabular}

The overall reliability analysis for the informational justice measure in this study is .947 (excellent). In Table 4.32, one can see that in the Scale Mean and Scale Variance if Item Deleted columns, the deletion of any one item does not greatly affect the value. There are no corrected item-total correlations less than .3. Finally, in the Cronbach's Alpha if Item Deleted column, there are no values of $\alpha$ greater than the overall $\alpha(.947)$.

Table 4.32. Item-Total Statistics for Informational Justice

\begin{tabular}{|lrrrr|}
\hline & $\begin{array}{c}\text { Scale Mean if } \\
\text { Item Deleted }\end{array}$ & $\begin{array}{c}\text { Scale Variance } \\
\text { if Item Deleted }\end{array}$ & $\begin{array}{c}\text { Corrected Item- } \\
\text { Total Correlation }\end{array}$ & $\begin{array}{c}\text { Cronbach's } \\
\text { Alpha if Item } \\
\text { Deleted }\end{array}$ \\
\hline JInfo1 & 13.12 & 21.061 & .815 & .941 \\
JInfo2 & 13.41 & 20.059 & .843 & .936 \\
JInfo3 & 13.36 & 19.846 & .890 & .928 \\
JInfo4 & 13.57 & 19.736 & .850 & .935 \\
Jinfo5 & 13.54 & 19.410 & .877 & .930 \\
\hline
\end{tabular}

Decision: Based on accumulation of evidence of three of the five goodness of fit indices and reliability findings, it is appropriate to include this four factor construct of organizational justice in the SEM. Although modification of the constructs are not performed in this study, a more conservative approach including review of standardized residuals is discussed in Appendix W. 


\section{Confirmatory Factor Analysis for Perceived Organizational Support}

Perceived Organizational Support (POS) (Rhoades et al., 2001) consists of eight indicators, POS1 through POS8 in Table 4.33. All eight indicators are included in the CFA. Figure 4.2 depicts the path diagram created. All paths are significant at the 0.000 level. The correlation matrix generated is presented in Appendix X. Upon review of the correlation matrix in Appendix X, the high correlations between the observed indicators suggests that multicollinearity may prove to be a concern during structural equation modelling, when all constructs are included simultaneously in the model. A brief discussion regarding these high correlations and its implications can be found later in this chapter at the end of the SEM section, and a more in depth discussion is located in the Discussion, Chapter 5.

\section{Table 4.33. POS Indicators}

\begin{tabular}{|lc|}
\hline Survey Item - POS & Label \\
\hline $\begin{array}{l}\text { The following statements represent possible opinions that YOU may } \\
\text { have about working at your organization. Please indicate the degree } \\
\text { of your agreement or disagreement with each statement. }\end{array}$ \\
$\begin{array}{l}\text { The organization values my contribution to its well-being. } \\
\text { The organization fails to appreciate any extra effort from me. }\end{array}$ \\
$\begin{array}{l}\text { The organization would ignore any complaint from me. } \\
\text { The organization really cares about my well-being. }\end{array}$ & POS2_Rec \\
Even if I did the best job possible, the organization would fail to notice. & POS3_Rec \\
The organization cares about my general satisfaction at work. & POS4 \\
The organization shows very little concern for me. & POS6 \\
The organization takes pride in my accomplishments at work. & POS7_Rec \\
\hline
\end{tabular}




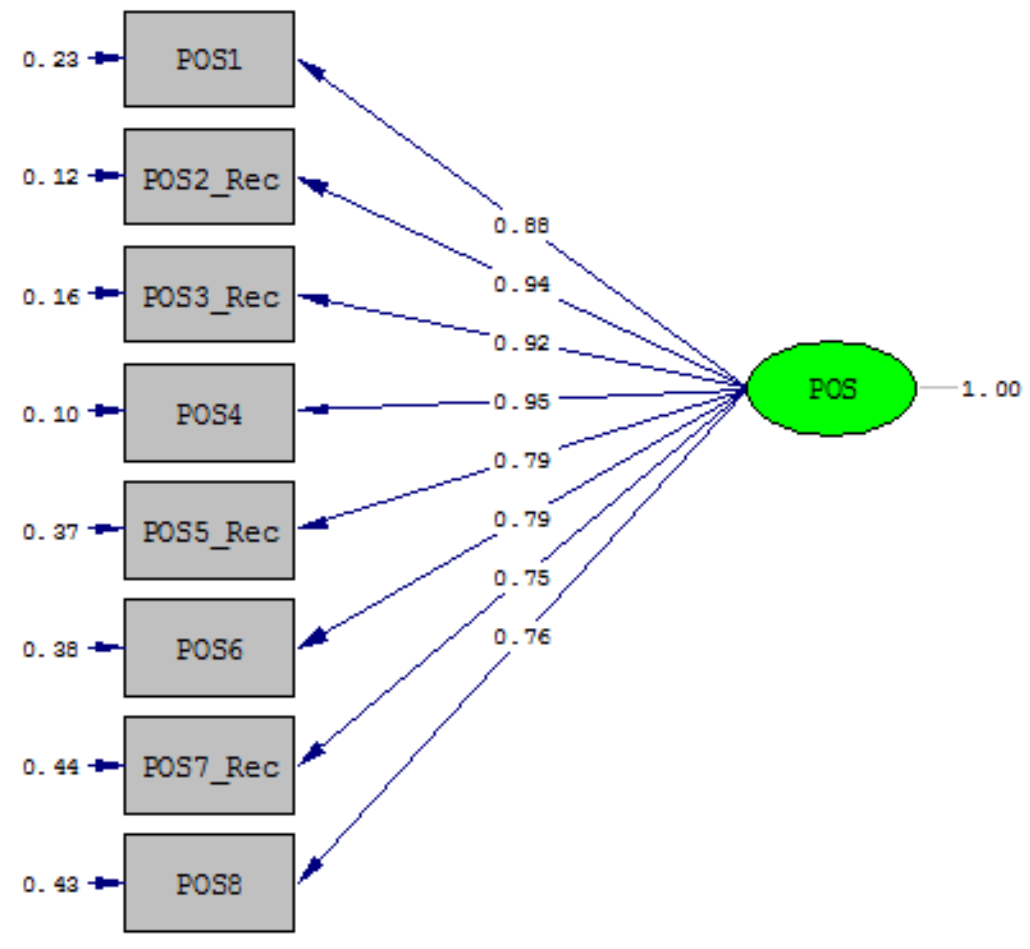

Figure 4.2. CFA Path Diagram for POS.

Goodness of fit indices. The CFA for the POS model yields the following goodness of fit indices: $\chi^{2}=813.222(\mathrm{P}=0.0000) ; d f=20$; RMSEA $=.242 ;$ SRMR $=.0757 ; \mathrm{NFI}=.921 ; \mathrm{CFI}=$ $.922 ; \mathrm{GFI}=.710$. Once again, determination of goodness of fit was based on the accumulation of evidence across all the statistics. Both the NFI and CFI are above .90, and SRMR is less than .08.

Reliability analysis. The overall reliability for the POS scale in this study is .925 (excellent). In Table 4.34, one can see that in the Scale Mean and Scale Variance if Item Deleted columns, the deletion of any one item would not greatly affect the value. There are no corrected item-total correlations less than .3. Finally, in the Cronbach's Alpha if Item Deleted column, there are no values of $\alpha$ greater than the overall $\alpha(.925)$. 
Table 4.34. POS Item-Total Statistics

\begin{tabular}{|lrrrr|}
\hline & $\begin{array}{c}\text { Scale Mean if } \\
\text { Item Deleted }\end{array}$ & $\begin{array}{c}\text { Scale Variance } \\
\text { if Item Deleted }\end{array}$ & $\begin{array}{c}\text { Corrected Item- } \\
\text { Total Correlation }\end{array}$ & $\begin{array}{c}\text { Alpha if Item } \\
\text { Deleted }\end{array}$ \\
\hline POS1 & 28.13 & 117.529 & .758 & .914 \\
POS2_Recode & 29.13 & 120.375 & .641 & .923 \\
POS3_Recode & 28.43 & 120.222 & .688 & .919 \\
POS4 & 28.64 & 115.608 & .784 & .912 \\
POS5_Recode & 28.79 & 116.881 & .748 & .915 \\
POS6 & 28.78 & 116.007 & .788 & .912 \\
POS7_Recode & 28.66 & 115.188 & .802 & .911 \\
POS8 & 28.50 & 118.674 & .756 & .914 \\
\hline
\end{tabular}

Decision: Based on accumulation of evidence of three of the five goodness of fit indices and reliability findings, and taking a less conservative approach to cut off values, it is appropriate to include this 1 factor POS construct in the SEM. Although modification of the construct is not performed in this study, a more conservative approach including review of standardized residuals is discussed in Appendix $Y$.

\section{Confirmatory Factor Analysis for Affective Commitment}

Affective commitment consists of eight targets (each with 3 items), for a total of 24 items; see Table 4.35. Affective Commitment Indicators (Morin et al., 2013). All 24 items are included in the CFA. Figure 4.3 depicts the path diagram created. All paths are significant at the 0.000 level. The correlation matrix for each measured item is presented in Appendix Z. The correlation matrix for independent variables (the latent constructs) can be found in Appendix AA. Upon review of the correlation matrices in Appendix $\mathrm{Z}$ and Appendix AA, no correlations are very high ( $\geq .8)$, indicating multicollinearity will most likely not be a concern in this model, as compared to the previous two models. 
Table 4.35. Affective Commitment Indicators

\begin{tabular}{|c|c|}
\hline \multirow{2}{*}{\multicolumn{2}{|c|}{$\begin{array}{l}\text { Survey Item - Affective Commitment } \\
\text { The following items express what YOU may feel about yourself as a member of your } \\
\text { organization. }\end{array}$}} \\
\hline & \\
\hline I am proud to say that I work for my organization & ACorg1 \\
\hline My organization means a lot to me & ACorg2 \\
\hline I don't like working for my organization & ACorg3_Rec \\
\hline $\begin{array}{l}\text { I like the values conveyed by the authority figure who conducts my performance } \\
\text { evaluation }\end{array}$ & ACsup1 \\
\hline $\begin{array}{l}\text { I feel privileged to work with someone like the authority figure who conducts my } \\
\text { performance evaluation }\end{array}$ & ACsup2 \\
\hline $\begin{array}{l}\text { When I talk to my friends about the authority figure who conducts my performance } \\
\text { evaluation, I describe him/her as a great person to work with }\end{array}$ & ACsup3 \\
\hline $\begin{array}{l}\text { I'm happy to work with my co-workers in my unit (includes interprofessional - a group of } \\
\text { individuals from different disciplines working and communicating with each other) }\end{array}$ & ACco1 \\
\hline My co-workers in my unit (includes interprofessional) make me feel like going to work & ACco2 \\
\hline $\begin{array}{l}\text { When I talk to my friends about my co-workers in my unit (includes interprofessional), I } \\
\text { describe them as great people to work with }\end{array}$ & ACco3 \\
\hline I really care about the satisfaction of my organization's patients & ACpt1 \\
\hline $\begin{array}{l}\text { Delivering quality care and/or services to my organization's patients is a major source of } \\
\text { satisfaction for me }\end{array}$ & ACpt2 \\
\hline In my opinion, the satisfaction of my organization's patients is a priority & ACpt3 \\
\hline Work is a priority in my life & ACprof1 \\
\hline I would be happy to practice this profession until retirement & ACprof2 \\
\hline I like my profession too much to think about changing & ACprof3 \\
\hline Work is a priority in my life & ACwrk1 \\
\hline One of the most satisfying things in my life is the fact that I work & ACwrk2 \\
\hline Most of my personal objectives are focused on work & ACwrk3 \\
\hline I find the tasks I perform in my current position stimulating & ACtsk1 \\
\hline I find the tasks I perform in my current position rewarding & ACtsk2 \\
\hline I don't like the tasks I perform in my current position & ACtsk3_Rec \\
\hline I would like to hold increasingly important positions throughout my career & ACcar1 \\
\hline It is important for me to move up the ranks or obtain promotions & ACcar2 \\
\hline I feel it is important to plan one's career & ACcar3 \\
\hline
\end{tabular}




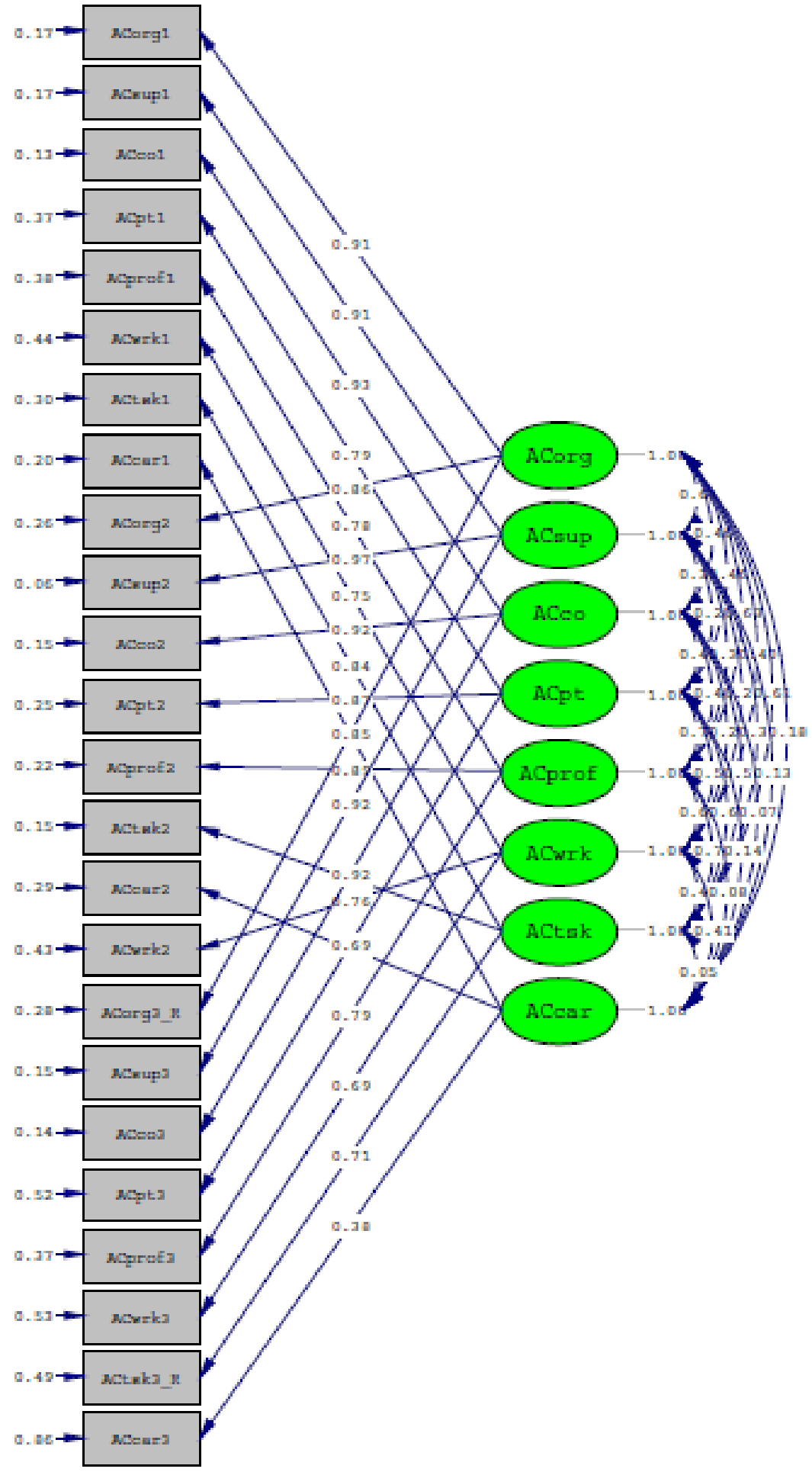

Figure 4.3. CFA Path Diagram for Affective Commitment. 
Goodness of Fit Indices. The CFA for the Affective Commitment model yielded the following goodness of fit indices: $\chi^{2}=1670.956(\mathrm{P}=0.0000)$; $d f=224$; RMSEA = 0.0978; SRMR $=0.0618 ; \mathrm{NFI}=0.935 ; \mathrm{CFI}=0.943 ; \mathrm{GFI}=0.831$. Once again, determination of goodness of fit was based on the accumulation of evidence across all the statistics. Both the NFI and CFI are above .90, and SRMR is less than .08.

Reliability analysis. The overall reliability for the affective commitment to the organization scale in this study is .863 (good). In Table 4.36, one can see that in the Scale Mean and Scale Variance if Item Deleted columns, the deletion of any one item would not greatly affect the value. There are no corrected item-total correlations less than .3. Finally, in the Cronbach's Alpha if Item Deleted column, there are no values of $\alpha$ greater than the overall $\alpha$ (.863).

Table 4.36. Item-Total Statistics for Affective Commitment to their Organization

\begin{tabular}{|lrrrr|}
\hline & $\begin{array}{c}\text { Scale Mean if } \\
\text { Item Deleted }\end{array}$ & $\begin{array}{c}\text { Scale Variance } \\
\text { if Item Deleted }\end{array}$ & $\begin{array}{c}\text { Corrected Item- } \\
\text { Total Correlation }\end{array}$ & $\begin{array}{c}\text { Cronbach's } \\
\text { Alpha if Item } \\
\text { Deleted }\end{array}$ \\
\hline ACorg1 & 7.70 & 4.376 & .786 & .766 \\
ACorg2 & 7.88 & 4.623 & .727 & .820 \\
ACorg3_recode & 7.68 & 4.099 & .715 & .837 \\
\hline
\end{tabular}

The overall reliability for the affective commitment to one's supervisor scale in this study is .933 (excellent). In Table 4.37, one can see that in the Scale if Item Deleted columns, the deletion of any one item would not greatly affect the value. There are no corrected item-total correlations less than .3. Finally, in the Cronbach's Alpha if Item Deleted column, there are no values of $\alpha$ greater than the overall $\alpha(.933)$.

Table 4.37. Item-Total Statistics for Affective Commitment to their Supervisor

\begin{tabular}{|lrrrr|}
\hline & $\begin{array}{c}\text { Scale Mean if } \\
\text { Item Deleted }\end{array}$ & $\begin{array}{c}\text { Scale Variance } \\
\text { if Item Deleted }\end{array}$ & $\begin{array}{c}\text { Corrected Item- } \\
\text { Total Correlation }\end{array}$ & $\begin{array}{c}\text { Cronbach's } \\
\text { Alpha if Item } \\
\text { Deleted }\end{array}$ \\
\hline ACsup1 & 6.70 & 6.554 & .844 & .918 \\
ACsup2 & 6.88 & 6.009 & .887 & .883 \\
ACsup3 & 6.80 & 6.173 & .858 & .907 \\
\hline
\end{tabular}

The overall reliability for the affective commitment to one’s co-workers scale in this study is .911 (excellent). In Table 4.38, one can see that in the Scale Mean and Scale Variance if Item Deleted 
columns, the deletion of any one item would not greatly affect the value. There are no corrected item-total correlations less than .3. Finally, in the Cronbach's Alpha if Item Deleted column, there are no values of $\alpha$ greater than the overall $\alpha(.911)$.

Table 4.38. Item-Total Statistics for Affective Commitment to their Co-workers

\begin{tabular}{|lrrrr|}
\hline & $\begin{array}{c}\text { Scale Mean if } \\
\text { Item Deleted }\end{array}$ & $\begin{array}{c}\text { Scale Variance } \\
\text { if Item Deleted }\end{array}$ & $\begin{array}{c}\text { Corrected Item- } \\
\text { Total Correlation }\end{array}$ & $\begin{array}{c}\text { Cronbach's } \\
\text { Alpha if Item } \\
\text { Deleted }\end{array}$ \\
\hline ACco1 & 8.15 & 3.843 & .819 & .879 \\
ACco2 & 8.48 & 3.302 & .823 & .873 \\
ACco3 & 8.35 & 3.443 & .832 & .863 \\
\hline
\end{tabular}

The overall reliability for the affective commitment to patients scale in this study is .625 (acceptable). In Table 4.39, one can see that there are no corrected item-total correlations less than .3. In the Scale if Item Deleted columns, the deletion of ACpt1 or ACpt2 would not greatly affect the value. However, are ACpt3 deleted, it would cause a decrease in the scale variance. Based on Cronbach's $\alpha$ if Item Deleted column, the deletion of ACpt3 would result in the increase of Cronbach's $\alpha$ to .641, suggesting that removal of this item would improve reliability. However, since improvement would only be slight, and the model would be left with only two measures, the decision was made not to remove the item.

Table 4.39. Item-Total Statistics for Affective Commitment to their Patients

\begin{tabular}{|lrrrr|}
\hline & $\begin{array}{c}\text { Scale Mean if } \\
\text { Item Deleted }\end{array}$ & $\begin{array}{c}\text { Scale Variance } \\
\text { if Item Deleted }\end{array}$ & $\begin{array}{c}\text { Corrected Item- } \\
\text { Total Correlation }\end{array}$ & $\begin{array}{c}\text { Cronbach's } \\
\text { Alpha if Item } \\
\text { Deleted }\end{array}$ \\
\hline ACpt1 & 9.17 & 1.580 & .466 & .525 \\
ACpt2 & 9.23 & 1.432 & .506 & .457 \\
ACpt3 & 9.53 & .907 & .428 & .641 \\
\hline
\end{tabular}

The overall reliability for affective commitment to profession is .763 (good). In Table 4.40, one can see that there are no corrected item-total correlations less than .3. In the Scale Mean and Scale Variance if Item Deleted columns, the deletion of ACprof1would result in an increase in scale variance. Based on Cronbach's $\alpha$ if Item Deleted column, should ACprof1 be deleted, the Cronbach's $\alpha$ would increase to .777, suggesting that removal of this item would improve reliability. However, the item was not removed as improvement would be slight, and the model would be left with only two measures. 
Table 4.40. Item-Total Statistics for Affective Commitment to their Profession

\begin{tabular}{|lrrrr|}
\hline & $\begin{array}{c}\text { Scale Mean if } \\
\text { Item Deleted }\end{array}$ & $\begin{array}{c}\text { Scale Variance } \\
\text { if Item Deleted }\end{array}$ & $\begin{array}{c}\text { Corrected Item- } \\
\text { Total Correlation }\end{array}$ & $\begin{array}{c}\text { Cronbach's } \\
\text { Alpha if Item } \\
\text { Deleted }\end{array}$ \\
\hline ACprof1 & 8.16 & 4.105 & .531 & .777 \\
ACprof2 & 8.56 & 2.594 & .686 & .572 \\
ACprof3 & 8.95 & 2.445 & .643 & .640 \\
\hline
\end{tabular}

The overall reliability for the affective commitment to their work scale in this study is .727 (good). In Table 4.41, one can see that in the Scale Mean and Scale Variance if Item Deleted columns, the deletion of any one item would not greatly affect the value. There are no corrected item-total correlations less than .3. Finally, in the Cronbach's Alpha if Item Deleted column, there are no values of $\alpha$ greater than the overall $\alpha(.727)$.

Table 4.41. Item-Total Statistics for Affective Commitment to their Work

\begin{tabular}{|lrrrr|}
\hline & $\begin{array}{c}\text { Scale Mean if } \\
\text { Item Deleted }\end{array}$ & $\begin{array}{c}\text { Scale Variance } \\
\text { if Item Deleted }\end{array}$ & $\begin{array}{c}\text { Corrected Item- } \\
\text { Total Correlation }\end{array}$ & $\begin{array}{c}\text { Cronbach's } \\
\text { Alpha if Item } \\
\text { Deleted }\end{array}$ \\
\hline ACwrk1 & 7.03 & 3.249 & .564 & .621 \\
ACwrk2 & 7.04 & 3.297 & .555 & .632 \\
ACwrk3 & 7.86 & 3.174 & .527 & .666 \\
\hline
\end{tabular}

The overall reliability for the affective commitment to tasks scale in this study is .810 (good). In Table 4.42, one can see that in the Scale Mean and Scale Variance if Item Deleted columns, the deletion of any one item would not greatly affect the value. There are no corrected item-total correlations less than .3. However, based on Cronbach's $\alpha$ if Item Deleted column, should ACtsk3_Recode be deleted, the Cronbach's $\alpha$ would increase to .827, suggesting that removal of this item would improve reliability. However, the item was not removed as improvement would be slight, and the model would be left with only two measures.

Table 4.42. Item-Total Statistics for Affective Commitment to Tasks Performed 


\begin{tabular}{|lrrrr|}
\hline & $\begin{array}{c}\text { Scale Mean if } \\
\text { Item Deleted }\end{array}$ & $\begin{array}{c}\text { Scale Variance } \\
\text { if Item Deleted }\end{array}$ & $\begin{array}{c}\text { Corrected Item- } \\
\text { Total Correlation }\end{array}$ & $\begin{array}{c}\text { Alpha if Item } \\
\text { Deleted }\end{array}$ \\
\hline ACtsk1 & 8.07 & 3.333 & .677 & .721 \\
ACtsk2 & 7.97 & 3.344 & .730 & .673 \\
ACtsk3_Recode & 8.18 & 3.224 & .585 & .827 \\
\hline
\end{tabular}

The overall reliability for affective commitment to career is .678 (acceptable). In Table 4.43, one can see that in the corrected item-total correlations column, ACcar3 is borderline .3. In the Scale Mean and Scale Variance if Item Deleted columns, the deletion of ACcar3 would result in an increase in scale variance. Based on Cronbach's $\alpha$ if Item Deleted column, are ACcar3 deleted, the Cronbach's $\alpha$ would increase to .806 , suggesting that removal of this item would improve reliability. Although it would be ideal to improve reliability, the item was not removed as the model would be left with only two measures.

Table 4.43. Item-Total Statistics for Affective Commitment to their Career

\begin{tabular}{|lrrrr|}
\hline & $\begin{array}{c}\text { Scale Mean if } \\
\text { Item Deleted }\end{array}$ & $\begin{array}{c}\text { Scale Variance } \\
\text { if Item Deleted }\end{array}$ & $\begin{array}{c}\text { Corrected Item- } \\
\text { Total Correlation }\end{array}$ & $\begin{array}{c}\text { Cronbach's } \\
\text { Alpha if Item } \\
\text { Deleted }\end{array}$ \\
\hline ACcar1 & 7.50 & 2.639 & .662 & .330 \\
ACcar2 & 8.12 & 2.484 & .603 & .424 \\
ACcar3 & 7.09 & 4.805 & .273 & .806 \\
\hline
\end{tabular}

Decision: Based on accumulation of evidence of three of the five goodness of fit indices and reliability findings, and taking a less conservative approach to cut off values, it is appropriate to include this eight factor construct of affective commitment in the SEM. Although modification is not performed in this study, a more conservative approach including review of standardized residuals is discussed in Appendix BB.

\section{Confirmatory Factor Analysis for Organizational Citizenship Behaviour}

OCBO and OCBI are measured using 8 items each, for a total of 16 items scale, see Table 4.44 (Lee \& Allen, 2002). All 16 items are included in the CFA. Figure 4.4 depicts the path diagram created. All paths are significant at the 0.000 level. The correlation matrix for each measured 
item is presented in Appendix CC. The correlation matrix for Independent variables (the latent constructs) can be found in Appendix DD. Upon review of the correlation matrices in Appendix CC and Appendix DD, no correlations are detected that are very high ( $>$.8), indicating multicollinearity will most likely not be a concern in this construct - in contrast to the previous two constructs.

Table 4.44. OCB Indicators

\begin{tabular}{|lr|}
\hline Survey Item - OCBI & Label \\
\hline To what extent do you agree with the following statements? & \\
I help others who have been absent. & OCBI1 \\
Willingly give your time to help others who have work-related problems. & OCBI2 \\
I adjust my work schedule to accommodate other employees’ requests for & OCBI3 \\
time off. & \\
I go out of the way to make newer employees feel welcome in the work & OCBI4 \\
group. & \\
I show genuine concern and courtesy toward coworkers, even under the & OCBI5 \\
most trying business or personal situations & \\
Give up time to help others who have work or nonwork problems. & OCBI6 \\
I assist others with their duties. & OCBI7 \\
Share personal property with others to help their work. & OCBI8 \\
$\begin{array}{l}\text { Attend functions that are not required but that help the organizational image. } \\
\text { Keep up with developments in the organization. }\end{array}$ & OCBO1 \\
$\begin{array}{l}\text { Defend the organization when other employees criticize it. } \\
\text { Show pride when representing the organization in public. }\end{array}$ & OCBO2 \\
$\begin{array}{l}\text { Offer ideas to improve the functioning of the organization. } \\
\text { Express loyalty toward the organization. }\end{array}$ & OCBO3 \\
Take action to protect the organization from potential problems. & OCBO4 \\
Demonstrate concern about the image of the organization. & OCBO5 \\
\hline
\end{tabular}




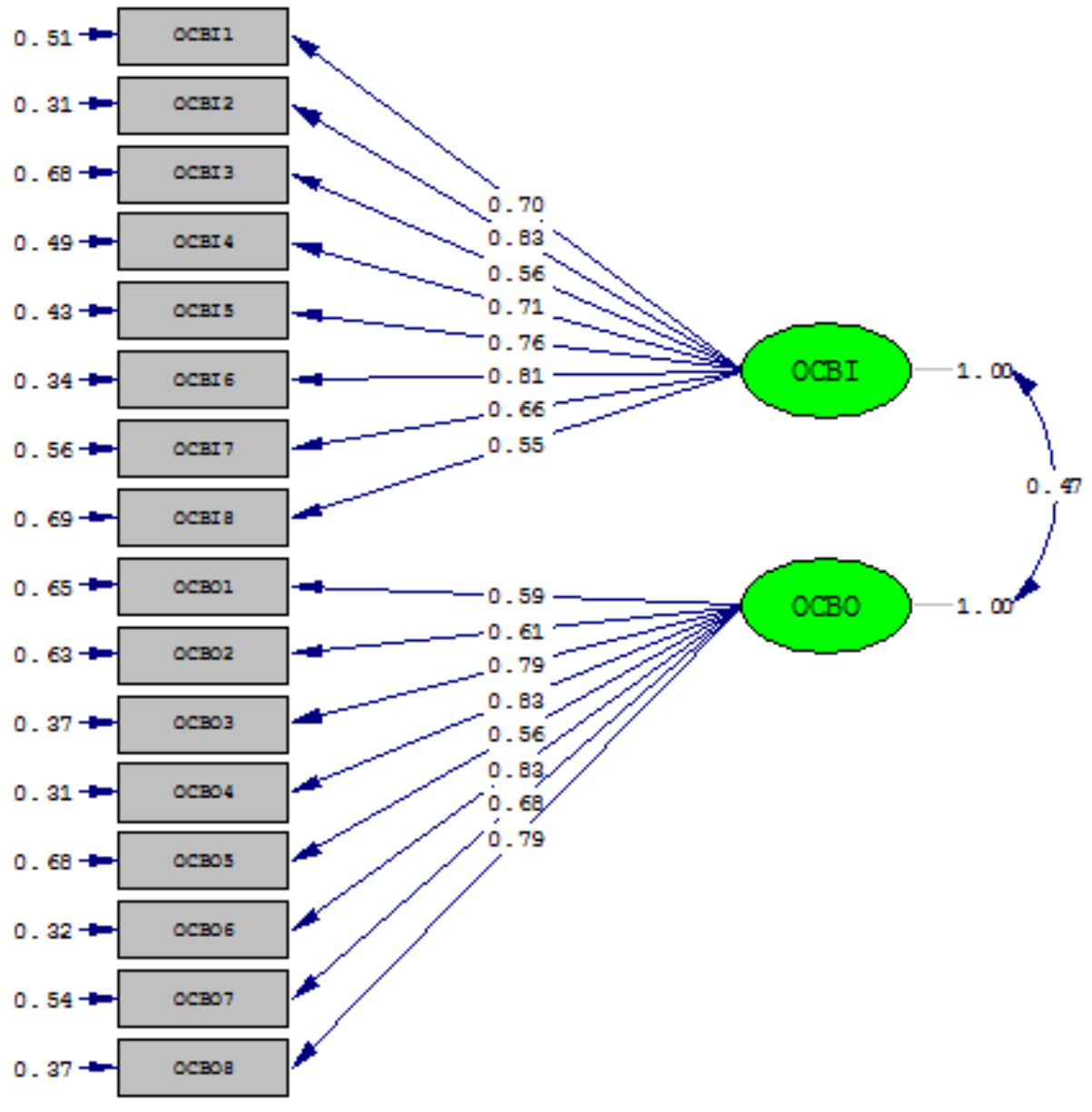

Figure 4.4. CFA Path Diagram for OCB.

Goodness of Fit Indices. The CFA for the OCB model yielded the following goodness of fit indices: $\chi^{2}=1154.463(\mathrm{P}=0.0000) ; d f=103$; RMSEA = 0.123; SRMR = 0.0642; NFI = 0.909; $\mathrm{CFI}=0.917$; GFI $=0.816$. Once again, determination of goodness of fit was based on the accumulation of evidence across all the statistics. Both the NFI and CFI are above .90, and SRMR is less than .08 .

Reliability analysis. The overall reliability for the OCBI scale in this study is .835 (good). In Table 4.45, one can see that in there are no corrected item-total correlations less than .3. In the Scale Mean and Scale Variance if Item Deleted columns, the deletion of OCBI8 would result in a decrease in scale variance. Based on Cronbach's $\alpha$ if Item Deleted column, if OCBI8 are deleted, 
the Cronbach's $\alpha$ would increase to .837 , suggesting that removal of this item would improve reliability. However, the item was not removed as improvement would be slight.

Table 4.45. Item-Total Statistics for OCBI

\begin{tabular}{|lrrrr|}
\hline & $\begin{array}{c}\text { Scale Mean if } \\
\text { Item Deleted }\end{array}$ & $\begin{array}{c}\text { Scale Variance } \\
\text { if Item Deleted }\end{array}$ & $\begin{array}{c}\text { Corrected Item- } \\
\text { Total Correlation }\end{array}$ & $\begin{array}{c}\text { Cronbach's } \\
\text { Alpha if Item } \\
\text { Deleted }\end{array}$ \\
\hline OCBI1 & 28.17 & 16.494 & .581 & .814 \\
OCBI2 & 28.10 & 16.284 & .671 & .804 \\
OCBI3 & 28.54 & 16.608 & .493 & .826 \\
OCBI4 & 27.81 & 17.168 & .543 & .819 \\
OCBI5 & 27.82 & 17.403 & .572 & .817 \\
OCBI6 & 28.31 & 15.551 & .692 & .799 \\
OCBI7 & 28.03 & 16.960 & .587 & .814 \\
OCBI8 & 28.85 & 15.273 & .487 & .837 \\
\hline
\end{tabular}

The overall reliability for the OCBO scale in this study is .869 (good). In Table 4.46, one can see that in the Scale Mean and Scale Variance if Item Deleted columns, the deletion of any one item would not greatly affect the value. There are no corrected item-total correlations less than .3. Finally, in the Cronbach's Alpha if Item Deleted column, there are no values of $\alpha$ greater than the overall $\alpha(.869)$.

Table 5.46. Item-Total Statistics for OCBO

\begin{tabular}{|lrrrr|}
\hline & $\begin{array}{c}\text { Scale Mean if } \\
\text { Item Deleted }\end{array}$ & $\begin{array}{c}\text { Scale Variance } \\
\text { if Item Deleted }\end{array}$ & $\begin{array}{c}\text { Corrected Item- } \\
\text { Total Correlation }\end{array}$ & $\begin{array}{c}\text { Cronbach's } \\
\text { Alpha if Item } \\
\text { Deleted }\end{array}$ \\
\hline OCBO1 & 25.92 & 23.838 & .530 & .863 \\
OCBO2 & 24.99 & 25.052 & .553 & .860 \\
OCBO3 & 25.65 & 22.844 & .667 & .847 \\
OCBO4 & 24.95 & 22.724 & .695 & .844 \\
OCBO5 & 25.25 & 24.560 & .512 & .864 \\
OCBO6 & 25.10 & 22.784 & .694 & .844 \\
OCBO7 & 25.13 & 23.439 & .603 & .855 \\
OCBO8 & 25.19 & 22.309 & .725 & .841 \\
\hline
\end{tabular}

Decision: Based on accumulation of evidence of three of the five goodness of fit indices and reliability findings, and taking a less conservative approach to cut off values, it is appropriate to include this 2 factor construct of OCB in the SEM. Although model modification was not performed in this study, a more conservative approach including review of standardized residuals is discussed in Appendix EE. 
A summary of all Goodness of fit Indices and Internal Consistency Reliability results are presented in Table 4.47.

Table 4.47. Summary of CFA Goodness of Fit Indices and Internal Consistency Reliability

\begin{tabular}{|c|c|c|c|c|c|c|c|c|}
\hline Construct & $\chi^{2}$ & $d f$ & NFI & CFI & GFI & RMSEA & SRMR & $\begin{array}{c}\text { Cronbach's } \\
\alpha\end{array}$ \\
\hline Justice (4 factor) & 1179.99* & 164 & 0.981 & 0.983 & 0.853 & 0.0957 & 0.0303 & - \\
\hline Distributive Justice & & & & & & & & .947 \\
\hline Procedural Justice & & & & & & & & .939 \\
\hline Interpersonal Justice & & & & & & & & .968 \\
\hline Informational Justice & & & & & & & & .947 \\
\hline $\begin{array}{l}\text { Perceived } \\
\text { Organizational Support }\end{array}$ & $813.22 *$ & 20 & 0.921 & 0.922 & 0.710 & 0.242 & 0.0757 & .925 \\
\hline $\begin{array}{l}\text { Affective Commitment } \\
\text { (8 factor) }\end{array}$ & 1670.96* & 224 & 0.935 & 0.943 & 0.831 & 0.0978 & 0.0618 & - \\
\hline AC to organization & & & & & & & & .863 \\
\hline AC to supervisor & & & & & & & & .933 \\
\hline AC to co-workers & & & & & & & & .911 \\
\hline AC to patients & & & & & & & & .625 \\
\hline AC to profession & & & & & & & & .763 \\
\hline AC to work & & & & & & & & .727 \\
\hline AC to task & & & & & & & & .810 \\
\hline AC to career & & & & & & & & .678 \\
\hline OCB (2 factor) & $1154.46^{*}$ & 103 & 0.909 & 0.917 & 0.816 & 0.123 & 0.0642 & - \\
\hline OCBI & & & & & & & & .835 \\
\hline ОСВО & & & & & & & & .869 \\
\hline
\end{tabular}

* indicates significant at 0.000 level

\section{Structural Equation Model}

The SEM correlation matrix is presented in Appendix FF. Measurement equations are presented in Appendix GG. Structural equations are presented in Appendix HH. Most of the relationships are significant at the 0.000 level, however all are significant at the 0.05 level. A simplified version 
of the full SEM is presented in Figure 4.5. Only significant paths are included. All non-significant paths are removed.

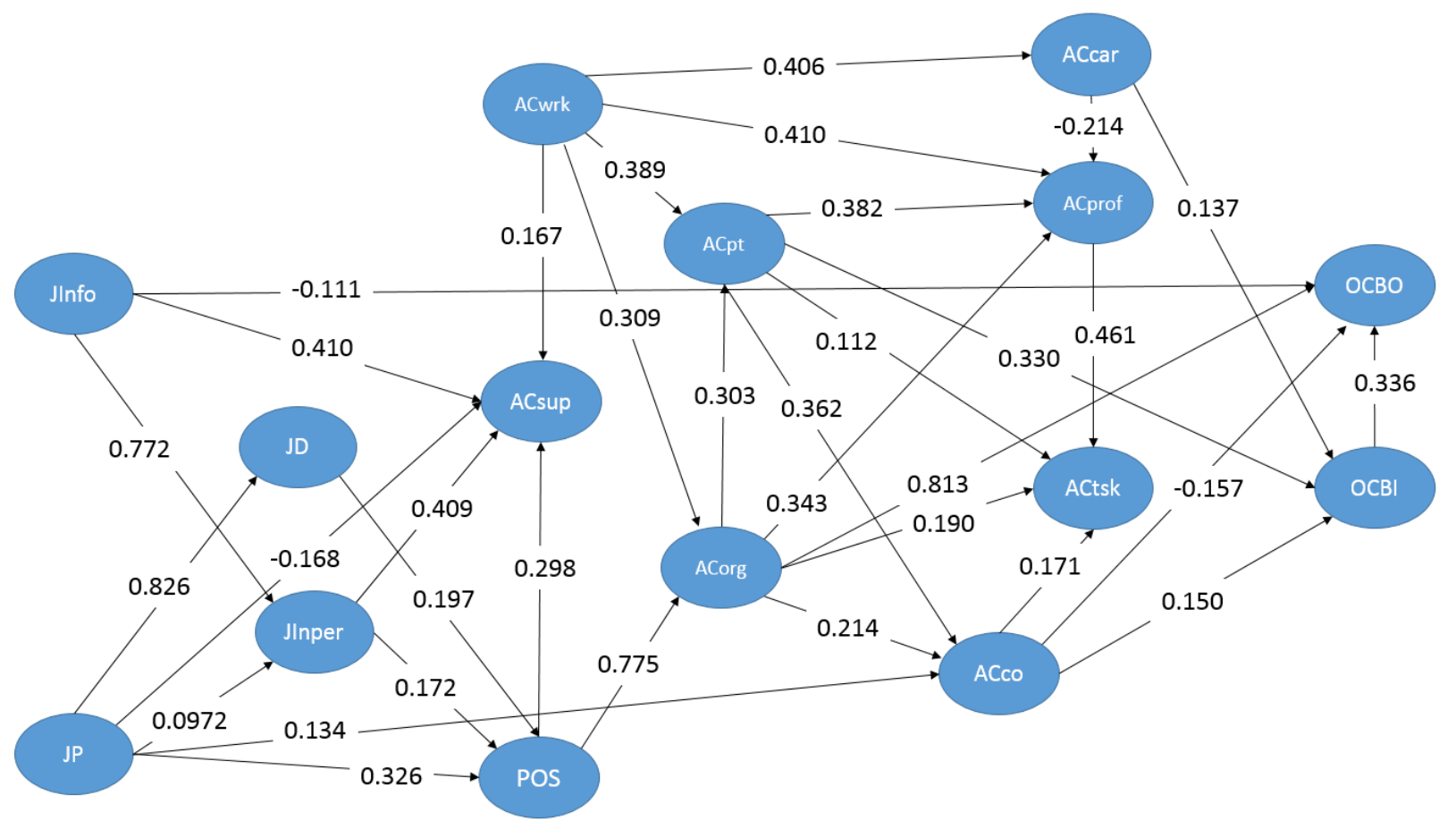

Figure 4.5. SEM

\section{Goodness of Fit Indices}

Figure 4.5 depicts the model with the best goodness of fit statistics $\left(\chi^{2}=10555.152(\mathrm{P}=0.0000)\right.$; $d f=2173$; RMSEA = 0.0755; SRMR = 0.0596; NFI = 0.946; CFI = 0.956; GFI = 0.700). However, if one is to only look at the accumulation of evidence across all five of the goodness of fit statistics, one might assume that based on RMSEA of .08, SRMR of .06, NFI of .95 and CFI of .96 that this model offered a good fit. Upon further examination of LISREL output, however, there is a warning indicating severe multicollinearity. Upon review of standardized residuals, the smallest standardized residual is $\mathbf{- 9 . 6 6 7}$ and the largest standardized residual is 16.905 , suggesting misfit in the model. Large residuals indicate misspecification in the model, affecting overall model fit. SRs greater than the absolute value of 3.29 are flags for possible concern, as in an average sample, SRs this high are unlikely to occur by chance. 
As discussed previously in the Methods Chapter, I opted to complete path analysis using average scores to mitigate the issue of multicollinearity.

\section{Path Analysis}

The correlation matrix for the path analysis can be found in Appendix II. A simplified version of the final path analysis, including path coefficients, is presented in Figure 4.6. The structural equations are presented in Appendix JJ. Only significant paths are included. All non-significant paths are removed.

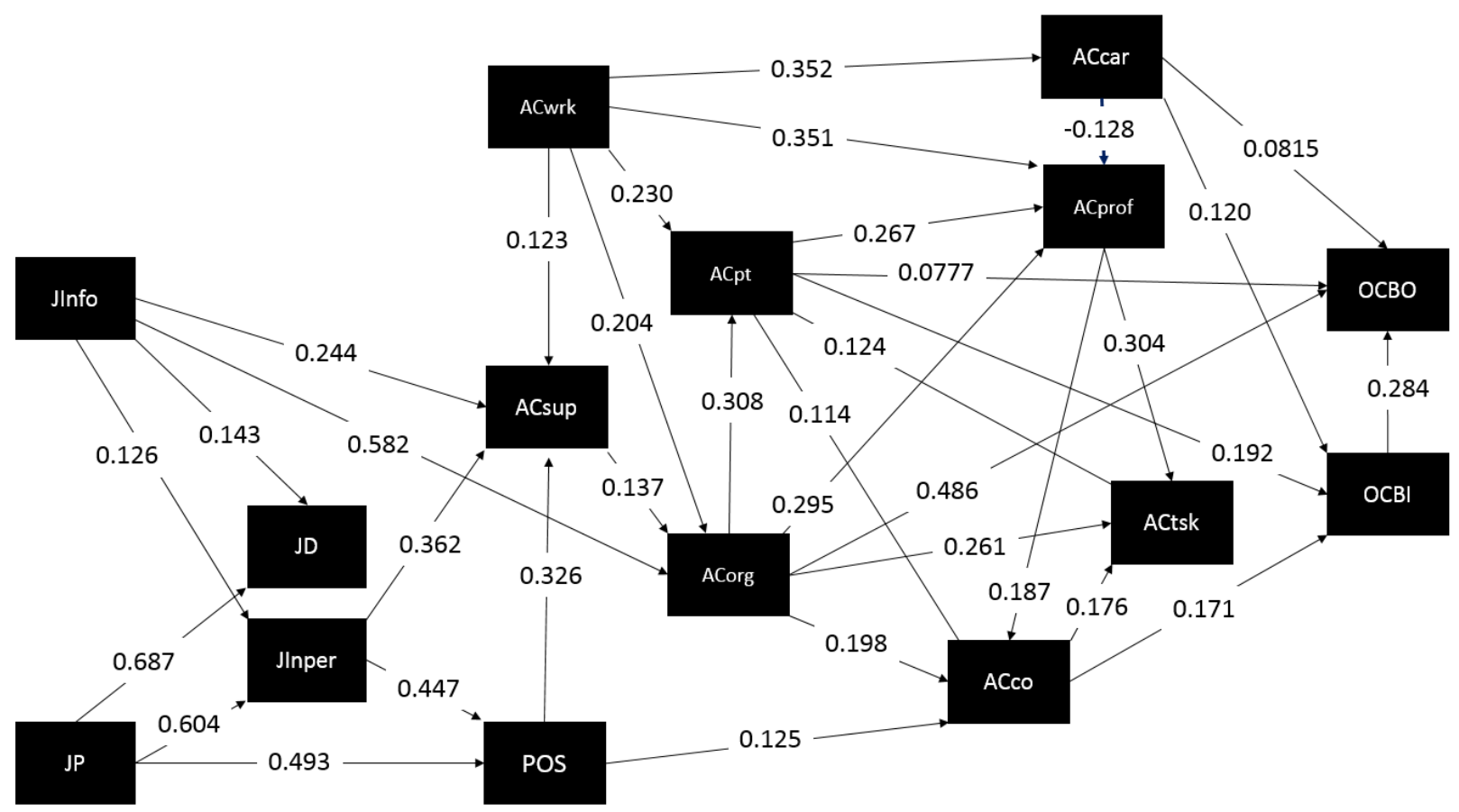

\section{Figure 4.6. Final Path Diagram}

The path analysis focused on the relationships between justice, POS, affective commitment, and OCBs. The general pattern and flow in the path analysis is the same as the hypothesized model in Chapter 2, represented by the red indicator bar below the path analysis in Figure 4.6. The flow, from left to right, is from perceptions of organizational justice to POS, to affective commitment, 
ending with OCBs. Having all of the unique constructs for justice (4), POS (1), affective commitment (8), and OCB (2) in the model, enables the evaluation of specific relationships between each of the individual constructs. All path coefficients are significant; most at the 0.001 level, however all at the 0.01 level.

The path analysis was generated using LISREL. Once again, determination of goodness of fit was based on the accumulation of evidence across all the statistics. The model yielded the following goodness of fit indices: $\chi^{2}=115.265(\mathrm{P}=0.0002)$; $d f=67$; RMSEA = 0.0326; SRMR $=0.0233 ; \mathrm{NFI}=0.987$; CFI $=0.995 ; \mathrm{GFI}=0.978$. Upon review of the standardized residual summary statistics, no standardized residual values exceed the absolute value of 3.29. With the exception of $\chi^{2}$, the indices indicate that the model is an excellent fit to the data.

\section{Mediation}

In the final path analysis, 18 potential mediating relationships are identified. These are depicted in Table 4.48.

Table 4.48. Potential Mediating Effects

\begin{tabular}{|ccc|}
\hline $\begin{array}{c}\mathbf{X} \\
\text { (Predictor) }\end{array}$ & Mediator & $\begin{array}{c}\mathbf{Y} \\
\text { (Outcome) }\end{array}$ \\
\hline JP & JInper & POS \\
Jlnfo & ACsup & ACorg \\
JInfo & JInper & ACsup \\
ACwrk & ACsup & ACorg \\
ACorg & ACpt & ACprof \\
ACorg & ACpt & ACtsk \\
JInper & POS & ACsup \\
ACwrk & ACcar & ACprof \\
ACorg & ACpt & ACco \\
ACwrk & ACpt & ACprof \\
ACorg & ACprof & ACtsk \\
ACorg & ACprof & ACco \\
ACorg & ACco & ACtsk \\
ACpt & ACco & ACtsk \\
ACprof & ACco & ACtsk \\
ACpt & OCBI & OCBO \\
ACorg & ACpt & OCBO \\
Accar & OCBI & OCBO \\
\hline
\end{tabular}


Each of the mediating or indirect effects were tested by conducting a one-step regression analysis in SPSS using Hayes’ PROCESS download tool for SPSS (http://www.afhayes.com). The results are presented in Table 4.49. All effects are significant except for the effect of JInfo on ACorg through ACsup, the second row highlighted yellow in Table 4.49. The effect size for each of the mediating effects is located in the last column of Table 4.49. Recall from the methods section that: a small effect $\left(\mathrm{k}^{2}=.01\right)$ suggests that the effect explains $1 \%$ of the total variance; a medium effects size $\left(k^{2}=.09\right)$ suggests the effect accounts for $9 \%$ of the total variance; and a large effect size $\left(k^{2}\right.$ $=.25$ ) suggests that the effect accounts for $25 \%$ of the variance (Field, 2014; Preacher \& Kelley, 2011).

There is one large significant indirect effect identified. This is a significant indirect effect of informational justice on affective commitment to one's supervisor through interpersonal justice $\left(k^{2}=.2846\right)$.

There are several medium size indirect effects identified. There is a significant indirect effect of procedural justice on POS through interpersonal justice $\left(k^{2}=.0958\right)$. There is a significant indirect effect of affective commitment to work on affective commitment to the organization through affective commitment to one's supervisor $\left(k^{2}=.088\right)$. There is a significant indirect effect of affective commitment to one's organization on affective commitment to one's profession through affective commitment to one's patients $\left(\left(k^{2}=.134\right)\right.$. There is a significant indirect effect of affective commitment to one's organization on affective commitment to tasks through affective commitment to one's patients $\left(k^{2}=.106\right)$. There is a significant indirect effect of interpersonal justice on affective commitment to one's supervisor through POS $\left(k^{2}=.201\right)$. There is a significant indirect effect of affective commitment to work on affective commitment to one's profession through affective commitment to one's patients $\left(k^{2}=.122\right)$. There is a significant indirect effect of affective commitment to one's organization on affective commitment to tasks through affective commitment to one's profession $\left(k^{2}=.193\right)$. There is a significant indirect effect of affective commitment to one's organization on affective commitment to co-workers through affective commitment to one's profession $\left(k^{2}=.104\right)$. There is a significant indirect effect of affective commitment to one's organization on affective commitment to tasks through affective 
commitment to one's co-workers $\left(k^{2}=.108\right)$. There is a significant indirect effect of affective commitment to patients on affective commitment to tasks through affective commitment to coworkers $\left(k^{2}=.100\right)$. There is a significant indirect effect of affective commitment to one's profession on affective commitment to tasks through affective commitment to one's co-workers $\left(k^{2}=.104\right)$. Finally, there is a significant indirect effect of affective commitment to patients on OCBs directed towards the organization through OCBs directed towards individuals $\left(k^{2}=.090\right)$.

There are several small size indirect effects identified. There is a negative significant indirect effect of affective commitment to work on affective commitment to one's profession through affective commitment to one's career $\left(k^{2}=.039\right)$. There is a significant indirect effect of affective commitment to one's organization on affective commitment to one's co-workers through affective commitment one's patients $\left(k^{2}=.066\right)$. There is a significant indirect effect of affective commitment to one's organization on OCBs directed toward the organization through affective commitment to patients $\left(k^{2}=.068\right)$. There is a significant indirect effect of affective commitment to one's career on OCBs directed towards their organization through OCBs directed towards individuals $\left(k^{2}=.063\right)$. 
Table 4.49. Mediating Effects

\begin{tabular}{|ccccccc|}
\hline X (Predictor) & $\begin{array}{c}\text { Path Coefficient } \\
\mathbf{X}>\mathbf{M} \\
\text { (significance) }\end{array}$ & Mediator & $\begin{array}{c}\text { Path Coefficient M }>\mathbf{Y} \\
\text { (significance) }\end{array}$ & Y (Outcome) & $\begin{array}{c}\text { Path Coefficient } \\
\mathbf{X} \rightarrow \mathbf{Y} \\
\text { (significance) }\end{array}$ & Effect Size \\
\hline JP & $.7601(0.0000)$ & JInper & $0.2185(0.0002)$ & POS & $.7240(0.0000)$ & 0.0958 \\
JInfo & $.8197(0.0000)$ & ACsup & $.4079(0.0000)$ & ACorg & $.0281(.5293)$ & - \\
JInfo & $.7778(0.0000)$ & JInper & $.4343(0.0000)$ & ACsup & $.4820(0.0000)$ & 0.2846 \\
ACwrk & $.2493(0.0000)$ & ACsup & $.3968(0.0000)$ & ACorg & $.2542(0.0000)$ & 0.0878 \\
ACorg & $.1952(0.0000)$ & ACpt & $.5289(0.0000)$ & ACprof & $.2882(0.0000)$ & 0.1335 \\
ACorg & $.1952(0.0000)$ & ACpt & $.4256(0.0000)$ & ACtsk & $.3638(0.0000)$ & 0.1057 \\
JInper & $.6534(0.0000)$ & POS & $.2596(0.0000)$ & ACsup & $.6418(0.0000)$ & 0.2012 \\
ACwrk & $.3522(0.0000)$ & ACcar & $-0.0925(0.0088)$ & ACprof & $.5004(0.0000)$ & 0.0388 \\
ACorg & $.1952(0.0000)$ & ACpt & $.3048(0.0000)$ & ACco & $.2859(0.0000)$ & 0.0658 \\
ACwrk & $.1994(0.0000)$ & ACpt & $.5531(0.0000)$ & ACprof & $.3575(0.0000)$ & 0.1217 \\
ACorg & $.3914(0.0000)$ & ACprof & $.4112(0.0000)$ & ACtsk & $.2859(0.0000)$ & 0.1927 \\
ACorg & $.3914(0.0000)$ & ACprof & $.2536(0.0000)$ & ACco & $.2462(0.0000)$ & 0.1036 \\
ACorg & $.3454(0.0000)$ & ACco & $.2453(0.0000)$ & ACtsk & $.3621(0.0000)$ & 0.1076 \\
ACpt & $.5121(0.0000)$ & ACco & $.3080(0.0000)$ & ACtsk & $.5315(0.0000)$ & 0.1002 \\
ACprof & $.3981(0.0000)$ & ACco & $.2416(0.0000)$ & ACtsk & $.4828(0.0000)$ & 0.1035 \\
ACpt & $.2869(0.0000)$ & OCBI & $.3978(0.0000)$ & OCBO & $.3412(0.0000)$ & 0.0901 \\
ACorg & $.1952(0.0000)$ & ACpt & $.2004(0.0000)$ & OCBO & $.3518(0.0000)$ & 0.0677 \\
ACcar & $.1111(0.0000)$ & OCBI & $.4496(0.0000)$ & OCBO & $.1252(0.0000)$ & 0.0634 \\
\hline
\end{tabular}

Note: no confidence intervals span zero; green highlight indicates a large effect size; blue highlight indicates medium effect size; no highlight indicates a small effect size; and yellow highlight indicates no mediating effect.

\section{Summary of Results}

The results of the statistical analysis are presented in this chapter. Descriptive statistics of the study variables are completed. There was no missing data. The final sample consisted of 676 cases. CFA was conducted to validate the measurement models. Although the results of the CFA indicate that the final measurement models provide adequate-good fit to the data, standardized residuals remained high and several of the measures are highly correlated with one another (>.08). Error covariances are not included to improve model fit. Model fit was assessed using $\chi^{2}$, RMSEA and SRMR, NFI, CFI, and GFI indices.

The SEM containing all of the constructs indicate multicollinearity. In an attempt to determine if I could view the relationships without the issue of multicollinearity, path analysis was performed as an alternate using average scores for each of the constructs to see if I could get a better look at the relationship. Fortunately, since path analysis does not include the correlations between each of the observed measures, this method did avoid the issue of multicollinearity in this circumstance. The goodness of fit indices indicate that the model is an excellent fit to the data. Seventeen significant mediating effects are identified in the model. 


\section{Chapter 5 \\ Discussion \& Conclusions}

\section{Discussion}

The purpose of this study is to better understand work attitudes and their relationships to one another, and to extra-role behaviours amongst nurses working in hospitals, the community, and long-term care settings in Ontario. External forces of work motivation present in the work environment include the presence, or lack, of organizational justice and organizational support. Internal forces of motivation include work attitudes, the perceptions of these two external forces in addition to one's emotional attachment to different targets. The behavioural outcome used in this study is a form of extra-role behaviour (ERB), organizational citizenship behaviours (OCBs), behaviours that attempt to benefit the organization, extending beyond existing role expectations (Organ et al., 2006). OCBs are of critical importance to health care organizations because they can lead to improved performance, care, patient safety, organizational productivity; positive relationships amongst employees, efficient use of scarce resources, and employee involvement in the organizational activities (Chu et al., 2005). While dyadic relationships amongst some of these concepts are established in disparate empirical studies, interrelationships amongst the entire set of concepts have not been explored. My study helps to identify which work attitudes impact extrarole work-related behaviours, contributing to the general overall goals of health service organizations.

A scoping review, together with a more in-depth review of the literature, aided in the development and testing of a comprehensive conceptual framework. Findings from this study help address four significant gaps identified in the work motivation and organizational behaviour literature: (1) it examines how affective commitment relates to behavioural efforts, specifically organizational citizenship behaviours; (2) it utilizes reliable and validated instruments; (3) it comprises a fairly large sample; and (4) by using a cross-sector design, it is generalizable to nurses actively working in hospitals, the community, and long-term care settings in Ontario Canada. 
The final path analysis (reiterated from the Results chapter) illustrates that the general pattern and flow is the same as the hypothesized model in Chapter 2, represented by the red indicator bar below the path analysis in Figure 5.1. The flow, from left to right, is from perceptions of organizational justice to POS, to affective commitment, ending with OCBs. What previously was presented in the literature as simple dyadic relationships, is now revealed as a complex web of interrelationships. This analysis also exposes the many significant mediating effects at play.

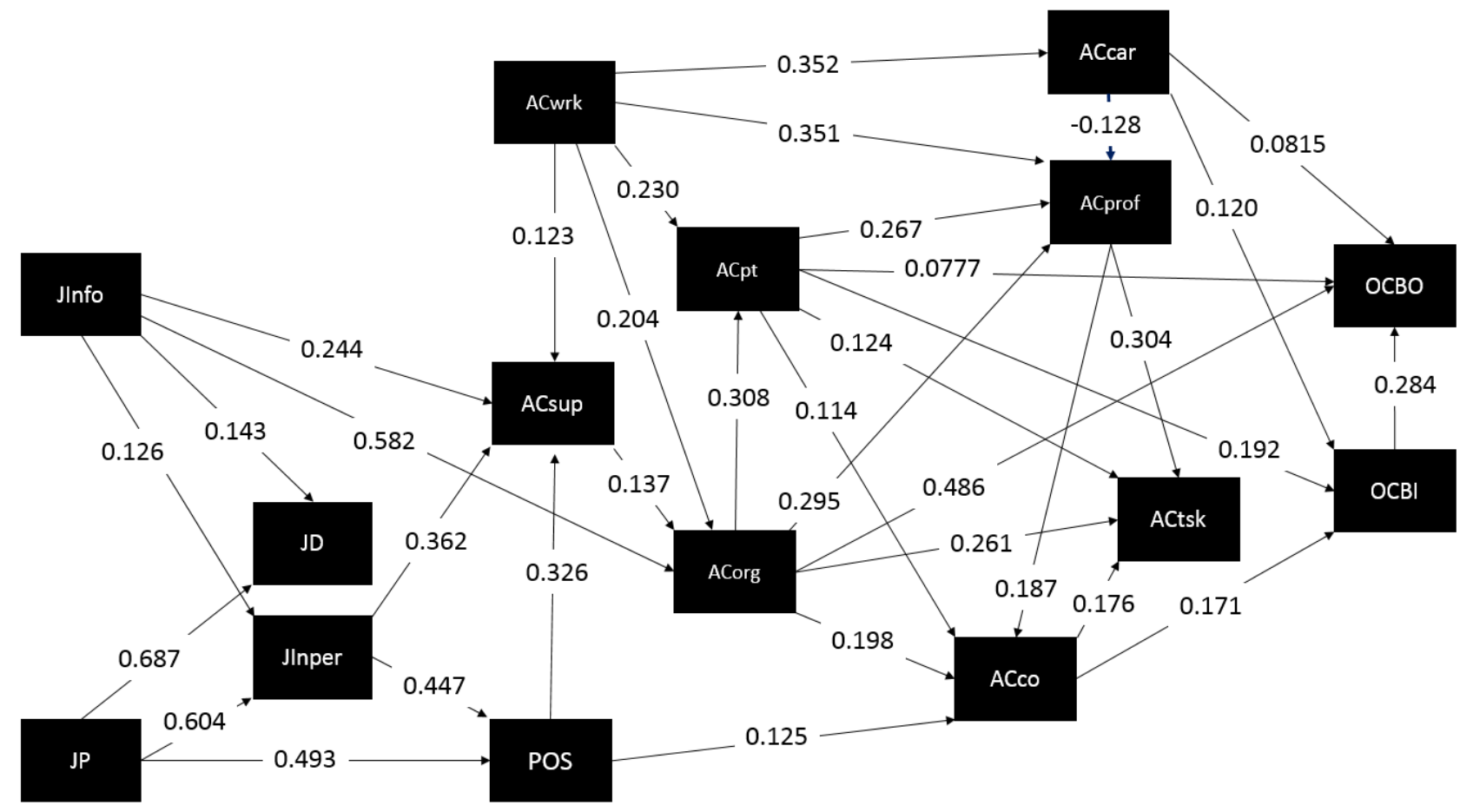

Figure 5.1. Final Path Diagram.

\section{Theoretical Implications}

The model that I test here is novel, in that it simultaneously includes all of the aforementioned constructs (a four factor justice model, a one factor POS model, an eight factor affective commitment model, and a two factor OCB model). This research reveals the complex 
relationships among these constructs, and highlights some potential limitations of prior research that focused on dyadic associations or global constructs.

Relationships amongst OCBs. My results demonstrate that in the health care sector, in which I conducted my research, OCBIs are directly associated with OCBOs, see Figure 5.2. The direction of association is contrary to work by Morin et al. (2011) which found OCBOs directly related to OCBIs. This is an important finding as it suggests that focusing resources on enhancing behaviours that benefit individuals positively impacts behaviours that benefit the organization. For example, improving relationships between co-workers and supervisors in a work setting like health care where there is extensive reliance on oral communication may enhance the quality of employee-toemployee communication and knowledge exchange, and improve the care provided. This is somewhat counter to some work that has suggested that OCBI detracts from organizational performance, as there is an over-focus on individual needs (Podsakoff \& MacKenzie, 1994); however health care may present an exception, since there is such high reliance on communication channels and relationships - where the contradicting studies were conducted in competitive sales driven settings (i.e. insurance agencies) where employees compete with one another to achieve set targets.

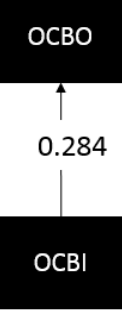

\section{Figure 5.2. OCBI Direct Effect on OCBO.}

Affective Commitment Direct Association with OCBs. As identified in my literature review, an abundance of research has focused on a global perspective of affective commitment to the organization, suggesting that 'organizational commitment' is the sum of one's commitment to all possible 'constituencies' of an organization and that this motivates work-related behaviours (Hunt 
\& Morgan, 1994; Morin et al., 2011). Therefore, organizational commitment acts as a key internal mediating force through which commitment to local constituencies relate to work outcomes. In essence, this is a similar rationale to the 'cohesion approach to commitment' which suggests that within-group interpersonal attachments create summative effects that result in organizational attachment (Morin et al., 2011; Wech, Mossholder, Steel, \& Bennett, 1998; Yoon, Baker, \& Ko, 1994). This global approach suggests that commitment to members of the organization, like supervisors and co-workers, will relate to organizational commitment and OCBOs which will lead to OCBs directed towards parallel targets ( Morin et al., 2011).

In research on attitude-behaviour relationships, an alternative to the global perspective approach is the 'target similarity approach' which proposes that attitudes more strongly relate to behaviours when they refer to similar targets, contexts, timelines, or actions (Lavelle, 2007; Lavelle et al., 2009). If one is affectively committed to one's co-workers, then these internal forces help drive her/him to engage in OCBs that benefit co-workers (OCBIs). No mediation by an overall 'global' organizational commitment or OCBO is expected to occur. This is in line with Lawler's (1992) choice process theory, whereby individuals develop stronger attitudes towards proximal entities (supervisors, groups) than towards distal entities (the organization) because proximal entities provide them with a greater sense of control over their work (Lawler, 1992; Morin et al., 2011; Mueller \& Lawler, 1999). In other words, individuals only engage in behaviours that benefit those constituencies to which they feel a commitment.

My findings did not support the global perspective for organizational commitment. There are no significant mediating effects of organizational commitment in my study. My findings align with the target similarity approach, however affective commitment to one's supervisor did not directly affect any OCBs. This is important as it suggests that affective commitment to one's supervisor is not a force that impacts OCBs directed towards individuals or the organization. It would be useful for future research to investigate factors that are influenced by affective commitment to one’s supervisor. My findings, see Figure 5.3, identify three affective commitment targets (patient, co-worker, career) as motivators of OCBIs, and three affective commitment targets (organization, patient, and career) as motivators of OCBOs. My findings suggest that utilizing a global 
perspective for organizational commitment may cloud results and prevent a clear understanding of what is really occurring. For example, if a global perspective of organizational commitment were used in my study, then it would be reasonable to assume that I would have found an association between organizational commitment and OCBs. However, by using a multi-factor structure approach, it becomes evident that not all targets of affective commitment (e.g., work, supervisor, tasks, and profession) are associated with OCBs. My results are contrary to Morin et al.’s (2011) research which found that commitment to co-workers, customers and supervisors displayed positive relationships with OCBs directed at parallel foci (OCBIs). Morin et al. (2011) found that commitment to the organization, partially and negatively mediated the relationships to co-workers and customers to parallel OCB dimensions (OCBIs). Morin et al. (2011) also found no commitment targets to be motivators of OCBOs. Thus, further research investigating the effect of OCBIs on OCBOs is warranted.

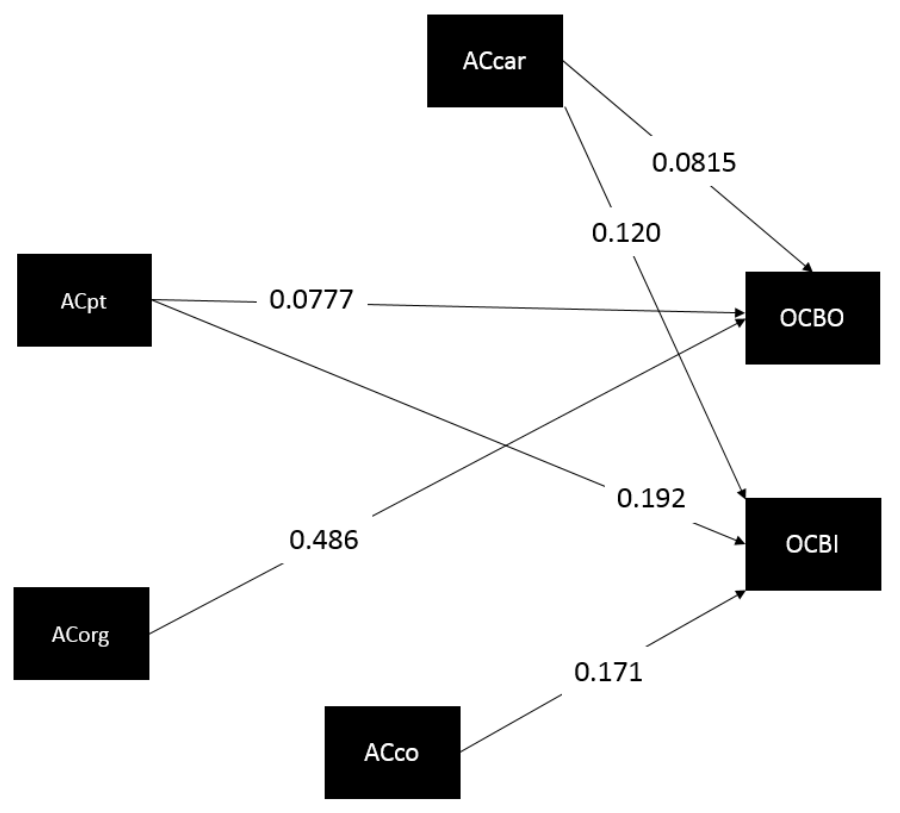

Figure 5.3. Affective Commitment and OCB Relationships. 
Relationships amongst Affective Commitment Targets. Morin et al. (2011) found that commitment to co-workers and commitment to customers are forces positively related to commitment to the organization. Although these findings were not replicated in my study, my findings identified several unique affective commitment relationships unprecedented in the literature, see Figure 5.4. My findings identify significant positive direct effects of affective commitment to one's organization on affective commitment to one's patients. My results also suggest significant positive direct effects of affective commitment to work, one's organization, and patients, and a significant negative direct effect of affective commitment to one's career on affective commitment to one's profession. The negative effect may be indicative of a potential conflict between one's career and one's profession, warranting future research. My study found significant positive direct effects of affective commitment to one' profession, organization, coworkers, and patients on affective commitment to tasks. There were also direct effects of affective commitment to work on affective commitment to one's supervisor, patient and career. The above findings may suggest that affective commitment to one's career may be a somewhat 'self-centered' target as it appears to suggest perhaps career may be considered more important than one' profession and influenced by one's affective commitment to work (e.g., they consider work satisfying, a priority, and all their personal objectives are focused on work). Additional findings include the direct effects of affective commitment to one's organization, patient and profession on affective commitment to one's co-workers and the direct effect of affective commitment to one's supervisor and work on affective commitment to one's organization. These results are depicted in Figure 5.4.

Future research may benefit from the inclusion of multi-factor structure models instead of global models or partial models, and further investigation into the inter-relationships between affective commitment targets in different contexts. 


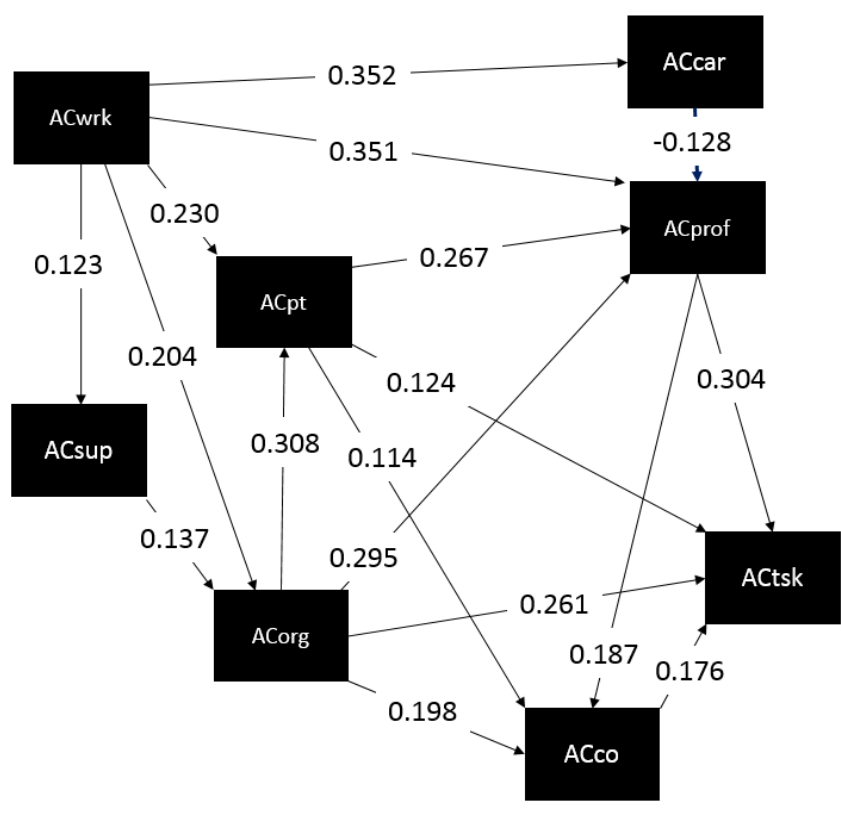

Figure 5.4. Relationships amongst Affective Commitment Targets

Direct Effect of Justice Constructs on POS. My findings account for a relatively high percentage of the variance of POS, predominantly with significant positive direct effects on procedural and interpersonal justice, see Figure 5. 5. These findings corroborate prior work undertaken by Loi (2006) and Moorman (1998). In comparison to Loi et al. (2006) who suggest that distributive justice contributes to the development of POS in solicitors working in Hong Kong law firms, my study does not display any evidence of this. One potential reason for the difference may be that Loi et al. (2006) looked at procedural and distributive justices whereas I used a four-factor structure approach. My findings may afford alternative ways of looking at relationships when compared to partial models. Including more factors may allow researchers to identify and confirm the presence of unique direct relationships and provide assurance that one variable is not being used synonymously for another, were it not to be included in the model. Moreover, my findings suggest that further research may be warranted to determine if dyadic approaches require further inquiry. 


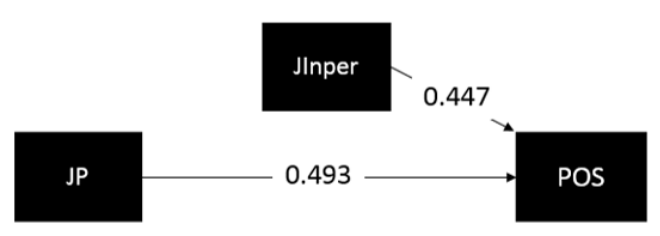

Figure 5.5. Direct Effect of Justice Constructs on POS.

Relationships between Justice, POS, and Affective Commitment Targets. My findings identify direct effects of POS on affective commitment to one's supervisor and co-workers, see Figure 5.6. My results indicate a direct association between interpersonal justice and affective commitment to one's supervisor, as well as direct associations between informational justice and affective commitment to one's supervisor, and between informational justice and affective commitment to one's organization. These findings are depicted in Figure 5.6 and Figure 5.7.

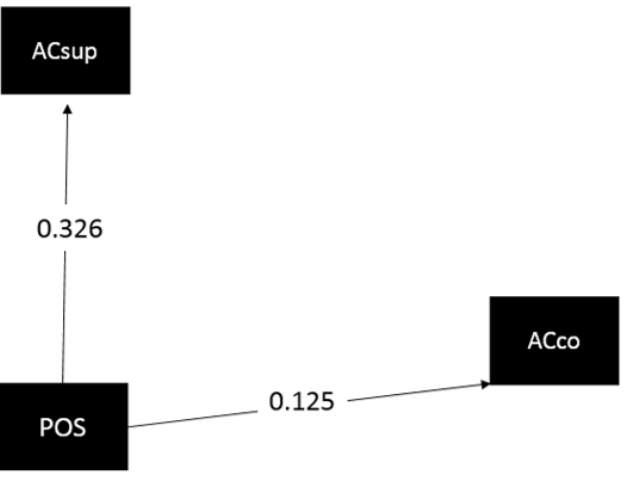

Figure 5.6. Direct Effect of POS on Affective Commitment Targets. 


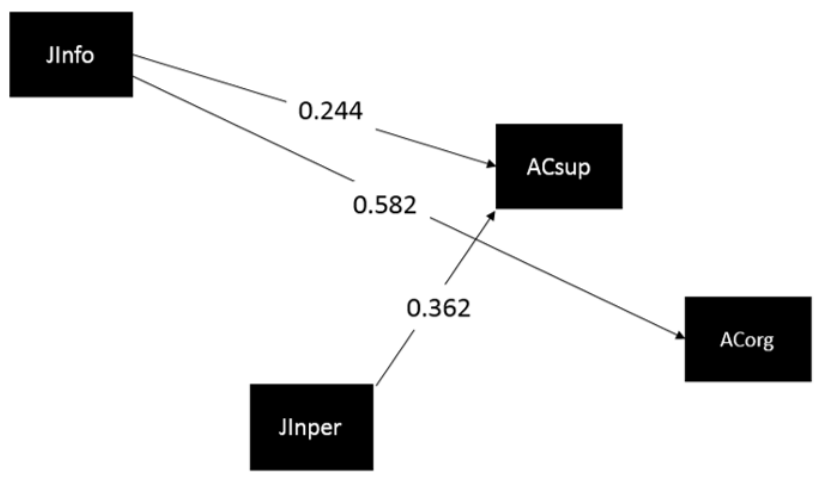

Figure 5.7. Direct Effect of Justice on Affective Commitment Targets

Thus one can see, as depicted in Figure 5.8, affective commitment to one's supervisor is associated with direct effects of interpersonal justice, POS, informational justice, and affective commitment to work. Also depicted in Figure 5.8 is the association of affective commitment to one's coworkers with affective commitment to one's organization, their profession, POS, and affective commitment to their patients. Contrary to findings from Rhoades et al. (2001), there is no evidence in my study that POS directly related and contributed to affective organizational commitment. Potential differences could be due to smaller samples and different settings (Eastern US university alumni) in Rhoades et al. (2001). Once again, my findings are important as they suggest that utilizing a global perspective for organizational commitment may potentially conceal results and prevent a clear understanding of relationships which are truly occurring. Further investigation may also be required to determine if the shorter 8-item version of POS scale as used in this study is, in fact, as valid and reliable as the 36 item scale (Rhoades \& Eisenberger, 2002) when used in combination with multi-factor structure models.

Several of my findings are inconsistent with existing literature, which suggests that all three dimensions of organizational justice (distributive, procedural, and interactional which is comprised of informational and interpersonal justices) positively relate to affective organizational commitment (McNabb, 2009; Beugre 1997) and that procedural justice strongly predicts organizational commitment (Greenberg 2009). Instead, I observe the direct effects of informational 
justice, affective commitment to work and one's supervisor on affective commitment to one's organization. Informational justice and interpersonal justice are each associated with affective commitment to one's supervisor. Finally, both distributive and procedural justice are not related to any affective commitment targets. These results are also depicted in Figure 5.8. My findings once again demonstrate the potential ramifications when utilizing a global perspective approach to organizational commitment; that is, the potential to miss alternate and unique relationships - for example my finding that only informational justice appears to be directly associated with affective commitment to one's organization. Future research investigating the precise nature of this association, and best strategies of enhancing informational justice, and examining the impact these strategies have on affective commitment to one's organization, and turnover intention, would be informative.

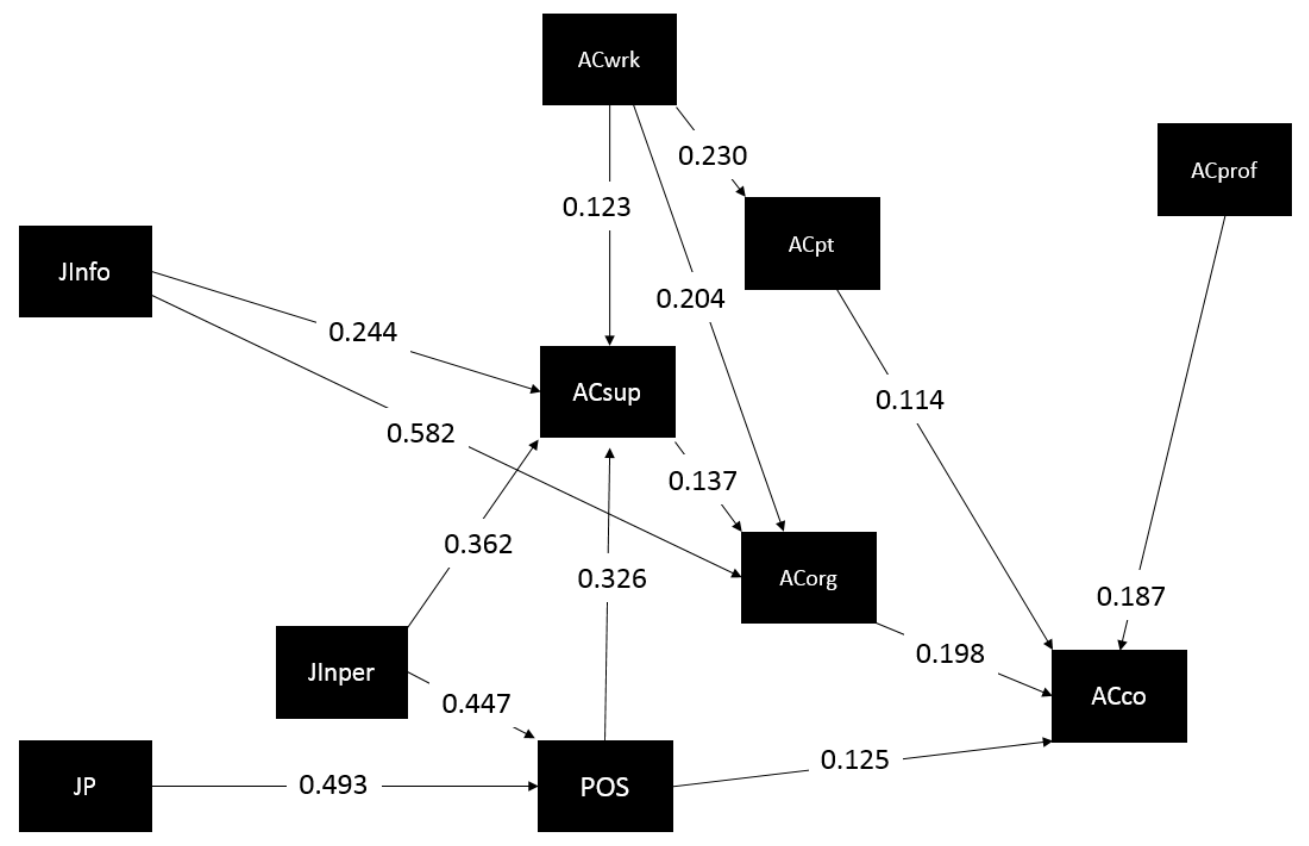

Figure 5.8. Relationships between Justice, POS \& Affective Commitment Targets 
Lack of Direct Association between Justice and OCBs. Contrary to prior research, organizational justice does not appear to be a directly associated with OCBs. My results show no evidence of the direct effects of perceived organizational justice on OCBs found by Suliman (2013), Greenberg (2009), and Organ (1988). This could potentially be due to my inclusion of POS and the eight factor structure of affective commitment, which are not included in the aforementioned studies. The inclusion of POS and a multi-factor structure model of affective commitment affords a more in-depth analysis of additional factors through which justice may indirectly act (e.g., informational justice has a direct effect on affective commitment to one's organization, which has a direct effect on OCBO). Henceforth, research might usefully include additional concepts such as POS measures and different targets of affective commitment when examining relationships between perceived organizational justice and OCBs. Additional examination is warranted to determine if these findings are found in different contexts and with different populations.

Relationships amongst Justice Constructs. My results do not suggest any direct relationships between procedural justice and informational justice, or between distributive justice and interpersonal justice, see Figure 5.9. This contradicts previous research by Colquitt (2001); however, he used smaller sample sizes and examined different populations (university undergraduate students and employees from an automobile manufacturing plant) and different outcome measures (Colquitt, 2001). The lack of association in my findings between procedural justice and informational justice, and between distributive justice and interpersonal justice, may be particularly characteristic of a health care environment. One can have fair procedures and poor distribution of information, and similarly, a supervisor may display distributive justice, but may interact poorly with staff. My results are in line with work by Murphy, Wayne, Liden, \& Erdogan (2003) who identify that distributive justice is not significantly related to leader-member exchange (Murphy, Wayne, Liden, \& Erdogan, 2003). My findings also suggest that future research determining the effect of procedurally just climates on distributive justice is warranted.

My results account for a large proportion of the variance of distributive justice. Almost all of this was due to the direct effects of procedural and informational justice, see Figure 5.9. The high 
association between procedural justice and distributive justice is important as it suggests that when employees perceive that there are fair procedures in place, they also are likely to perceive high levels of distributive justice. Tripp, Bies, \& Aquino (2007) recommend that if the perception is one of high procedural justice, then the procedures to establish distributive justice will be trusted (Tripp, Bies, \& Aquino, 2007).

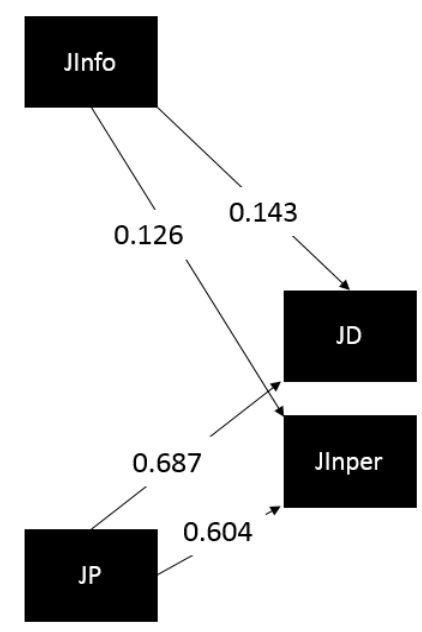

Figure 5.9. Relationships amongst Organizational Justice Constructs

Mediation. The evaluation of mediating effects as noted in the Results Chapter, suggests that perhaps this area is under explored and worthy of further investigation. Although there is one large mediating effect of informational justice on affective commitment to one's supervisor through interpersonal justice, the majority of mediating effects are medium sized. My findings imply that the mediating effects are far more complex than previously exposed in the literature. By utilizing full multi-factor structure models I am able to identify novel mediating effects.

A number of mediation effects, identified in the literature, are not found in my study. I found no evidence for POS' mediation between: procedural justice and affective commitment to the organization (Rhoades, 2001), nor between procedural justice and OCBs (Moorman, 1998). Further, I did not observe a mediating effect of organizational commitment on the positive relationship between procedural fairness and OCB, most likely emerging when constructs are in reference to the same target (Lavelle et al., (2009). Finally, I did not observe POS' mediation 
between: procedural justice and organizational commitment, nor between distributive justice and organizational commitment (Loi, 2006). The major differences between my work and the work of Loi (2006) and Lavelle et al. (2009) are related to contexts, sample sizes, and the use of partial verses complete factor structure models. My study included multi-factor structure models of organizational justice (all four constructs), affective commitment (all eight targets), and OCBs (OCBI and OCBO). As discussed earlier, these findings call attention to the potential for hidden results when utilizing global perspectives for organizational commitment, and suggests additional examination is warranted to determine if inclusion of multi-factor structure models with distinct factors provide a clearer understanding of perhaps indirect relationships or mediating factors compared to the adoption of partial models or global perspective approaches. Simply stated, factors that are not included in the model, are difficult to account for. Omission of factors prevents identification of both indirect and mediation effects.

\section{Practical Implications for Nurse Managers and Leadership}

Results provide more fulsome insight into what leaders might leverage to meet organizational goals. Exposing the intricate relationships between work attitudes and extra-role workplace behaviours can help leadership determine where to focus resources to develop strategies to positively influence work-related behaviours that aid in attaining organizational goals. For example, in this study, findings suggest that informational justice is a force directly associated with affective commitment to the organization, which is directly related to OCBOs. Thus focusing resources on training initiatives to help supervisors communicate more effectively may improve the manner in which outcomes and procedures are communicated, thereby impacting affective commitment to the organization, and as a result affect behaviours that benefit the organization.

The lack of evidence in my study relating perceived organizational justice with OCBs and affective commitment to one's supervisor with OCBs directed towards individuals or the organization, suggests that leadership strategies focusing on enhancing employee affective commitment to their supervisors, may not be effective in enhancing behaviours between coworkers or directed towards the organization. Results suggesting OCBs directed towards individuals (OCBIs) are positively associated with OCBs directed towards the organization (OCBOs), and not the reverse, suggest 
that if the end goal of senior leadership is to have employees that go above and beyond their job descriptions for their organization, then it may be of benefit to focus attention on team-building type strategies that enhance OCBIs. In addition, my findings identify potential areas for managers to focus attention depending on their desired results. If the end goal is to impact OCBIs, then much may be gained by determining ways to enhance employee affective commitment to patients, co-workers or their career. If the end goal is to increase OCBOs, then time and resources may be better placed on developing affective employee affective commitment to the organization, patient, and their career.

Study results suggest that there may be more value in adopting a target similarity approach, whereby attitudes are forces that more strongly relate to behaviours when they refer to similar targets, contexts, timelines, or actions, as compared to a global perspective of organizational commitment. Depending on the desired behavioural outcome, understanding these relationships could help leaders determine which targets to focus on, and strategies to use, when attempting to modify employee behaviour. The findings suggest that leadership actions play a vital role in affective commitment to one's supervisor, the organization, and employee perceptions of organizational support.

The finding that affective commitment to one's organization and work is associated with affective commitment to one's patients indicates that there may be benefit to identification and selection of employees affectively committed to their organization and work, if the desire is to encourage staff commitment to their patients. Results also reveal that strategies focusing on affective commitment to work, the organization, and patients, may assist with enhancing commitment to the profession. The finding that affective commitment to career is negatively associated with affective commitment to one's profession, suggests that nurses focused on moving up in their career, perhaps to more administrative or management positions, may be less committed to their actual profession (e.g., nursing), as their attention shifts to where they want to be, as compared to the profession for which they are currently in.

It is not uncommon for employees in all professions to perform tasks that they many not particularly enjoy doing. My findings suggest that there may be value in nurse managers 
highlighting and reinforcing the value of these tasks and their benefit in reference to their profession, organization, co-workers, or patients. For example, if the task is 'additional' documentation for a research trial, perhaps it will make a difference and aid in task completion by letting staff know that this research has the potential to advance their profession, make their organization a centre of excellence, decrease turnover of co-workers, or even improve patient survival rates.

My findings also suggest that both distributive and procedural justice are forces not directly related to any affective commitment targets, suggesting that that although procedures and the distribution of outcomes may not always be fair within an organization, what matters to employees is that they be treated with dignity, in a polite and respectful manner (interpersonal justice). Employees want truthful, thorough explanations of procedures with pertinent details in a timely manner, tailored to their specific needs (informational justice). Hence, leadership strategies that focus on distributive and procedural justice to enhance affective commitment of employees may prove not to be effective in health care environments. Informational justice, however, is associated with affective commitment to one's organization, hence these findings suggest that it may be well advised for nurse managers and leadership to be conscious of the manner in which outcomes and procedures are communicated. Both informational justice and interpersonal justice are associated with affective commitment to one's supervisor, which has a direct effect on affective commitment to one's organization. This suggests that the nurse managers and leadership may want to evaluate the way they communicate and interact with their employees.

This research offers insights into some of the organizational characteristics that affect work conditions of nurses. This study identifies the nuanced relationships in health care between work attitudes and behaviours. Results of strong association between procedural justice and distributive justice are important to nurse managers. Having fair procedures in place is strongly associated with employee perceptions of distributive justice, which may be useful during times of conflict or dispute to ensure maintenance of a health work environment. Victims of offense may be more likely to seek distributive justice through formal channels rather than seeking it themselves through revenge. 


\section{Implications for the Definition of Work Motivation}

Work motivation has been inconsistently operationalized with over 140 definitions (Kleinginna Jr \& Kleinginna, 1981). Pinder (2008) provides one of the most comprehensive definitions to date of work motivation, defining it as a set of energetic forces that originate within and beyond an individual's being, to initiate work-related behaviour, and to determine its form, direction, intensity, and duration. My work helps to clarify the, heretofore, inconsistently defined concept of work motivation, identifying a successive element such that external forces precede and/or impact internal forces. For example, perceived actions of one’s supervisor (e.g., fair distribution of rewards, consistent following of procedures, ethical behaviour, treating others with dignity and respect) and perceived acts of support from the organization (e.g., appreciates efforts, recognizes and takes pride in accomplishments) are consciously and/or subconsciously interpreted to help inform decision-making. In addition to the influence of external forces, the employee also has internal instincts and personal emotional attachment to different targets, based upon what is held to be important to them: their goals, preferences and past experiences. The strength of the attachment to particular targets may determine the intensity of the driving force. Although my research aids in helping to determine which forces map to specific behaviours, what remains unknown about work motivation relates to behavioural patterns such as choice, spontaneous behaviour, and persistence.

\section{Summary}

It is worthwhile for leadership involved in making policy decisions, to understand the relationships amongst work attitudes and behaviour outcomes identified by this research. It is important that leadership comprehend that each decision they make (e.g., whether it be regarding new procedures, distribution of outcomes/resources, reporting structures, mandatory tasks, or patient interaction), has a potential impact elsewhere. Although my work is conducted from an organizational behaviour perspective, my findings are consistent with literature in nursing leadership literature,

and addresses significant gaps identified within the literature. My work investigates nursing leadership practices and interactions with staff on behaviour outcomes. This is consistent with 
work by Wong, Cummings, \& Ducharme (2013), who conducted a systematic review of studies that examine the relationship between nursing leadership practices and patient outcomes, and found a positive relationship between relational leadership and a variety of patient outcomes, and that efforts by organizations and individuals to develop transformational and relational leadership reinforces organizational strategies to improve patient outcomes. Wong et al. (2013) suggest future examination of the mechanisms of influence on outcomes (Wong, Cummings, \& Ducharme, 2013).

The purpose of this study was to better understand work attitudes and their relationships to one another, and to extra-role behaviours amongst nurses working in hospitals, the community, and long-term care settings in Ontario. My research helps to identify the relationships between leadership practices, as they relate to perceived organizational justice and perceived organizational support, and employee behaviours. My results provide insights into what leaders may leverage to optimize productivity, performance, safety, quality care, employee retention, a healthy work environment, and OCBs as they relate to nurses and nursing practice. In the nursing literature, a systematic review by Brady, Germain, \& Cummings (2010) found that nurse performance may be improved by addressing relationships amongst nurses, their colleagues and leaders, and resource accessibility. Brady et al. (2010) suggest that nurse managers and leaders may enhance their nurses' performance by understanding and addressing the factors that affect their ability and motivation to perform (Brady Germain \& Cummings, 2010). A second systematic review by Cummings et al. (2010) document evidence of various forms of leadership and their differential effects on the nursing workforce and work environments. Efforts by organizations and individuals to encourage and develop leadership practices are needed to enhance nurse satisfaction, recruitment, retention, and healthy work environments, particularly in current and worsening nursing shortage (Cummings et al., 2010). This corroborates earlier work by Pearson et al. (2007), that found a combination of leadership styles and characteristics contribute to the development and sustainability of a healthy work environment (Pearson et al., 2007).

Finally, my work emphasizes the need to develop healthy work environments for health care providers, with the end result, optimization of patient care. Similarly, Cummings et al. (2008) 
conducted a systematic review of factors contributing to nursing leadership, identified that weak study designs provide limited evidence for specific factors that could increase the effectiveness of current nursing leadership or guide the identification of future nurse leaders. Cummings et al. (2010) suggest that theory and research on interventions to develop and promote viable nursing leadership for the future are needed to achieve the goal of developing healthy work environments for health care providers and optimizing care for patients (Cummings et al., 2008).

\section{Methodological Observations}

Addressing Methodological Gaps in the Literature. This study contributed to addressing three significant methodological gaps identified in the work motivation literature. First, as described in the methodology, Chapter 3, this study utilizes reliable and validated instruments. Second, as compared to the studies in my comprehensive literature review, this study utilizes a large sample. Finally, by using a cross-sector design and further verification using z-tests, even though there was only a response rate of $18 \%$, results suggest that findings may be generalizable to nurses actively working in health care across Ontario, Canada.

Model Specification. My research raises concern that the use of partial models or global perspectives has the potential to hide relationships and may lead to inaccurate or faulty conclusions. Omitting concepts or combining them together globally, may make it difficult to determine clearly unique contributions of specific factors and whether or not said factors are being misinterpreted for others. Likewise, since my study findings suggest that there are no direct effects of organizational justice on OCBs, it is worth considering the effect of POS and the eight affective commitment targets. Henceforth, researchers may want to include POS measures and different targets of affective commitment when examining relationships between organizational justice and OCBs.

Multicollinearity. Niemelä-Nyrhinen \& Leskinen (2014) point out that there is a misconception that SEM is robust enough to deal with multicollinearity (Niemelä-Nyrhinen \& Leskinen, 2014). This however is not the case. Even with SEM, multicollinearity can distort the interpretation of multiple regression results. As Meyers et al. (2013) explain, if two or more 
variables are highly correlated, they are largely confounded with one another, essentially measuring the same characteristic, making it impossible to determine which of the variables is more relevant (Meyers et al, 2013). In addition, the values of the standardized regression coefficients of the highly correlated independent variables are distorted, exceeding the expected range of \pm 1 . Another problem with multicollinearity is standard errors of the regression weights of those multicollinear predictors can be inflated, increasing confidence intervals (sometimes including zero). When this occurs, one cannot determine if an increase in the predictor is associated with an increase or decrease in the criterion variable.

Not all of the instruments used in this study had been used with this population of nurses. In the CFA, the correlation matrices identified that there are many variables within constructs that are highly correlated $(r>8)$. As Field (2014) notes, the effect of two variables that correlate with $r=$ .9 for example, might be less than the effect of say three variables that all correlate at $r=.6$. Hence simply eliminating highly correlating variables might not address the root cause of the multicollinearity. This was found in my study. Removal of items from the structural model, did not address high standardized residuals. The only way to address the numerous high standardized residuals, would be to correlate a very large number of errors, which then raises the question that if such a large number of modifications is required, are some of the measurement models, in fact, a good fit. Although this needs further investigation, it does not nullify my findings as multicollinearity proved not to be an issue in the path analysis.

As discussed in the Results Chapters, the second method for dealing with multicollinearity, the model comparison approach whereby paths are restrained, did not change results. This brings the discussion to two critical points: 1) the importance of determining model fit by using an accumulation of evidence available, and 2) the significance of purposefully searching for the presence of multicollinearity. In addition to using multiple goodness-of-fit indices, it is important to also review standardized residuals. If only goodness of fit indices were reviewed, and not the correlation matrix or the standardized residuals, my original structural equation model could have easily been accepted as accurate. 
In this study, since many of the observed measures and the latent constructs are highly correlated (>.8). Instead of deleting measured items and potentially altering factor structures for each of the latent constructs, the decision was made to conduct a path analysis using average scores for each constructs. Since path analysis does not include the correlations between each of the observed measures, this avoided the issue of multicollinearity in this circumstance, allowing for the identification of relationships without the presence of multicollinearity. Unfortunately, path analysis has been used extensively in sociological and econometric modeling in the guise of SEM (Elston, Olson, \& Palmer, 2002). If one is truly conducting a SEM analysis, both structural and measurement models should be reported. However, when utilizing path analysis, it is important to remember that two of the main detracting features of using path analysis are that latent variables are not included and measurement error is not accounted for.

\section{Study Limitations}

There are a number of limitations to this study. First, internal consistency reliability testing demonstrated that there was room for improvement in the affective commitment scale when used in the health care setting. Future research in the development of scales with higher internal consistency reliability could help researchers achieve more accurate results, especially within health care. Secondly, since path analysis was used in this study, it is important to remember that two of the main detracting features of this method are that latent variables are not included, and measurement error is not accounted for (Meyers et al., 2013). Finally, a third potential limitation is that of common method variance. Single source data can introduce common method variance, measurement error that originates from the use of the specific method, rather than the study constructs. Measurement error can jeopardize construct validity, and inflate correlations amongst variables. In this study, this could have resulted from: social acceptability rather than true feelings, the attempt to remain cognitively consistent in responses, or respondent mood (Dillman et al., 2014). Precautions taken to control for common method variance were: using a monomethod approach; ensuring the items were clear, concise and specific; a minimal number of negative items were included; different scale anchors were used; and assuring respondent anonymity. While it is likely these factors limit the extent to which monomethod bias is a problem in this study, 
knowledge in this area would be strengthened by inclusion of some non-self-reported independent or outcome measures.

\section{Future Research}

A coherent understanding of relationships amongst employee attitudes and work-related behaviours in health care settings had yet to be established. Further work to refine and elaborate the model is relevant to nurse managers, leadership, and to researchers interested in organizational behaviour. Revelations regarding the use of multi-factor structure models instead of partial or global models, may have significant implications regarding previous pioneer work in this area. This preliminary work sets the stage for more in-depth comprehension into the complex network of relationships, to help leaders both predict and optimize work-related behaviours.

\section{Contexts}

This was a preliminary look at the relationships between organizational justice, perceived organizational support, affective commitment to a multitude of distinct targets, and organizational citizenship behaviours of frontline nurses working in hospitals, the community, and long-term care settings in Ontario. Next steps require validation of the model with additional health care practitioners in Ontario, then extending this work to testing the model in other Canadian provinces, and in countries with different health care systems. It would be interesting to see if my proposed framework would differ across health systems with different remuneration policies aimed at either patient care or rewarding clinician performance (e.g., pay-for-performance, fee-for-service, or bundled-payment programs). To further improve generalizability of my model, applying the model in different non-health care settings, with different population, with different professions, and with different levels of leadership would help to determine if the relationships hold true in these different settings and with different populations. It may become apparent that there are additional variables that can be added to help improve model reliability. The use and application of my model may provide researchers with new insights into the relationships between work attitudes and work-related behaviours. 


\section{Multicollinearity}

Further investigation is required into the presence of multicollinearity amongst work attitude and behaviour constructs. Determination of the optimal level of correlation is required. That is to say, at what point are high correlations detrimental to models. This is important to prevent distortion of the interpretation of results.

\section{Analysis}

Further exploration of work attitude and behaviour is desired using SEM, specifically in attempts to select constructs where multicollinearity will not be concern, and obtain high goodness of fit indices with low standardized residuals. This is important as there is much to be learned in regards to work attitude and behaviour relationships, by including latent variables in models.

\section{Model Expansion}

There is further opportunity to refine and improve the model. The model can be expanded to include intentional behaviours (e.g., turnover intention) and destructive behaviours (e.g., such as workplace deviance). Also of merit would be the investigation of different responsibilities attributed to different hierarchies of leaderships (e.g., shift supervisors, unit managers, nurse managers, and organizational managers), and the impact, if any, level of leadership has on the relationships identified in this study. In addition, the testing of leadership models that examine the mechanisms of influence on outcomes is warranted. Expansion of the model is important for a more fulsome understanding of how work attitudes impact a full continuum of workplace outcomes/behaviours.

\section{Causal Relationships}

A logical next step from association, presented here in my research, is future research on causal relationships. Further examination of the processes linking leadership practices with employee well-being is warranted. This is essential for future research to determine effective interventions. Of interest to nurse managers and leadership, would be investigation of interventions to enhance affective commitment to different targets, and the measurement of how successful they are. Efforts 
by organizations and individuals to encourage and develop transformational and relational leadership are needed to enhance nurse satisfaction, recruitment, retention, and healthy work environments, particularly the current, and worsening, nursing shortage.

\section{Additional Relationships}

Further investigation is warranted evaluating moderator effects, specifically the addition of factors such as workplace climate and culture into my model. The interrelationship of the work environment and work experiences on workers in health care requires additional exploration. It would be worth measuring in the future whether the organization's reward system plays a moderating role in relationships amongst commitments and OCBs, and whether having fair procedures in place actually encourage the seeking out of distributive justice through formal channels rather than seeking it themselves through revenge. Finally, strategies focusing on affective commitment to work, the organization, and patients, may assist with enhancing commitment to the profession. Once this is accomplished, development and evaluation of strategies that target and enhance affective commitment to specific targets could prove extremely useful for managers when attempting to align employee behaviours with organizational goals.

\section{Conclusions}

The purpose of my research is to better understand work attitudes and their relationships to extrarole behaviours amongst nurses working in hospitals, the community, and long-term care settings in Ontario. This study presents new evidence to enhance knowledge regarding the relationships between organizational justice, perceived organizational support, affective commitment to eight distinct targets, and organizational citizenship behaviours. In examining the relationships of these constructs in a single model, novel insights are afforded regarding the complexity of their interrelationships and the importance of this complexity to health care leadership desirous of improving work productivity. 


\section{References or Bibliography}

Adler, P. A., \& Adler, P. (1988). Intense Loyalty in Organizations: A Case Study of College Athletics. Administrative Science Quarterly, 33(3), 401-417.

Ajzen, I. (1991). The theory of planned behavior. Organizational behavior and human decision processes, 50(2), 179-211.

Alameddine, M., Baumann, A., Laporte, A., \& Deber, R. (2012). A narrative review on the effect of economic downturns on the nursing labour market: implications for policy and planning. Human resources for health, 10(1), 23.

Allison, P. D. (1999). Multiple regression: A primer: Pine Forge Press.

Arksey, H., \& O'Malley, L. (2005). Scoping Studies: Towards a Methodological Framework. International Journal of Social Research Methodology, 8(1), 19-32.

Ayupp, K., \& Kong, W. (2010). The impact of task and outcome interdependence and selfefficacy on employees' work motivation: an analysis of the Malaysian retail industry. Asia Pacific Business Review, 16(1/2), 123-142.

Bedny, G., \& Karwowski, W. (2006). The self-regulation concept of motivation at work. Theoretical Issues in Ergonomics Science, 7(4), 413-436.

Bentler, P. M. (1992). On the fit of models to covariances and methodology to the Bulletin. Psychological bulletin, 112(3), 400.

Bentler, P. M. (1995). EQS structural equations program manual: Multivariate Software.

Beugre, C. D. (1997). Analyzing the effects of perceived fairness on organizational commitment and workplace aggression. (.57), ProQuest Information \& Learning; US, Troy NY.

Bhat, S., \& Shah, H. (2010). Managing Work Motivation at the Bottom-A Case from Footwear Manufacturing Organization in India. Vilakshan: The XIMB Journal of Management, 7(1), 141-156.

Bhatti, N., G, A. A. S., \& Shaikh, F. M. (2012). Job Satisfaction and Motivation in Banking Industry in Pakistan. Journal of Asian Business Strategy, 2(3), 54.

Bies, R. J., \& Moag, J. S. (1986). Interactional justice: Communication criteria of fairness. Research on negotiation in organizations, 1(1), 43-55.

Bipp, T. (2010). What do people want from their jobs? The big five, core self-evaluations and work motivation. International Journal of Selection and Assessment, 18(1), 28-39.

Bipp, T., \& Kleinbeck, U. (2011). The effect of neuroticism in the process of goal pursuit. Personality and Individual Differences, 51(4), 454-459.

Boezeman, E. J., \& Ellemers, N. (2008). Pride and respect in volunteers' organizational commitment. European Journal of Social Psychology, 38(1), 159-172.

Brady Germain, P., \& Cummings, G. (2010). The influence of nursing leadership on nurse performance: a systematic literature review. Journal of nursing management, 18(4), 425439.

Brekke, K. A., \& Nyborg, K. (2010). Selfish bakers, caring nurses? A model of work motivation. Journal of Economic Behavior \& Organization, 75(3), 377-394. 
Brewer, G. A., \& Brewer, J. G. A. (2011). Parsing Public/Private Differences in Work Motivation and Performance: An Experimental Study. Journal of Public Administration Research \& Theory, 21(suppl_3), i347-i362.

Buchner, T. W. (2007). Performance management theory: A look from the performer's perspective with implications for HRD. Human Resource Development International, 10(1), 59-73.

Byrne, B. M. (2014). Structural equation modeling with LISREL, PRELIS, and SIMPLIS: Basic concepts, applications, and programming: Psychology Press.

Chandler, C. I., Chonya, S., Mtei, F., Reyburn, H., \& Whitty, C. J. (2009). Motivation, money and respect: a mixed-method study of Tanzanian non-physician clinicians. Social Science \& Medicine, 68(11), 2078-2088.

Chu, C., Lee, M.-S., Hsu, H.-M., \& Chen, C. (2005). Clarification of the Antecedents of Hospital Nurse Organizational Citizenship Behavior - An Example From a Taiwan Regional Hospital. Journal of Nursing Research, 13(4), 313-324.

CNO. (2015). Membership Statistics Highlights. Retrieved March 252015 from http://www.cno.org/Global/docs/general/43069_stats/43069_MembershipStatisticsHighlights.pdf

Colquitt, J. A. (2001). On the dimensionality of organizational justice: a construct validation of a measure. Journal of Applied Psychology, 86(3), 386-400.

Cortina, J. M., Chen, G., \& Dunlap, W. P. (2001). Testing interaction effects in LISREL: Examination and illustration of available procedures. Organizational Research Methods, 4(4), 324-360.

Cummings, G., Lee, H., MacGregor, T., Davey, M., Wong, C., Paul, L., \& Stafford, E. (2008). Factors contributing to nursing leadership: a systematic review. Journal of Health Services Research \& Policy, 13(4), 240-248.

Cummings, G., MacGregor, T., Davey, M., Lee, H., Wong, C. A., Lo, E., . . . Stafford, E. (2010). Leadership styles and outcome patterns for the nursing workforce and work environment: a systematic review. International Journal of Nursing Studies, 47(3), 363-385.

Dargahi, H., Alirezaie, S., \& Shaham, G. (2012). Organizational Citizenship Behavior Among Iranian Nurses. Iranian Journal of Public Health, 41(5), 85-90.

de Jonge, J., Le Blanc, P. M., Peeters, M. C., \& Noordam, H. (2008). Emotional job demands and the role of matching job resources: A cross-sectional survey study among health care workers. International Journal of Nursing Studies, 45(10), 1460-1469.

Dickin, K. L., Dollahite, J. S., \& Habicht, J.-P. (2011). Enhancing the intrinsic work motivation of community nutrition educators: how supportive supervision and job design foster autonomy. Journal of Ambulatory Care Management, 34(3), 260-273.

Dillman, D. A., Smyth, J. D., \& Melani, L. (2011). Internet, mail, and mixed-mode surveys: the tailored design method. Toronto: Wiley \& Sons.

Dillman, D. A., Smyth, J. D., \& Christian, L. M. (2014). Internet, phone, mail, and mixed-mode surveys: the tailored design method. John Wiley \& Sons.

Dunlop, P. D., \& Lee, K. (2004). Workplace deviance, organizational citizenship behavior, and business unit performance: the bad apples do spoil the whole barrel. Journal of Organizational Behavior, 25(1), 67-80. 
Dwivedula, R., \& Bredillet, C. N. (2010). Profiling work motivation of project workers. International Journal of Project Management, 28(2), 158-165.

Dysvik, A., \& Kuvaas, B. (2008). The relationship between perceived training opportunities, work motivation and employee outcomes. International Journal of Training and Development, 12(3), 138-157. doi: http://dx.doi.org/10.1111/j.1468-2419.2008.00301.x

Eisenberger, R., Huntington, R., Hutchison, S., \& Sowa, D. (1986). Perceived Organizational support. Journal of Applied Psychology, 71(3), 500-507.

Elston, R. C., Olson, J. M., \& Palmer, L. (2002). Biostatistical genetics and genetic epidemiology: John Wiley \& Sons.

Fernet, C., Austin, S., \& Vallerand, R. J. (2012). The effects of work motivation on employee exhaustion and commitment: An extension of the JD-R model. Work \& Stress, 26(3), 213-229.

Fernet, C., Gagne, M., \& Austin, S. (2010). When does quality of relationships with coworkers predict burnout over time? The moderating role of work motivation. Journal of Organizational Behavior, 31(8), 1163-1180.

Field, A. (2014). Discovering statistics using IBM SPSS statistics: Sage.

Franco, L. M., Bennett, S., \& Kanfer, R. (2002). Health sector reform and public sector health worker motivation: a conceptual framework. Social science \& medicine, 54(8), 12551266.

Gaki, E., Kontodimopoulos, N., \& Niakas, D. (2013). Investigating demographic, work-related and job satisfaction variables as predictors of motivation in Greek nurses. Journal of nursing management, 21(3), 483-490.

Gallie, D., Zhou, Y., Felstead, A., \& Green, F. (2012). Teamwork, Skill Development and Employee Welfare. British Journal of Industrial Relations, 50(1), 23-46.

Gillet, N., Huart, I., Colombat, P., \& Fouquereau, E. (2013). Perceived organizational support, motivation, and engagement among police officers. Professional Psychology: Research and Practice, 44(1), 46-55. doi: http://dx.doi.org/10.1037/a0030066

Grant, A. M. (2008). The significance of task significance: Job performance effects, relational mechanisms, and boundary conditions. Journal of Applied Psychology, 93(1), 108-124.

Grant, A. M., Campbell, E. M., Chen, G., Cottone, K., Lapedis, D., \& Lee, K. (2007). Impact and the art of motivation maintenance: The effects of contact with beneficiaries on persistence behavior. Organizational behavior and human decision processes, 103(1), 53-67.

Greenberg, J. (1987). A Taxonomy of Organizational Justice Theories. The Academy of Management Review, 12(1), 9-22.

Greenberg, J. (1994). Using Socially Fair Treatment to Promote Acceptance of a Work Site Smoking Ban. Journal of Applied Psychology, 79(2), 288-297.

Greenberg, J. (2009). Promote procedural and interactional justice to enhance individual and organizational outcomes. Handbook of principles of organizational behavior: Indispensable knowledge for evidence-based management, 255-271.

Haagh, L. (2011). Working Life, Well-Being and Welfare Reform: Motivation and Institutions Revisited. World Development, 39(3), 450-473. doi: 10.1016/j.worlddev.2010.08.014

Hancock, G., \& Mueller, C. W. (2015). Introduction to Structural Equation Modeling: University of MD. 
Hayduk, L. A. (2014). Shame for disrespecting evidence: the personal consequences of insufficient respect for structural equation model testing. BMC medical research methodology, 14(1), 124.

Hinsz, V. B., Nickell, G. S., \& Park, E. S. (2007). The role of work habits in the motivation of food safety behaviors. Journal of Experimental Psychology: Applied, 13(2), 105-114.

Hunt, S. D., \& Morgan, R. M. (1994). Organizational commitment: one of many commitments or key mediating construct? Academy of Management Journal, 37(6), 1568-1587.

Jöreskog, K. G., \& Sörbom, D. (1989). LISREL 7: A guide to the program and applications: Spss.

Jöreskog, K. G., \& Sörbom, D. (2002). PRELIS 2: User’s Reference Guide. Lincolnwood, IL: Scientific Software International: Inc.

Jung, D., \& Sosik, J. J. (2006). Who Are the Spellbinders? Identifying Personal Attributes of Charismatic Leaders. Journal of Leadership \& Organizational Studies (Baker College), 12(4), 12-26.

Kaplan, D. (2009). Structural equation modeling: Foundations and extensions (Vol. 10): Sage Publications.

Kenny, D. A. (2012). Measuring model fit. Retrieved March 252015 from http://davidakenny.net/cm/fit.htm

Kleinginna Jr, P. R., \& Kleinginna, A. M. (1981). A categorized list of emotion definitions, with suggestions for a consensual definition. Motivation and emotion, 5(4), 345-379.

Kline, P. (2013). Handbook of psychological testing: Routledge.

Kline, R. B. (2005). Principles and Practice of Structural Equation Modeling. 2005. New York, NY: Guilford.

Kline, R. B. (2011). Principles and practice of structural equation modeling: Guilford press.

Korman, A. K., Greenhaus, J. H., \& Badin, I. J. (1977). Personnel Attitudes and Motivation. Annual Review of Psychology, 28(1), 175-196.

Kuvaas, B. (2006). Performance appraisal satisfaction and employee outcomes: mediating and moderating roles of work motivation. International Journal of Human Resource Management, 17(3), 504-522.

Kuvaas, B. (2006). Work performance, affective commitment, and work motivation: The roles of pay administration and pay level. Journal of Organizational Behavior, 27(3), 365-385.

Latham, G. P., \& Pinder, C. C. (2005). Work Motivation Theory and Research at the Dawn of the Twenty-First Century. Annual Review of Psychology, 56, 485-516.

Lavelle, J. J., Rupp, D. E., \& Brockner, J. (2007). Taking a Multifoci Approach to the Study of Justice, Social Exchange, and Citizenship Behavior: The Target Similarity Model†. Journal of management, 33(6), 841-866.

Lavelle, J. J., Brockner, J., Konovsky, M. A., Price, K. H., Henley, A. B., Taneja, A., \& Vinekar, V. (2009). Commitment, procedural fairness, and organizational citizenship behavior: A multifoci analysis. Journal of Occupational Behaviour, 30(3), 337-357.

Lawler, E. J. (1992). Affective attachments to nested groups: A choice-process theory. American Sociological Review, 327-339.

Lee, K., \& Allen, N. J. (2002). Organizational citizenship behavior and workplace deviance: the role of affect and cognitions. Journal of Applied Psychology, 87(1), 131-142. 
Lewis, T. (2011). Assessing social identity and collective efficacy as theories of group motivation at work. International Journal of Human Resource Management, 22(4), 963980.

Loi, R., Hang-Yue, N., \& Foley, S. (2006). Linking employees' justice perceptions to organizational commitment and intention to leave: The mediating role of perceived organizational support. Journal of Occupational and Organizational Psychology, 79(1), 101-120.

MacCallum, R. C., Roznowski, M., \& Necowitz, L. B. (1992). Model modifications in covariance structure analysis: the problem of capitalization on chance. Psychological bulletin, 111(3), 490.

Marsh, H. W., Dowson, M., Pietsch, J., \& Walker, R. (2004). Why Multicollinearity Matters: A Reexamination of Relations Between Self-Efficacy, Self-Concept, and Achievement. Journal of Educational Psychology, 96(3), 518.

Mathieu, J. E., \& Zajac, D. M. (1990). A Review and Meta-Analysis of the Antecedents, Correlates, and Consequences of Organizational Commitment. Psychological bulletin, 108(2), 171-194.

McNabb, N. S. (2009). The daily floggings will continue until morale improves: An examination of the relationships among organizational justice, job satisfaction, organizational commitment and intention to turnover. (Dissertation/Thesis), ProQuest Information \& Learning; US.

McNeely, B. L., \& Meglino, B. M. (1994). The role of dispositional and situational antecedents in prosocial organizational behavior: An examination of the intended beneficiaries of prosocial behavior. Journal of Applied Psychology, 79(6), 836-844.

Meyer, J. P., Allen, N. J., \& Smith, C. A. (1993). Commitment to organizations and occupations: Extension and test of a three-component conceptualization. Journal of Applied Psychology, 78(4), 538-551.

Meyers, L. S., Gamst, G., \& Guarino, A. (2013). Applied multivariate research: Design and interpretation (Second ed.): Sage.

Mitchell, T. R. (1982). Motivation: New directions for theory, research, and practice. Academy of Management Review, 7(1), 80-88.

Moorman, R. H., Blakely, G. L., \& Niehoff, B. P. (1998). Does perceived organizational support mediate the relationship between procedural justice and organizational citizenship behavior? Academy of Management Journal, 41(3), 351-357.

Morin, A. J., Madore, I., Morizot, J., Boudrias, J. S., \& Tremblay, M. (2009). Multiple Targets of workplace affective commitment: Factor structure and measurement invariance of the workplace affective commitment multidimensional questionnaire. Advances in psychology research, 59(1), 45-75.

Morin, A. J., Vandenberghe, C., Boudrias, J. S., Madore, I., Morizot, J., \& Tremblay, M. (2011). Affective commitment and citizenship behaviors across multiple foci. Journal of Managerial Psychology, 26(8), 716-738.

Morin, A. J., Vandenberghe, C., Boudrias, J. S., Madore, I., Morizot, J., \& Tremblay, M. (2011). Affective commitment and citizenship behaviors across multiple foci. Journal of Managerial Psychology, 26(8), 716-738.

Morin, A. J., Vandenberghe, C., Turmel, M. J., Madore, I., \& Maïano, C. (2013). Probing into 
commitment's nonlinear relationships to work outcomes. Journal of Managerial Psychology, 28(2), 202-223.

Motlagh, F. S., Yarmohammadian, M. H., \& Yaghoubi, M. (2012). The association of perceived organizational justice and organizational expectations with nurses' efforts. Iranian journal of nursing and midwifery research, 17(3), 211.

Mowday, R. T. (1982). Employee-organization linkages : the psychology of commitment, absenteeism, and turnover. New York: Academic Press.

Mueller, C. W., \& Lawler, E. J. (1999). Commitment to nested organizational units: Some basic principles and preliminary findings. Social Psychology Quarterly, 325-346.

Murphy, S. M., Wayne, S. J., Liden, R. C., \& Erdogan, B. (2003). Understanding social loafing: The role of justice perceptions and exchange relationships. Human Relations, 56(1), 6184.

Muse, L. A., \& Stamper, C. L. (2007). Perceived organizational support: Evidence for a mediated association with work performance. Journal of Managerial Issues, 517-535.

Nafziger, J. (2011). Motivational Job Assignments. Economica, 78(312), 676-696.

Negussie, N. (2012). Relationship between rewards and nurses' work motivation in addis ababa hospitals. Ethiopian Journal of Health Sciences, 22(2), 107-112.

Niemelä-Nyrhinen, J., \& Leskinen, E. (2014). Multicollinearity in Marketing Models: Notes on the Application of Ridge Trace Estimation in Structural Equation Modelling. Electronic Journal of Business Research Methods, 12(1).

Niu, C. P., Wang, A. C., \& Cheng, B. S. (2009). Effectiveness of a moral and benevolent leader: Probing the interactions of the dimensions of paternalistic leadership. Asian Journal of Social Psychology, 12(1), 32-39.

Norman, G. R., \& Streiner, D. L. (2003). Chapter 17: Path Analysis and Structural Equation Modeling. PDQ Statistics. Third Edition. London: BC Decker Inc, 156-177.

O'Reilly, C. A. (1991). Organizational behavior: Where we've been, where we're going. Annual Review of Psychology, 42(1), 427-458.

Organ, D. W. (1988). Organizational citizenship behavior: The good soldier syndrome. Lexington Books/DC Heath and Com.

Organ, D. W. (1990). The motivational basis of organizational citizenship behavior. Research in organizational behavior, 12(1), 43-72.

Organ, D. W., Podsakoff, P. M., \& MacKenzie, S. B. (2005). Organizational citizenship behavior: Its nature, antecedents, and consequences. Sage Publications.

Othman, A. K., Abdullah, H. S., \& Ahmad, J. (2009). The Influence of Work Motivation on Emotional Intelleigence and Team Effectiveness. Vision (09722629), 13(4), 1-14.

Park, S. M. (2010). The Effects of Personnel Reform Systems on Georgia State Employees' Attitudes. Public Management Review, 12(3), 403-437.

Park, S. M., \& Rainey, H. G. (2012). Work motivation and social communication among public managers. International Journal of Human Resource Management, 23(13), 2630-2660.

Pearson, A., Laschinger, H., Porritt, K., Jordan, Z., Tucker, D., \& Long, L. (2007). Comprehensive systematic review of evidence on developing and sustaining nursing leadership that fosters a healthy work environment in healthcare. International Journal of Evidence-Based Healthcare, 5(2), 208-253. 
Pinder, C. C. (2008). Work motivation in organizational behavior. New York, NY: Psychology Press.

Podsakoff, P. M., \& MacKenzie, S. B. (1994). Organizational citizenship behaviors and sales unit effectiveness. Journal of Marketing Research, 31(3), 351-363.

Podsakoff, P., MacKenzie, S., Paine, J., \& Bachrach, D. (2000). Organizational Citizenship Behaviors: A Critical Review of the Theoretical and Empirical Literature and Suggestions for Future Research. Journal of Management, 26(3), 513-563.

Preacher, K. J., \& Kelley, K. (2011). Effect size measures for mediation models: quantitative strategies for communicating indirect effects. Psychological methods, 16(2), 93.

Price, J. L., \& Mueller, C. W. (1986). Absenteeism and turnover of hospital employees: JAI press.

Purohit, B., \& Bandyopadhyay, T. (2014). Beyond job security and money: driving factors of motivation for government doctors in India. Human resources for health, 12(1), 12.

Rhoades, L., \& Eisenberger, R. (2002). Perceived organizational support: a review of the literature. Journal of Applied Psychology, 87(4), 698.

Rhoades, L., Eisenberger, R., \& Armeli, S. (2001). Affective commitment to the organization: the contribution of perceived organizational support. Journal of Applied Psychology, 86(5), 825.

RNAO. (2015). About RNAO. Retrieved March 252015 from http://rnao.ca/about

Rupp, D. E., \& Cropanzano, R. (2002). The mediating effects of social exchange relationships in predicting workplace outcomes from multifoci organizational justice. Organizational behavior and human decision processes, 89(1), 925-946.

Sahoo, F. M., Sahoo, K., \& Das, N. (2011). Need Saliency and Management of Employee Motivation: Test of an Indigenous Model. Vilakshan: The XIMB Journal of Management, 7(3), 21-36.

Schumacker, R., \& Lomax, R. (2004). A beginner's guide to structural equation modeling, 1996. Mahwah, New Jersey: Lawrence Erlbaum Associates, 288, 144.

Shamir, B. (1991). Meaning, self and motivation in organizations. Organization Studies, 12(3), 405-424.

Solinger, O. N., van Olffen, W., \& Roe, R. A. (2008). Beyond the Three-Component Model of Organizational Commitment. Journal of Applied Psychology, 93(1), 70-83.

Suliman, A., \& Kathairi, M. A. (2013). Organizational justice, commitment and performance in developing countries: The case of the UAE. Employee Relations, 35(1), 98-115.

Sulu, S., Ceylan, A., \& Kaynak, R. (2010). Work alienation as a mediator of the relationship between organizational injustice and organizational commitment: implications for healthcare professionals. International Journal of Business and Management, 5(8), P27.

Sung Min, P. (2010). The Effects of Personnel Reform Systems on Georgia State Employees' Attitudes. Public Management Review, 12(3), 403-437.

Sung Min, P., \& Word, J. (2012). Driven to Service: Intrinsic and Extrinsic Motivation for Public and Nonprofit Managers. Public Personnel Management, 41(4), 705-734.

Tadic, M., Bakker, A. B., \& Oerlemans, W. G. (2013). Work happiness among teachers: a day reconstruction study on the role of self-concordance. Journal of School Psychology, 51(6), 735-750.

Teh, P. L., \& Yong, C. C. (2011). Knowledge sharing in IS personnel: organizational behavior's 
perspective. Journal of Computer Information Systems, 51(4), 11.

Tolli, A. P., \& Schmidt, A. M. (2008). The role of feedback, causal attributions, and self-efficacy in goal revision. Journal of Applied Psychology, 93(3), 692-701.

Toode, K., Routasalo, P., \& Suominen, T. (2011). Work motivation of nurses: A literature review. International Journal of Nursing Studies, 48(2), 246-257.

Tourangeau, A., Cranley, L., Spence Laschinger, H. K., \& Pachis, J. (2010). Relationships among leadership practices, work environments, staff communication and outcomes in long-term care. Journal of nursing management, 18(8), 1060-1072.

Tremblay, M. A., Blanchard, C. M., Taylor, S., Pelletier, L. G., \& Villeneuve, M. (2010). Correction to Tremblay et al (2009). Canadian Journal of Behavioural Science/Revue canadienne des sciences du comportement, 42(1), 70.

Tripp, T. M., Bies, R. J., \& Aquino, K. (2007). A vigilante model of justice: Revenge, reconciliation, forgiveness, and avoidance. Social Justice Research, 20(1), 10-34.

Tsai, W. C., Chen, C. C., \& Liu, H. L. (2007). Test of a model linking employee positive moods and task performance. Journal of Applied Psychology, 92(6), 1570.

Valluzzi, J. L., Larson, S. L., \& Miller, G. E. (2003). Indications and limitations of structural equation modeling in complex surveys: Implications for an application in the Medical Expenditure Panel Survey (MEPS). In Joint Statistical Meetings-Section on Survey Research Methods, Agency for Healthcare Research and Quality (pp. 4345-4352).

van Beek, A. P., Wagner, C., Frijters, D. H., Ribbe, M. W., \& Groenewegen, P. P. (2013). The ties that bind? Social networks of nursing staff and staff's behaviour towards residents with dementia. Social Networks, 35(3), 347-356.

Vancouver, J. B. (2008). Integrating self-regulation theories of work motivation into a dynamic process theory. Human Resource Management Review, 18(1), 1-18.

Von Bonsdorff, M. E. (2011). Age-related differences in reward preferences. International Journal of Human Resource Management, 22(6), 1262-1276.

Wech, B. A., Mossholder, K. W., Steel, R. P., \& Bennett, N. (1998). Does work group cohesiveness affect individuals' performance and organizational commitment? A crosslevel examination. Small Group Research, 29(4), 472-494.

Wegge, Jeppesen, H. J., Weber, W. G., Pearce, C. L., Silva, S. A., Pundt, A., . . Piecha, A. (2010). Promoting work motivation in organizations: Should employee involvement in organizational leadership become a new tool in the organizational psychologist's kit? Journal of Personnel Psychology, 9(4), 154-171.

Wei Ting, H., Kou Hsien, W., Yi Ching, W., Chia Huei, H., \& Hui Chin, W. (2013). Autonomy and Structure Can Enhance Motivation of Volunteers in Sport Organizations. Perceptual \& Motor Skills, 117(3), 709-719.

Werner, P. (2004). Reasoned action and planned behavior. Middle range theories: Application to nursing research, 125-147.

Weston, R., Gore, P. A., Chan, F., \& Catalano, D. (2008). An introduction to using structural equation models in rehabilitation psychology. Rehabilitation Psychology, 53(3), 340.

Williams, \& Anderson, S. E. (1991). Job satisfaction and organizational commitment as predictors of organizational citizenship and in-role behaviors. Journal of Management, 17(3), 601-617. 
Williams, \& Shiaw, W. T. (1999). Mood and organizational citizenship behavior: the effects of positive affect on employee organizational citizenship behavior intentions. Journal of Psychology, 133(6), 656-668.

Wilson, B., Squires, M., Widger, K., Cranley, L., \& Tourangeau, A. (2008). Job satisfaction among a multigenerational nursing workforce. Journal of nursing management, 16(6), 716-723.

Wong, Cummings, G., \& Ducharme, L. (2013). The relationship between nursing leadership and patient outcomes: a systematic review update. Journal of nursing management, 21(5), 709-724.

Wong, H., Wong, M. C., Wong, S. Y., \& Lee, A. (2010). The association between shift duty and abnormal eating behavior among nurses working in a major hospital: a cross-sectional study. International Journal of Nursing Studies, 47(8), 1021-1027.

Wright, B. E. (2007). Public service and motivation: Does mission matter? Public Administration Review, 67(1), 54-64.

Yildirim, D. (2009). Bullying among nurses and its effects. International Nursing Review, 56(4), 504-511.

Yoon, J., Baker, M. R., \& Ko, J.-W. (1994). Interpersonal attachment and organizational commitment: Subgroup hypothesis revisited. Human Relations, 47(3), 329-351. 


\section{Appendices}

\section{List of Appendices}

Appendix A. Work Motivation - Chronological Summary and Key Findings up until 2005 ...................119

Appendix B. Electronic Search Strategy - PsychINFO ............................................................................133

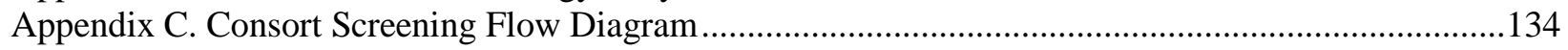

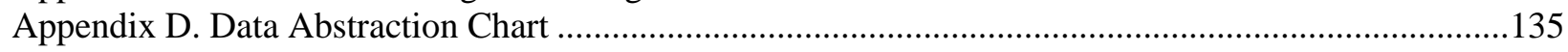

Appendix E. Conceptual Framework - Characteristics Influencing Motivation......................................153

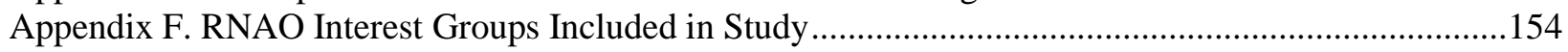

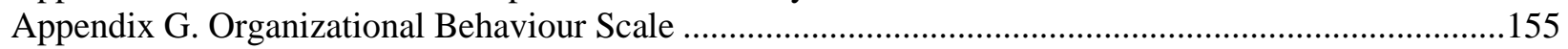

Appendix H. Workplace Affective Commitment Multidimensional Questionnaire (SHORT)...................156

Appendix I. WACMQ - Modifications for Use in Health Care .............................................................160

Appendix J. Organizational Justice Scale..............................................................................................162

Appendix K. Perceived Organizational Support Questionnaire …...........................................................163

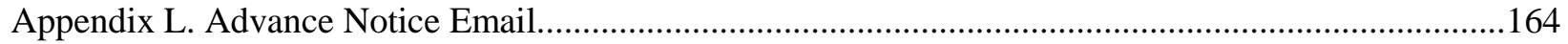

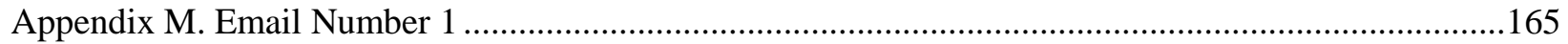

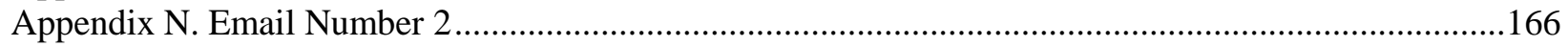

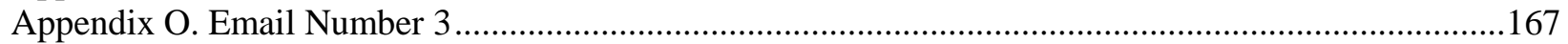

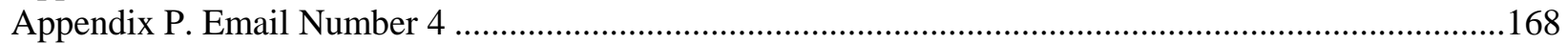

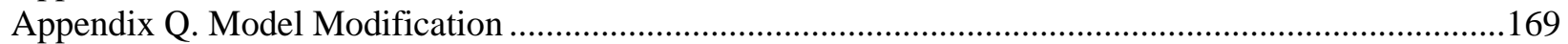

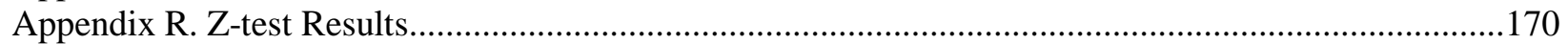

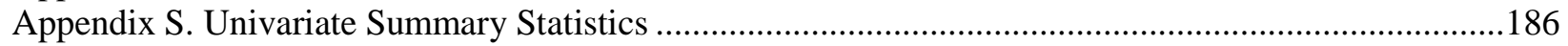

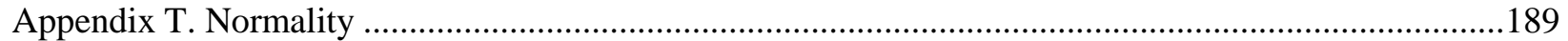

Appendix U. Correlation Matris for Justice Measures ...........................................................................220

Appendix V. Corrlation Matrix for Justic Independent Variables ..........................................................221

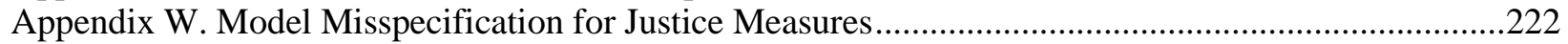

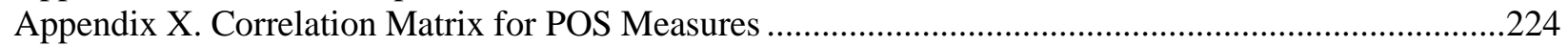

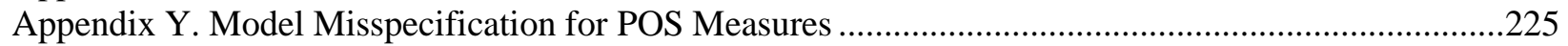

Appendix Z. Correlation Matrix for Affective Commitment ...........................................................226

Appendix AA. Correlation Matrix for Affective Commitment Independent Variables ............................227

Appendix BB. Model Misspecification for Affective Commitment ....................................................228

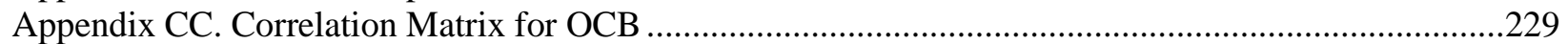

Appendix DD. Correlation Matrix for OCB Independen Variables.......................................................230

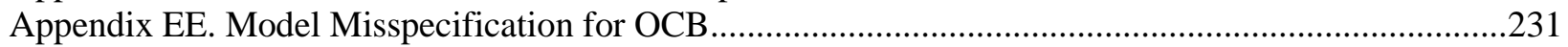

Appendix FF. SEM Correlation Matrix.............................................................................................232

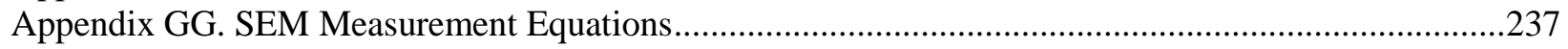

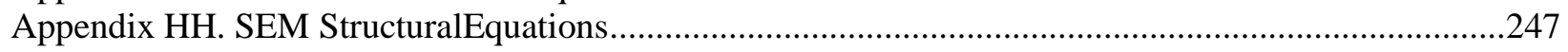

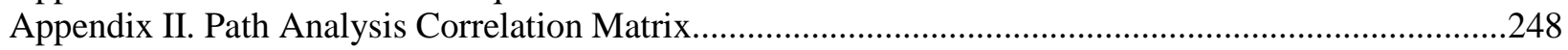

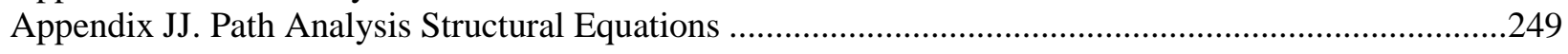




\section{Appendix A. Chronological Summary of Work Motivation Theories and Key Findings up until 2005}

\begin{tabular}{|c|c|c|}
\hline Year & Work Motivation Theory or Major Contribution (1911 - 2005) & Source \\
\hline 1911 & Taylor - Scientific Management Theory - wage incentives, time \& motion analysis , task \& tool design, job design $\&$ engineering & Stajkovic 2006 \\
\hline 1927 & Spearman: Ability - General intelligence factor (g); precursor of the related works on other various forms of ability & Stajkovic 2006 \\
\hline 1939 & $\begin{array}{c}\text { Hawthorne studies - Roethlisberger \& Dickson - Started with external determinants of performance, then attitudes; precipitated } \\
\text { Human Relations Movement }\end{array}$ & Stajkovic 2006 \\
\hline 1943 & Maslow’s (1943) hierarchical need theory - Primary, safety, love, esteem, and self-actualization & $\begin{array}{l}\text { Latham 2005; } \\
\text { Stajkovic 2006 }\end{array}$ \\
\hline 1951 & Allport - traits long been considered needs or drivers: satisfaction leads to pleasure, and lack of fulfillment leads to displeasure & Latham 2005 \\
\hline 1953 & Reinforcement theory - Skinner - reinforcement, contingent reinforcers, observable behaviours; exclusive focus on environment & Stajkovic 2006 \\
\hline 1954 & Social comparison theory - Festinger - Social comparison processes, especially slightly upward & Stajkovic 2006 \\
\hline 1957 & Cognitive dissonance theory - Festinger - Creation and dealing with cognitive dissonance & Stajkovic 2006 \\
\hline 1960 & $\begin{array}{l}\text { McGregor's (1960) Theory X - human adults are by nature indolent (work as little as possible; lack ambition, dislike } \\
\text { responsibility, and prefer to be led by others; are inherently selfish and indifferent to org needs and goals; are resistant to change; } \\
\text { are gullible, not intelligent, and easily duped; theory Y - people are not passive; possess potential to develop, assume responsibility } \\
\text { \& behave accordingly to org goals; management should structure org policies so humans can achieve own goals while pursuing } \\
\text { goals of the org }\end{array}$ & $\begin{array}{c}\text { Latham } \\
\text { 2005/06 } \\
\text { Pinder } 2008\end{array}$ \\
\hline 1960 & $\begin{array}{c}\text { McGregor (1960) - people have } 5 \text { needs; goal to satisfy lower needs, physiological \& security, before focusing on satisfying } \\
\text { higher needs for affiliation, esteem, self-actualization }\end{array}$ & Latham 2006 \\
\hline 1961 & nAch., nPow., nAff. - McClelland (1961) Needs for achievement, power, and affiliation & Stajkovic 2006 \\
\hline
\end{tabular}




\begin{tabular}{|c|c|c|}
\hline $\begin{array}{l}1961- \\
1963\end{array}$ & $\begin{array}{l}\text { Porter's (1961-1963) studies showed that people in low level jobs are concerned with satisfying lower order needs such as job } \\
\text { security; people not concerned with their higher order needs until they progressed to higher level jobs where their lower level } \\
\text { needs had been satisfied }\end{array}$ & Latham 2006 \\
\hline 1964 & VIE theory - Vroom (1964) Valence, expectancies (E1 and E2), and instrumentality as motivational force & Stajkovic 2006 \\
\hline 1965 & Equity theory - Adams (1965) - Degree if equity or inequity of outcomes (distributive justice) is input into job performance & Stajkovic 2006 \\
\hline 1966 & $\begin{array}{c}\text { Two-factor theory of motivation - Herzberg (1966) Hygiene factors (prevent dissatisfaction) and internal motivators (cause } \\
\text { motivation) }\end{array}$ & Stajkovic 2006 \\
\hline 1966 & Job enrichment Herzberg (1966) - enriching the jobs vertically with intrinsic motivators & Stajkovic 2006 \\
\hline 1968 & $\begin{array}{c}\text { Goal-setting theory - Locke (1968) - specific and difficulty goals are regulators of performance; Goal commitment considered } \\
\text { important moderator }\end{array}$ & Stajkovic 2006 \\
\hline 1968 & $\begin{array}{c}\text { Porter and Lawler model - Porter \& Lawler (1968) - refined and extended VIE; adds ability and perceived equitable rewards, } \\
\text { performance causing job satisfaction }\end{array}$ & Stajkovic 2006 \\
\hline 1968 & $\begin{array}{l}\text { Locke (1968) - specific high goals lead to higher performance; given goal commitment, the higher the goal, the higher one's } \\
\text { performance; and variables like monetary incentives, participation in decision making, competition, and feedback only increase a } \\
\text { person's performance to the extent that they lead to the setting of and commitment to a specific high goal }\end{array}$ & Latham 2006 \\
\hline 1969 & ERG theory - Alderfer (1969) - response to Maslow, three needs instead of five are focused: existence, relatedness, and growth & Stajkovic 2006 \\
\hline 1970 & Self-regulation theory - people monitor their own behaviours and consciously adjust those behaviours in pursuit of personal goals & Bedny 2006 \\
\hline 1970 & $\begin{array}{l}\text { Lawler (1970) - money motivates employees if they value the amount offered, they believe their performance will lead to } \\
\text { attainment of a desired amount, and they believe their effort will result in effective performance }\end{array}$ & Latham 2006 \\
\hline 1972 & Sociotechnical approach - Steiner (1972) - interface and harmony among personal, social, and technical functioning & Stajkovic 2006 \\
\hline 1973 & $\begin{array}{c}\text { Attribution theory - Kelley (1973); Weiner (1985) - Attributions about past outcomes; dimensions: loci, stability, controllability; } \\
\text { consensus, consistency, distinctiveness }\end{array}$ & Stajkovic 2006 \\
\hline
\end{tabular}




\begin{tabular}{|c|c|c|}
\hline 1975 & $\begin{array}{l}\text { Cognitive evaluation theory Deci (1975) - intrinsic versus extrinsic motivation: External rewards are controlling when task is } \\
\text { intrinsically motivating }\end{array}$ & Stajkovic 2006 \\
\hline 1976 & $\begin{array}{c}\text { Herzberg's job enrichment theory - job enrichment only motivates employees with higher order growth needs for autonomy, } \\
\text { responsibility, task variety, feedback, \& recognition }\end{array}$ & Latham 2006 \\
\hline 1977 & $\begin{array}{c}\text { Triandis's Model of Intentional Behaviour - behaviour can be predicted by people's intentions in conjunction with their habits for } \\
\text { engaging in the behaviour }\end{array}$ & Hinsz 2007 \\
\hline 1978 & $\begin{array}{c}\text { Social info processing - Salancik \& Pfeffer (1978) - Attitudes and task design; cognitive evaluation of the task, past actions, and } \\
\text { information from the social context }\end{array}$ & Stajkovic 2006 \\
\hline 1978 & $\begin{array}{l}\text { Latham and Dossett (1978) - field experiment of unionized employees found inexperienced unionized employees had higher } \\
\text { performance when a bonus was paid on a continuous rather than on a variable ratio schedule }\end{array}$ & Latham 2006 \\
\hline 1979 & $\begin{array}{c}\text { Social categorization - Tajfel and Turner (1979) - through social categorization, social groups become able to provide } \\
\text { identification to their members, these identifications being comparative, classifying individuals as different from or better than } \\
\text { counterparts in other groups }\end{array}$ & Lewis 2011 \\
\hline 1980 & $\begin{array}{c}\text { Spill over theory (Staines) - an employee's work experiences can carry over into the home and that experiences at home can affect } \\
\text { one’s work }\end{array}$ & Lim 2006 \\
\hline 1980 & $\begin{array}{c}\text { Job characteristics model - Hackman \& Oldham (1980) Three job characteristics lead to three psychological states, which lead to } \\
\text { outcomes; moderated by growth need strength }\end{array}$ & Stajkovic 2006 \\
\hline 1980 & Theory of Reasoned Action - attitudes and subjective norms of individuals predict their intentions (Ajzen \& Fishbein) & Hinsz 2007 \\
\hline 1981 & $\begin{array}{c}\text { Control theory (feedback control or cybernetics) - ongoing comparative process aimed at reducing discrepancy b/w standards for } \\
\text { behaviour \& observed effects of actual behaviour }\end{array}$ & Schmidt 2012 \\
\hline 1984 & $\begin{array}{l}\text { Model of Altruistic Motivation - Staw (1984) proposed a model of altruistic motivation in which the motivation to perform is a } \\
\text { function of (1) identification with the organization and 2) perceived links between individual performance \& important outcomes }\end{array}$ & Dickin 2011 \\
\hline
\end{tabular}




\begin{tabular}{|c|c|c|}
\hline 1985 & $\begin{array}{l}\text { Self-determination theory - Ryan, Connell, and Deci - adopt the concept of internalization; There is a distinction between } \\
\text { autonomous motivation (acting with a sense of volition and having the experience of choice, i.e. intrinsic motivation) and } \\
\text { controlled motivation. There are three categories of motivation: amotivation (a lack of motivation and features an absence of } \\
\text { intentional regulation); extrinsic motivation (may have up to four different levels that vary in degree of autonomy vs control they } \\
\text { entail for the individual); and intrinsic motivation (inherently autonomous, and enjoyable for the person) }\end{array}$ & Fernet 2012 \\
\hline 1985 & $\begin{array}{c}\text { Procedural justice - Folger \& Greenberg (1985) - perceived fairness of the work procedure used in decision making; interacts with } \\
\text { distributive justice in prediction }\end{array}$ & Stajkovic 2006 \\
\hline 1985 & $\begin{array}{c}\text { Emotional Intelligence - Happy employees are more motivated at their job; high emotionally intelligence employees are able to } \\
\text { suppress their negative feelings, such as unhappy with the recent pay increase or dissatisfied with this year performance appraisal, } \\
\text { through the Regulation of Emotion ability }\end{array}$ & Othman 2009 \\
\hline 1986 & $\begin{array}{l}\text { Social Cognitive Theory - a theory of human agency; It is a person's belief about his or her capacity to succeed at a specific task; } \\
\text { motivation is influenced by the interaction of three key elements: the work environment itself, what the performer thinks, and what } \\
\text { the performer does. }\end{array}$ & Buchner 2010 \\
\hline 1986 & $\begin{array}{c}\text { Values - rooted in needs, provide a basis for goals (Locke \& Henne 1986) and influence behaviour b/c they are normative } \\
\text { standards used to judge \& choose among alternative behaviours }\end{array}$ & Latham 2005 \\
\hline 1986 & $\begin{array}{c}\text { Participation in decision making - Schweiger \& Lena (1986) - whether different forms of participation in decision making lead to } \\
\text { different work outcomes }\end{array}$ & Stajkovic 2006 \\
\hline 1986 & $\begin{array}{c}\text { Impression management, organizational socialization - Jones (1986) - managing impressions others form about a person; potential } \\
\text { implications for performance evaluation }\end{array}$ & Stajkovic 2006 \\
\hline 1987 & Prosocial motivation - the desire to expend effort to benefit other people & Grant 2008 \\
\hline 1987 & $\begin{array}{c}\text { Discrepancy theory - discrepancies increase motivation; holding a goal end state will increase motivation to form specific plans to } \\
\text { meet that goal. According to these models, awareness of the discrepancy elicits planning processes that allow smooth self- } \\
\text { regulation toward the goal }\end{array}$ & Koo 2010 \\
\hline 1987 & $\begin{array}{l}\text { Greenberg's (1987) conceptualization of organizational justice - to motivate people, leaders, in addition to being fair, must be seen } \\
\text { as fair }\end{array}$ & Latham 2006 \\
\hline 1989 & enhancing human capital - the accumulation of investments in people through their education and on-the-job training & Wu 2007 \\
\hline
\end{tabular}




\begin{tabular}{|c|c|c|}
\hline 1989 & $\begin{array}{c}\text { Kanfer \& Ackerman - on a task that is complex for people, urging them to do their best results in higher performance than does } \\
\text { setting a specific high performance goal. }\end{array}$ & Latham 2005 \\
\hline 1989 & Person-organization fit - Chatman (1989) - the better the fit, the better the outcomes & Stajkovic 2006 \\
\hline 1989 & $\begin{array}{c}\text { Kanfer and Ackerman (1989) - contrary to prediction of goal setting theory, there are circumstances when urging people to do their } \\
\text { best can lead to higher performance than the setting of a specific high goal }\end{array}$ & Latham 2006 \\
\hline 1990 & Locke \& Latham presented their first comprehensive statement of goal setting as a theory & Latham 2005 \\
\hline 1990 & $\begin{array}{c}\text { Public Service Motivation - (Perry and Wise ) - an individual's predisposition to respond to motives grounded primarily or } \\
\text { uniquely in public institutions and organizations }\end{array}$ & $\begin{array}{l}\text { Groeneveld } \\
2009\end{array}$ \\
\hline 1991 & Kanfer - needs as internal tensions that influence the mediating cognitive processes that result in behavioural variability; & Latham 2005 \\
\hline 1991 & $\begin{array}{c}\text { Action Theory (Frese) - (a) an action starts with a goal, (b) proceeds to considerations by an employee of events that may occur in } \\
\text { the future, then (c) to the development of plans or strategies to attain the goal, (d) the selection of one of those strategies, (e) the } \\
\text { implementation and (f) self-monitoring of the selected strategy, and (g) the processing of feedback resulting from the } \\
\text { implementation of the strategy }\end{array}$ & Gagne 2005 \\
\hline 1991 & $\begin{array}{l}\text { Theory of Planned Behaviour - in addition to the attitude and subjective norm constructs, the theory of planned behaviour } \\
\text { stipulates that people's beliefs about how much control they have over their behaviour also influence their intentions to engage in } \\
\text { the action. Perceived behavioural control reflects a person's perceptions about how capable he or she is of engaging in the } \\
\text { behaviour as well as the perceived ease or difficulty of performing the behaviour. }\end{array}$ & Hinsz 2007 \\
\hline 1992 & Personality - George (1992) - predictor of work outcomes; review of numerous variables examined and their role in organizations & Stajkovic 2006 \\
\hline 1992 & Affect - George \& Brief (1992) - affect as predictor of work outcomes (e.g., positive \& negative affect) & Stajkovic 2006 \\
\hline 1993 & $\begin{array}{c}\text { Erez \& Earley (1993) - model of “cultural self-representation” to guide individual behaviour and managerial practices in cross- } \\
\text { cultural settings; people strive to fulfill values for self-enhancement, efficacy, and self-consistency; model based on two } \\
\text { collectivism versus individualism, and power distance }\end{array}$ & Latham 2005 \\
\hline 1993 & $\begin{array}{c}\text { Meta-analyses by Sadri \& Robertson (1993) and Stajkovic \&Luthans (1998) - wide-ranging methodological and analytic work- } \\
\text { related laboratory and field studies provide overwhelming evidence that efficacy beliefs influence the level of motivation and } \\
\text { performance }\end{array}$ & Latham 2005 \\
\hline
\end{tabular}




\begin{tabular}{|c|c|c|}
\hline 1993 & $\begin{array}{c}\text { Organizational commitment - Meyer, Allen, \& Smith (1993) - OC as antecedent and consequence of work outcomes; three types } \\
\text { cost, normative, emotional }\end{array}$ & Stajkovic 2006 \\
\hline 1994 & $\begin{array}{c}\text { Organizational citizenship behaviour (OCB) - Van Dyne, Graham, \& Dienesch (1994); Predicting non-required behaviours at work } \\
\text { that contribute to various positive outcomes }\end{array}$ & Stajkovic 2006 \\
\hline 1994 & Lord \& Levy (1994) - self-regulation was an automatic data-driven process & Latham 2005 \\
\hline 1995 & Mount \& Barrick - conscientiousness is important in jobs that allow autonomy & Latham 2005 \\
\hline 1995 & $\begin{array}{l}\text { Job autonomy can facilitate the time necessary for learning and development, which in turn improves job performance (Wall \& } \\
\text { Jackson 1995) }\end{array}$ & Latham 2005 \\
\hline 1995 & $\begin{array}{c}\text { Rousseau (1995) studied affect and behaviour from the standpoint of idiosyncratic psychological contracts and effect they have on } \\
\text { trust in the workplace }\end{array}$ & Latham 2005 \\
\hline 1996 & $\begin{array}{c}\text { Winters \& Latham (1996) replicated Kanfer \& Ackerman’s (1989) - on complex tasks, urging to do their best results in higher } \\
\text { performance than setting a specific high performance goal }\end{array}$ & Latham 2005 \\
\hline 1996 & Weiss and Cropanzano (1996) - affective events theory which explains effects of mood and emotion on a person's performance & Latham 2006 \\
\hline 1996 & $\begin{array}{c}\text { Gellatly - conscientiousness was significantly related to performance; effect completely moderated by self-efficacy and two } \\
\text { measures of personal goals }\end{array}$ & Latham 2005 \\
\hline 1996 & $\begin{array}{l}\text { Winters and Latham (1996) - on tasks where people have yet to master the requisite knowledge \& skills, urging people to do their } \\
\text { best is indeed superior to setting a high goal for a specific performance outcome But, setting a specific high learning goal leads to } \\
\text { even higher performance on tasks the person has yet to master than urging people to do their best. }\end{array}$ & Latham 2006 \\
\hline 1996 & Foreman \& Murphy (1996) applied a valence expectancy approach to predict job-seeking behaviour. & Latham 2005 \\
\hline 1996 & $\begin{array}{l}\text { Ashford \& Black (1996) - suggested } 3 \text { primary motives for feedback seeking: instrumental to attain a goal and perform well, ego- } \\
\text { based to defend or enhance one’s ego, and image-based to protect or enhance the impression others have of oneself }\end{array}$ & Latham 2005 \\
\hline 1996 & $\begin{array}{c}\text { De Shon et al. (1996) - empirical support for this assertion; self-regulation does not require a significant amount of attentional } \\
\text { resources }\end{array}$ & Latham 2005 \\
\hline
\end{tabular}




\begin{tabular}{|c|c|c|}
\hline 1996 & $\begin{array}{c}\text { Affective events' theory - Weiss and Cropanzano (1996), a -ve workplace event causes negative emotional reactions, leading to a } \\
\text { decrease of intrinsic work motivation over time }\end{array}$ & deLange 2011 \\
\hline 1996 & $\begin{array}{c}\text { Wiggins (1996) - Five Factor Model (FFM). - extroverts are attracted to enriched jobs, neurotics are attracted to jobs that excel on } \\
\text { hygiene variables (e.g., fringe benefits, the physical working conditions), and people who score high on conscientiousness are } \\
\text { attracted to jobs that allow them a high degree of autonomy }\end{array}$ & Latham 2006 \\
\hline 1997 & $\begin{array}{l}\text { Cole and Latham (1997) - adherence to procedural justice principles by managers during disciplinary action increases feelings of } \\
\text { fairness by employees, union leaders, \& labor lawyers }\end{array}$ & Latham 2006 \\
\hline 1997 & $\begin{array}{l}\text { Regulatory focus theory- Higgins (1997) - there are two motivational or self-regulatory systems, labelled as promotion and } \\
\text { prevention, which focus on different underlying needs (growth and development versus safety and security). To adapt to changes } \\
\text { in biological, psychological and social functioning, people strive towards maximization of gains (promotion) and minimization of } \\
\text { losses (prevention) }\end{array}$ & deLange 2011 \\
\hline 1997 & Lee et al. (1997) - that if goals are perceived as impossible, offering a bonus for goal attainment can lower motivation & Latham 2005 \\
\hline 1997 & $\begin{array}{l}\text { Cordery (1997) - the necessity of differentiating importance of } 3 \text { dimensions of job autonomy (1) method control (2) timing } \\
\text { control, and (3) discretion in setting performance goals; Four interrelated dimensions that affect job autonomy, the extent to which } \\
\text { the supervisor (1) provides clear attainable goals, (2) exerts control over work activities, (3) ensures that the requisite resources are } \\
\text { available, and (4) gives timely accurate feedback on progress toward goal attainment. }\end{array}$ & Latham 2005 \\
\hline 1997 & $\begin{array}{l}\text { Ajila - the practical significance of Maslow’s theory is widely accepted; Physiological needs are considered in decisions regarding } \\
\text { space, lighting, \& working conditions; safety in terms of work practices; love in regard to forming cohesive work teams; esteem } \\
\text { through responsibility and recognition; and self-actualization in terms of opportunities for creative and challenging jobs/tasks }\end{array}$ & Latham 2005 \\
\hline 1997 & $\begin{array}{l}\text { Kanfer \& Heggestad - developmental theory that distinguishes between distal influences on action, in the form of relatively stable } \\
\text { motivational traits, and proximal influences associated with individual differences in self-regulatory or motivational skills. }\end{array}$ & Latham 2005 \\
\hline 1997 & $\begin{array}{l}\text { Judge et al. (1997) - theory of traits labeled core self-evaluations that represent one's appraisal of people, events, and things in } \\
\text { relation to self; Core evaluations are manifested in four traits (self-esteem, locus of control, neuroticism, and generalized self- } \\
\text { efficacy) }\end{array}$ & Latham 2005 \\
\hline 1997 & Social cognitive theories - (Bandura 1997) - positive feedback in relation to goal pursuit increases effort and goal difficulty levels & Latham 2005 \\
\hline
\end{tabular}




\begin{tabular}{|c|c|c|}
\hline 1997 & $\begin{array}{l}\text { Variables affected by fairness perceptions include retribution (Mclean Parks 1997), workplace retaliation (Skarlicki \& Folger } \\
\text { 1997) }\end{array}$ & Latham 2005 \\
\hline 1997 & $\begin{array}{c}\text { Nigeria, Ajila (1997) - the satisfaction of lower order needs on the part of employees take precedent over the satisfaction of their } \\
\text { higher order needs }\end{array}$ & Latham 2006 \\
\hline 1997 & Cordery (1997) - inherently routine structured jobs mitigate the beneficial effects of granting people autonomy & Latham 2006 \\
\hline 1998 & $\begin{array}{l}\text { Stajkovic and Luthans (1998) - meta-analysis confirmed importance of self- efficacy to a person's motivation and performance; } \\
\text { people with high self-efficacy commit to high goals. }\end{array}$ & Latham 2006 \\
\hline 1998 & $\begin{array}{c}\text { Hogan \& Shelton - social skill, a learned ability, is necessary for motivation to lead to success; high needs for achievement or } \\
\text { power are frustrated, among people low in social skill }\end{array}$ & Latham 2005 \\
\hline 1998 & Variables affected by fairness perceptions include reactions to being laid off (Skarlicki et al. 1998) & Latham 2005 \\
\hline 1998 & Folger's (1998) moral virtues model adds ethical to the instrumental and relational models of justice & Latham 2005 \\
\hline 1998 & $\begin{array}{l}\text { Parker \& Wall (1998) - unenriched jobs can lead to psychological depression as well as cardiovascular disease; adverse effects are } \\
\text { minimized, if not eliminated by introducing job autonomy, participation in decision making, and the opportunity to acquire new } \\
\text { skills }\end{array}$ & Latham 2006 \\
\hline 1999 & $\begin{array}{c}\text { Osteraker (1999) - model of dynamic triangle of motivation - posits a relation among culture, org culture, \& individual } \\
\text { characteristics in shaping perspectives of motivation }\end{array}$ & Worthley 2009 \\
\hline 1999 & $\begin{array}{l}\text { Dweck (1999) - people's conception of their ability influences the goals pursued; incrementalists have a learning goal orientation; } \\
\text { focus on the acquisition of knowledge and the perfecting of competence; choose tasks that are challenging for them. Errors are } \\
\text { viewed as allowing opportunities to learn from mistakes. Entitists view ability as fixed, \& have a performance goal orientation } \\
\text { whereby they choose tasks allowing them to easily demonstrate proficiency at expense of learning something new }\end{array}$ & Latham 2005 \\
\hline 1999 & $\begin{array}{l}\text { Brett \& VandeWalle (1999) - goal orientation not have a significant relationship with performance, but was mediated by content of } \\
\text { goals; individuals selected importance of personality in predicting, understanding, \& influencing choice, affect, \& performance has } \\
\text { been shown, as has the importance of job characteristics as a mediator/moderator. Taxonomy of motivational traits \& skills, and } \\
\text { three theories: socioanalytic, core self-evaluations, \& goal orientation- dominating literature }\end{array}$ & Latham 2005 \\
\hline
\end{tabular}




\begin{tabular}{|c|c|c|}
\hline 1999 & $\begin{array}{l}\text { Gollwitzer (1999) - goal intentions accompanied by implementation intentions on complex tasks, lead to a higher rate of goal } \\
\text { attainment than do goal intentions only; by forming implementation intentions, people strategically switch from conscious effortful } \\
\text { control of their goal-directed behaviour to being automatically controlled by situational cues }\end{array}$ & Latham 2005 \\
\hline 1999 & Williams et al. (1999) found that a feedback source that is perceived as supportive increases feedback seeking & Latham 2005 \\
\hline 1999 & $\begin{array}{l}\text { Gollwitzer \& Bayer (1999) - a time perspective on goal striving and self-regulatory processes as mediating the effects of intentions } \\
\text { on behaviour; latter consists of } 4 \text { phases: predecisional, preactional, actional, and postactional }\end{array}$ & Latham 2005 \\
\hline 1999 & $\begin{array}{c}\text { Ambrose \& Kulik (1999) - little or no advances have been made in expectancy theory research in the past decade; few theoretical } \\
\text { or applied reasons for additional research on the application of this theory to organizational behaviour }\end{array}$ & Latham 2005 \\
\hline 1999 & $\begin{array}{l}\text { Kamalanabhan, Uma, and Vasanthi (1999) - bank clerks in India stated that the satisfaction of their need for job security was most } \\
\text { important to them, while bank officers are more concerned with satisfaction of their higher order needs }\end{array}$ & Latham 2006 \\
\hline 2000 & $\begin{array}{l}\text { Seijts \& Latham - examined applicability of goal-setting principles when personal goals are potentially incompatible with those of } \\
\text { the group; found that social dilemmas are boundary conditions for the usual positive effects of goal setting. Self-enhancing } \\
\text { personal goals have a detrimental effect on a group’s performance. Seven-person groups more competitive than those in groups of } \\
\text { three. Only when individual's goal was compatible with group’s goal was group’s performance enhanced }\end{array}$ & Latham 2005 \\
\hline 2000 & $\begin{array}{l}\text { Haslam et al. - When personal identity is salient, needs to self-actualize and enhance self-esteem through personal advancement } \\
\text { and growth become dominant; when social identity is salient, need to enhance group-based self-esteem through sense of } \\
\text { relatedness, respect, peer recognition, and attainment of group goals dominate }\end{array}$ & Latham 2005 \\
\hline 2000 & $\begin{array}{l}\text { Three principles assist design and interpretation of motivation and reward systems: identify the cultural characteristics of a country } \\
\text { regarding collectivism/individualism and power distance; understand yourself and cultural values you represent; and understand } \\
\text { meaning of various managerial practices in each country (Erez 2000) }\end{array}$ & Latham 2005 \\
\hline 2000 & $\begin{array}{l}\text { Bargh \& Ferguson (2000) - research findings that show that automatic or nonconscious goals produce the same outcomes as } \\
\text { conscious goal pursuit in information processing, memory storage, social behaviour, and task performance, as well as in self- } \\
\text { efficacy, self-evaluation, and mood state }\end{array}$ & Latham 2005 \\
\hline
\end{tabular}




\begin{tabular}{|c|c|c|}
\hline 2000 & $\begin{array}{c}\text { Feedback is a moderator to guide behaviour toward automatized goal (Bargh \& Ferguson 2000). Environment can activate a } \\
\text { person's goal within given situation as part of the preconscious analysis of the situation. The habitual plan for carrying out the goal } \\
\text { is activated automatically without conscious planning }\end{array}$ & Latham 2005 \\
\hline 2000 & Control theory - (Carver et al. 2000) - failure motivates more than success & Latham 2005 \\
\hline 2001 & Job satisfaction - Judge, Thoresen, Bono, \& Patton (2001) - job satisfaction as antecedent and consequence of work outcomes & Stajkovic 2006 \\
\hline 2001 & Forgas and George (2001) - affect infusion model, showing how one's affect colors one's cognitive appraisal of one's job & Latham 2006 \\
\hline 2001 & $\begin{array}{c}\text { Houkes et al. (2001) - Dutch bank/school - a positive relationship between work content (skill variety) \& work motivation, \& b/w } \\
\text { erosion of work content \& emotional exhaustion }\end{array}$ & Latham 2005 \\
\hline 2001 & A meta-analysis by Colquitt et al. (2001) showed employee perceptions of justice correlate highly with job performance. & Latham 2006 \\
\hline 2001 & $\begin{array}{c}\text { Cropanzano, Byrne, Bobocel, and Rupp (2001) - importance of justice principles tied to satisfaction of person's needs (for control, } \\
\text { belonging, self-esteem \& meaningful existence) }\end{array}$ & Latham 2006 \\
\hline 2001 & A meta-analysis - core self-evaluation is a strong dispositional predictor of job satisfaction (Judge \& Bono 2001) & Latham 2005 \\
\hline 2001 & Baum et al. (2001) - relationship between personality and performance is mediated by situationally specific goals and self-efficacy & Latham 2005 \\
\hline 2001 & $\begin{array}{c}\text { Erez \& Judge (2001) - motivation mediated 1/2 relationship b/w core self-evals \& performance; core self-eval is a motivational } \\
\text { trait, explains its effect on job performance }\end{array}$ & Latham 2005 \\
\hline 2001 & A meta-analysis showed that core self-evaluation is a strong dispositional predictor of job satisfaction (Judge \& Bono 2001) & Latham 2005 \\
\hline 2001 & $\begin{array}{l}\text { Bandura (2001) - obstacles and set-backs provide the challenge and excitement to spur them on, to increase their effort, to persist } \\
\text { until the goal is attained, and to set even higher goal upon its attainment; people with low self-efficacy look for tangible reasons, to } \\
\text { abandon their pursuit of a difficult goal }\end{array}$ & Latham 2006 \\
\hline
\end{tabular}




\begin{tabular}{|c|c|c|}
\hline 2001 & $\begin{array}{l}\text { Vancouver, Thompson, \&Williams (2001) - A boundary condition or moderator for the normally +ve effects of high self-efficacy } \\
\text { are tasks where performance on } 1 \text { trial yields no useful info for performing well on subsequent trial; high self-efficacy on the part } \\
\text { of a gambler who consistently plays roulette will prove beneficial for the gambling casino only }\end{array}$ & Latham 2006 \\
\hline 2001 & $\begin{array}{l}\text { Brown et al. (2001) - people with high self-efficacy use feedback to increase motivation, task focus, and effort and decrease } \\
\text { anxiety and self-debilitating thoughts }\end{array}$ & Latham 2005 \\
\hline 2001 & $\begin{array}{l}\text { SCT research shows the effect of environmental antecedents and consequences are mediated by cognitive variables; SCT } \\
\text { emphasizes dual control systems in self-regulation of motivation (Bandura 2001) }\end{array}$ & Latham 2005 \\
\hline 2001 & $\begin{array}{c}\text { Eden (2001) showed that a person’s belief in efficacy of tools available to perform requisite work, can be as motivating as self- } \\
\text { efficacy }\end{array}$ & Latham 2005 \\
\hline 2001 & Lind's (2001) fairness heuristic theory - decisions can be automatic as well as deliberate & Latham 2005 \\
\hline 2001 & $\begin{array}{l}\text { Justice matters to people - it facilitates maximization of personal gain, provides info re: their value to leader/team, \& is aligned } \\
\text { with basic respect for human worth (Cropanzano et al.) }\end{array}$ & Latham 2005 \\
\hline 2001 & $\begin{array}{l}\text { Rational Control Theory - people are not automatically reactive to set discrepancy thresholds and can handle range in behaviour- } \\
\text { standard gap size; humans able to and set higher goals in response to goal achievement, machines do not; factor in human } \\
\text { tendencies to past success \& expectancies for future success - controlling behaviour (Donovan) }\end{array}$ & Buchner 2007 \\
\hline 2001 & $\begin{array}{l}\text { Korman (2001) theory of work motivation - contextual elements of the workplace combine with dispositional factors to influence } \\
\text { two independent self-regulatory processes: the self-enhancement motivational system and the self-protective motivational system. }\end{array}$ & Whitaker 2012 \\
\hline 2002 & $\begin{array}{l}\text { Variables affected by fairness perceptions include theft (Greenberg 2002), exploitation and self-sacrificing decision allocations } \\
\text { (Turillo et al. 2002), the aesthetically pleasing attributes of workplace revenge (Trip et al. 2002), sabotage (Ambrose et al. 2002) }\end{array}$ & Latham 2005 \\
\hline 2002 & $\begin{array}{l}\text { Justice matters because it facilitates maximization of personal gain, provides info as to their value to leader/team, and it is aligned } \\
\text { with a basic respect for human worth (Ambrose) }\end{array}$ & Latham 2005 \\
\hline 2002 & $\begin{array}{c}\text { Cable \& DeRue (2002) - employees differentiate among three varieties of fit: person-environment fit; “needs-supplies” fit and job } \\
\text { demands- employee abilities fit }\end{array}$ & Latham 2005 \\
\hline
\end{tabular}




\begin{tabular}{|c|c|c|}
\hline 2002 & $\begin{array}{l}\text { Holtom et al. (2002) - matching employees’ preferences for full- or part-time work status benefited job satisfaction, commitment, } \\
\text { \& retention plus extra-role and in-role behaviours }\end{array}$ & Latham 2005 \\
\hline 2002 & $\begin{array}{l}\text { Verplanken \& Holland (2002) - how values affect choices; outcomes with potential to activate a person's central values instigate } \\
\text { the acquisition of info and motivate choice decisions in accordance with pursuing the values in question; activation and } \\
\text { information collection mediate the relationship between values and decision behaviour }\end{array}$ & Latham 2005 \\
\hline 2002 & $\begin{array}{l}\text { Day, Schleicher, Unckless, and Hiller (2002) - a self-monitoring personality often leads to leadership positions; self-monitors are } \\
\text { sensitive to the expectations of others, which in turn increasing their likeability (a key to one's job progression) }\end{array}$ & Latham 2006 \\
\hline 2002 & $\begin{array}{c}\text { Steers \& Sanchez-Runde (2002) - national culture determines three sets of distal sources of motivation: people’s self-concept, } \\
\text { including personal beliefs, needs, and values; norms about work ethic and the nature of “achievement,” tolerance for ambiguity, } \\
\text { locus of control, etc.; and environmental factors such as education and socialization experiences, economic prosperity, and } \\
\text { political/legal systems }\end{array}$ & Latham 2005 \\
\hline 2002 & Perceived value of feedback increases, people seek it actively and frequently (Tuckey et al. 2002) & Latham 2005 \\
\hline 2002 & Goal-setting (Locke\&Latham 2002) - positive feedback in relation to goal pursuit increases effort and goal difficulty levels & Latham 2005 \\
\hline 2002 & $\begin{array}{c}\text { Erez \& Isen (2002) - people with higher levels of positive affect exhibited higher levels of persistence, effort, self-reported } \\
\text { motivation, and performance on different tasks. }\end{array}$ & Latham 2005 \\
\hline 2002 & $\begin{array}{l}\text { Socioemotional selectivity theory - that individuals will select goals in accordance with their perceptions of the future as being } \\
\text { limited or open-ended (Lang \& Carstensen) }\end{array}$ & deLange 2011 \\
\hline 2003 & $\begin{array}{l}\text { Hogan \& Warremfeltz - people have innate biological needs for acceptance and approval; status, power, and control of resources; } \\
\text { and predictability and order. Needs translate into behaviours for getting along with others, getting ahead, and making sense of the } \\
\text { world }\end{array}$ & Latham 2005 \\
\hline 2003 & $\begin{array}{c}\text { Schmitt et al. - personality is the primary predictor of elements of motivation; research now shows traits predict \&/or influence job } \\
\text { search \& choice of job, \& job performance \& satisfaction; traits include extroversion, conscientiousness, self-regulatory and self- } \\
\text { monitoring strategies, tenacity, core self-evaluations, and goal orientation }\end{array}$ & Latham 2005 \\
\hline
\end{tabular}




\begin{tabular}{|c|c|c|}
\hline 2003 & $\begin{array}{c}\text { Tett \& Burnett (2003) - person-situation interactionist model of job performance, laying groundwork for specifying conditions } \\
\text { under which particular personality traits predict and explain performance in specific jobs; variance in trait-expressive behaviour is } \\
\text { maximized in "weak" situations; "strong” situations, extrinsic rewards overpower individual differences in intrinsic rewards } \\
\text { associated with trait expression }\end{array}$ & Latham 2005 \\
\hline 2003 & $\begin{array}{c}\text { Witt \& Ferris - the relationship between conscientiousness and job performance that requires interpersonal effectiveness is } \\
\text { moderated by social skill }\end{array}$ & Latham 2005 \\
\hline 2003 & $\begin{array}{l}\text { Parker (2003) - unenriched simplified jobs stemming from lean processes (LP) can affect an employee's level of job depression, } \\
\text { the mediator - job characteristics which also partially mediated organizational commitment; to the extent LP can be introduced in } \\
\text { so as to allow job autonomy, skill use, and participative decision making, the employee's well-being and motivation increase }\end{array}$ & Latham 2005 \\
\hline 2003 & $\begin{array}{l}\text { People with low self-esteem lack the resilience to seek negative feedback because it may corroborate a negative self-appraisal } \\
\text { (Bernichon et al. 2003). }\end{array}$ & Latham 2005 \\
\hline 2003 & $\begin{array}{l}\text { Socio-analytic theory - (Hogan, 2003; Hogan \& Holland, 2003; Hogan \& Warremfeltz, 2003) - people have innate needs for (1) } \\
\text { acceptance and approval, (2) status, power and control of resources, and (3) predictability and order. }\end{array}$ & Latham 2006 \\
\hline 2003 & $\begin{array}{l}\text { However, Lord et al. (2003) illustrated the potential value of neuropsychologically based models for explaining expectancy theory. } \\
\text { A major criticism of the theory, is that the computations required are unrealistically time-consuming and exceed working memory } \\
\text { capacity. Using simulation methodology and neural networks that operate implicitly, authors reinterpreted the theory so that } \\
\text { cognitive resources are not exhausted by simple computations. }\end{array}$ & Latham 2005 \\
\hline 2003 & $\begin{array}{l}\text { Pritchard \& Payne (2003) updated motivational component of Naylor, Pritchard, \& Ilgen's “NPI” theory (1980). Motivation - the } \\
\text { process that determines how energy is used to satisfy needs, is a resource-allocation process where time and energy are allocated to } \\
\text { an array of tasks; includes the direction, intensity, and persistence of this allocation process; is a future-oriented concept in that } \\
\text { people anticipate the amount of need satisfaction that will occur when outcomes are received. Perceived relationship between } \\
\text { applying energy to actions and the resulting need satisfaction influences how much of the energy pool is devoted to that action }\end{array}$ & Latham 2005 \\
\hline 2004 & $\begin{array}{l}\text { Van-Dijk and Kluger (2004) - drew on need hierarchy theory to determine whether people raise their goal upon attaining it; found } \\
\text { once lower order needs are satisfied, individual's goal for food or safety is not increased, but, when higher order goal for self- } \\
\text { esteem or actualization is attained, an even higher goal is set for the satisfaction of these two needs }\end{array}$ & Latham 2006 \\
\hline
\end{tabular}




\begin{tabular}{|c|c|c|}
\hline 2004 & $\begin{array}{l}\text { Kluger (2004) - experiments showed people who receive positive feedback under a promotion focus or negative feedback under a } \\
\text { prevention focus have higher motivation than those who receive feedback incongruent with their regulation focus }\end{array}$ & Latham 2005 \\
\hline 2004 & Cognitive ability - Schmidt \& Hunter (2004) - General mental ability (GMA) as a predictor of work outcomes & Stajkovic 2006 \\
\hline 2004 & $\begin{array}{l}\text { Collective-efficacy - people derive meaning from being linked to social collectives through their identities (Ellemers, De Gilder } \\
\text { and Haslam) }\end{array}$ & Lewis 2011 \\
\hline 2005 & $\begin{array}{c}\begin{array}{c}\text { Skarlicki and Latham (2005) - adherence to justice principles by union leaders increases union citizenship behaviour among union } \\
\text { members }\end{array} \\
\end{array}$ & Latham 2006 \\
\hline
\end{tabular}




\section{Appendix B. Electronic Search Strategy - PsychINFO}

@. Wolters Kluwer
Health

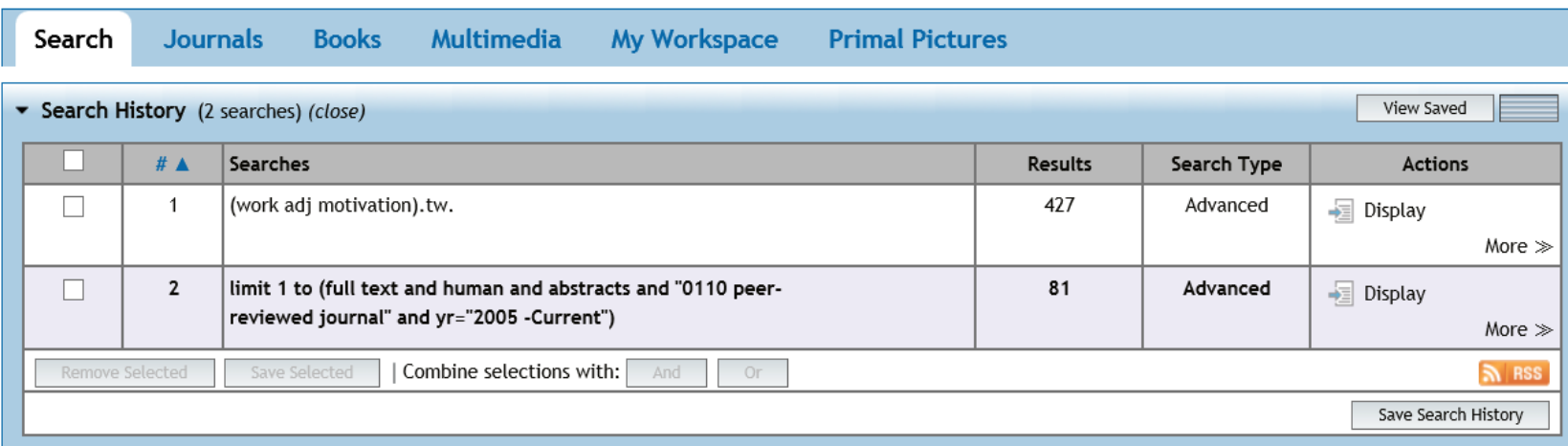

Advanced Search | Basic Search | Find Citation | Search Tools | Search Fields | Multi-Field Search

1 Resource selected I Hide I Change

(1) PsycINFO 2002 to March Week 42014 


\section{Appendix C. Consort Screening Flow Diagram}
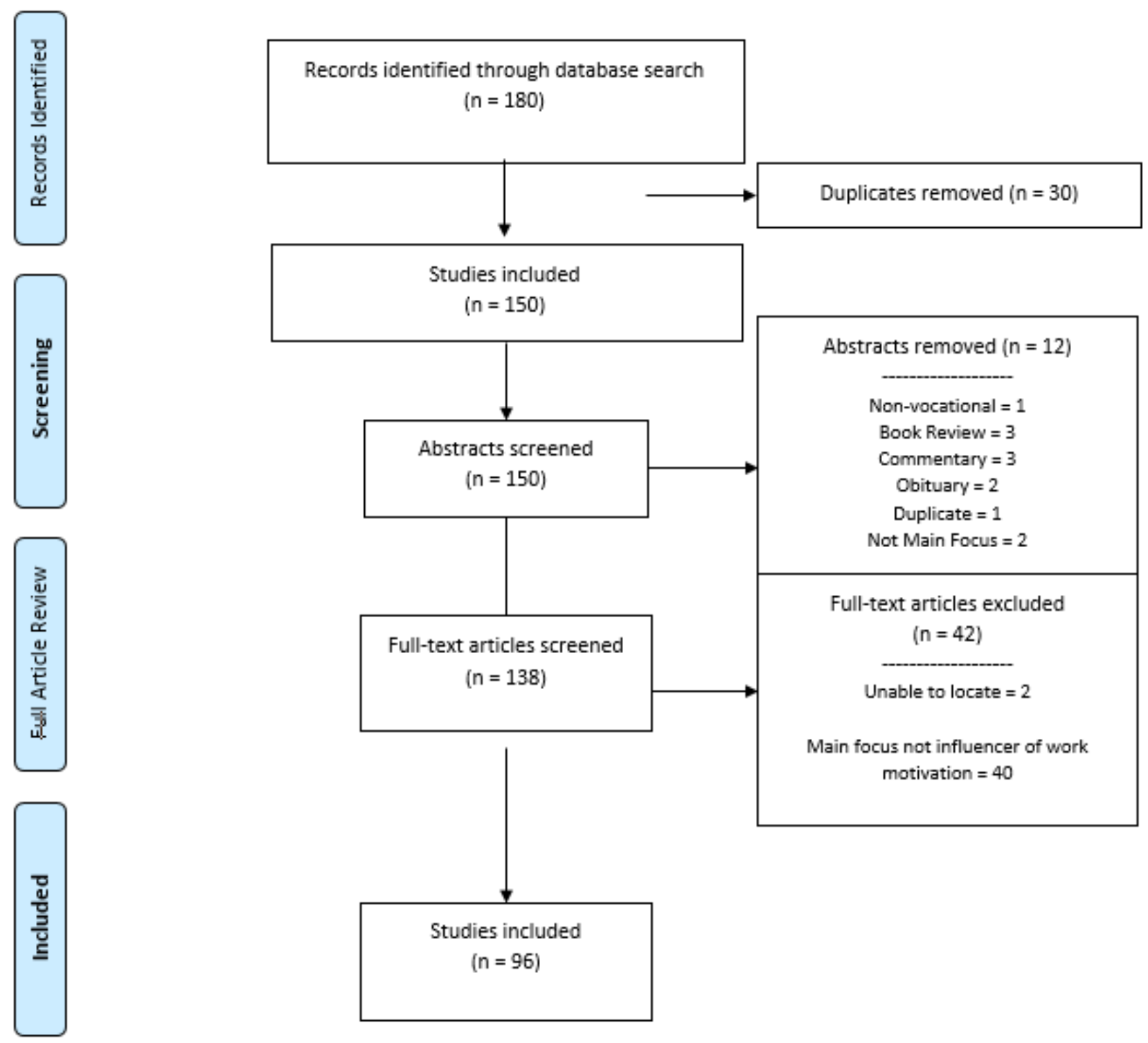


\section{Appendix D. Data Abstraction Chart}

\begin{tabular}{|c|c|c|c|c|c|c|c|c|c|}
\hline First Author & Year & $\begin{array}{l}\text { Country of } \\
\text { Origin }\end{array}$ & Industry & $\begin{array}{c}\text { Major Theories/ } \\
\text { Focus Area }\end{array}$ & $\begin{array}{l}\text { Population } \\
\text { Examined }\end{array}$ & Sample Size & $\begin{array}{l}\text { Theoretical/ } \\
\text { Empirical }\end{array}$ & Methodology & Main Findings \\
\hline Ayupp & 2010 & Malaysia & $\begin{array}{l}\text { Retail } \\
\text { industries }\end{array}$ & self-efficacy & employees & 84 & empirical & quantitative & $\begin{array}{l}\text { relationship b/w outcome interdependence and self-efficacy towards } \\
\text { employees work motivation }\end{array}$ \\
\hline Bambi & 2013 & $\begin{array}{l}\text { Tuscany, } \\
\text { Italy }\end{array}$ & Health care & bullying & $\begin{array}{c}\text { nurses in ED } \\
\text { and ICU }\end{array}$ & 444 & empirical & $\begin{array}{l}\text { exploratory- } \\
\text { descriptive } \\
\text { study, } \\
\text { through } \\
\text { closed-ended } \\
\text { questionnaire. }\end{array}$ & $\begin{array}{l}\text { most reported gossiping, complaints shared with others but not } \\
\text { discussed with concerned person, \& sarcasm; more common in EDs } \\
\text { than ICUs; symptoms - low morale, anxiety, and sleep disturbances }\end{array}$ \\
\hline Bateman & 2012 & USA & Variety & $\begin{array}{l}\text { goal setting } \\
\text { theory }\end{array}$ & variety & 25 & empirical & $\begin{array}{l}\text { qualitative - } \\
\text { theory } \\
\text { elaboration }\end{array}$ & $\begin{array}{l}\text { most research findings on psychology of work motivation based on } \\
\text { short-term studies; consider long-term motivation (goals \& goal } \\
\text { pursuit, \& self-regulation) and development of integrative model }\end{array}$ \\
\hline Bedny & 2006 & USA & $\begin{array}{c}\text { Food, } \\
\text { Manufacturing }\end{array}$ & $\begin{array}{l}\text { organizational } \\
\text { participation, } \\
\text { shared } \\
\text { leadership, and } \\
\text { organizational } \\
\text { democracy }\end{array}$ & $\begin{array}{l}\text { engineers, } \\
\text { musician }\end{array}$ & 5 & conceptual & $\begin{array}{l}\text { functional } \\
\text { analysis }\end{array}$ & $\begin{array}{l}\text { maintenance of motivation considered cyclic process; work } \\
\text { motivation construed as dynamic system, dependent on complex } \\
\text { relationships b/w various mechanisms of self-regulation; motivation } \\
\text { is not homogeneous process, rather comprised of different stages; } 5 \\
\text { motivational stages: (1) pre-conscious motivational stage; (2) goal- } \\
\text { related motivational stage; (3) task evaluative motivational stage; (4) } \\
\text { executive or process-related motivational stage; \& (5) result-related } \\
\text { motivational stage. }\end{array}$ \\
\hline
\end{tabular}




\begin{tabular}{|c|c|c|c|c|c|c|c|c|c|}
\hline Bhat & 2010 & India & Manufacturing & \begin{tabular}{|c} 
Herzberg's two \\
factor; Maslow; \\
Vroom's \\
Expectancy \\
Theory; Adam's \\
equity; Skinner's \\
operant \\
conditioning \\
\end{tabular} & $\begin{array}{c}\text { sales } \\
\text { employees }\end{array}$ & 112 & empirical & mixed & $\begin{array}{l}\text { significant relationship b/w motivation factors \& performance; } \\
\text { motivation \& performance of organization are directly linked }\end{array}$ \\
\hline Bhatti & 2012 & Pakistan & Business & $\begin{array}{l}\text { job design; job } \\
\text { characteristic }\end{array}$ & $\begin{array}{c}\text { middle- } \\
\text { upper } \\
\text { management } \\
\text { bankers }\end{array}$ & 200 & empirical & quantitative & $\begin{array}{l}\text { positive and significant relationship between job characteristics and } \\
\text { personal outcomes }\end{array}$ \\
\hline Bipp & 2011 & Germany & Education & $\begin{array}{c}\text { goal setting; } \\
\text { goal commitment }\end{array}$ & undergrads & 158 & empirical & quantitative & $\begin{array}{l}\text { neuroticism is indirectly related to attainment of assigned goals via } \\
\text { motivational variables in the process of goal pursuit }\end{array}$ \\
\hline Bipp 1/2 & 2010 & Germany & Education & $\begin{array}{l}\text { Herzberg's two- } \\
\text { factor theory ; } \\
\text { core self- } \\
\text { evaluation; job } \\
\text { characteristics } \\
\text { model (and age) }\end{array}$ & $\begin{array}{l}\text { students } \\
\text { facing } \\
\text { graduation }\end{array}$ & 114 & empirical & quantitative & $\begin{array}{l}\text { two personality traits (openness to experience and core self- } \\
\text { evaluations) are related to the preference concerning work } \\
\text { characteristics }\end{array}$ \\
\hline Bipp 2/2 & & & & & $\begin{array}{l}\text { full-time } \\
\text { employees }\end{array}$ & 114 & & & \\
\hline Boezeman & 2008 & Netherlands & $\begin{array}{l}\text { Volunteer } \\
\text { organization }\end{array}$ & $\begin{array}{l}\text { social identity } \\
\text { theory }\end{array}$ & volunteers & 89 & empirical & quantitative & $\begin{array}{l}\text { volunteer organizations might convey importance of volunteer work } \\
\& \text { provide organizational support to induce pride } \& \text { respect to } \\
\text { enhance organizational commitment among volunteers }\end{array}$ \\
\hline
\end{tabular}




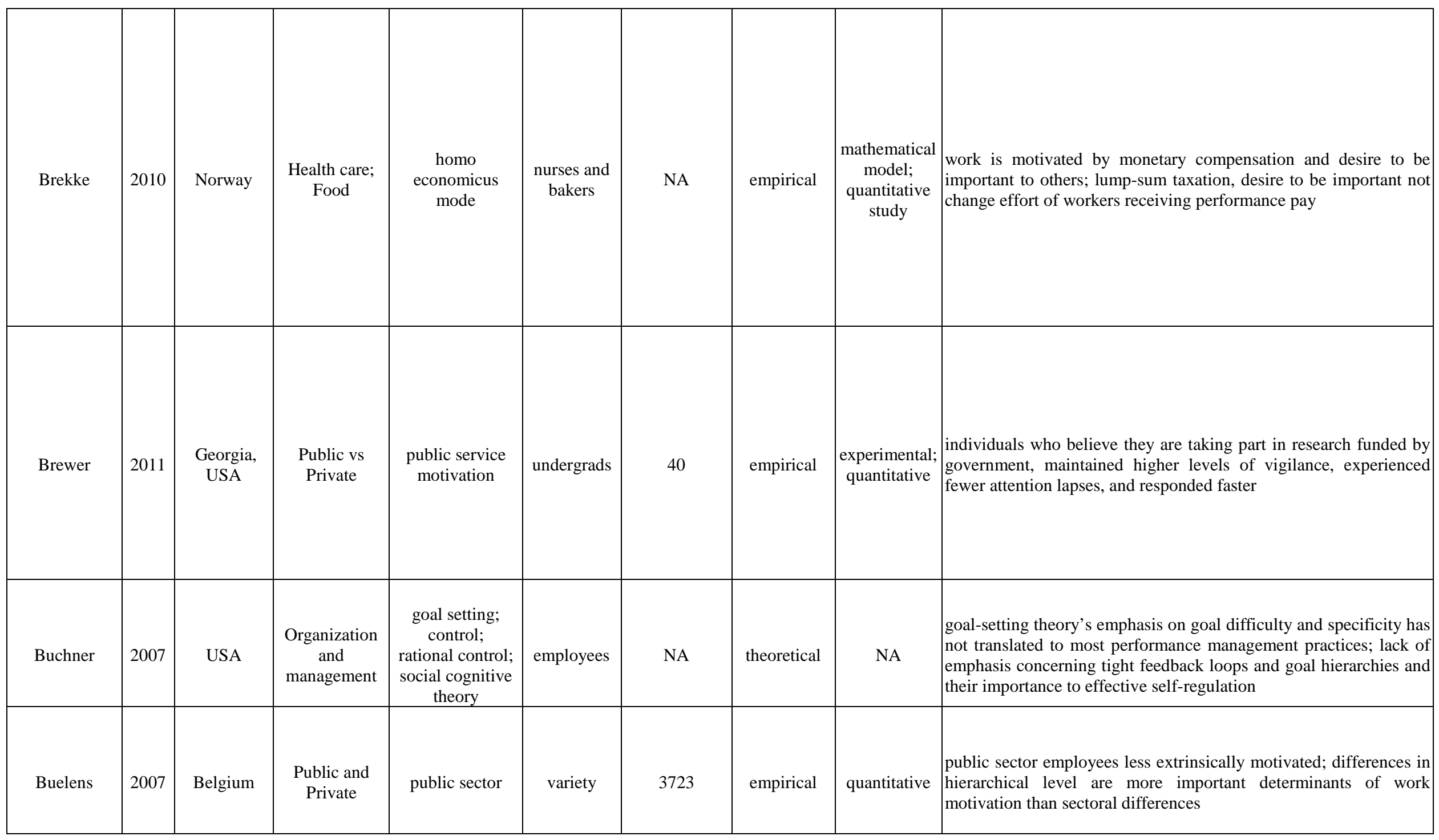




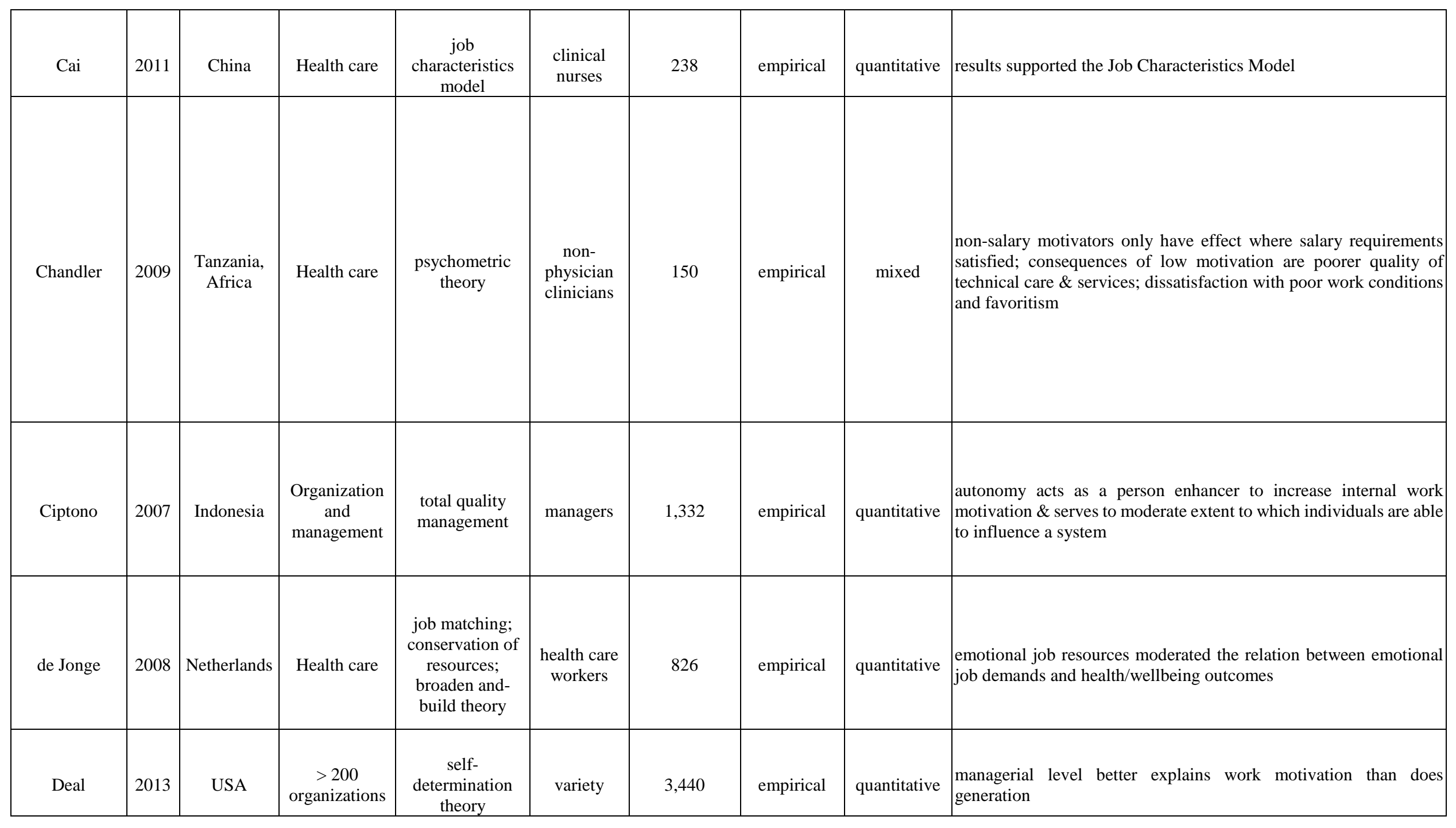




\begin{tabular}{|c|c|c|c|c|c|c|c|c|c|}
\hline deLange & 2011 & Netherlands & Health care & $\begin{array}{l}\text { social exchange; } \\
\text { affective events; } \\
\text { socioemotional; } \\
\text { regulatory focus; } \\
\text { lifespan theory of } \\
\text { control } \\
\end{array}$ & employees & 90 & empirical & quantitative & $\begin{array}{l}\text { relational contract breach predicts lower work motivation; age- } \\
\text { related processes such as future time perspective and regulatory } \\
\text { focus are important variables to include in future psychological } \\
\text { contract research }\end{array}$ \\
\hline Dickin & 2011 & $\begin{array}{l}\text { New York, } \\
\text { USA }\end{array}$ & Health care & $\begin{array}{l}\text { altruistic; } \\
\text { intrinsic and } \\
\text { extrinsic }\end{array}$ & $\begin{array}{c}\text { para- } \\
\text { professional } \\
\text { community } \\
\text { nutrition } \\
\text { educators; } \\
\text { supervisors } \\
\end{array}$ & 147 & empirical & mixed & $\begin{array}{l}\text { high levels of autonomy, associated with supervisors' delegation and } \\
\text { support, decision-making on scheduling and curricula, and job } \\
\text { satisfaction }\end{array}$ \\
\hline Dwivedula & 2010 & India & $\begin{array}{l}\text { Various } \\
\text { industries - } \\
\text { project based } \\
\text { organizations }\end{array}$ & $\begin{array}{l}\text { traditional vs } \\
\text { project based } \\
\text { organizations; } \\
\text { goal; Adam's } \\
\text { Equity Theory }\end{array}$ & $\begin{array}{c}\text { project } \\
\text { workers }\end{array}$ & 199 & empirical & quantitative & development of 5 factor structure of work motivation \\
\hline Dysvik & 2008 & Norway & Service & social exchange & trainees & 343 & empirical & quantitative & $\begin{array}{l}\text { relationship between perceived training opportunities, and both task } \\
\text { performance and citizenship behaviours are fully mediated; the } \\
\text { relationship between perceived training opportunities and turnover } \\
\text { intention was partially mediated by intrinsic motivation }\end{array}$ \\
\hline Eliasa & 2012 & USA & $\begin{array}{c}\text { Social } \\
\text { Sciences }\end{array}$ & $\begin{array}{l}\text { technology } \\
\text { acceptance } \\
\text { model; theory of } \\
\text { reasoned action }\end{array}$ & employees & 612 & empirical & quantitative & $\begin{array}{l}\text { older employees exhibit strongest relationships with the outcome } \\
\text { variables when possessing a high attitude towards technology }\end{array}$ \\
\hline
\end{tabular}




\begin{tabular}{|c|c|c|c|c|c|c|c|c|c|}
\hline Farmakas & 2014 & Greece & Health care & $\begin{array}{c}\text { work } \\
\text { environment }\end{array}$ & nurses & 248 & empirical & $\begin{array}{l}\text { descriptive, } \\
\text { comparative }\end{array}$ & $\begin{array}{l}\text { RNs working in a psychiatric hospital perceived professional } \\
\text { practice environment more negatively than community RNs }\end{array}$ \\
\hline Fernet & 2012 & $\begin{array}{l}\text { Quebec, } \\
\text { Canada }\end{array}$ & Education & $\begin{array}{l}\text { self- } \\
\text { determination } \\
\text { theory }\end{array}$ & principals & 586 & empirical & quantitative & $\begin{array}{l}\text { job resources had a positive effect on autonomous motivation but } \\
\text { negative effect on controlled motivation; autonomous motivation } \\
\text { had a negative effect on exhaustion, positive effect on commitment; } \\
\text { controlled motivation had a positive effect on exhaustion }\end{array}$ \\
\hline Fernet & 2010 & $\begin{array}{l}\text { Quebec, } \\
\text { Canada }\end{array}$ & Education & $\begin{array}{l}\text { self- } \\
\text { determination } \\
\text { theory }\end{array}$ & $\begin{array}{c}\text { college } \\
\text { employees }\end{array}$ & 533 & empirical & $\begin{array}{l}\text { longitudinal; } \\
\text { prospective; } \\
\text { quantitative }\end{array}$ & $\begin{array}{l}\text { negative main effects for high-quality relationships \& self- } \\
\text { determined motivation on burnout; high-quality relationships with } \\
\text { coworkers is crucial for those who exhibit less self-determined } \\
\text { motivation }\end{array}$ \\
\hline Frey & 2008 & Switzerland & Business & $\begin{array}{l}\text { awards; goal } \\
\text { setting; } \\
\text { reinforcement; } \\
\text { social cognitive; } \\
\text { Herzberg's two } \\
\text { factor Theory; } \\
\text { need }\end{array}$ & researchers & 52 & empirical & $\begin{array}{l}\text { mixed } \\
\text { methods }\end{array}$ & $\begin{array}{l}\text { awards cannot be equated with monetary compensation; essential for } \\
\text { award to be accompanied by substantial monetary bonus; gifts did } \\
\text { not work as well as payments in cash; important to consider effect of } \\
\text { awards after conferral as non-recipients substantially decrease } \\
\text { contributions; winners increase contributions even further }\end{array}$ \\
\hline Gagne & 2005 & Canada & $\begin{array}{l}\text { Organization } \\
\text { and } \\
\text { Management }\end{array}$ & $\begin{array}{l}\text { self- } \\
\text { determination } \\
\text { theory }\end{array}$ & NA & NA & theoretical & NA & $\begin{array}{l}\text { self-determination theory detailed the processes through which } \\
\text { extrinsic motivation can become autonomous; research suggests } \\
\text { intrinsic motivation and autonomous extrinsic are related to } \\
\text { performance }\end{array}$ \\
\hline Gaki & 2013 & Greece & Health care & $\begin{array}{l}\text { Herzberg' two } \\
\text { factor theory; } \\
\text { Maslow's } \\
\text { motivation } \\
\text { theories }\end{array}$ & nurses & 152 & empirical & quantitative & $\begin{array}{l}\text { job satisfaction, work sector and age related to motivational factors; } \\
\text { emphasis on motivators not strictly relating to economic rewards }\end{array}$ \\
\hline
\end{tabular}




\begin{tabular}{|c|c|c|c|c|c|c|c|c|c|}
\hline Gallie & 2012 & Britain & $\begin{array}{c}\text { Industrial and } \\
\text { Service sectors }\end{array}$ & teamwork & employees & 14,344 & empirical & quantitative & $\begin{array}{l}\text { benefits of teamwork, in terms of both enhancing work motivation } \\
\text { and employee welfare, are confined to self-directive teams; non-self- } \\
\text { directive teams suppress use of personal initiative and discretion }\end{array}$ \\
\hline Gelfand & 2007 & $\begin{array}{l}\text { Israel, } \\
\text { Turkey, } \\
\text { USA }\end{array}$ & $\begin{array}{l}\text { Organization } \\
\text { and } \\
\text { Management }\end{array}$ & cross-cultural OB & NA & NA & $\begin{array}{c}\text { literature } \\
\text { review }\end{array}$ & NA & $\begin{array}{l}\text { cross-cultural research in OB expanded; cultural differences take } \\
\text { various forms; research still mainly focuses on main effects; efforts } \\
\text { to explain cultural differences still too narrow }\end{array}$ \\
\hline Gillet 2/2 & & & Policing & $\begin{array}{l}\text { self- } \\
\text { determination } \\
\text { theory }\end{array}$ & police & 147 & empirical & quantitative & $\begin{array}{l}\text { results from study } 1 \text { are replicated in a training session; after one } \\
\text { month }\end{array}$ \\
\hline Grant 1/3 & \multirow[t]{3}{*}{2007} & \multirow[t]{3}{*}{ USA } & $\begin{array}{l}\text { University } \\
\text { fundraising } \\
\text { organization }\end{array}$ & \multirow{3}{*}{$\begin{array}{c}\text { job design; game } \\
\text { theory }\end{array}$} & employees & 39 & \multirow{3}{*}{ empirical } & \multirow{3}{*}{$\begin{array}{l}\text { follow-up; } \\
\text { longitudinal; } \\
\text { field; } \\
\text { quantitative } \\
\text { study }\end{array}$} & $\begin{array}{l}\text { intervention group displayed significant greater persistence and job } \\
\text { performance }\end{array}$ \\
\hline Grant 2/3 & & & Education & & undergrads & 30 & & & respectful contact with beneficiaries increased persistence \\
\hline Grant 3/3 & & & Education & & undergrads & 122 & & & $\begin{array}{l}\text { contact with beneficiaries and task significance interacted to increase } \\
\text { persistence }\end{array}$ \\
\hline Grant 1/3 & \multirow{3}{*}{2008} & \multirow{3}{*}{ USA } & Non-profit & \multirow{3}{*}{$\begin{array}{l}\text { expectancy; } \\
\text { intrinsic } \\
\text { motivation }\end{array}$} & $\begin{array}{c}\text { callers for } \\
\text { fundraising } \\
\text { organization }\end{array}$ & 33 & empirical & quantitative & task significance intervention increased levels of job performance \\
\hline Grant 2/3 & & & Recreation & & lifeguards & 32 & empirical & quantitative & task significance increased job dedication and helping behaviour \\
\hline Grant 3/3 & & & Non-profit & & $\begin{array}{c}\text { callers for } \\
\text { fundraising } \\
\text { organization }\end{array}$ & 34 & empirical & quantitative & $\begin{array}{l}\text { conscientiousness and prosocial values moderated effects of task } \\
\text { significance on performance of new workers }\end{array}$ \\
\hline
\end{tabular}




\begin{tabular}{|c|c|c|c|c|c|c|c|c|c|}
\hline Groeneveld & 2009 & Netherlands & Public sector & $\begin{array}{l}\text { public service } \\
\text { motivation; } \\
\text { Herzberg's two } \\
\text { factor theory }\end{array}$ & employees & 4469 & empirical & quantitative & $\begin{array}{l}\text { both extrinsic and public service motivations of employees are } \\
\text { greater when unemployment was higher }\end{array}$ \\
\hline Haagh & 2011 & $\begin{array}{l}\text { Sao Paulo, } \\
\text { Brazil }\end{array}$ & Business & $\begin{array}{l}\text { self-development } \\
\text { motive; } \\
\text { incentives }\end{array}$ & \begin{tabular}{|l} 
employment \\
seekers \& \\
cash grant \\
recipients \\
\end{tabular} & 752 & empirical & quantitative & $\begin{array}{l}\text { income security supports an Aristotelian principle of work } \\
\text { motivation as individual development; labor market institutions and } \\
\text { opportunity levels affect this link }\end{array}$ \\
\hline Hinsz & 2007 & USA & Food & $\begin{array}{l}\text { reasoned action; } \\
\text { planned } \\
\text { behaviour; } \\
\text { Triandis's model } \\
\text { of intentional } \\
\text { behaviour; } \\
\text { integrated } \\
\text { framework of } \\
\text { motivated work } \\
\text { behaviour } \\
\end{array}$ & $\begin{array}{c}\text { plant } \\
\text { workers }\end{array}$ & 174 & empirical & quantitative & $\begin{array}{l}\text { attitudes and subjective norms predicted intentions; these intentions, } \\
\text { plus perceived behaviour control \& work habits, predicted } \\
\text { behaviours }\end{array}$ \\
\hline Hsieh & 2010 & Taiwan & Policing & $\begin{array}{c}\text { intrinsic work } \\
\text { motivation; stress }\end{array}$ & $\begin{array}{l}\text { frontline } \\
\text { police }\end{array}$ & 337 & empirical & quantitative & $\begin{array}{l}\text { policy viewed as disclosure of personal information; intrinsic work } \\
\text { motivation significantly lower }\end{array}$ \\
\hline Inceoglu & 2012 & UK & Variety & $\begin{array}{c}\text { selective } \\
\text { optimization with } \\
\text { compensation } \\
\text { theory; } \\
\text { socioemotional } \\
\text { theory; } \\
\text { generativity; role } \\
\end{array}$ & \begin{tabular}{|l} 
individuals \\
who \\
completed \\
survey \\
\end{tabular} & 11,900 & empirical & quantitative & $\begin{array}{l}\text { shift in people's motives rather than a general decline in motivation } \\
\text { with age; older employees more motivated by intrinsically rewarding } \\
\text { job features }\end{array}$ \\
\hline Jakobsen & 2013 & Denmark & Public & $\begin{array}{l}\text { social exchange } \\
\text { theory }\end{array}$ & $\begin{array}{l}\text { frontline } \\
\text { employees }\end{array}$ & $>800$ & empirical & $\begin{array}{l}\text { field study; } \\
\text { quantitative }\end{array}$ & $\begin{array}{l}\text { positive treatment effect when local front-line managers felt less } \\
\text { supported prior to intervention. }\end{array}$ \\
\hline
\end{tabular}




\begin{tabular}{|c|c|c|c|c|c|c|c|c|c|}
\hline Josiam & 2009 & USA & $\begin{array}{c}\text { Hospitality and } \\
\text { management }\end{array}$ & $\begin{array}{l}\text { career stage } \\
\text { theory }\end{array}$ & undergrads & 376 & empirical & quantitative & $\begin{array}{l}\text { Gen Y - positive attitudes to work, low cynicism; increasing age \& } \\
\text { work experience, positive work attitude enhanced, while negative } \\
\text { attitudes ameliorated }\end{array}$ \\
\hline Jung & 2006 & USA & $\begin{array}{c}\text { Variety - } \\
\text { technology, } \\
\text { biotech, IT, } \\
\text { finance, } \\
\text { insurance, } \\
\text { aerospace } \\
\text { engineering. }\end{array}$ & $\begin{array}{l}\text { House's model of } \\
\text { charismatic } \\
\text { leadership }\end{array}$ & $\begin{array}{l}\text { engineers, } \\
\text { scientists, } \\
\text { corporate } \\
\text { employees } \\
\text { (various } \\
\text { management } \\
\text {-levels) }\end{array}$ & 1,163 & empirical & quantitative & $\begin{array}{l}\text { managers rated by subordinates as high on charismatic leadership } \\
\text { reported higher levels of self-monitoring, self-actualization, motive } \\
\text { to attain social power and self-enhancement; managers rated by } \\
\text { superiors as high on charismatic leadership are associated with } \\
\text { followers who reported higher levels of extra effort and OCB }\end{array}$ \\
\hline Kahkonen & 2010 & $\begin{array}{l}\text { Helsinki, } \\
\text { Finland } \\
\text { Stockholm, } \\
\text { Sweden }\end{array}$ & Business & $\begin{array}{l}\text { socio- } \\
\text { psychological } \\
\text { stress theories } \\
\text { and x-efficiency } \\
\text { theory }\end{array}$ & employees & 1,535 & empirical & qualitative & $\begin{array}{l}\text { high allocative and technical efficiency claims may lead to } \\
\text { inefficiency; too much competition does not raise efficiency }\end{array}$ \\
\hline Katz & 2005 & USA & Technology & $\begin{array}{l}\text { Hackman and } \\
\text { Oldham's } \\
\text { framework }\end{array}$ & employees & NA & conceptual & NA & $\begin{array}{l}5 \text { dimension of task characteristics (skill variety, task identity, task } \\
\text { significance, autonomy, feedback) elicit high levels of intrinsic } \\
\text { motivation }\end{array}$ \\
\hline Koo 1/5 & \multirow{5}{*}{2010} & \multirow{5}{*}{$\begin{array}{l}\text { USA; } \\
\text { South } \\
\text { Korea }\end{array}$} & Education & \multirow{5}{*}{$\begin{array}{l}\text { goal; discrepancy } \\
\text { theory; intrinsic } \\
\text { vs extrinsic }\end{array}$} & undergrads & 86 & \multirow{5}{*}{ empirical } & \multirow{5}{*}{ quantitative } & \multirow{5}{*}{$\begin{array}{l}\text { focus on remaining actions increases motivation to move up; focus } \\
\text { on completed actions increases satisfaction derived from present }\end{array}$} \\
\hline Koo 2/5 & & & Education & & students & 95 & & & \\
\hline Koo 3/5 & & & Education & & undergrads & 179 & & & \\
\hline Koo 4/5 & & & Advertising & & employees & 66 & & & \\
\hline Koo 5/5 & & & Education & & undergrads & 68 & & & \\
\hline
\end{tabular}




\begin{tabular}{|c|c|c|c|c|c|c|c|c|c|}
\hline Kooij & 2011 & Netherlands & Education & $\begin{array}{l}\text { lifespan theories } \\
\text { - selection } \\
\text { optimization and } \\
\text { compensation; } \\
\text { socio-emotional } \\
\text { selectivity theory } \\
\text { (SST) }\end{array}$ & $\begin{array}{l}\text { university } \\
\text { employees }\end{array}$ & 600 & empirical & $\begin{array}{l}\text { longitudinal; } \\
\text { quantitative }\end{array}$ & $\begin{array}{l}\text { losses in subjective general health negatively predicted open-ended } \\
\text { future time perspective (FTP), which was associated with an increase } \\
\text { in growth motives; limited FTP was associated with increase in } \\
\text { generativity motives }\end{array}$ \\
\hline Kooij & 2011 & Netherlands & Multiple & $\begin{array}{l}\text { life span } \\
\text { psychology }\end{array}$ & NA & NA & $\begin{array}{l}\text { literature } \\
\text { review; } \\
\text { meta- } \\
\text { analysis }\end{array}$ & NA & $\begin{array}{l}\text { positive relationship between age and intrinsic motives; negative } \\
\text { relationship between age and strength of growth and extrinsic } \\
\text { motives }\end{array}$ \\
\hline Kuvaas & 2006 & Norway & $\begin{array}{l}\text { Energy- } \\
\text { intensive } \\
\text { industries }\end{array}$ & $\begin{array}{l}\text { expectancy; } \\
\text { reinforcement; } \\
\text { instrumentality; } \\
\text { equity; cognitive } \\
\text { evaluation; self- } \\
\text { determination } \\
\text { theory }\end{array}$ & employees & 634 & empirical & quantitative & $\begin{array}{l}\text { base pay level, related to self-reported work performance and } \\
\text { affective unit commitment }\end{array}$ \\
\hline Latham & 2005 & Canada & $\begin{array}{l}\text { Organization } \\
\text { and } \\
\text { Management }\end{array}$ & review of many & NA & NA & $\begin{array}{l}\text { literature } \\
\text { review }\end{array}$ & NA & $\begin{array}{l}\text { goal-setting, social cognitive, and organizational justice theories are } \\
\text { the most important approaches to work motivation over last } 30 \text { years }\end{array}$ \\
\hline Lather & 2007 & India & $\begin{array}{l}\text { Organization } \\
\text { and } \\
\text { Management }\end{array}$ & $\begin{array}{l}\text { personality; } \\
\text { Hawthorne } \\
\text { studies }\end{array}$ & associates & 100 & empirical & quantitative & $\begin{array}{l}\text { dynamos higher on achievement, order, and autonomy; drones } \\
\text { higher on aggression and heterosexuality resulting in poor } \\
\text { interpersonal relationship }\end{array}$ \\
\hline
\end{tabular}




\begin{tabular}{|c|c|c|c|c|c|c|c|c|c|}
\hline Lewis & 2011 & $\begin{array}{l}\text { Trinidad \& } \\
\text { Tobago }\end{array}$ & $\begin{array}{l}\text { Organization } \\
\text { and } \\
\text { management }\end{array}$ & $\begin{array}{l}\text { social cognitive - } \\
\text { self efficacy; } \\
\text { collective } \\
\text { efficacy; social } \\
\text { identity; } \\
\text { social } \\
\text { categorization } \\
\end{array}$ & NA & NA & conceptual & NA & $\begin{array}{l}\text { development of a model to organize studies on teamwork processes } \\
\text { and outcomes; model includes four types of variables (contextual, } \\
\text { independent, moderator, and dependent) }\end{array}$ \\
\hline Lim & 2006 & Singapore & Financial & $\begin{array}{l}\text { spillover theory } \\
\text { intrinsic } \\
\text { motivation }\end{array}$ & $\begin{array}{l}\text { undergrads } \\
\& \text { parents }\end{array}$ & 250 & empirical & quantitative & $\begin{array}{l}\text { spillover effect of paternal perceived job insecurity on paternal } \\
\text { money anxiety; crossover effect of parental money anxiety on } \\
\text { youths' money anxiety }\end{array}$ \\
\hline Lundberg & 2009 & Sweden & $\begin{array}{c}\text { Hospitality and } \\
\text { tourism }\end{array}$ & $\begin{array}{l}\text { Herzberg's two- } \\
\text { factor theory; } \\
\text { need theory; } \\
\text { process theory; } \\
\text { personality trait - } \\
\text { Big } 5\end{array}$ & $\begin{array}{l}\text { seasonal } \\
\text { workers }\end{array}$ & 613 & empirical & mixed & $\begin{array}{l}\text { migrant community of workers less concerned about wage level; } \\
\text { more concerned about meeting new people than resident workers }\end{array}$ \\
\hline Manolopoulos & 2008 & Greece & Public sector & $\begin{array}{l}\text { public sector; } \\
\text { goal theory; } \\
\text { environmental } \\
\text { forces }\end{array}$ & employees & 1,226 & empirical & quantitative & $\begin{array}{l}\text { expected work outcome is directly influenced by a multifaceted } \\
\text { context of motivators; extrinsic rewards exert stronger influence }\end{array}$ \\
\hline Moran & 2014 & $\begin{array}{l}\text { USA, } \\
\text { north } \\
\text { eastern }\end{array}$ & Health care & $\begin{array}{l}\text { self- } \\
\text { determination } \\
\text { theory }\end{array}$ & $\begin{array}{l}\text { mental } \\
\text { health peer } \\
\text { workers }\end{array}$ & 31 & empirical & $\begin{array}{l}\text { qualitative; } \\
\text { grounded } \\
\text { theory }\end{array}$ & $\begin{array}{l}\text { external motivations included generic occupational goals and getting } \\
\text { away from negative work experiences; internal motivations } \\
\text { corresponded with SDT basic needs }\end{array}$ \\
\hline
\end{tabular}




\begin{tabular}{|c|c|c|c|c|c|c|c|c|c|}
\hline Nafziger & 2011 & Denmark & Business & $\begin{array}{l}\text { self-efficacy; } \\
\text { context }\end{array}$ & employees & NA & conceptual & NA & $\begin{array}{l}\text { the higher the employee's self-efficacy, the higher his work } \\
\text { motivation and the lower the bonus the firm has to pay }\end{array}$ \\
\hline Negussie & 2012 & Ethiopia & Health care & $\begin{array}{c}\text { framework } \\
\text { developed by } \\
\text { Khan, Farooq \& } \\
\text { Ullan; conceptual } \\
\text { model of } \\
\text { motivation theory } \\
\text { (payment, } \\
\text { promotion, } \\
\text { benefit, } \\
\text { recognition) }\end{array}$ & nurses & 230 & empirical & quantitative & $\begin{array}{l}\text { payment is most important; difference in nurse work motivation } \\
\text { based on age, educational qualification and work experience }\end{array}$ \\
\hline Niu & 2009 & Taiwan & $\begin{array}{l}\text { Private } \\
\text { organizations }\end{array}$ & $\begin{array}{l}\text { paternalistic } \\
\text { leadership }\end{array}$ & employees & 265 & empirical & quantitative & $\begin{array}{l}\text { benevolence and morality increased subordinates' deference to } \\
\text { supervisor and work motivation }\end{array}$ \\
\hline Nomura & 2012 & $\begin{array}{l}\text { Tokyo, } \\
\text { Japan }\end{array}$ & Health care & gender & $\begin{array}{c}\text { private } \\
\text { medical } \\
\text { school } \\
\text { alumnae }\end{array}$ & 1684 & empirical & quantitative & $\begin{array}{l}\text { those with strongest perception of gender-based career obstacles are } \\
\text { more likely to work part-time }\end{array}$ \\
\hline Othman & 2009 & $\begin{array}{l}\text { Selangor \& } \\
\text { Kuala } \\
\text { Lumpur }\end{array}$ & Service & $\begin{array}{l}\text { emotional } \\
\text { intelligence }\end{array}$ & $\begin{array}{c}\text { service } \\
\text { providers } \\
\text { and } \\
\text { superiors }\end{array}$ & 167 & empirical & quantitative & $\begin{array}{l}\text { interactions between work motivation and Self Emotional Appraisal } \\
\& \text { b/w work motivation and Others' Emotional Appraisal have } \\
\text { significant affect on team role effectiveness }\end{array}$ \\
\hline
\end{tabular}




\begin{tabular}{|c|c|c|c|c|c|c|c|c|c|}
\hline Park & 2012 & $\begin{array}{l}\text { Illinois, } \\
\text { Georgia } \\
\text { USA }\end{array}$ & $\begin{array}{l}\text { Public } \\
\text { agencies \& } \\
\text { Nonprofit } \\
\text { organizations }\end{array}$ & $\begin{array}{c}\text { self- } \\
\text { determination } \\
\text { theory; public } \\
\text { service } \\
\text { motivation; } \\
\text { NPSM }\end{array}$ & managers & 1,220 & empirical & quantitative & $\begin{array}{l}\text { four different motivational constructs; public and nonprofit } \\
\text { managers are similar in terms of importance of intrinsic motivation }\end{array}$ \\
\hline Park & 2012 & USA & Public agency & \begin{tabular}{|c} 
public service \\
motivation; \\
expectancy; self- \\
determination \\
theory \\
\end{tabular} & managers & 790 & empirical & quantitative & $\begin{array}{l}\text { intrinsic motivation is associated with job involvement, perceptions } \\
\text { of red tape, \& organizational effectiveness; communication provides } \\
\text { more autonomy \& discretion, leading to more positive organizational } \\
\text { dispositions }\end{array}$ \\
\hline Polesie & 2013 & Sweden & Construction & autonomy & $\begin{array}{l}\text { contractor } \\
\text { project } \\
\text { managers }\end{array}$ & 15 & empirical & qualitative & $\begin{array}{l}\text { managers needed to be able to influence planning of activities, then } \\
\text { standardization would not motivation }\end{array}$ \\
\hline Purohit & 2014 & India & Health care & $\begin{array}{l}\text { Herzberg two- } \\
\text { factor theory }\end{array}$ & $\begin{array}{l}\text { doctors (or } \\
\text { medical } \\
\text { officers) }\end{array}$ & 92 & empirical & quantitative & $\begin{array}{l}\text { motivational importance to intrinsic factors (job security most } \\
\text { important, then interesting work, respect \& recognition) }\end{array}$ \\
\hline Riketta & 2007 & Germany & Pharma & $\begin{array}{c}\text { social } \\
\text { identification }\end{array}$ & employees & 399 & empirical & quantitative & $\begin{array}{l}\text { perceived compatibility correlated positively with both network } \\
\text { identification and network motivation }\end{array}$ \\
\hline Sahoo 1/4 & & & $\begin{array}{l}\text { Public and } \\
\text { private }\end{array}$ & & employees & 220 & & & $\begin{array}{l}\text { salient need satisfaction bears positive correlation with job } \\
\text { involvement }\end{array}$ \\
\hline Sahoo 2/4 & 2011 & India & Finance & $\begin{array}{l}\text { hierarchy; } \\
\text { Herzberg's two } \\
\text { factor theory }\end{array}$ & $\begin{array}{l}\text { officers and } \\
\text { assistants }\end{array}$ & 240 & empirical & quantitative & relationship between salient need satisfaction and involvement \\
\hline
\end{tabular}




\begin{tabular}{|c|c|c|c|c|c|c|c|c|c|}
\hline Sahoo 3/4 & & & Education & & teachers & 180 & & & $\begin{array}{l}\text { association between salient need satisfaction and involvement is } \\
\text { significant }\end{array}$ \\
\hline Sahoo 4/4 & & & Military & & $\begin{array}{c}\text { officers, } \\
\text { junior \& non } \\
\text { commission }\end{array}$ & 203 & & & $\begin{array}{l}\text { security was most important need; respect \& recognition also salient } \\
\text { need }\end{array}$ \\
\hline Schmidt & 2009 & USA & Education & $\begin{array}{l}\text { social cognitive } \\
\text { theory - self } \\
\text { efficacy; } \\
\text { control theory }\end{array}$ & $\begin{array}{l}\text { undergrad } \\
\text { students }\end{array}$ & 89 & empirical & quantitative & $\begin{array}{l}\text { following poor performances, self-efficacy positively related to } \\
\text { subsequent performance; following successful prior performances, } \\
\text { self-efficacy negatively related to subsequent performance }\end{array}$ \\
\hline Seo & 2010 & USA & Financial & $\begin{array}{l}\text { expectancy; } \\
\text { control }\end{array}$ & employees & 118 & empirical & quantitative & $\begin{array}{l}\text { core affect is related to all behavioural outcomes of motivation, } \\
\text { generative orientation, effort, and persistence }\end{array}$ \\
\hline Sloof & 2010 & Amsterdam & Business & $\begin{array}{l}\text { expectancy } \\
\text { theory }\end{array}$ & employees & 94 & empirical & $\begin{array}{c}\text { quantitative; } \\
\text { lab } \\
\text { experiment }\end{array}$ & $\begin{array}{l}\text { subjects exert significantly more effort in the volatile environment } \\
\text { than in the stable environment }\end{array}$ \\
\hline Snel & 2008 & Netherlands & Social Policy & $\begin{array}{l}\text { transitional labor } \\
\text { markets }\end{array}$ & $\begin{array}{l}\text { incapacity } \\
\text { benefit } \\
\text { claimants }\end{array}$ & 687,800 & empirical & quantitative & $\begin{array}{l}\text { careful explaining outcomes between ethnic groups as 'cultural } \\
\text { phenomena' as other explanations may exist: differences in work } \\
\text { motivation, lack of 'transition facilities' in companies and } \\
\text { differential treatment }\end{array}$ \\
\hline Stajkovic & 2006 & USA & Psychology & $\begin{array}{c}\text { psychology } \\
\text { (social, clinical, } \\
\text { developmental); } \\
\text { social } \\
\text { anthropology }\end{array}$ & employees & NA & conceptual & NA & $\begin{array}{l}\text { confident employees may be better able to cope with contemporary } \\
\text { work dynamics than those harboring doubt }\end{array}$ \\
\hline Stoeber & 2013 & Britain & $\begin{array}{l}\text { Professional } \\
\text { services }\end{array}$ & $\begin{array}{l}\text { self- } \\
\text { determination } \\
\text { theory }\end{array}$ & $\begin{array}{l}\text { service \& } \\
\text { student } \\
\text { employees }\end{array}$ & 133 & empirical & quantitative & $\begin{array}{l}\text { high levels of work motivation explain why self-oriented } \\
\text { perfectionists are workaholic }\end{array}$ \\
\hline
\end{tabular}




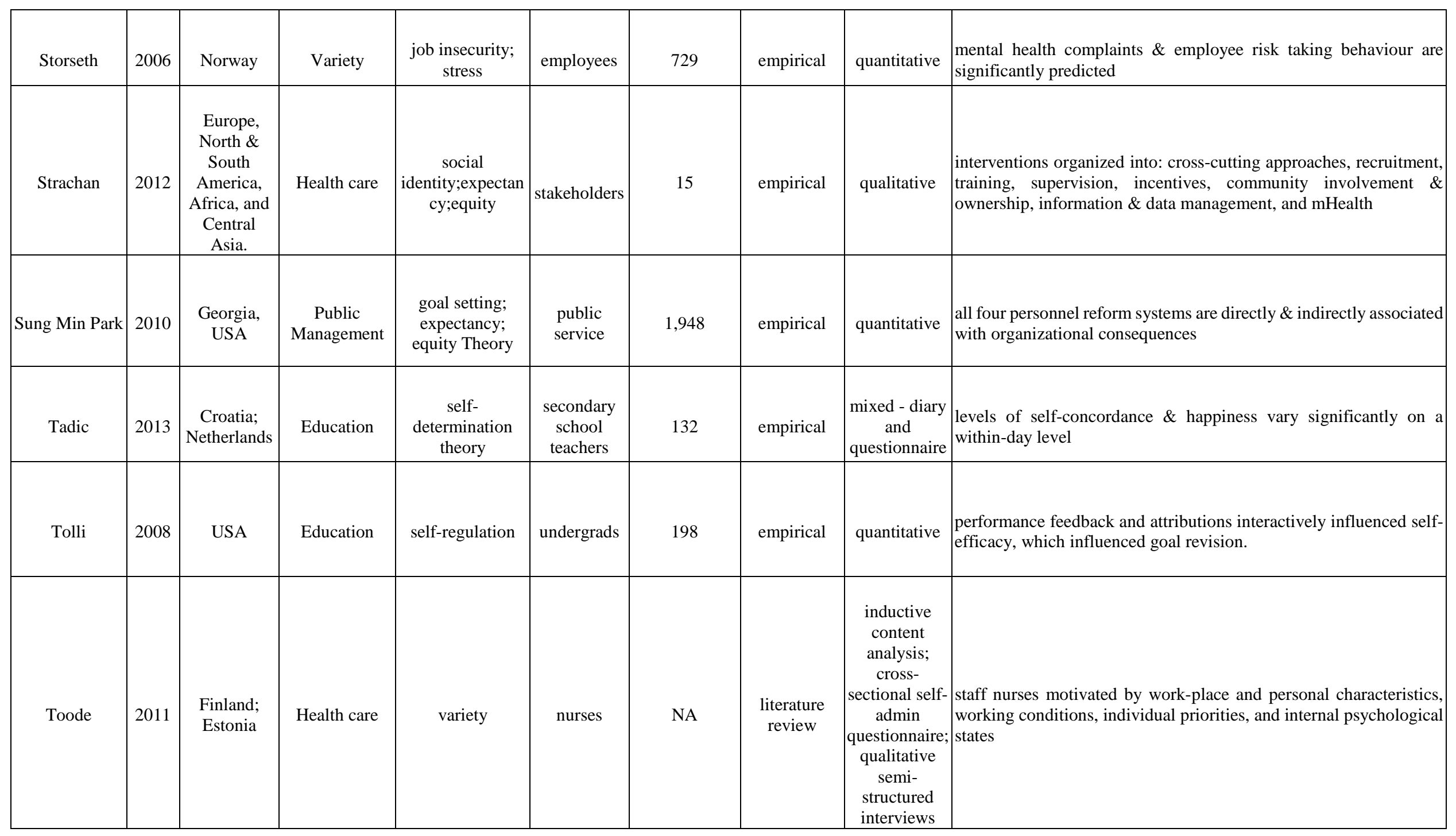




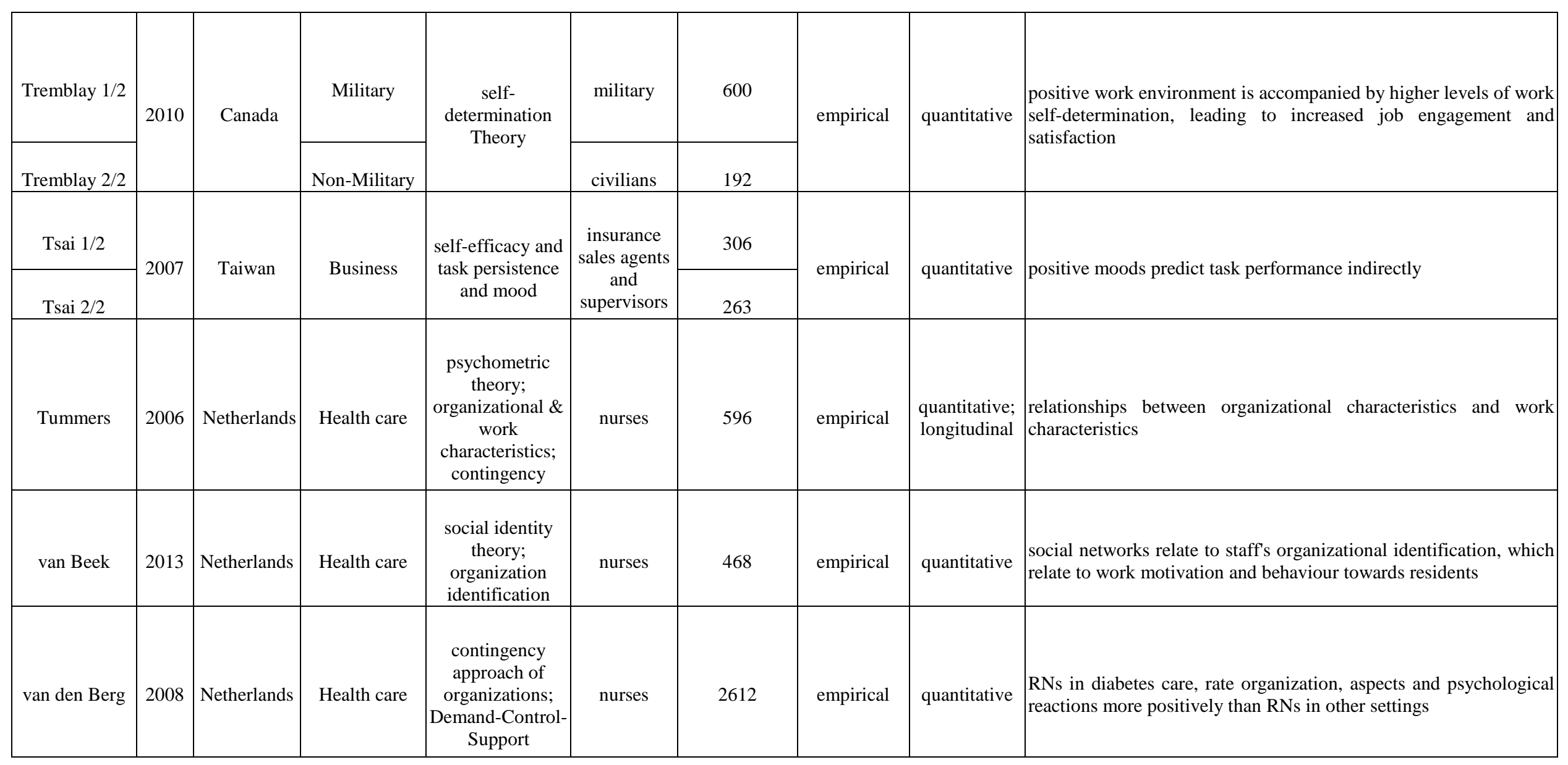




\begin{tabular}{|c|c|c|c|c|c|c|c|c|c|}
\hline Vancouver & 2008 & USA & $\begin{array}{l}\text { Human } \\
\text { Resource } \\
\text { Management }\end{array}$ & $\begin{array}{l}\text { self-regulation } \\
\text { theories - goal, } \\
\text { valence and } \\
\text { expectancy; } \\
\text { dynamic process }\end{array}$ & employees & NA & $\begin{array}{l}\text { conceptual } \\
\text { theory } \\
\text { building }\end{array}$ & NA & $\begin{array}{l}\text { work motivation theories becoming more comprehensive, self- } \\
\text { regulatory or goal-oriented, and dynamic }\end{array}$ \\
\hline Von Bonsdorff & 2011 & Finland & Health care & $\begin{array}{l}\text { needs based; } \\
\text { content theories }\end{array}$ & nurses & 628 & empirical & quantitative & $\begin{array}{l}\text { financial and non-financial rewards are highly appreciated; age- } \\
\text { related differences among respondents' financial reward preferences }\end{array}$ \\
\hline Wallgren & 2011 & Sweden & IT & $\begin{array}{l}\text { intrinsic, } \\
\text { extrinsic, } \\
\text { interactive } \\
\text { motivation }\end{array}$ & consultants & 12 & empirical & qualitative & \begin{tabular}{|l} 
primary motivators are task variety $\&$ opportunity to \\
influence/manage projects
\end{tabular} \\
\hline Wegge & 2010 & $\begin{array}{l}\text { Europe, } \\
\text { USA }\end{array}$ & $\begin{array}{l}\text { Organizational } \\
\text { Leadership }\end{array}$ & $\begin{array}{l}\text { organizational } \\
\text { participation, } \\
\text { shared } \\
\text { leadership, and } \\
\text { organizational } \\
\text { democracy }\end{array}$ & employees & NA & $\begin{array}{l}\text { literature } \\
\text { review }\end{array}$ & meta-analysis & $\begin{array}{l}\text { participation and collaboration-promoting leadership motivates } \\
\text { group members to overtly reflect upon and communicate about their } \\
\text { collective objectives, strategies, and processes }\end{array}$ \\
\hline Wegge1/2 & 2006 & Germany & $\begin{array}{l}\text { Service } \\
\text { Industry - call } \\
\text { centre }\end{array}$ & $\begin{array}{l}\text { job } \\
\text { characteristics } \\
\text { model (JCM); } \\
\text { social identity } \\
\text { theory; job } \\
\text { design; } \\
\text { organizational } \\
\text { identification }\end{array}$ & call agents & 211 & empirical & quantitative & $\begin{array}{l}\text { employees experiencing a high motivating potential reported more } \\
\text { OCB, higher job satisfaction, and less turnover intentions; } \\
\text { organizational identification was an independent predictor of job } \\
\text { satisfaction, turnover intentions, OCB, and well-being }\end{array}$ \\
\hline Wegge $2 / 2$ & & & & & & 161 & & & \\
\hline
\end{tabular}




\begin{tabular}{|c|c|c|c|c|c|c|c|c|c|}
\hline Wei Ting & 2013 & Taiwan & $\begin{array}{c}\text { non-profit } \\
\text { (sport) }\end{array}$ & $\begin{array}{c}\text { self- } \\
\text { determination } \\
\text { theory }\end{array}$ & volunteers & 489 & empirical & quantitative & $\begin{array}{l}\text { autonomy support predicted autonomous motivation; structure } \\
\text { served as DV and autonomy support as a predictor }\end{array}$ \\
\hline Wetlesen & 2013 & Norway & Multiple & $\begin{array}{l}\text { generation; } \\
\text { gender }\end{array}$ & families & 12 & empirical & $\begin{array}{l}\text { interview; } \\
\text { case study; } \\
\text { qualitative }\end{array}$ & $\begin{array}{l}\text { no gender difference regarding careers; work motivation and } \\
\text { preferences about the structure of working time differed by gender }\end{array}$ \\
\hline Worthley & 2009 & Japan & Variety & $\begin{array}{l}\text { Herzberg's } \\
\text { motivation- } \\
\text { hygiene (two- } \\
\text { factor theory) }\end{array}$ & employees & 623 & empirical & quantitative & $\begin{array}{l}\text { Japanese men value intrinsic motivators more than extrinsic; females } \\
\text { rate extrinsic factors higher }\end{array}$ \\
\hline Wright & 2007 & $\begin{array}{l}\text { New York, } \\
\text { USA }\end{array}$ & Public Service & $\begin{array}{l}\text { goal theory; } \\
\text { public service } \\
\text { motivation }\end{array}$ & $\begin{array}{c}\text { external } \\
\text { consultants }\end{array}$ & 807 & empirical & quantitative & $\begin{array}{l}\text { importance of organization's mission increases employee work } \\
\text { motivation }\end{array}$ \\
\hline Wu & 2007 & USA & IT & $\begin{array}{l}\text { altruism, } \\
\text { reciprocity; } \\
\text { expectancy- } \\
\text { value theory }\end{array}$ & $\begin{array}{c}\text { software } \\
\text { developers }\end{array}$ & 148 & empirical & quantitative & $\begin{array}{l}\text { satisfaction \& intentions to continue is influenced by helping } \\
\text { behaviour \& economic incentives }\end{array}$ \\
\hline Yildirim & 2009 & Turkey & Health care & bullying & nurses & 286 & empirical & $\begin{array}{l}\text { quantitative, } \\
\text { descriptive }\end{array}$ & bullying is measurable; has -ve effect on psychology \& performance \\
\hline
\end{tabular}


Appendix E. Conceptual Framework - Scoping Review Results (individual-, unit-, organization-level characteristics and processes influencing Motivation)

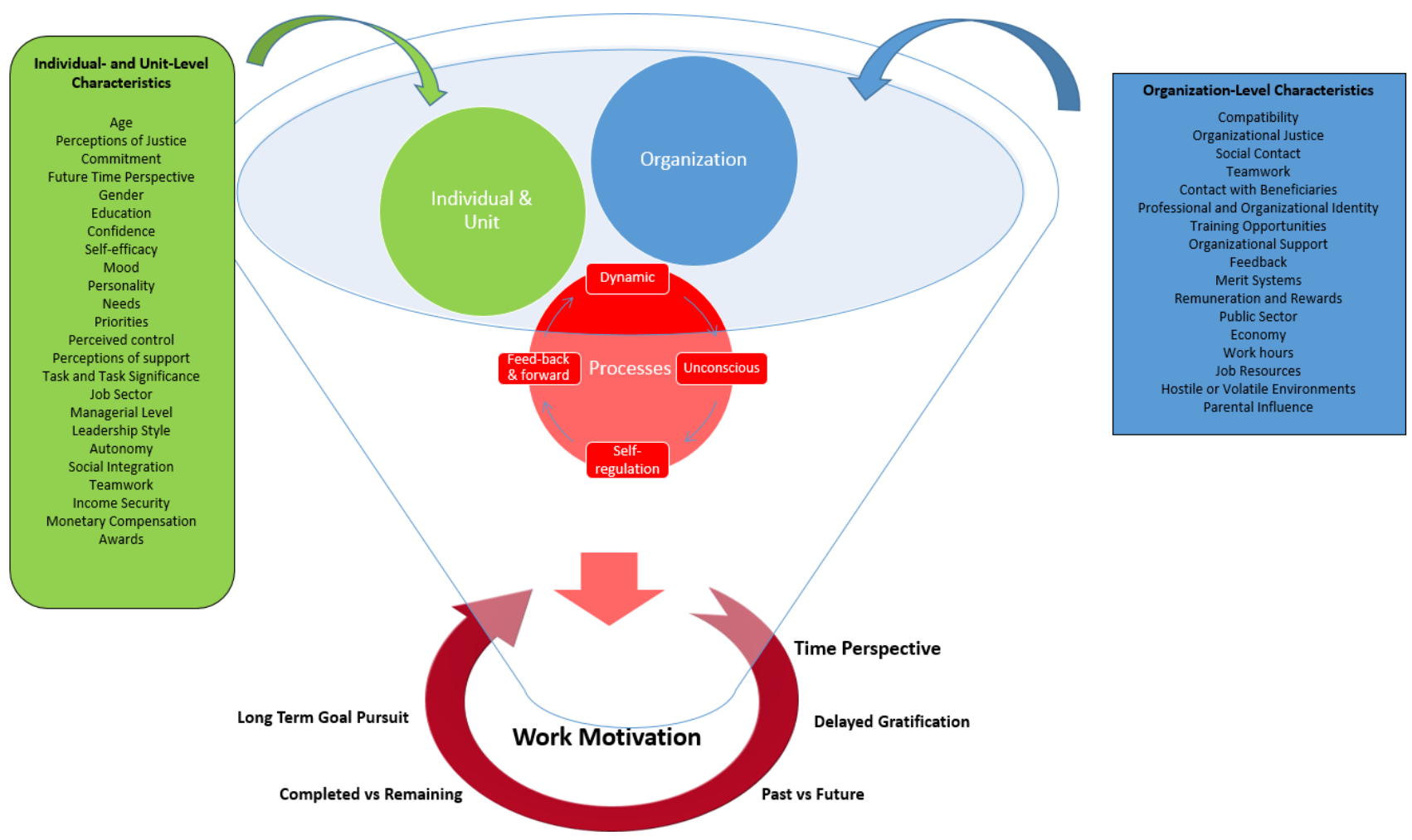




\section{Appendix F. RNAO Interest Groups Included in Study}

\begin{tabular}{|c|}
\hline Clinical Nurse Specialist Association of Ontario \\
\hline Community Health Nurses' Initiatives Group (CHNIG) \\
\hline Complementary Therapies Nurses' Interest Group (CTNIG) \\
\hline$\underline{\text { Diabetes Nursing Interest Group (DNIG) }}$ \\
\hline Gerontological Nursing Association Ontario (GNAO) \\
\hline$\underline{\text { Independent Practice Nurses Interest Group (IPNIG) }}$ \\
\hline$\underline{\text { International Nursing Interest Group (INIG) }}$ \\
\hline$\underline{\text { Maternal Child Nurses' Interest Group (MCNIG) }}$ \\
\hline$\underline{\text { Men in Nursing Interest Group (MINIG) }}$ \\
\hline$\underline{\text { Mental Health Nursing Interest Group (MHNIG) }}$ \\
\hline$\underline{\text { Ontario Association of Rehabilitation Nurses (OARN) }}$ \\
\hline$\underline{\text { Ontario Correctional Nurses' Interest Group (OCNIG) }}$ \\
\hline$\underline{\text { Ontario Family Practice Nurses (OFPN) }}$ \\
\hline$\underline{\text { Ontario Nurses for the Environment Interest Group (ONEIG) }}$ \\
\hline$\underline{\text { Ontario Nursing Informatics Group (ONIG) }}$ \\
\hline$\underline{\text { Ontario PeriAnesthesia Nurses Association (OPANA) }}$ \\
\hline$\underline{\text { Palliative Care Nurses Interest Group (PCNIG) }}$ \\
\hline$\underline{\text { Parish Nursing Interest Group (PNIG) }}$ \\
\hline$\underline{\text { Pediatric Nurses Interest Group (PedNIG) }}$ \\
\hline$\underline{\text { Rainbow Nursing Interest Group (RNIG) }}$ \\
\hline$\underline{\text { RN First Assistant Interest Group (RNFA) }}$ \\
\hline$\underline{\text { Staff Nurse Interest Group (SNIG) }}$ \\
\hline \\
\hline
\end{tabular}




\section{Appendix G. Organizational Behaviour Scale}

\section{OCBI Items}

1. Help others who have been absent.

2. Willingly give your time to help others who have work-related problems.

3. Adjust your work schedule to accommodate other employees' requests for time off.

4. Go out of the way to make newer employees feel welcome in the work group.

5. Show genuine concern and courtesy toward coworkers, even under the most trying business or personal situations.

6. Give up time to help others who have work or nonwork problems.

7. Assist others with their duties.

8. Share personal property with others to help their work.

\section{OCBO Items}

1. Attend functions that are not required but that help the organizational image.

2. Keep up with developments in the organization.

3. Defend the organization when other employees criticize it.

4. Show pride when representing the organization in public.

5. Offer ideas to improve the functioning of the organization.

6. Express loyalty toward the organization.

7. Take action to protect the organization from potential problems.

8. Demonstrate concern about the image of the organization. 


\section{Appendix H. Workplace Affective Commitment Multidimensional Questionnaire (SHORT)}

\section{Your commitment}

The following items express what people may feel about themselves as members of their organization (entreprise XYZ). Please circle the choice which best reflect your personal opinion.

\footnotetext{
I am proud to say that I work for this

1 organization (COMPANY XYZ)

I like the values my immediate supervisor

2 conveys

I'm happy to work with my co-workers (in 3 my unit)

I really care about the satisfaction of

4 COMPANY XYZ customers

$5 \quad$ I'm proud to say this is my profession

6 Work is a priority in my life
}

1

2

3

4

5

1

2

3

4

5

1

2

3

4

5

1

2

3

4

5

1

2

3

4

5 
I find the tasks I perform in my current

7 position stimulating

I would like to hold increasingly important

8 positions throughout my career

This organization (COMPANY XYZ)

9 means a lot to me

I feel privileged to work with someone like

10. my immediate supervisor

1

2

3

4

5

My co-workers (in my unit) make me feel

11 like going to work

1

2

3

4

5

Delivering quality products and/or services

12 to COMPANY XYZ customers is a major source of satisfaction for me

I would be happy to practice this profession

13 all my life

1

2

3

4

5

I find the tasks I perform in my current

14 position rewarding 
It is important for me to move up the ranks
$\mathbf{1 5}$ or obtain promotions.

One of the most satisfying things in my life

16 is the fact that I work

I don't like working for this organization

17 (COMPANY XYZ)

When I talk about my immediate

18 supervisor to my friends, I describe him/her as a great person to work with

When I talk about my co-workers (in my

19 unit) to my friends, I describe them as great people to work with

In my opinion, the satisfaction of

20 COMPANY XYZ customers is a priority

I like my profession too much to think

21 about changing

Most of my personal objectives are focused

22 on work

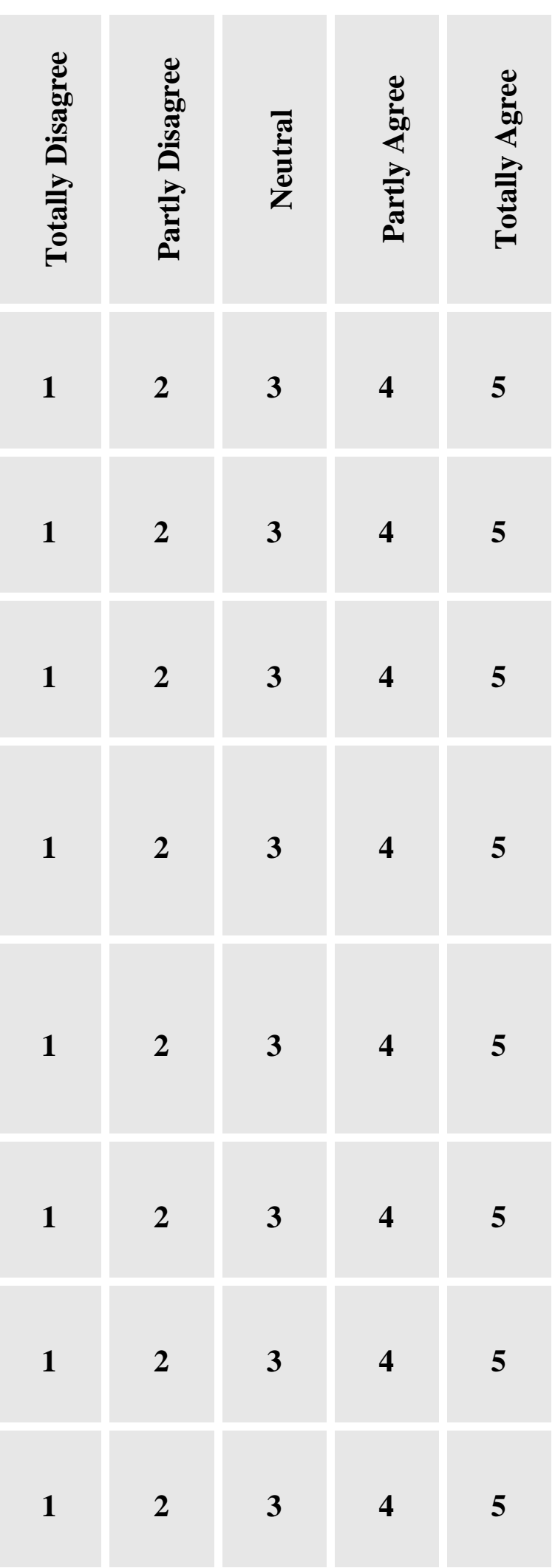




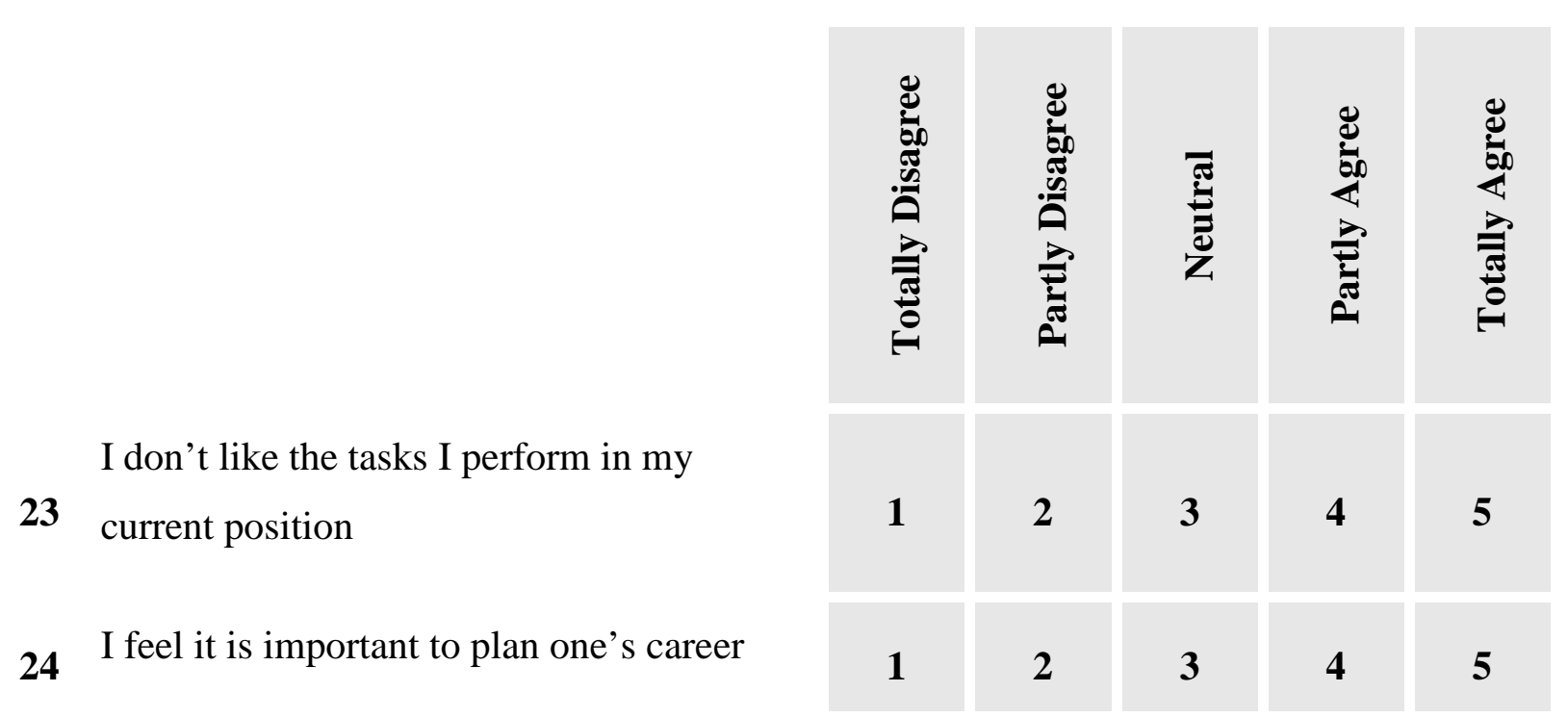




\section{Appendix I. WACMQ - Modifications for Use in Health Care}

\begin{tabular}{|c|c|c|c|}
\hline \multicolumn{4}{|c|}{ WACMQ - Modifications for Use in Health Care } \\
\hline $\begin{array}{c}\# \\
\text { Items }\end{array}$ & $\begin{array}{l}\text { Specific } \\
\text { Measure }\end{array}$ & Original Question & MODIFIED Question \\
\hline & & $\begin{array}{l}\text { The following items express what people } \\
\text { may feel about themselves as members of } \\
\text { their organization (enterprise XYZ). } \\
\text { Please circle the choice which best reflect } \\
\text { your personal opinion. }\end{array}$ & $\begin{array}{l}\text { The following items express what YOU } \\
\text { may feel about yourself as a member of } \\
\text { your organization. }\end{array}$ \\
\hline 1 & Organization & $\begin{array}{c}\text { I am proud to say that I work for this } \\
\text { organization (COMPANY XYZ) }\end{array}$ & $\begin{array}{l}\text { I am proud to say that I work for my } \\
\text { organization }\end{array}$ \\
\hline 2 & Supervisor & $\begin{array}{l}\text { I like the values my immediate supervisor } \\
\text { conveys }\end{array}$ & $\begin{array}{l}\text { I like the values conveyed by the authority } \\
\text { figure who conducts my performance } \\
\text { evaluation }\end{array}$ \\
\hline 3 & co-workers & $\begin{array}{l}\text { I'm happy to work with my co-workers } \\
\text { (in my unit) }\end{array}$ & $\begin{array}{l}\text { I'm happy to work with my co-workers in } \\
\text { my unit (includes interprofessional) }\end{array}$ \\
\hline 4 & Patients & $\begin{array}{l}\text { I really care about the satisfaction of } \\
\text { COMPANY XYZ customers }\end{array}$ & $\begin{array}{l}\text { I really care about the satisfaction of my } \\
\text { organization's patients }\end{array}$ \\
\hline 9 & Organization & $\begin{array}{l}\text { This organization (COMPANY XYZ) } \\
\text { means a lot to me }\end{array}$ & My organization means a lot to me \\
\hline 10 & supervisor & $\begin{array}{l}\text { I feel privileged to work with someone } \\
\text { like my immediate supervisor }\end{array}$ & $\begin{array}{c}\text { I feel privileged to work with someone like } \\
\text { the authority figure who conducts my } \\
\text { performance evaluation }\end{array}$ \\
\hline 11 & co-workers & $\begin{array}{l}\text { My co-workers (in my unit) make me } \\
\text { feel like going to work }\end{array}$ & $\begin{array}{l}\text { My co-workers in my unit (includes } \\
\text { interprofessional) make me feel like going } \\
\text { to work }\end{array}$ \\
\hline 12 & patients & $\begin{array}{l}\text { Delivering quality products and/or } \\
\text { services to COMPANY XYZ customers } \\
\text { is a major source of satisfaction for me }\end{array}$ & $\begin{array}{c}\text { Delivering quality care and/or services to } \\
\text { my organization's patients is a major } \\
\text { source of satisfaction for me }\end{array}$ \\
\hline 13 & profession & $\begin{array}{l}\text { I would be happy to practice this } \\
\text { profession all my life }\end{array}$ & $\begin{array}{l}\text { I would be happy to practice this } \\
\text { profession until retirement }\end{array}$ \\
\hline 17 & organization & $\begin{array}{l}\text { I don't like working for this organization } \\
\text { (COMPANY XYZ) }\end{array}$ & I don't like working for my organization \\
\hline 18 & supervisor & $\begin{array}{l}\text { When I talk about my immediate } \\
\text { supervisor to my friends, I describe } \\
\text { him/her as a great person to work with }\end{array}$ & $\begin{array}{l}\text { When I talk to my friends about the } \\
\text { authority figure who conducts my } \\
\text { performance evaluation, I describe him/her } \\
\text { as a great person to work with }\end{array}$ \\
\hline
\end{tabular}




\begin{tabular}{|c|c|c|c|}
\hline 19 & co-workers & $\begin{array}{c}\text { When I talk about my co-workers (in my } \\
\text { unit) to my friends, I describe them as } \\
\text { great people to work with }\end{array}$ & $\begin{array}{c}\text { When I talk to my friends about my co- } \\
\text { workers in my unit (includes } \\
\text { interprofessional), I describe them as great } \\
\text { people to work with }\end{array}$ \\
\hline 20 & patient & $\begin{array}{c}\text { In my opinion, the satisfaction of } \\
\text { COMPANY XYZ customers is a priority }\end{array}$ & $\begin{array}{c}\text { In my opinion, the satisfaction of my } \\
\text { organization's patients is a priority }\end{array}$ \\
\hline
\end{tabular}




\section{Appendix J. Organizational Justice Scale}

\section{Procedural justice}

The following items refer to the procedures used to arrive at your (outcome). To what extent:

1. Have you been able to express your views and feelings during those procedures?

2. Have you had influence over the (outcome) arrived at by those procedures?

3 . Have those procedures been applied consistently?

4. Have those procedures been free of bias?

5. Have those procedures been based on accurate information?

6. Have you been able to appeal the (outcome) arrived at by those procedures?

7. Have those procedures upheld ethical and moral standards?

\section{Distributive justice}

The following items refer to your (outcome). To what extent:

1. Does your (outcome) reflect the effort you have put into your work?

2. Is your (outcome) appropriate for the work you have completed?

3. Does your (outcome) reflect what you have contributed to the organization?

4. Is your (outcome) justified, given your performance?

\section{Interpersonal justice}

The following items refer to (the authority figure who enacted the procedure). To what extent:

1. Has (he/she) treated you in a polite manner?

2. Has (he/she) treated you with dignity?

3. Has (he/she) treated you with respect?

4. Has (he/she) refrained from improper remarks or comments?

Informational justice

The following items refer to (the authority figure who enacted the procedure). To what extent:

1. Has (he/she) been candid in (his/her) communications with you?

2. Has (he/she) explained the procedures thoroughly?

3 . Were (his/her) explanations regarding the procedures reasonable?

4. Has (he/she) communicated details in a timely manner?

5. Has (he/she) seemed to tailor (his/her) communications to individuals' specific needs?

Note. All items use a 5-point scale with anchors of $1=t o$ a small extent and $5=$ to a large extent.

(Colquitt, 2001) 


\section{Appendix K. Perceived Organizational Support Questionnaire}

1. The organization values my contribution to its well-being.

2. The organization fails to appreciate any extra effort from me.

3. The organization would ignore any complaint from me.

4. The organization really cares about my well-being.

5. Even if I did the best job possible, the organization would fail to notice.

6. The organization cares about my general satisfaction at work.

7. The organization shows very little concern for me.

8. The organization takes pride in my accomplishments at work. 


\section{Appendix L. Advance Notice Email}

\section{Jan 232015}

Subject: Advance notice email: RN Workplace Survey and chance to Win \$100 VISA pre-paid gift card

Nurses are the largest group of health professionals among hospital staff and a fundamental component in the health sector. Little is known regarding how you feel about your work, your commitment, and the effect of perceived organizational support on workplace behaviours in health care. Researchers from the University of Toronto are interested in this area. Our research team is working with the Registered Nurses Association of Ontario to distribute this survey to RNs. Your input will be of great value.

We would like to invite you to complete a short survey. It will be distributed on Friday January $\mathbf{3 0}^{\text {th }}$, 2015. The survey will require approximately 20 minutes to complete, and includes questions regarding your perceptions of fairness in the workplace, perceived organizational support, commitment, behaviours, and some basic demographic information. Unfortunately you will not be able to start the survey, save your input, and return to the survey at a later time.

By completing and submitting your survey, you are consenting to participate in this study. You can discontinue the completion of the survey at any time, with no repercussions. Exiting the survey prior to completing it and-or pressing the "submit" button will erase your responses such that they will not be captured in the database. None of the survey questions can or will be used to identify you. The aggregated anonymous data will be viewed only by the research team from the University of Toronto.

As a small token of appreciation from us for your time, upon submitting your survey, you will have the opportunity to enter your name and email address for a chance to win one of three \$100 pre-paid VISA gift cards. Your personal information will not be linked with your survey answers. Once the winners are selected, all names and email addresses will be permanently deleted.

Please keep a look out for the opportunity to participate. Your input is of great value. If you have any questions regarding the survey or research, please feel free to contact Tyrone Perreira atty.perreira@mail.utoronto.ca or 647-404-6744 for more details. If you have any questions concerning your rights as a participant of this study, please contact the University of Toronto's Office of Research Ethics (ethics.review@utoronto.ca or 416-946-3273).

Kindest Regards,

Tyrone A. Perreira $\mathrm{PhD}$ (c)

Institute for Health Policy, Management and Evaluation

Health Sciences Building, 155 College Street, Suite 425

Toronto, Ontario, M5T 3M6, Canada 


\section{Appendix M. Email Number 1}

\section{Jan $30^{\text {th }} 2015$}

\section{Subject: RN Workplace Questionnaire}

Nurses are the largest group of health professionals and a fundamental component in the health sector. Little is known regarding how you feel about your work, your commitment, and the effect of perceived organizational support on workplace behaviours in health care. Researchers from the University of Toronto are interested in this area. Our research team is working with the Registered Nurses Association of Ontario to distribute this survey to RNs. This is a great opportunity to share your first hand insights regarding factors that are important to nurses. Your input will be of great value.

We would like to invite you to complete a short survey. The survey will require approximately $\mathbf{2 0}$ minutes to complete, and includes questions regarding your perceptions of fairness in the workplace, perceived organizational support, commitment, behaviours, and some basic demographic information. Unfortunately you will not be able to start the survey, save your input, and return to the survey at a later time.

By completing and submitting your survey, you are consenting to participate in this study. You can discontinue the completion of the survey at any time, with no repercussions. Exiting the survey prior to completing it and-or pressing the "submit" button will erase your responses such that they will not be captured in the database. None of the survey questions can or will be used to identify you. The aggregated anonymous data will be viewed only by the research team from the University of Toronto.

As a small token of appreciation from us for your time, upon submitting your survey, you will have the opportunity to enter your name and email address for a chance to win one of three \$100 pre-paid VISA gift cards. This draw will occur one week after the survey closes. Your personal information will not be linked with your survey answers. Once the winners are selected, all names and email addresses will be permanently deleted.

To start the survey, please click here: http://fluidsurveys.com/s/RNWorkplace/

If you are experiencing problems with the URL, please copy and paste it into your web browser.

If you have any questions regarding the survey or research, please feel free to contact Tyrone Perreira at ty.perreira@mail.utoronto.ca or 647-404-6744 for more details. If you have any questions concerning your rights as a participant of this study, please contact the University of Toronto's Office of Research Ethics (ethics.review@utoronto.ca or 416-946-3273).

Kindest Regards,

Tyrone A. Perreira PhD (c)

Institute for Health Policy, Management and Evaluation

Health Sciences Building, 155 College Street, Suite 425

Toronto, Ontario, M5T 3M6, Canada 


\section{Appendix N. Email Number 2}

\section{Friday February 6, 2015}

\section{Subject: RN Workplace Questionnaire: Follow-up}

Hello everyone, I just wanted to touch base with you to see if you had an opportunity to complete the RN Workplace Questionnaire. If you have already completed the survey, thank you very much. Your input is extremely valuable.

Nurses are the largest group of health professionals and a fundamental component in the health sector. Little is known regarding how you feel about your work, your commitment, and the effect of perceived organizational support on workplace behaviours in health care. Researchers from the University of Toronto are interested in this area. Our research team is working with the Registered Nurses Association of Ontario to distribute this survey to RNs. This is a great opportunity to share your first hand insights regarding factors that are important to nurses. Your input will be of great value.

We would like to invite you to complete a short survey. The survey will require approximately $\mathbf{2 0}$ minutes to complete, and includes questions regarding your perceptions of fairness in the workplace, perceived organizational support, commitment, behaviours, and some basic demographic information. Unfortunately you will not be able to start the survey, save your input, and return to the survey at a later time.

By completing and submitting your survey, you are consenting to participate in this study. You can discontinue the completion of the survey at any time, with no repercussions. Exiting the survey prior to completing it and-or pressing the "submit" button will erase your responses such that they will not be captured in the database. None of the survey questions can or will be used to identify you. The aggregated anonymous data will be viewed only by the research team from the University of Toronto.

As a small token of appreciation from us for your time, upon submitting your survey, you will have the opportunity to enter your name and email address for a chance to win one of three $\mathbf{\$ 1 0 0}$ pre-paid VISA gift cards. This draw will occur one week after the survey closes. Your personal information will not be linked with your survey answers. Once the winners are selected, all names and email addresses will be permanently deleted.

To start the survey, please click here: http://fluidsurveys.com/s/RNWorkplace/

If you are experiencing problems with the URL, please copy and paste it into your web browser.

If you have any questions regarding the survey or research, please feel free to contact Tyrone Perreira at ty.perreira@mail.utoronto.ca or 647-404-6744 for more details. If you have any questions concerning your rights as a participant of this study, please contact the University of Toronto's Office of Research Ethics (ethics.review@utoronto.ca or 416-946-3273).

Kindest Regards,

Tyrone A. Perreira PhD (c)

Institute for Health Policy, Management and Evaluation

Health Sciences Building, 155 College Street, Suite 425

Toronto, Ontario, M5T 3M6, Canada

\section{Appendix O. Email Number 3}


Feb 13, 2015

Subject: RN Workplace Survey: Still time to win one of three \$100 pre-paid VISA gift cards

I wanted to take a moment to thank all those who participated in the survey. Your input is greatly appreciated. As we communicated last week, the survey will soon be closing. For those who still wish to participate, we would love to hear from you.

The survey requires just a few minutes of your time to complete. Unfortunately you will not be able to start the survey, save your input, and return to the survey at a later time. All participants will be asked basic demographic information. Depending upon your responses, you may be asked additional questions regarding your perceptions of fairness, perceived organizational support, factors that motivate you, and workplace behaviours.

As a small token of appreciation from us for your time, upon submitting your survey, you will have the opportunity to enter your name and email address for a chance to win one of three \$100 pre-paid VISA gift cards. This draw will occur one week after the survey closes. Your personal information will not be linked with your survey answers. Once the winners are selected, all names and email addresses will be permanently deleted.

Nurses are the largest group of health professionals and a fundamental component in the health sector. Little is known regarding how you feel about your work, your commitment, and the effect of perceived organizational support on workplace behaviours in health care. Researchers from the University of Toronto are interested in this area. Our research team is working with the Registered Nurses Association of Ontario to distribute this survey to RNs. This is a great opportunity to share your first hand insights regarding factors that are important to nurses.

By completing and submitting your survey, you are consenting to participate in this study. You can discontinue the completion of the survey at any time, with no repercussions. Exiting the survey prior to completing it and-or pressing the "submit" button will erase your responses such that they will not be captured in the database.

None of the survey questions can or will be used to identify you. The aggregated anonymous data will be viewed only by the research team from the University of Toronto.

To start the survey, please click here: http://fluidsurveys.com/s/RNWorkplace/

If you are experiencing problems with the URL, please copy and paste it into your web browser.

If you have any questions regarding the survey or research, please feel free to contact Tyrone Perreira at ty.perreira@mail.utoronto.ca. If you have any questions concerning your rights as a participant of this study, please contact the University of Toronto’s Office of Research Ethics (ethics.review@utoronto.ca or 416-946-3273).

Kindest Regards,

Tyrone A. Perreira PhD (c)

Institute for Health Policy, Management and Evaluation

Health Sciences Building, 155 College Street, Suite 425

Toronto, Ontario, M5T 3M6, Canada

\section{Appendix P. Email Number 4}


Feb 20, 2015

Subject: RN Workplace Survey Closing: LAST CHANCE to win a \$100 pre-paid VISA gift card

Hello everyone,

If you already completed the survey, thank you very much for participating.

The RN Workplace Survey will be CLOSING at 11:59 pm on Tuesday February 24, 2015.

For those who still wish to participate, we would love to hear from you. The survey requires just a few minutes of your time to complete.

All participants will be asked basic demographic information. Depending upon your responses, you may be asked additional questions regarding your perceptions of fairness, perceived organizational support, factors that motivate you, and workplace behaviours. As a small token of appreciation from us for your time, upon submitting your survey, you will have the opportunity to enter your name and email address for a chance to win one of three \$100 pre-paid VISA gift cards. This draw will occur one week after the survey closes. Your personal information will not be linked with your survey answers. Once the winners are selected, all names and email addresses will be permanently deleted.

None of the survey questions can or will be used to identify you. The aggregated anonymous data will be viewed only by the research team from the University of Toronto.

To start the survey, please click here: http://fluidsurveys.com/s/RNWorkplace/

If you are experiencing problems with the URL, please copy and paste it into your web browser.

If you have any questions regarding the survey or research, please feel free to contact Tyrone Perreira at ty.perreira@mail.utoronto.ca. If you have any questions concerning your rights as a participant of this study, please contact the University of Toronto's Office of Research Ethics (ethics.review@utoronto.ca or 416-946-3273).

Kindest Regards,

Tyrone A. Perreira PhD (c)

Institute for Health Policy, Management and Evaluation

Health Sciences Building, 155 College Street, Suite 425

Toronto, Ontario, M5T 3M6, Canada

\section{Appendix Q. Model Modification}


Determination of goodness of fit was based on the accumulation of evidence across all the statistics/indices. The essence of SEM is to determine the fit between the restricted (predicted) covariance model (the hypothesized model), and the sample covariance matrix. If the model describes the data well, the values should be small and evenly distributed. The Standardized Residual (SR) matrix, often gives clues as to which original covariance or correlations are not well accounted for by the model (Schumacker \& Lomax, 2004). Large residuals indicate misspecification in the model, affecting overall model fit. Any discrepancy between the two appears in the residual covariance matrix (Byrne, 2014). SRs greater than the absolute value of 3.29 are flags for possible concern, as in an average sample, SRs this high are unlikely to occur by chance (Field, 2009).

The modification index is the expected value that $\chi^{2}$ would decrease by if such a parameter are to be included; large values indicate potentially useful parameters. Modifications suggested by the LISREL program in the output, suggest added paths to help address these high SRs. These measurement error covariances represent systematic, rather than random, measurement error in item responses, and may be attributed from characteristics specific to the respondents or the items. If they represent respondent characteristics, they may be indicative of bias such as social desirability, or yea-saying or nay-saying (systematic way of responding) (Byrne, 2014). Another potential reason for correlated errors is high degree of overlap in item content. In other words, items essentially ask the same question, even though worded differently (Byrne, 2014).

According to Byrne (2014), should one decide to re-specify or re-estimate the model, analyses would shift from confirmatory to exploratory. The term for this is 'specification searches,' as the analyses turns the focus to the detection of misfitting parameters in the originally hypothesized model (Byrne, 2014). The decision regarding whether or not to proceed with a specification search depends on whether adding the additional path makes theoretical/conceptual sense, and whether or not the re-specified model would lead to an overfitted model. Correlating errors that make substantive sense is done mainly in social psychological research (Byrne, 2014).

\section{Appendix R. Z-test Results}

Z-test to compare two proportion

Analysed: Sat Jul 04, 2015 @ 01:50 
Age:

18-24

Inputs

\begin{tabular}{|c|c|c|}
\hline & Sample 1 & Sample 2 \\
\hline Sample Proportion & 0.05 & 0.041 \\
\hline Sample size & 676 & 104298 \\
\hline Significance level & 0.05 & \\
\hline 1- or 2-tailed test & 2-tailed & \\
\hline
\end{tabular}

Results

\begin{tabular}{|l|l|ll|}
\hline & Sample 1 & Sample 2 & Difference \\
\hline Sample proportion & 0.05 & 0.041 & 0.009 \\
\hline 95\% Cl (asymptotic) & $0.0336-0.0664$ & $0.0398-0.0422$ & $-0.006-0.024$ \\
\hline Z-value & 1.2 & & \\
\hline P-value & 0.2398 & & \\
Interpretation & $\begin{array}{l}\text { Not significant, } \\
\text { accept null hypothesis that } \\
\text { sample proportions are equal }\end{array}$ & \\
n by pi & $\mathrm{n}$ * pi >5, test ok & \\
\hline
\end{tabular}

25-29

Inputs

\begin{tabular}{|c|c|c|}
\hline & Sample 1 & Sample 2 \\
\hline Sample Proportion & 0.105 & 0.1 \\
\hline Sample size & 676 & 104298 \\
\hline Significance level & 0.05 & \\
\hline 1- or 2-tailed test & 2-tailed & \\
\hline
\end{tabular}

Results

\begin{tabular}{|c|c|c|c|}
\hline & Sample 1 & Sample 2 & Difference \\
\hline Sample proportion & 0.105 & 0.1 & 0.00499999999999999 \\
\hline 95\% Cl (asymptotic) & $0.0819-0.1281$ & $0.0982-0.1018$ & $-0.0177-0.0277$ \\
\hline z-value & 0.4 & & \\
\hline P-value & 0.6658 & & \\
\hline Interpretation & $\begin{array}{l}\text { Not significant, } \\
\text { accept null hypothesis that } \\
\text { sample proportions are equal }\end{array}$ & & \\
\hline n by pi & $n *$ pi $>5$, test ok & & \\
\hline
\end{tabular}

30-34

Inputs

\begin{tabular}{|l|l|l|}
\hline & Sample 1 & Sample 2 \\
\hline Sample Proportion & 0.093 & 0.095 \\
\hline
\end{tabular}




\begin{tabular}{|l|ll|}
\hline Sample size & 676 & 104298 \\
\hline Significance level & 0.05 & \\
\hline 1- or 2-tailed test & 2-tailed & \\
\hline
\end{tabular}

\section{Results}

\begin{tabular}{|c|c|c|c|}
\hline & Sample 1 & Sample 2 & Difference \\
\hline Sample proportion & 0.093 & 0.095 & 0.002 \\
\hline 95\% Cl (asymptotic) & $0.0711-0.1149$ & $0.0932-0.0968$ & $3-0.0202-0.0242$ \\
\hline z-value & 0.2 & & \\
\hline P-value & 0.8597 & & \\
\hline Interpretation & $\begin{array}{l}\text { Not significant, } \\
\text { accept null hypothesis that } \\
\text { sample proportions are equal }\end{array}$ & & \\
\hline n by pi & $n *$ pi $>5$, test ok & & \\
\hline
\end{tabular}

\section{5-39}

Inputs

\begin{tabular}{|l|ll|}
\hline & Sample 1 & Sample 2 \\
\hline Sample Proportion & 0.071 & 0.097 \\
\hline Sample size & 676 & 104298 \\
\hline Significance level & 0.05 & \\
\hline 1- or 2-tailed test & 2-tailed & \\
\hline
\end{tabular}

\section{Results}

\begin{tabular}{|l|lll|}
\hline & Sample 1 & Sample 2 & Difference \\
\hline Sample proportion & 0.071 & 0.097 & 0.026 \\
\hline 95\% Cl (asymptotic) & $0.0516-0.0904$ & $0.0952-0.09880 .0036-0.0484$ \\
\hline Z-value & 2.3 & & \\
\hline P-value & 0.0227 & & \\
\hline & $\begin{array}{l}\text { Statistically significant, } \\
\text { Interpretation }\end{array}$ & & \\
& reject null hypothesis that \\
sample proportions are equal & & \\
\hline n by pi & $\mathrm{n}$ * pi >5, test ok & \\
\hline
\end{tabular}

40-44

Inputs

\begin{tabular}{|l|ll|}
\hline \multicolumn{4}{|c|}{ Sample 1 } & Sample 2 \\
\hline Sample Proportion & 0.084 & 0.112 \\
\hline Sample size & 676 & 104298 \\
\hline Significance level & 0.05 & \\
\hline 1- or 2-tailed test & 2-tailed & \\
\hline
\end{tabular}

Results

\begin{tabular}{|l|lll|}
\hline & Sample 1 & Sample 2 & Difference \\
\hline Sample proportion & 0.084 & 0.112 & 0.028 \\
\hline
\end{tabular}




\begin{tabular}{|lll|}
\hline 95\% Cl (asymptotic) & $0.0631-0.1049$ & $0.1101-0.11390 .0042-0.0518$ \\
\hline Z-value & 2.3 & \\
\hline P-value & 0.0213 \\
& $\begin{array}{l}\text { Statistically significant, } \\
\text { reject null hypothesis that } \\
\text { sample proportions are equal }\end{array}$ \\
Interpretation & $\mathrm{n} *$ pi >5, test ok
\end{tabular}

\section{5-49}

Inputs

\begin{tabular}{|l|ll|}
\hline & Sample 1 & Sample 2 \\
\hline \multicolumn{1}{|l|}{ Sample Proportion } & 0.126 & 0.137 \\
\hline Sample size & 676 & 104298 \\
\hline Significance level & 0.05 & \\
\hline 1- or 2-tailed test & 2-tailed & \\
\hline
\end{tabular}

Results

\begin{tabular}{|c|c|c|c|}
\hline & Sample 1 & Sample 2 & Difference \\
\hline Sample proportion & 0.126 & 0.137 & 0.011 \\
\hline 95\% Cl (asymptotic) & $0.101-0.151$ & $0.1349-0.1391$ & $-0.015-0.037$ \\
\hline z-value & 0.8 & & \\
\hline P-value & 0.407 & & \\
\hline Interpretation & $\begin{array}{l}\text { Not significant, } \\
\text { accept null hypothesis that } \\
\text { sample proportions are equal }\end{array}$ & & \\
\hline n by pi & $n *$ pi $>5$, test ok & & \\
\hline
\end{tabular}

\section{0-54}

Inputs

\begin{tabular}{|l|ll|}
\hline & Sample 1 & Sample 2 \\
\hline Sample Proportion & 0.157 & 0.14 \\
Sample size & 676 & 104298 \\
\hline Significance level & 0.05 & \\
\hline 1- or 2-tailed test & 2-tailed & \\
\hline
\end{tabular}

\section{Results}

\begin{tabular}{|l|lll|}
\hline & Sample 1 & Sample 2 & Difference \\
\hline Sample proportion & 0.157 & 0.14 & 0.017 \\
\hline
\end{tabular}




\begin{tabular}{|lll|}
\hline 95\% Cl (asymptotic) & $0.1296-0.1844$ & $0.1379-0.1421-0.0093-0.0433$ \\
\hline Z-value & 1.3 & \\
\hline P-value & 0.2043 \\
\hline Interpretation & $\begin{array}{l}\text { Not significant, } \\
\text { accept null hypothesis that } \\
\text { sample proportions are equal }\end{array}$ \\
n by pi & $\mathrm{n}$ * pi >5, test ok
\end{tabular}

\section{5-59}

Inputs

\begin{tabular}{|l|ll|}
\hline & Sample 1 & Sample 2 \\
\hline Sample Proportion & 0.161 & 0.13 \\
Sample size & 676 & 104298 \\
\hline Significance level & 0.05 & \\
\hline 1- or 2-tailed test & 2-tailed & \\
\hline
\end{tabular}

Results

\begin{tabular}{|l|lll|}
\hline & Sample 1 & Sample 2 & Difference \\
\hline Sample proportion & 0.161 & 0.13 & 0.031 \\
\hline 95\% Cl (asymptotic) & $0.1333-0.1887$ & $0.128-0.1320 .0055-0.0565$ \\
\hline Z-value & 2.4 & & \\
\hline P-value & 0.017 & & \\
\hline & $\begin{array}{l}\text { Statistically significant, } \\
\text { Interpretation }\end{array}$ & reject null hypothesis that \\
& sample proportions are equal & \\
n by pi & $\mathrm{n}$ * pi >5, test ok & \\
\hline
\end{tabular}

\section{0-64}

Inputs

\begin{tabular}{|l|ll|}
\hline & Sample 1 & Sample 2 \\
\hline Sample Proportion & 0.112 & 0.092 \\
Sample size & 676 & 104298 \\
\hline Significance level & 0.05 & \\
\hline 1- or 2-tailed test & 2-tailed & \\
\hline
\end{tabular}

\section{Results}

\begin{tabular}{|l|lll|}
\hline & Sample 1 & Sample 2 & Difference \\
\hline Sample proportion & 0.112 & 0.092 & 0.02 \\
\hline
\end{tabular}




\begin{tabular}{|lll|}
\hline 95\% Cl (asymptotic) & $0.0882-0.1358$ & $0.0902-0.0938-0.0019-0.0419$ \\
\hline Z-value & 1.8 & \\
\hline P-value & 0.0731 \\
\hline Interpretation & $\begin{array}{l}\text { Not significant, } \\
\text { accept null hypothesis that } \\
\text { sample proportions are equal }\end{array}$ \\
n by pi & $\mathrm{n}$ * pi >5, test ok
\end{tabular}

$>=65$

Inputs

\begin{tabular}{|l|ll|}
\hline & Sample 1 & Sample 2 \\
\hline Sample Proportion & 0.04 & 0.046 \\
Sample size & 676 & 104298 \\
\hline Significance level & 0.05 & \\
1- or 2-tailed test & 2-tailed & \\
\hline
\end{tabular}

Results

\begin{tabular}{|l|lll|}
\hline & Sample 1 & Sample 2 & Difference \\
\hline Sample proportion & 0.04 & 0.046 & 0.006 \\
\hline 95\% Cl (asymptotic) & $0.0252-0.0548$ & $0.0447-0.0473-0.0098-0.0218$ \\
\hline Z-value & 0.7 & & \\
\hline P-value & 0.4577 & \\
\hline & Not significant, & \\
Interpretation & accept null hypothesis that & \\
& sample proportions are equal \\
n by pi & $\mathrm{n}$ * pi >5, test ok & \\
\hline
\end{tabular}

\section{Gender}

Male

Inputs

\begin{tabular}{|l|ll|}
\hline & Sample 1 & Sample 2 \\
\hline Sample Proportion & 0.041 & 0.061 \\
\hline Sample size & 676 & 104298 \\
\hline Significance level & 0.05 & \\
\hline 1- or 2-tailed test & 2-tailed & \\
\hline
\end{tabular}

Results

\begin{tabular}{|l|l|l|}
\hline Sample 1 & Sample 2 & Difference \\
\hline
\end{tabular}




\begin{tabular}{|llll|}
\hline Sample proportion & 0.041 & 0.061 & 0.02 \\
\hline 95\% Cl (asymptotic) & $0.0261-0.0559$ & $0.0595-0.0625$ & $0.0019-0.0381$ \\
\hline Z-value & 2.2 & & \\
\hline P-value & 0.0302 & \\
\hline Interpretation & $\begin{array}{l}\text { Statistically significant, } \\
\text { reject null hypothesis that } \\
\text { sample proportions are equal } \\
\text { n by pi }\end{array}$ & \\
\hline
\end{tabular}

\section{Female}

Inputs

\begin{tabular}{|l|l|l|}
\hline & Sample 1 & Sample 2 \\
\hline Sample Proportion & 0.959 & 0.939 \\
\hline Sample size & 676 & 104298 \\
\hline Significance level & 0.05 & \\
\hline 1- or 2-tailed test & 2-tailed & \\
\hline
\end{tabular}

Results

\begin{tabular}{|c|c|c|c|}
\hline & Sample 1 & Sample 2 & Difference \\
\hline Sample proportion & 0.959 & 0.939 & 0.02 \\
\hline 95\% Cl (asymptotic) & $0.9441-0.9739$ & $0.9375-0.9405$ & $0.0019-0.0381$ \\
\hline z-value & 2.2 & & \\
\hline P-value & 0.0302 & & \\
\hline Interpretation & $\begin{array}{l}\text { Statistically significant, } \\
\text { reject null hypothesis that } \\
\text { sample proportions are equal }\end{array}$ & & \\
\hline $\mathrm{n}$ by pi & $n *$ pi $>5$, test ok & & \\
\hline
\end{tabular}

\section{Employment Status}

Full-time

Inputs

\begin{tabular}{|l|ll|}
\hline & Sample 1 & Sample 2 \\
\hline Sample Proportion & 0.679 & 0.665 \\
Sample size & 676 & 104298 \\
\hline Significance level & 0.05 & \\
\hline 1- or 2-tailed test & 2-tailed & \\
\hline
\end{tabular}




\begin{tabular}{|l|l|ll|}
\hline & Sample 1 & Sample 2 & Difference \\
\hline Sample proportion & 0.679 & 0.665 & 0.014 \\
\hline $95 \% \mathrm{Cl}$ (asymptotic) & $0.6438-0.7142$ & $0.6621-0.6679$ & $-0.0217-0.0497$ \\
\hline Z-value & 0.8 & & \\
\hline P-value & 0.442 & & \\
Interpretation & $\begin{array}{l}\text { Not significant, } \\
\text { accept null hypothesis that } \\
\text { sample proportions are equal }\end{array}$ & \\
\hline $\mathrm{n}$ by pi & $\mathrm{n}$ * pi >5, test ok & \\
\hline
\end{tabular}

Part-time

Inputs

\begin{tabular}{|l|ll|}
\hline & Sample 1 & Sample 2 \\
\hline Sample Proportion & 0.263 & 0.262 \\
Sample size & 676 & 104298 \\
\hline Significance level & 0.05 & \\
1- or 2-tailed test & 2-tailed & \\
\hline
\end{tabular}

Results

\begin{tabular}{|l|l|l|l|}
\hline & Sample 1 & Sample 2 & Difference \\
\hline Sample proportion & 0.263 & 0.262 & 0.001 \\
\hline 95\% Cl (asymptotic) & $0.2298-0.2962$ & $0.2593-0.2647$ & $-0.0323-0.0343$ \\
\hline Z-value & 0.1 & & \\
\hline P-value & 0.953 & & \\
Interpretation & $\begin{array}{l}\text { Not significant, } \\
\text { accept null hypothesis that } \\
\text { sample proportions are equal }\end{array}$ & \\
n by pi & $\mathrm{n}$ * pi >5, test ok & \\
\hline
\end{tabular}

\section{Casual}

Inputs

\begin{tabular}{|c|c|c|}
\hline & Sample 1 & Sample 2 \\
\hline Sample Proportion & 0.058 & 0.072 \\
\hline Sample size & 676 & 104298 \\
\hline Significance level & 0.05 & \\
\hline 1- or 2-tailed test & 2-tailed & \\
\hline
\end{tabular}




\begin{tabular}{|c|c|c|c|}
\hline & Sample 1 & Sample 2 & Difference \\
\hline Sample proportion & 0.058 & 0.072 & 0.014 \\
\hline 95\% Cl (asymptotic) & $0.0404-0.0756$ & $0.0704-0.0736$ & $-0.0055-0.0335$ \\
\hline z-value & 1.4 & & \\
\hline P-value & 0.1602 & & \\
\hline Interpretation & $\begin{array}{l}\text { Not significant, } \\
\text { accept null hypothesis that } \\
\text { sample proportions are equal }\end{array}$ & & \\
\hline $\mathrm{n}$ by pi & $n *$ pi $>5$, test ok & & \\
\hline
\end{tabular}

\section{Employers}

\section{One Employer}

Inputs

\begin{tabular}{|c|c|c|}
\hline & Sample 1 & Sample 2 \\
\hline Sample Proportion & 0.794 & 0.842 \\
\hline Sample size & 676 & 104298 \\
\hline Significance level & 0.05 & \\
\hline 1- or 2-tailed test & 2-tailed & \\
\hline
\end{tabular}

Results

\begin{tabular}{|c|c|c|c|}
\hline & Sample 1 & Sample 2 & Difference \\
\hline Sample proportion & 0.794 & 0.842 & 0.0479999999999999 \\
\hline 95\% Cl (asymptotic) & $0.7635-0.8245$ & $0.8398-0.8442$ & $0.0204-0.0756$ \\
\hline z-value & 3.4 & & \\
\hline P-value & 0.0007 & & \\
\hline Interpretation & $\begin{array}{l}\text { Statistically significant, } \\
\text { reject null hypothesis that } \\
\text { sample proportions are equal }\end{array}$ & & \\
\hline $\mathrm{n}$ by pi & $n *$ pi $>5$, test ok & & \\
\hline
\end{tabular}

Two - employers

Inputs

\begin{tabular}{|l|ll|}
\hline & Sample 1 & Sample 2 \\
\hline Sample Proportion & 0.182 & 0.138 \\
\hline Sample size & 676 & 104298 \\
\hline Significance level & 0.05 & \\
\hline 1- or 2-tailed test & 2-tailed & \\
\hline
\end{tabular}

Results 


\begin{tabular}{|l|l|ll|}
\hline & Sample 1 & Sample 2 & Difference \\
\hline Sample proportion & 0.182 & 0.138 & 0.044 \\
\hline $95 \% \mathrm{Cl}$ (asymptotic) & $0.1529-0.2111$ & $0.1359-0.1401$ & $0.0179-0.0701$ \\
\hline Z-value & 3.3 & & \\
\hline P-value & 0.001 & & \\
Interpretation & $\begin{array}{l}\text { Statistically significant, } \\
\text { reject null hypothesis that } \\
\text { sample proportions are equal }\end{array}$ & \\
n by pi & $\mathrm{n}$ * pi >5, test ok & \\
\hline
\end{tabular}

Three - Employers

Inputs

\begin{tabular}{|l|ll|}
\hline & Sample 1 & Sample 2 \\
\hline Sample Proportion & 0.023 & 0.02 \\
\hline Sample size & 676 & 104298 \\
\hline Significance level & 0.05 & \\
\hline 1- or 2-tailed test & 2-tailed & \\
\hline
\end{tabular}

Results

\begin{tabular}{|l|l|ll|}
\hline & Sample 1 & Sample 2 & Difference \\
\hline Sample proportion & 0.023 & 0.02 & 0.003 \\
\hline 95\% Cl (asymptotic) & $0.0117-0.0343$ & $0.0192-0.0208$ & $-0.0076-0.0136$ \\
\hline Z-value & 0.6 & & \\
\hline P-value & 0.5788 & & \\
Interpretation & $\begin{array}{l}\text { Not significant, } \\
\text { accept null hypothesis that } \\
\text { sample proportions are equal }\end{array}$ & \\
n by pi & $\mathrm{n}$ * pi >5, test ok & \\
\hline
\end{tabular}

\section{LHIN}

Central

Inputs

\begin{tabular}{|l|ll|}
\hline & Sample 1 & Sample 2 \\
\hline Sample Proportion & 0.081 & 0.086 \\
\hline Sample size & 676 & 104298 \\
\hline Significance level & 0.05 & \\
\hline 1- or 2-tailed test & 2-tailed & \\
\hline
\end{tabular}




\begin{tabular}{|l|l|ll|}
\hline & Sample 1 & Sample 2 & Difference \\
\hline Sample proportion & 0.081 & 0.086 & 0.00499999999999999 \\
\hline $95 \% \mathrm{Cl}$ (asymptotic) & $0.0604-0.1016$ & $0.0843-0.0877$ & $-0.0162-0.0262$ \\
\hline Z-value & 0.5 & & \\
\hline P-value & 0.6439 & & \\
Interpretation & $\begin{array}{l}\text { Not significant, } \\
\text { accept null hypothesis that } \\
\text { sample proportions are equal }\end{array}$ & \\
n by pi & $\mathrm{n}$ * pi >5, test ok & \\
\hline
\end{tabular}

\section{Central East}

Inputs

\begin{tabular}{|l|ll|}
\hline & Sample 1 & Sample 2 \\
\hline Sample Proportion & 0.089 & 0.084 \\
\hline Sample size & 676 & 104298 \\
\hline Significance level & 0.05 & \\
\hline 1- or 2-tailed test & 2-tailed & \\
\hline
\end{tabular}

Results

\begin{tabular}{|c|c|c|c|}
\hline & Sample 1 & Sample 2 & Difference \\
\hline Sample proportion & 0.089 & 0.084 & 0.00499999999999999 \\
\hline 95\% Cl (asymptotic) & $0.0675-0.1105$ & $0.0823-0.0857$ & $-0.016-0.026$ \\
\hline z-value & 0.5 & & \\
\hline P-value & 0.6405 & & \\
\hline Interpretation & $\begin{array}{l}\text { Not significant, } \\
\text { accept null hypothesis that } \\
\text { sample proportions are equal }\end{array}$ & & \\
\hline n by pi & $n * p i>5$, test ok & & \\
\hline
\end{tabular}

\section{Central West}

Inputs

\begin{tabular}{|l|ll|}
\hline & Sample 1 & Sample 2 \\
\hline Sample Proportion & 0.038 & 0.033 \\
\hline Sample size & 676 & 104298 \\
\hline Significance level & 0.05 & \\
\hline 1- or 2-tailed test & 2-tailed & \\
\hline
\end{tabular}




\begin{tabular}{|l|l|ll|}
\hline & Sample 1 & Sample 2 & Difference \\
\hline Sample proportion & 0.038 & 0.033 & 0.005 \\
\hline $95 \% \mathrm{Cl}$ (asymptotic) & $0.0236-0.0524$ & $0.0319-0.0341$ & $-0.0085-0.0185$ \\
\hline Z-value & 0.7 & & \\
\hline P-value & 0.4684 & & \\
Interpretation & $\begin{array}{l}\text { Not significant, } \\
\text { accept null hypothesis that } \\
\text { sample proportions are equal }\end{array}$ & \\
\hline $\mathrm{n}$ by pi & $\mathrm{n}$ * pi >5, test ok & \\
\hline
\end{tabular}

\section{Champlain}

Inputs

\begin{tabular}{|l|ll|}
\hline & Sample 1 & Sample 2 \\
\hline Sample Proportion & 0.12 & 0.106 \\
\hline Sample size & 676 & 104298 \\
\hline Significance level & 0.05 & \\
\hline 1- or 2-tailed test & 2-tailed & \\
\hline
\end{tabular}

Results

\begin{tabular}{|l|lll|}
\hline & Sample 1 & Sample 2 & Difference \\
\hline Sample proportion & 0.12 & 0.106 & 0.014 \\
\hline 95\% Cl (asymptotic) & $0.0955-0.1445$ & $0.1041-0.1079$ & $-0.0093-0.0373$ \\
\hline Z-value & 1.2 & & \\
\hline P-value & 0.2387 & \\
\hline Interpretation & Not significant, \\
& accept null hypothesis that \\
sample proportions are equal & \\
n by pi & $\mathrm{n}$ * pi >5, test ok & \\
\hline
\end{tabular}

\section{Erie St Clair}

Inputs

\begin{tabular}{|l|ll|}
\hline & Sample 1 & Sample 2 \\
\hline Sample Proportion & 0.028 & 0.046 \\
\hline Sample size & 676 & 104298 \\
\hline Significance level & 0.05 & \\
\hline 1- or 2-tailed test & 2-tailed & \\
\hline
\end{tabular}




\begin{tabular}{|l|l|ll|}
\hline & Sample 1 & Sample 2 & Difference \\
\hline Sample proportion & 0.028 & 0.046 & 0.018 \\
\hline $95 \% \mathrm{Cl}$ (asymptotic) & $0.0156-0.0404$ & $0.0447-0.0473$ & $0.0022-0.0338$ \\
\hline Z-value & 2.2 & & \\
\hline P-value & 0.0258 & & \\
Interpretation & $\begin{array}{l}\text { Statistically significant, } \\
\text { reject null hypothesis that } \\
\text { sample proportions are equal }\end{array}$ & \\
n by pi & $\mathrm{n}$ * pi >5, test ok & \\
\hline
\end{tabular}

\section{Hamilton Niagara Haldimand Brant}

\section{Inputs}

\begin{tabular}{|l|ll|}
\hline & Sample 1 & Sample 2 \\
\hline Sample Proportion & 0.062 & 0.108 \\
Sample size & 676 & 104298 \\
\hline Significance level & 0.05 & \\
\hline 1- or 2-tailed test & 2-tailed & \\
\hline
\end{tabular}

\section{Results}

\begin{tabular}{|l|lll|}
\hline & Sample 1 & Sample 2 & Difference \\
\hline Sample proportion & 0.062 & 0.108 & 0.046 \\
\hline 95\% Cl (asymptotic) & $0.0438-0.0802$ & $0.1061-0.1099$ & $0.0226-0.0694$ \\
\hline z-value & 3.8 & & \\
\hline P-value & 0.0001 & & \\
\hline Interpretation & $\begin{array}{l}\text { Statistically significant, } \\
\text { reject null hypothesis that } \\
\text { sample proportions are equal } \\
\text { n by pi }\end{array}$ & & \\
\hline
\end{tabular}

\section{Mississauga Halton}

Inputs

\begin{tabular}{|c|c|c|}
\hline & Sample 1 & Sample 2 \\
\hline Sample Proportion & 0.072 & 0.068 \\
\hline Sample size & 676 & 104298 \\
\hline Significance level & 0.05 & \\
\hline 1- or 2-tailed test & 2-tailed & \\
\hline
\end{tabular}




\begin{tabular}{|l|l|ll|}
\hline & Sample 1 & Sample 2 & Difference \\
\hline Sample proportion & 0.072 & 0.068 & 0.00399999999999999 \\
\hline $95 \% \mathrm{Cl}$ (asymptotic) & $0.0525-0.0915$ & $0.0665-0.0695$ & $-0.015-0.023$ \\
\hline Z-value & 0.4 & & \\
\hline P-value & 0.6806 & & \\
Interpretation & $\begin{array}{l}\text { Not significant, } \\
\text { accept null hypothesis that } \\
\text { sample proportions are equal }\end{array}$ & \\
n by pi & $\mathrm{n}$ * pi >5, test ok & \\
\hline
\end{tabular}

\section{North East}

Inputs

\begin{tabular}{|l|ll|}
\hline & Sample 1 & Sample 2 \\
\hline Sample Proportion & 0.05 & 0.054 \\
Sample size & 676 & 104298 \\
\hline Significance level & 0.05 & \\
\hline 1- or 2-tailed test & 2-tailed & \\
\hline
\end{tabular}

\section{Results}

\begin{tabular}{|l|lll|}
\hline & Sample 1 & Sample 2 & Difference \\
\hline Sample proportion & 0.05 & 0.054 & 0.004 \\
\hline 95\% Cl (asymptotic) & $0.0336-0.0664$ & $0.0526-0.0554-0.0131-0.0211$ \\
\hline Z-value & 0.5 & & \\
\hline P-value & 0.6464 & \\
\hline Interpretation & Not significant, & \\
& accept null hypothesis that & & \\
sample proportions are equal & & \\
n by pi & $\mathrm{n}$ * pi >5, test ok & \\
\hline
\end{tabular}

\section{North Simcoe Muskoka}

Inputs

\begin{tabular}{|c|c|c|}
\hline & Sample 1 & Sample 2 \\
\hline Sample Proportion & 0.033 & 0.034 \\
\hline Sample size & 676 & 104298 \\
\hline Significance level & 0.05 & \\
\hline 1- or 2-tailed test & 2-tailed & \\
\hline
\end{tabular}




\begin{tabular}{|l|l|ll|}
\hline & Sample 1 & Sample 2 & Difference \\
\hline Sample proportion & 0.033 & 0.034 & 0.001 \\
\hline $95 \% \mathrm{Cl}$ (asymptotic) & $0.0195-0.0465$ & $0.0329-0.0351$ & $-0.0127-0.0147$ \\
\hline Z-value & 0.1 & & \\
\hline P-value & 0.8863 & & \\
Interpretation & $\begin{array}{l}\text { Not significant, } \\
\text { accept null hypothesis that } \\
\text { sample proportions are equal }\end{array}$ & \\
\hline $\mathrm{n}$ by pi & $\mathrm{n}$ * pi >5, test ok & \\
\hline
\end{tabular}

\section{North West}

\section{Inputs}

\begin{tabular}{|l|ll|}
\hline & Sample 1 & Sample 2 \\
\hline Sample Proportion & 0.04 & 0.026 \\
\hline Sample size & 676 & 104298 \\
\hline Significance level & 0.05 & \\
\hline 1- or 2-tailed test & 2-tailed & \\
\hline
\end{tabular}

\section{Results}

\begin{tabular}{|l|lll|}
\hline & Sample 1 & Sample 2 & Difference \\
\hline Sample proportion & 0.04 & 0.026 & 0.014 \\
\hline 95\% Cl (asymptotic) & $0.0252-0.0548$ & $0.025-0.027$ & $0.0019-0.0261$ \\
\hline Z-value & 2.3 & & \\
P-value & 0.0228 & & \\
\hline \multirow{2}{*}{ Interpretation } & $\begin{array}{l}\text { Statistically significant, } \\
\text { reject null hypothesis that } \\
\text { sample proportions are equal }\end{array}$ & & \\
n by pi & $\mathrm{n}$ * pi >5, test ok & & \\
\hline
\end{tabular}

\section{South East}

\section{Inputs}

\begin{tabular}{|c|c|c|}
\hline & Sample 1 & Sample 2 \\
\hline Sample Proportion & 0.05 & 0.046 \\
\hline Sample size & 676 & 104298 \\
\hline Significance level & 0.05 & \\
\hline 1- or 2-tailed test & 2-tailed & \\
\hline
\end{tabular}




\begin{tabular}{|c|c|c|c|}
\hline & Sample 1 & Sample 2 & Difference \\
\hline Sample proportion & 0.05 & 0.046 & 0.004 \\
\hline 95\% Cl (asymptotic) & $0.0336-0.0664$ & $0.0447-0.0473$ & $3-0.0118-0.0198$ \\
\hline z-value & 0.5 & & \\
\hline P-value & 0.6208 & & \\
\hline Interpretation & $\begin{array}{l}\text { Not significant, } \\
\text { accept null hypothesis that } \\
\text { sample proportions are equal }\end{array}$ & & \\
\hline $\mathrm{n}$ by pi & $n *$ pi $>5$, test ok & & \\
\hline
\end{tabular}

\section{South West}

\section{Inputs}

\begin{tabular}{|l|ll|}
\hline & Sample 1 & Sample 2 \\
\hline Sample Proportion & 0.109 & 0.087 \\
Sample size & 676 & 104298 \\
\hline Significance level & 0.05 & \\
\hline 1- or 2-tailed test & 2-tailed & \\
\hline
\end{tabular}

\section{Results}

\begin{tabular}{|c|c|c|c|}
\hline & Sample 1 & Sample 2 & Difference \\
\hline Sample proportion & 0.109 & 0.087 & 0.022 \\
\hline 95\% Cl (asymptotic) & $0.0855-0.1325$ & $0.0853-0.0887$ & $7 e-04-0.0433$ \\
\hline z-value & 2 & & \\
\hline P-value & 0.0432 & & \\
\hline Interpretation & $\begin{array}{l}\text { Statistically significant, } \\
\text { reject null hypothesis that } \\
\text { sample proportions are equal }\end{array}$ & & \\
\hline n by pi & $n *$ pi $>5$, test ok & & \\
\hline
\end{tabular}

\section{Toronto Central}

Inputs

\begin{tabular}{|c|c|c|}
\hline & Sample 1 & Sample 2 \\
\hline Sample Proportion & 0.176 & 0.175 \\
\hline Sample size & 676 & 104298 \\
\hline Significance level & 0.05 & \\
\hline 1- or 2-tailed test & 2-tailed & \\
\hline
\end{tabular}




\begin{tabular}{|l|lll|}
\hline & Sample 1 & Sample 2 & Difference \\
\hline Sample proportion & 0.176 & 0.175 & 0.001 \\
\hline 95\% Cl (asymptotic) & $0.1473-0.2047$ & $0.1727-0.1773$ & $-0.0277-0.0297$ \\
\hline Z-value & 0.1 & & \\
\hline P-value & 0.9456 & \\
\hline \multirow{2}{*}{ Interpretation } & Not significant, & \\
& accept null hypothesis that \\
sample proportions are equal & \\
n by pi & $\mathrm{n}$ * pi >5, test ok & \\
\hline
\end{tabular}

\section{Waterloo Wellington}

Inputs

\begin{tabular}{|l|l|l|}
\hline & Sample 1 & Sample 2 \\
\hline Sample Proportion & 0.05 & 0.046 \\
Sample size & 676 & 104298 \\
\hline Significance level & 0.05 & \\
\hline 1- or 2-tailed test & 2-tailed & \\
\hline
\end{tabular}

\section{Results}

\begin{tabular}{|l|lll|}
\hline & Sample 1 & Sample 2 & Difference \\
\hline Sample proportion & 0.05 & 0.046 & 0.004 \\
\hline 95\% Cl (asymptotic) & $0.0336-0.0664$ & $0.0447-0.0473-0.0118-0.0198$ \\
\hline Z-value & 0.5 & & \\
\hline P-value & 0.6208 & \\
\hline Interpretation & Not significant, & \\
& accept null hypothesis that & & \\
sample proportions are equal & & \\
n by pi & $\mathrm{n}$ * pi >5, test ok & \\
\hline
\end{tabular}




\section{Appendix S. Univariate Summary Statistics}

$\begin{array}{cccccccccc}\text { Var } & \text { Mean } & \text { SD } & \text { Skew } & \text { Kurt } & \text { Min } & \text { Freq. } & \text { Max } & \text { Freq. } \\ \text { JD1 } & 3.132 & 1.110 & -0.032 & -0.471 & 1.120 & 71 & 5.254 & 58 \\ \text { JD2 } & 3.104 & 1.089 & -0.046 & -0.421 & 1.086 & 66 & 5.309 & 46 \\ \text { JD3 } & 2.923 & 1.120 & 0.025 & -0.511 & 1.020 & 88 & 5.228 & 42 \\ \text { JD4 } & 3.195 & 1.102 & -0.058 & -0.432 & 1.180 & 70 & 5.341 & 55 \\ \text { JP1 } & 3.209 & 1.191 & -0.056 & -0.646 & 1.078 & 74 & 5.178 & 96 \\ \text { JP2 } & 2.914 & 1.124 & 0.034 & -0.524 & 1.041 & 94 & 5.231 & 42 \\ \text { JP3 } & 2.939 & 1.136 & 0.039 & -0.539 & 1.065 & 97 & 5.211 & 48 \\ \text { JP4 } & 2.993 & 1.145 & 0.016 & -0.546 & 1.065 & 91 & 5.249 & 51 \\ \text { JP5 } & 3.114 & 1.097 & -0.024 & -0.448 & 1.151 & 75 & 5.283 & 51 \\ \text { POS3_R } & 4.290 & 1.870 & -0.061 & -0.627 & 0.699 & 53 & 7.407 & 89\end{array}$




\begin{tabular}{|c|c|c|c|c|c|c|c|c|}
\hline POS4 & 4.081 & 1.932 & 0.016 & -0.693 & 0.845 & 88 & 7.540 & 70 \\
\hline POS5_R & 3.936 & 1.935 & 0.007 & -0.726 & 0.660 & 85 & 7.249 & 82 \\
\hline POS6 & 3.942 & 1.903 & 0.058 & -0.684 & 0.891 & 101 & 7.538 & 57 \\
\hline POS7_R & 4.065 & 1.920 & -0.010 & -0.731 & 0.780 & 82 & 7.292 & 87 \\
\hline POS8 & 4.220 & 1.817 & -0.012 & -0.650 & 1.033 & 75 & 7.384 & 77 \\
\hline ACorg1 & 3.930 & 1.098 & -0.433 & -0.740 & 1.420 & 30 & 5.124 & 256 \\
\hline ACsup1 & 3.491 & 1.262 & -0.203 & -0.858 & 1.145 & 67 & 5.153 & 176 \\
\hline ACco1 & 4.339 & 0.912 & -0.799 & -0.422 & 1.434 & 5 & 5.0893 & 374 \\
\hline ACpt1 & 4.791 & 0.527 & -2.063 & 2.931 & 2.547 & 3 & 5.020 & 564 \\
\hline ACprof1 & 4.672 & 0.709 & -1.640 & 1.413 & 2.117 & 6 & 5.041 & 522 \\
\hline ACwrk1 & 3.938 & 1.032 & -0.380 & -0.587 & 1.406 & 20 & 5.151 & 226 \\
\hline ACtsk1 & 4.043 & 0.995 & -0.438 & -0.561 & 1.532 & 18 & 5.148 & 251 \\
\hline ACcar1 & 3.857 & 1.145 & -0.419 & -0.791 & 1.306 & 34 & 5.100 & 256 \\
\hline ACorg2 & 3.750 & 1.085 & -0.287 & -0.659 & 1.296 & 29 & 5.124 & 193 \\
\hline ACsup2 & 3.312 & 1.335 & -0.132 & -0.955 & 1.060 & 93 & 5.133 & 163 \\
\hline ACco2 & 4.012 & 1.061 & -0.491 & -0.674 & 1.405 & 21 & 5.121 & 273 \\
\hline ACpt2 & 4.738 & 0.582 & -1.737 & 1.756 & 2.404 & 3 & 5.027 & 535 \\
\hline ACprof2 & 4.275 & 1.077 & -0.920 & -0.397 & 1.533 & 25 & 5.090 & 403 \\
\hline ACtsk2 & 4.142 & 0.949 & -0.490 & -0.521 & 1.666 & 16 & 5.143 & 275 \\
\hline ACcar2 & 3.234 & 1.248 & -0.068 & -0.774 & 1.084 & 85 & 5.156 & 119 \\
\hline ACwrk2 & 3.925 & 1.025 & -0.366 & -0.568 & 1.292 & 15 & 5.147 & 220 \\
\hline ACorg3_r & 3.951 & 1.234 & -0.618 & -0.776 & 1.133 & 34 & 5.088 & 324 \\
\hline ACsup3 & 3.388 & 1.328 & -0.172 & -0.948 & 1.072 & 84 & 5.142 & 175 \\
\hline ACco3 & 4.138 & 1.014 & -0.595 & -0.611 & 1.514 & 17 & 5.112 & 309 \\
\hline ACpt3 & 4.435 & 0.909 & -1.023 & -0.160 & 1.905 & 17 & 5.084 & 426 \\
\hline
\end{tabular}




$\begin{array}{cccccccccc}\text { ACprof3 } & 3.885 & 1.162 & -0.461 & -0.762 & 1.174 & 27 & 5.114 & 266 \\ \text { ACwrk3 } & 3.105 & 1.091 & -0.037 & -0.430 & 0.967 & 52 & 5.187 & 58 \\ \text { ACtsk3_R } & 3.930 & 1.109 & -0.464 & -0.714 & 1.150 & 18 & 5.108 & 265 \\ \text { ACcar3 } & 4.266 & 0.804 & -0.567 & -0.560 & 1.713 & 4 & 5.047 & 309 \\ \text { OCBI1 } & 4.064 & 0.817 & -0.320 & -0.424 & 1.735 & 8 & 5.076 & 211 \\ \text { OCBI2 } & 4.132 & 0.765 & -0.326 & -0.581 & 1.661 & 3 & 5.033 & 233 \\ \text { OCBI3 } & 3.697 & 0.897 & -0.155 & -0.332 & 1.341 & 12 & 5.076 & 125 \\ \text { OCBI4 } & 4.420 & 0.735 & -0.715 & -0.410 & 2.118 & 6 & 5.055 & 360 \\ \text { OCBI5 } & 4.413 & 0.664 & -0.601 & -0.510 & 2.071 & 2 & 5.025 & 338 \\ \text { OCBI6 } & 3.923 & 0.864 & -0.247 & -0.503 & 1.491 & 8 & 5.057 & 185 \\ \text { OCBI7 } & 4.200 & 0.728 & -0.341 & -0.587 & 1.896 & 4 & 5.035 & 247 \\ \text { OCBI8 } & 3.386 & 1.156 & -0.130 & -0.630 & 1.093 & 50 & 5.134 & 125 \\ \text { OCBO1 } & 2.964 & 1.006 & -0.006 & -0.309 & 1.046 & 59 & 5.164 & 32 \\ \text { OCBO2 } & 3.889 & 0.791 & -0.205 & -0.191 & 1.375 & 3 & 5.070 & 141 \\ \text { OCBO5 } & 3.629 & 0.917 & -0.144 & -0.336 & 1.200 & 11 & 5.068 & 117 \\ \text { OCBO3 } & 3.232 & 0.980 & -0.042 & -0.241 & 1.131 & 36 & 5.070 & 64 \\ \text { OCBO4 } & 3.938 & 0.966 & -0.351 & -0.583 & 1.435 & 14 & 5.094 & 218 \\ \text { OCBO } & 3.692 & 0.989 & -0.211 & -0.497 & 1.196 & 15 & 5.082 & 154\end{array}$




\section{Appendix T. Normality}

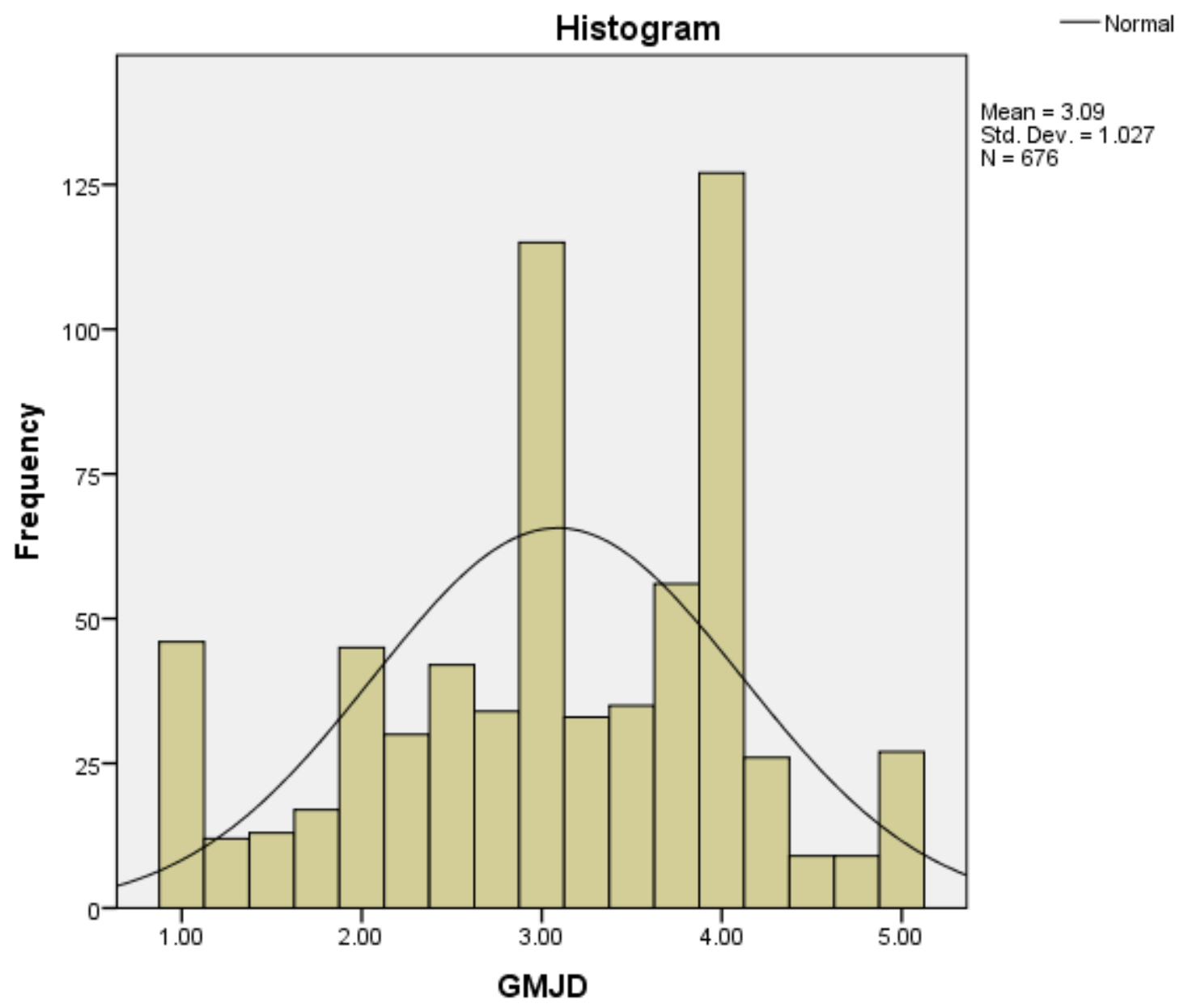




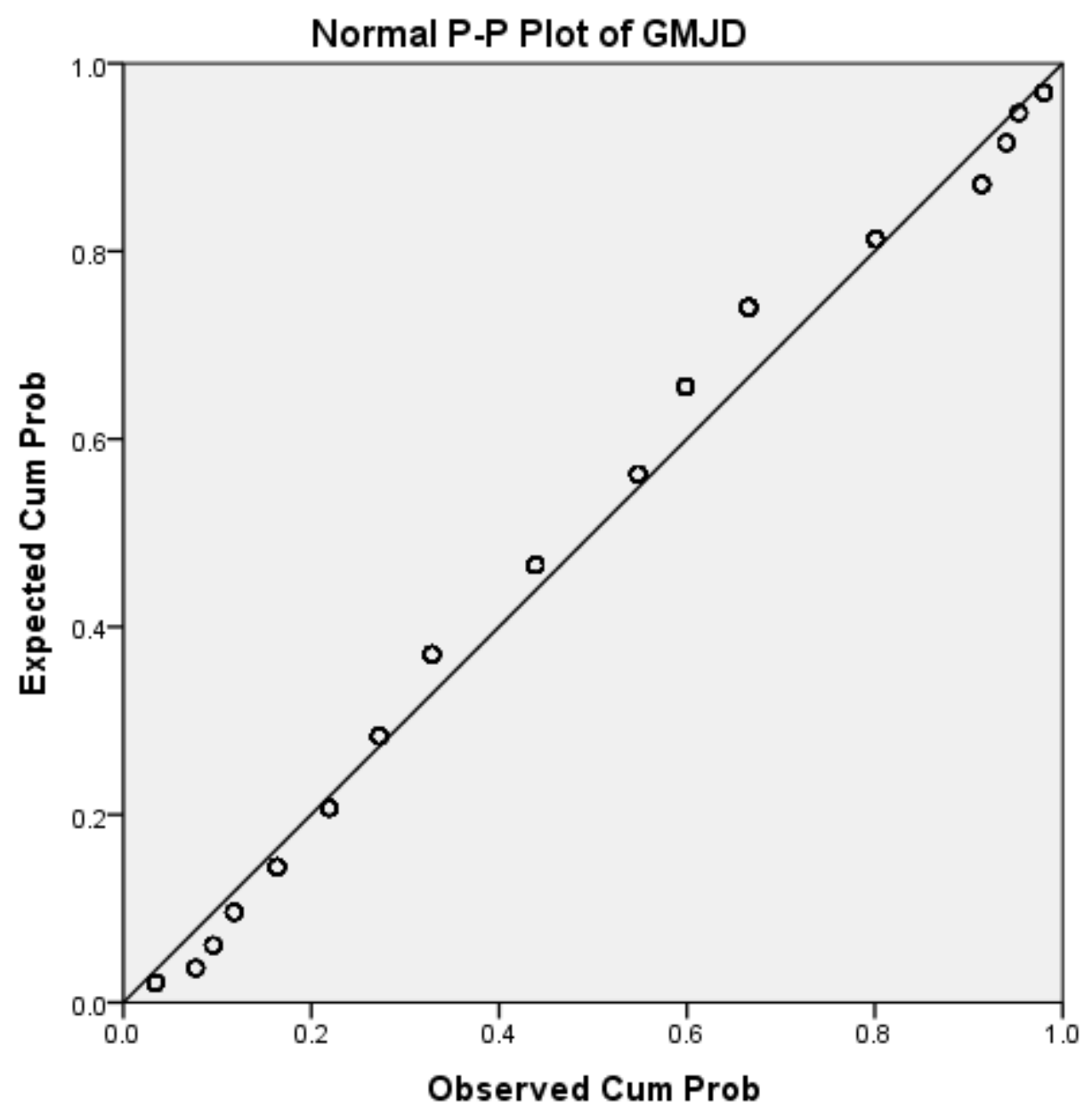




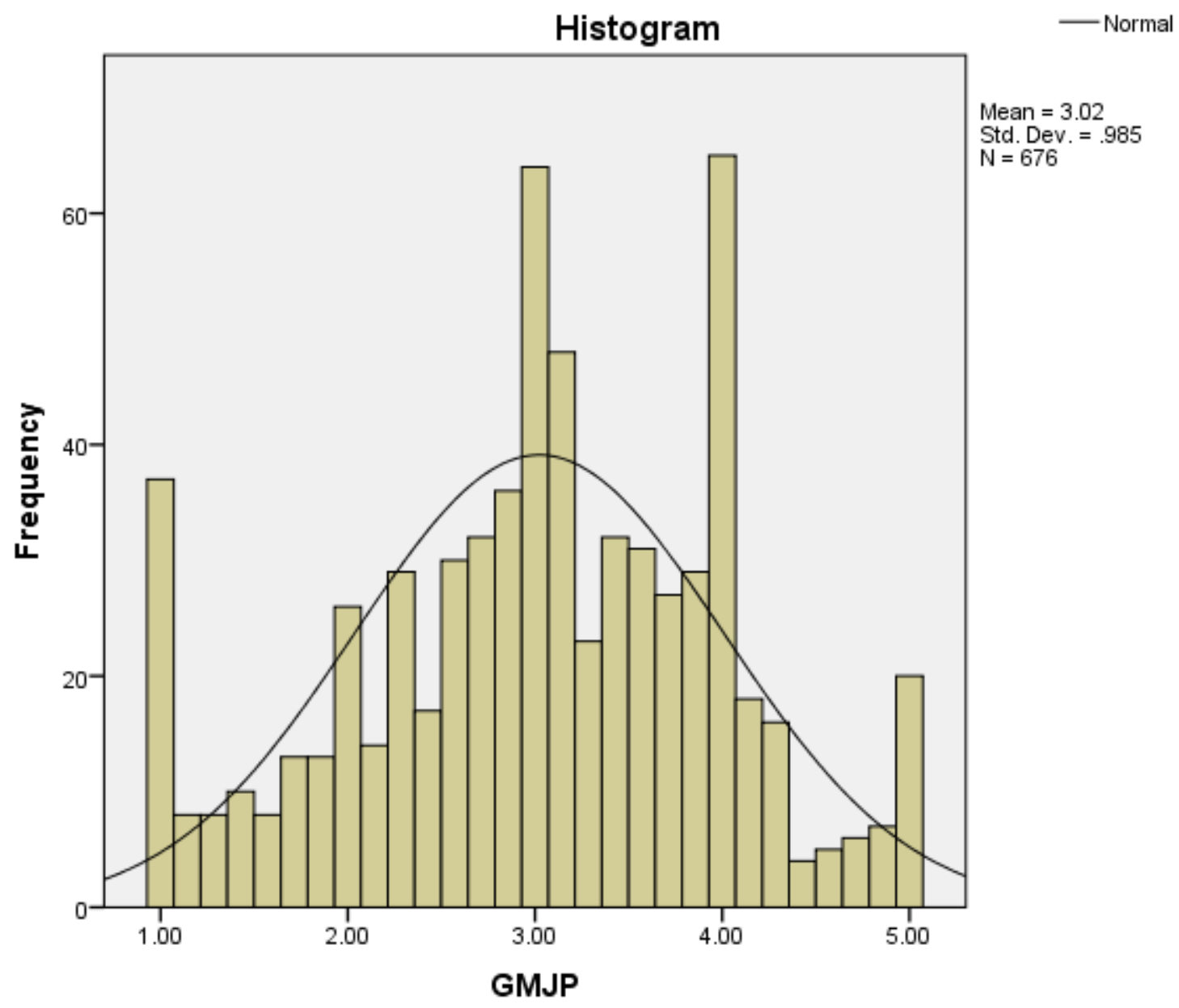




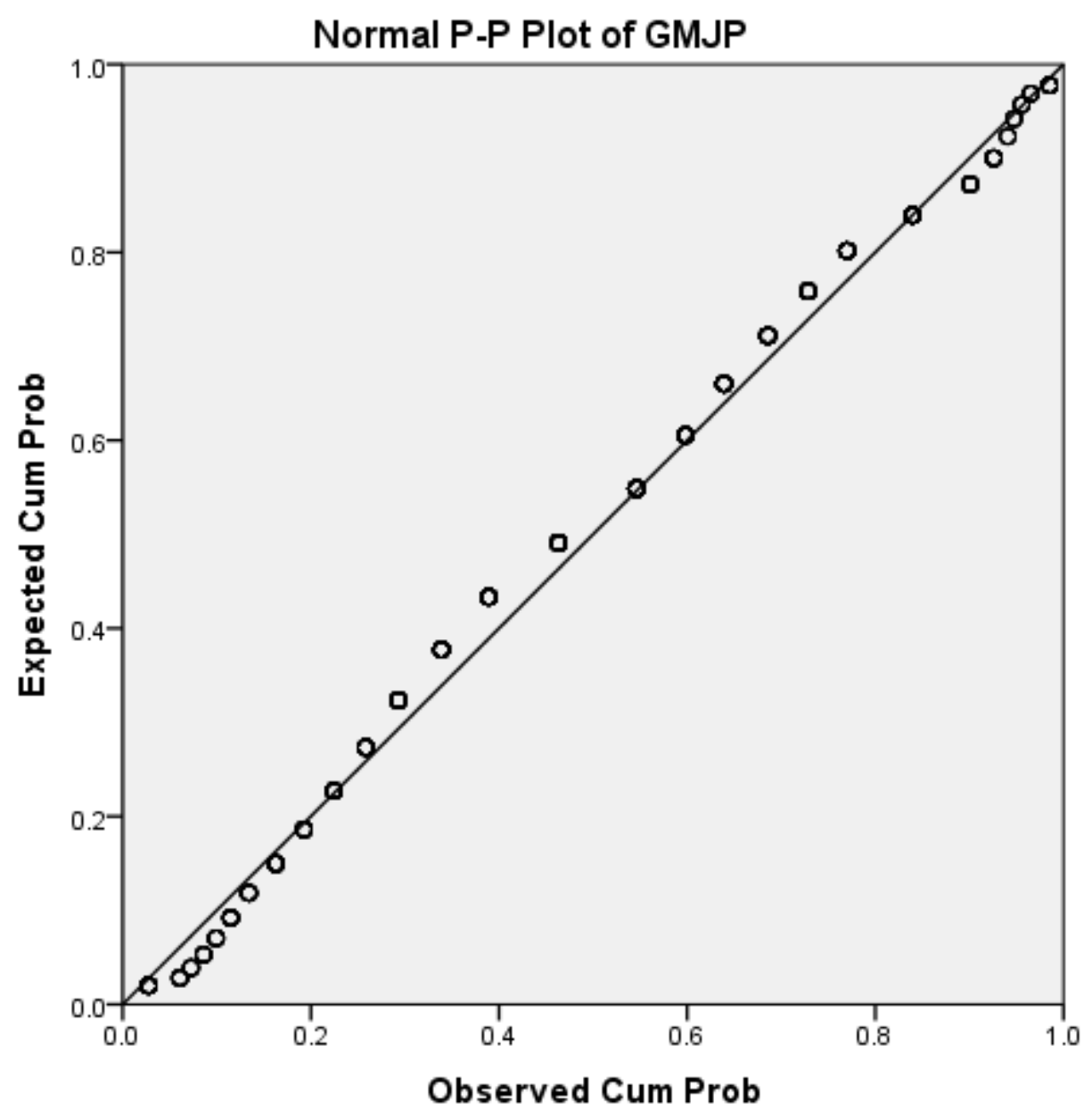




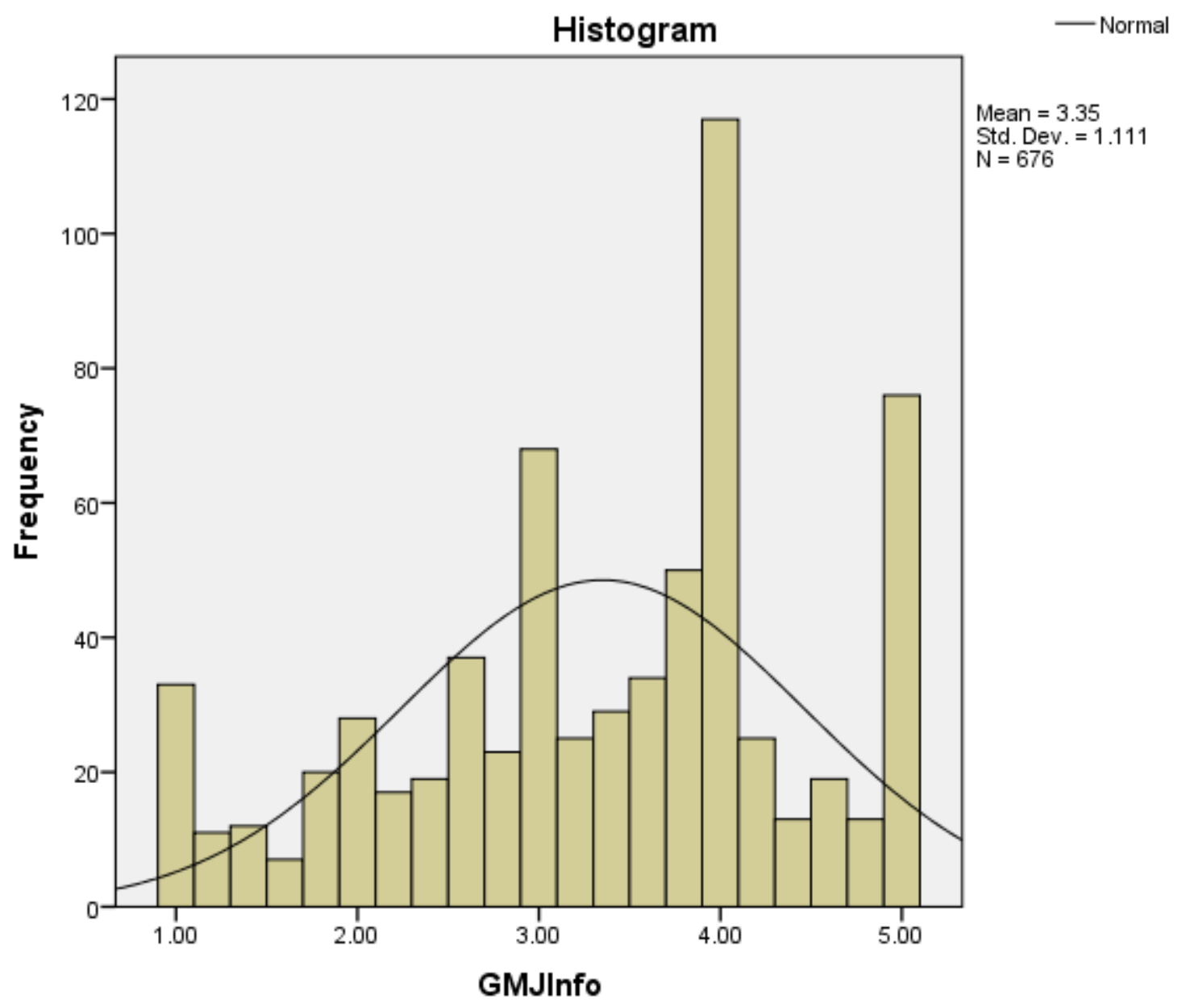




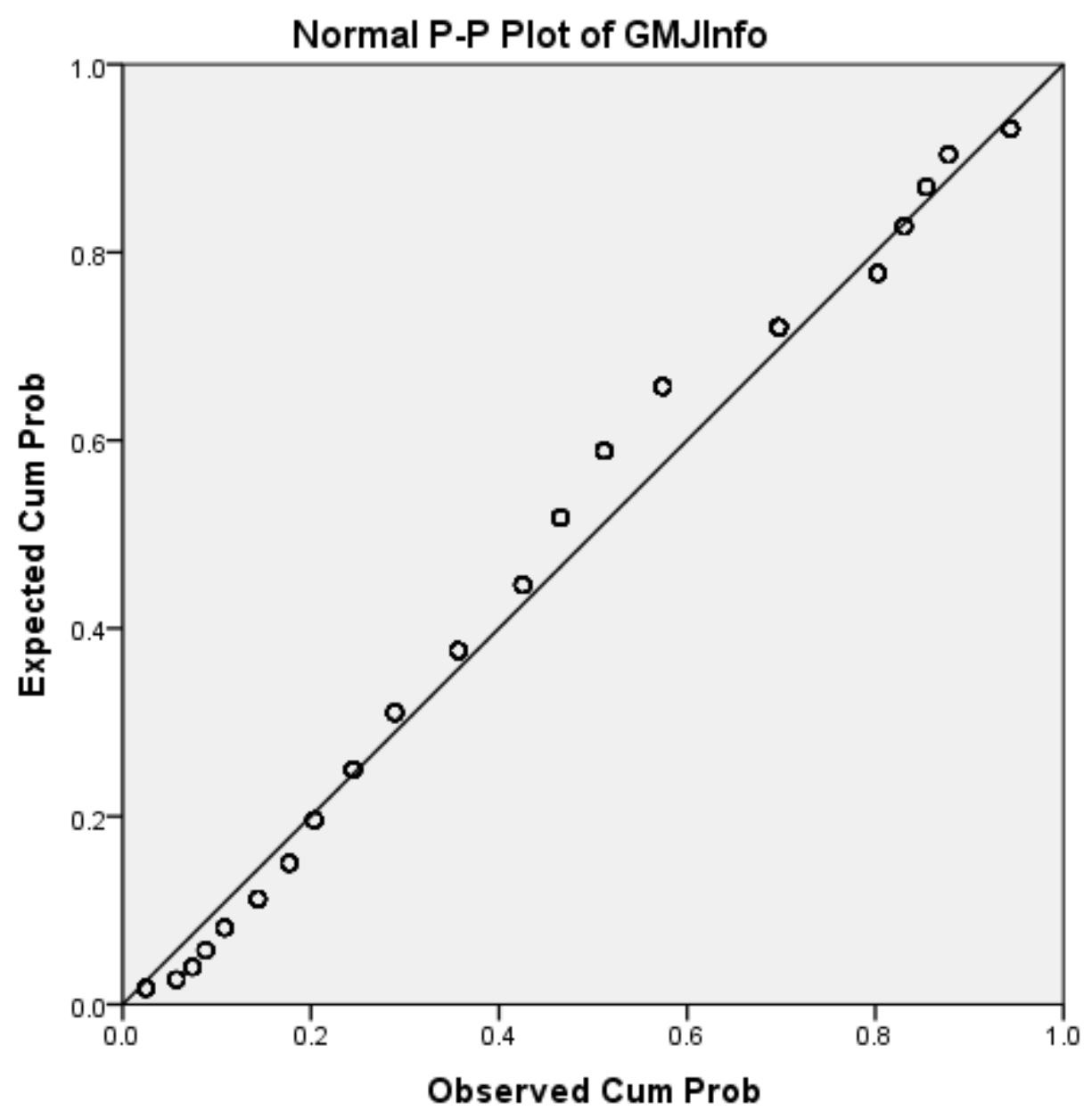




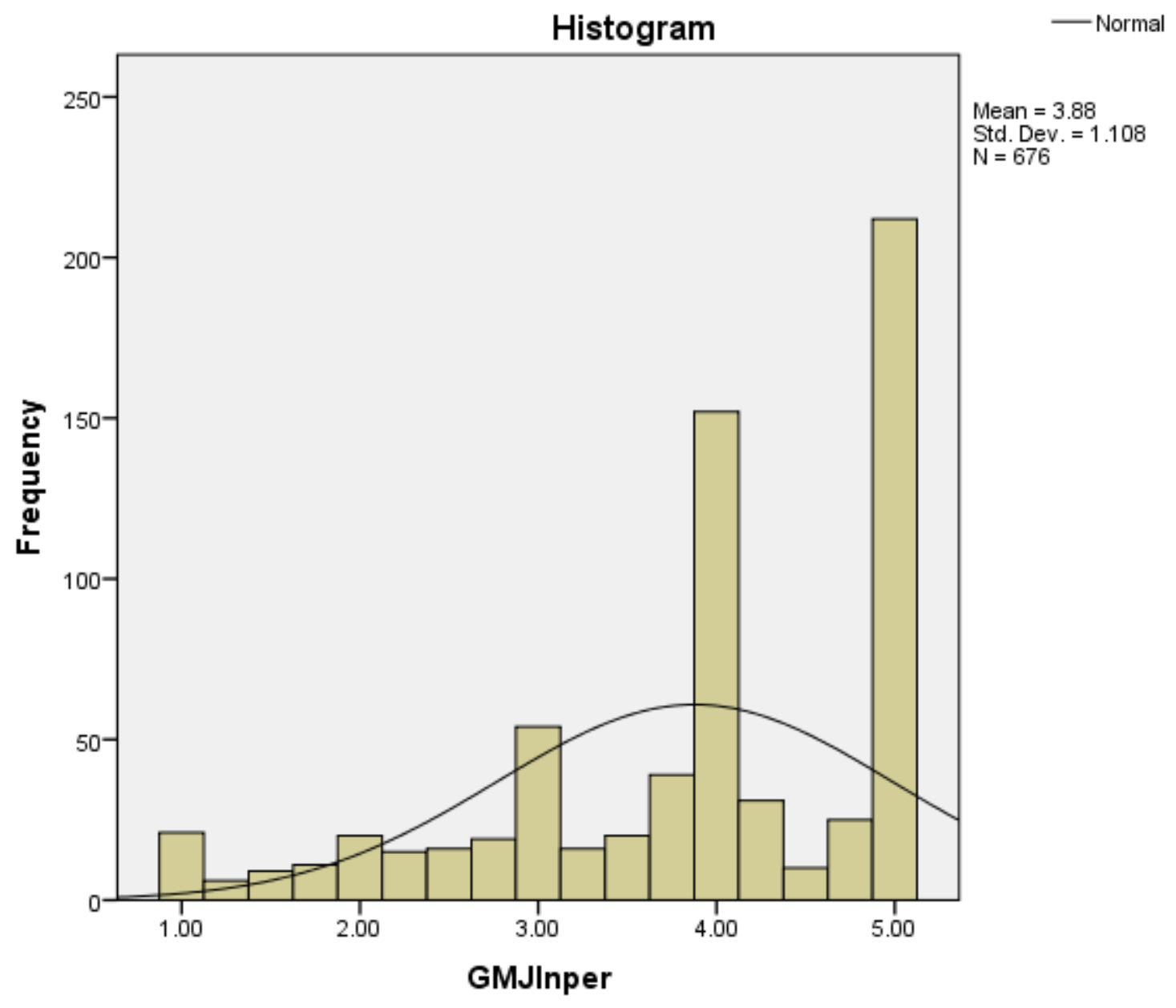




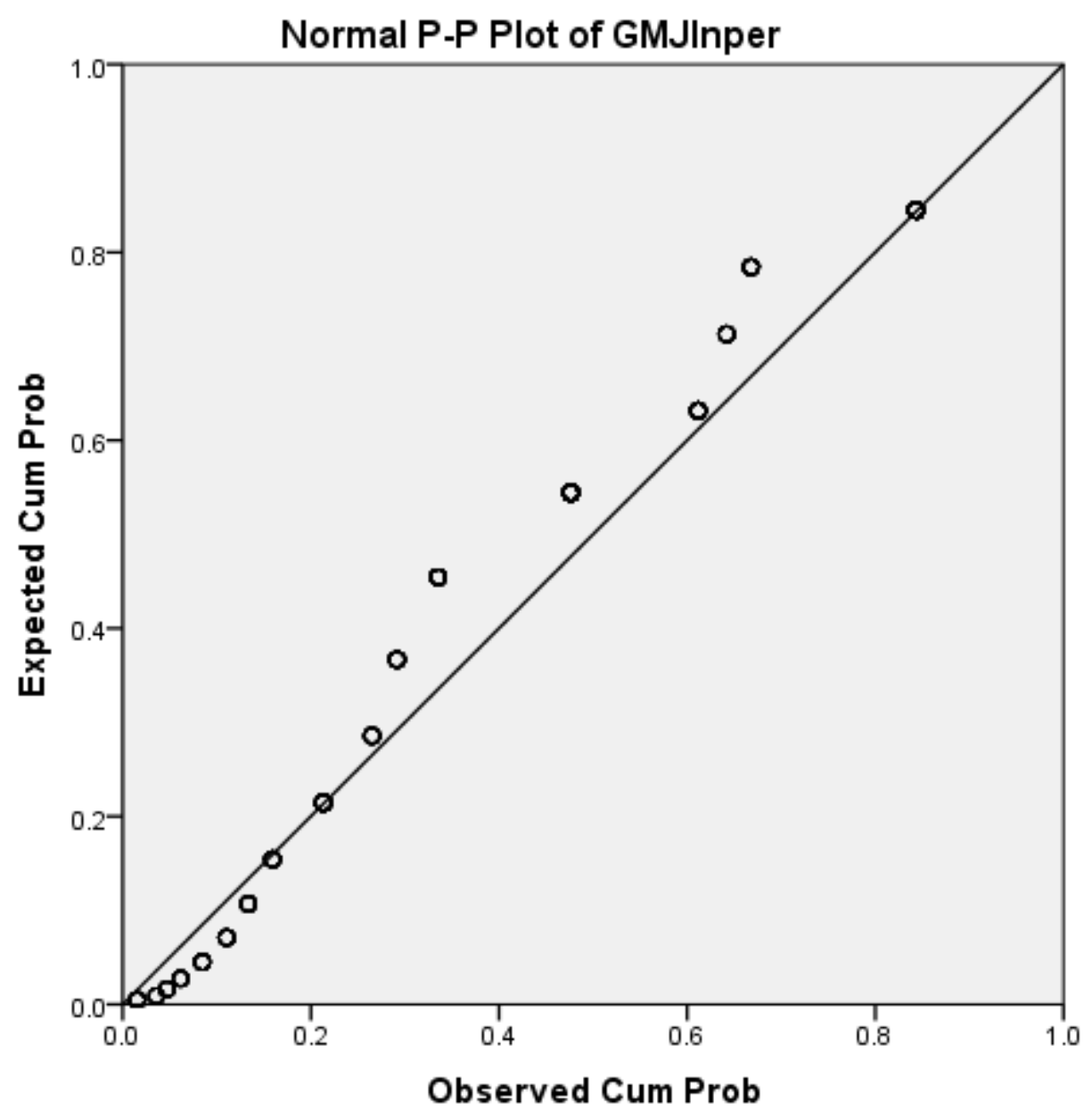




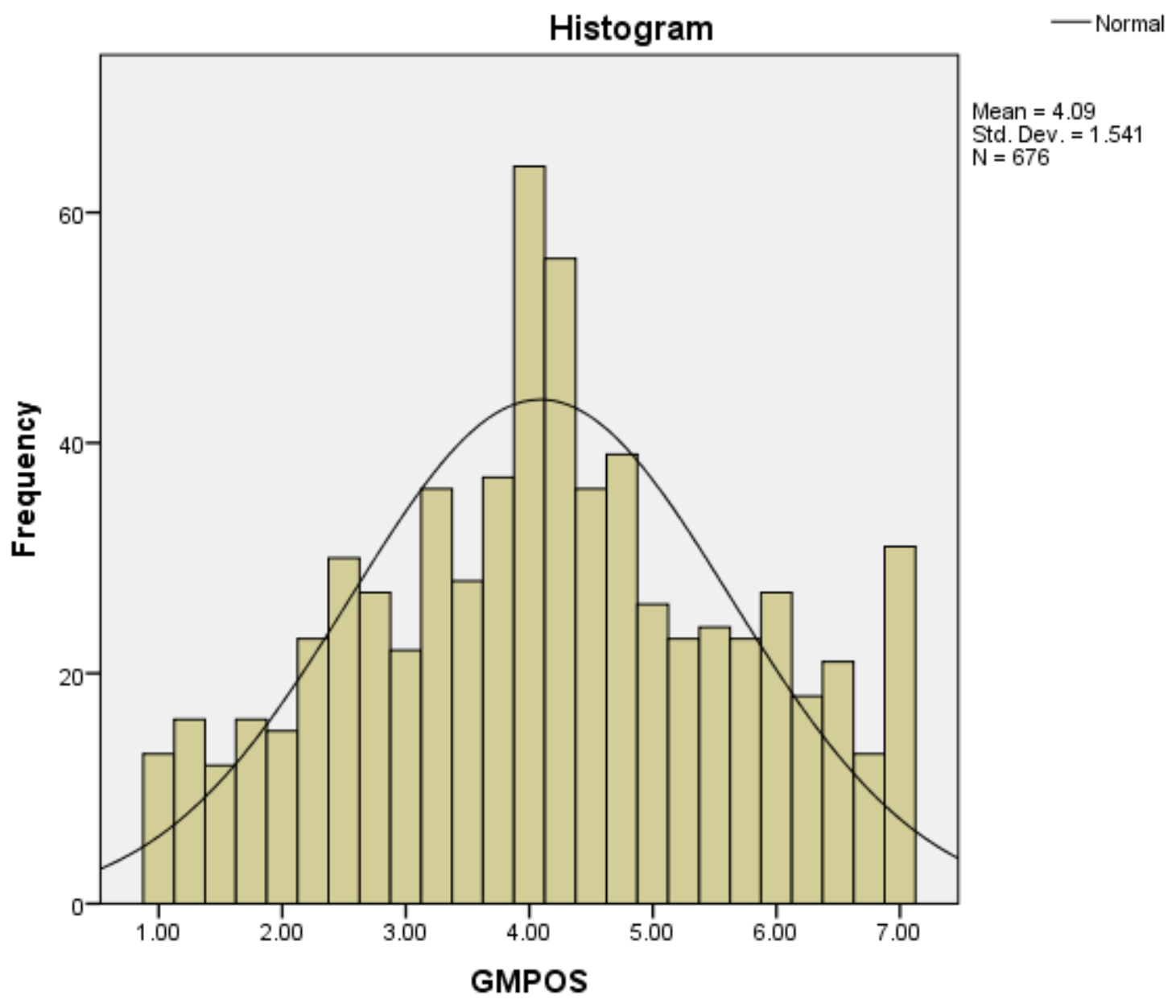




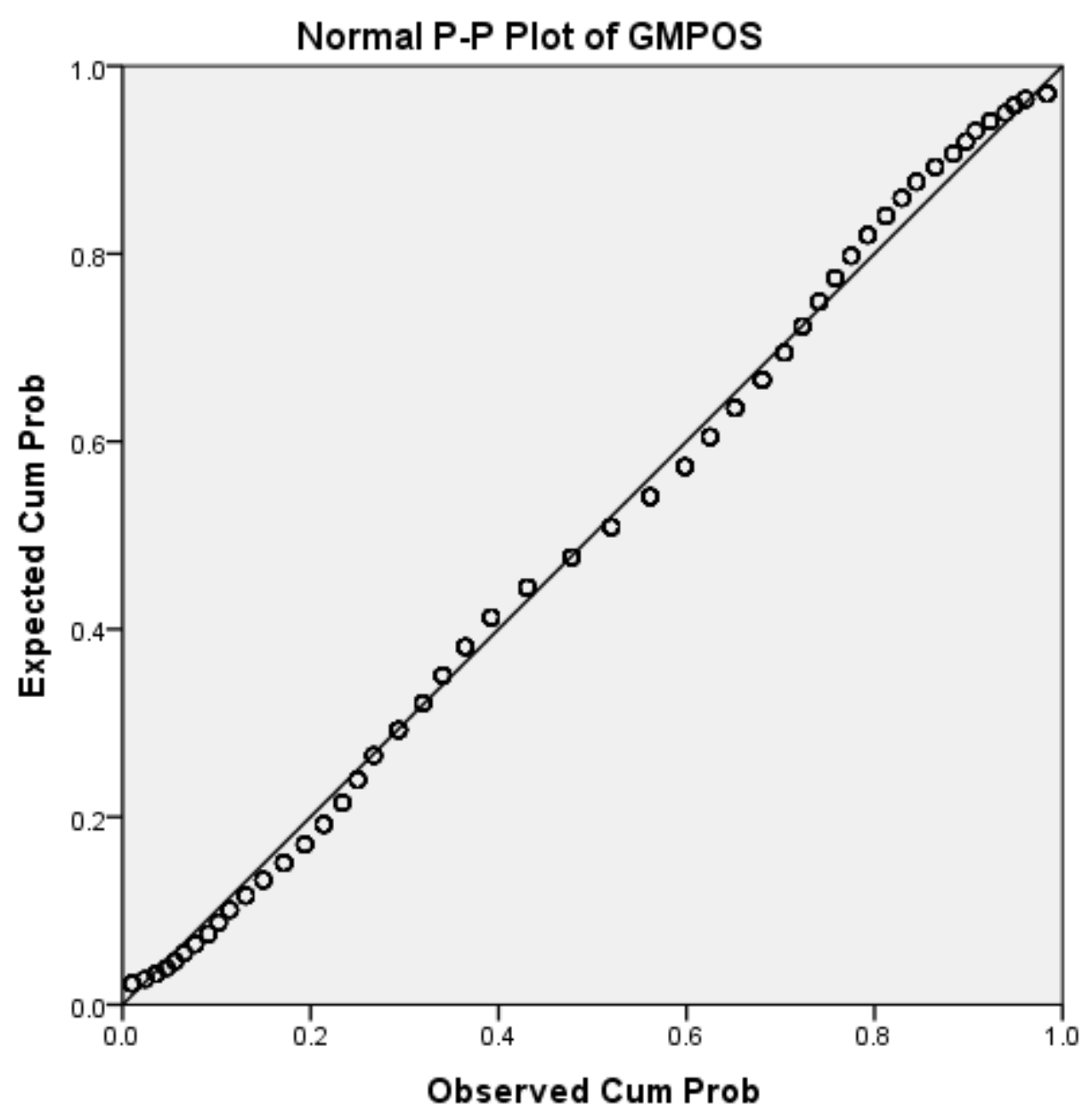




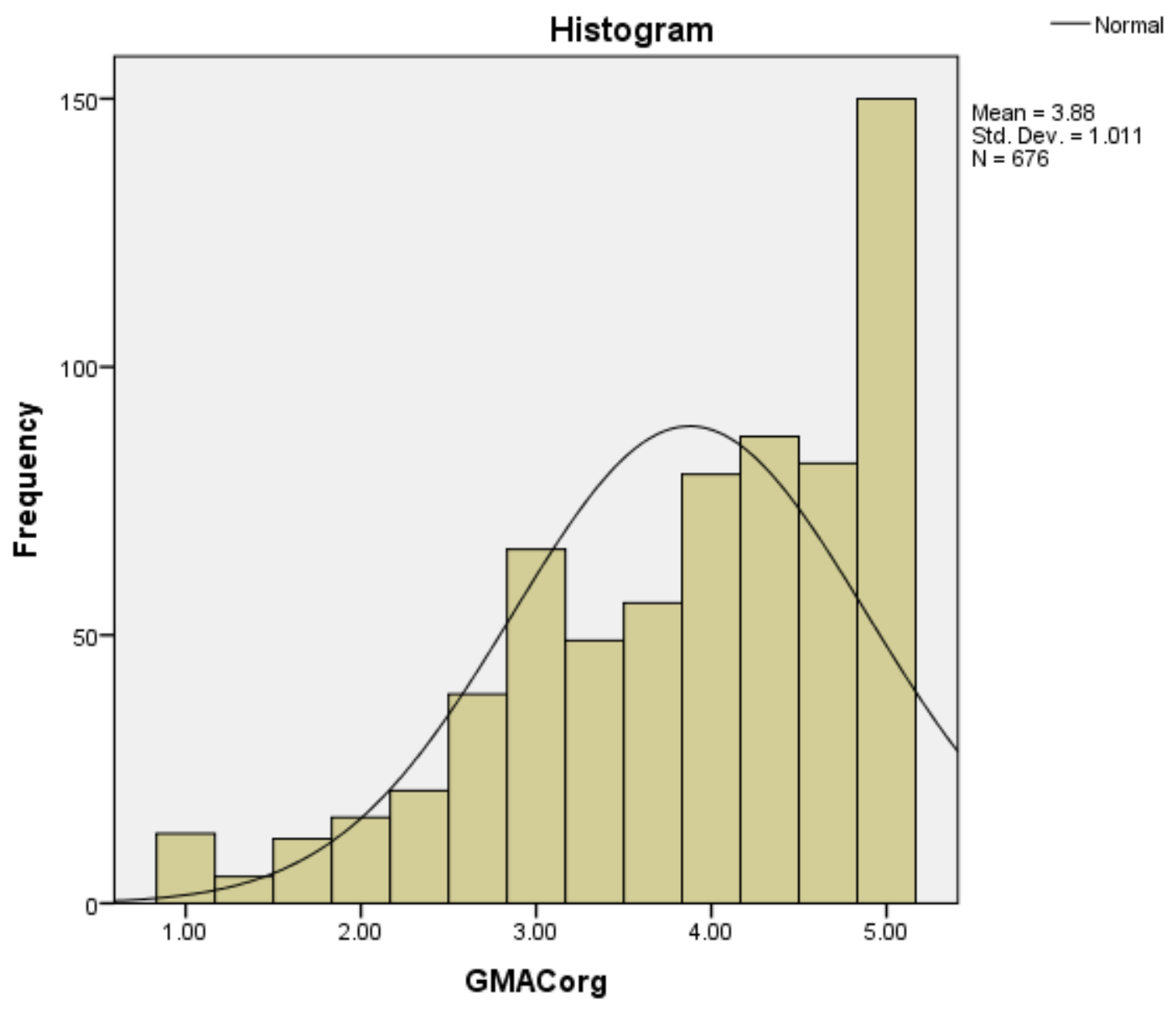




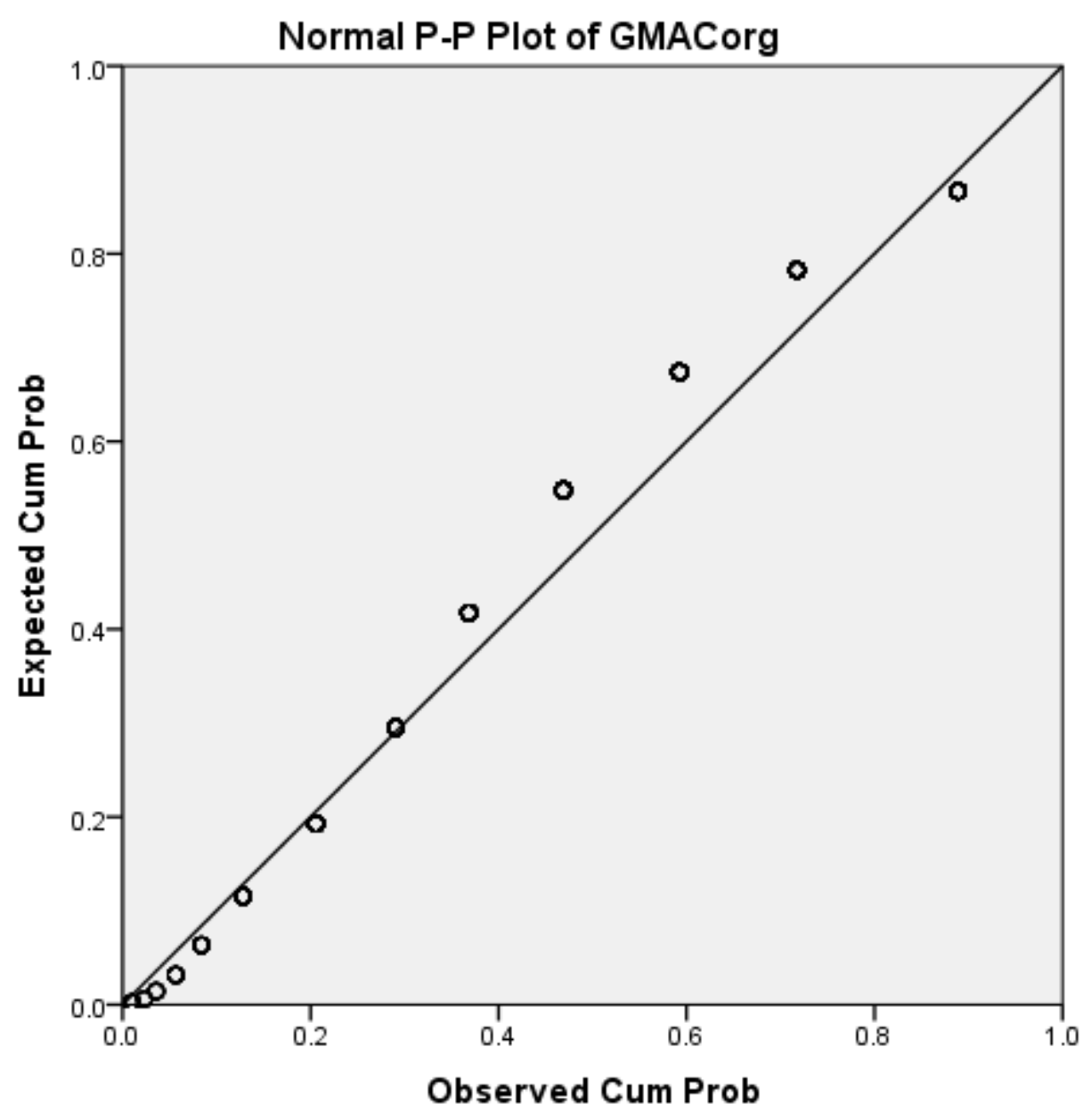




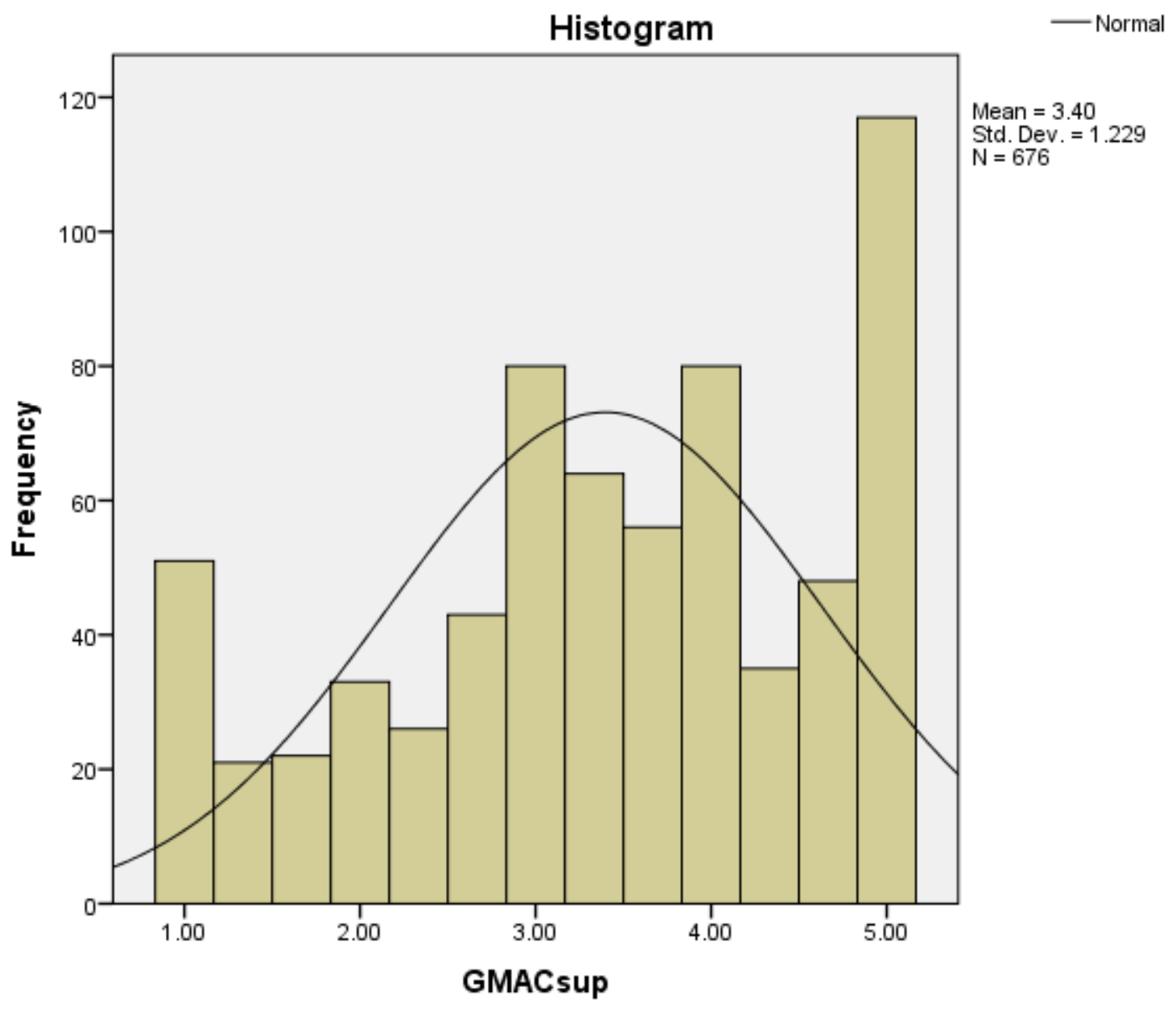




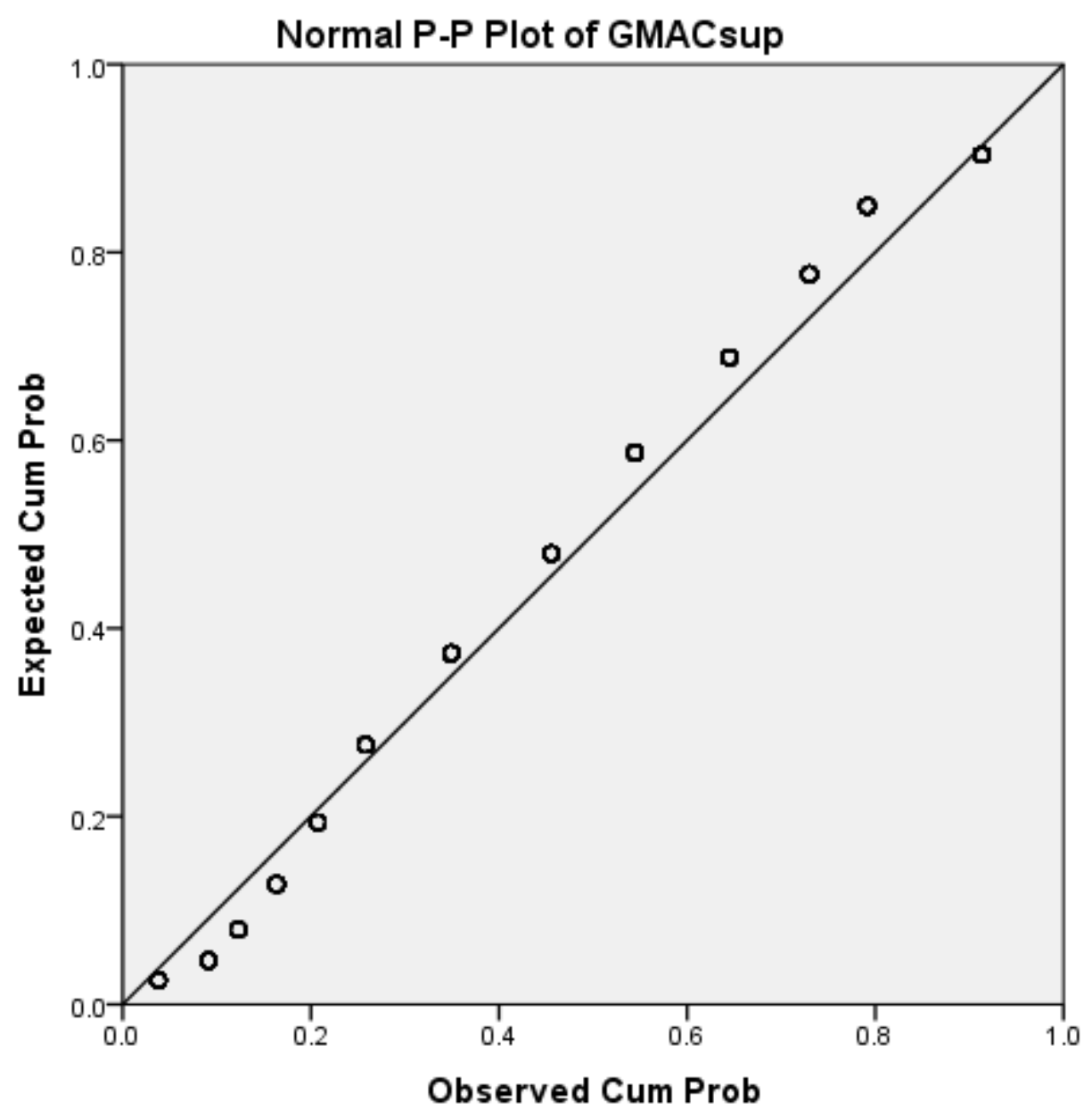




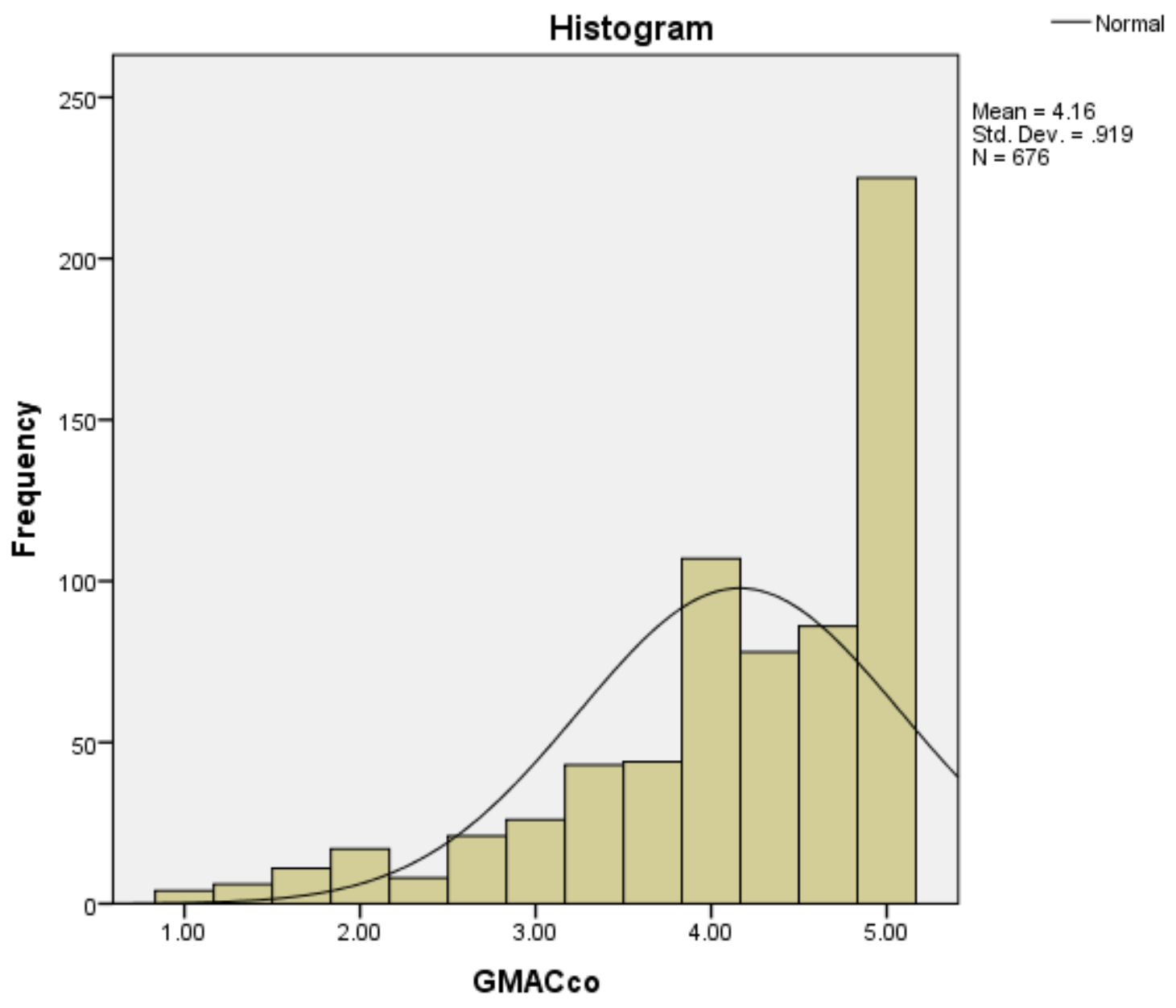




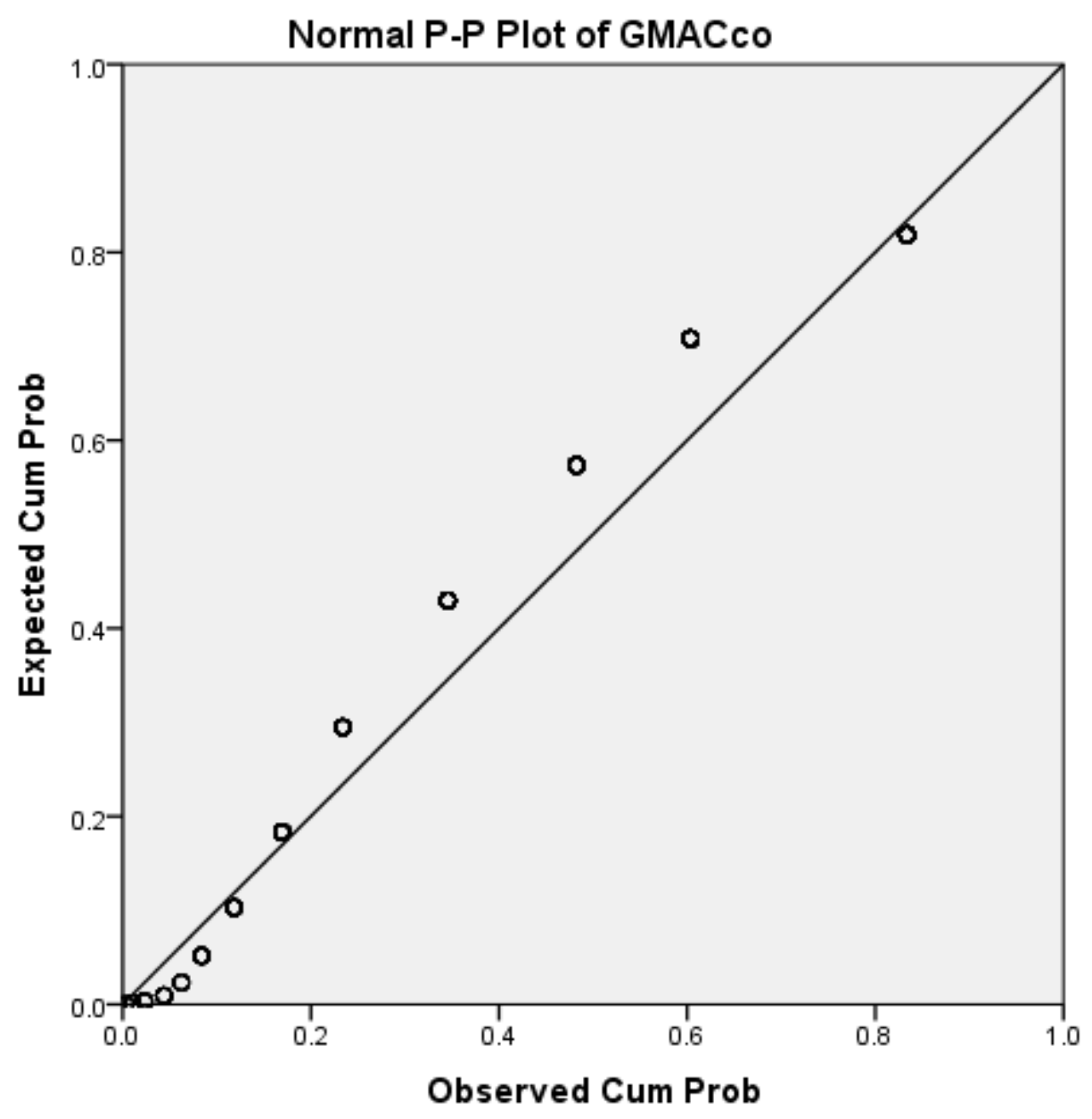




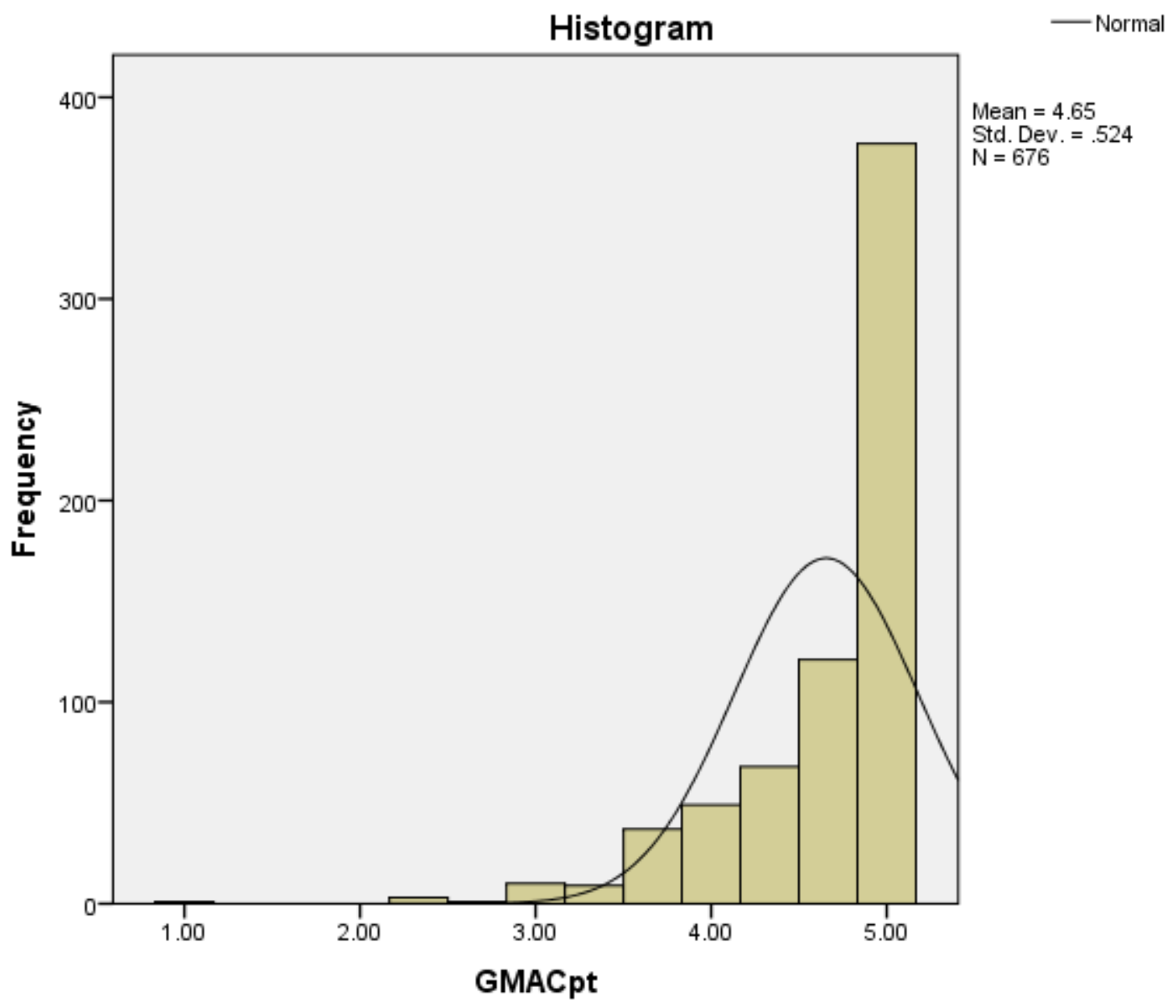




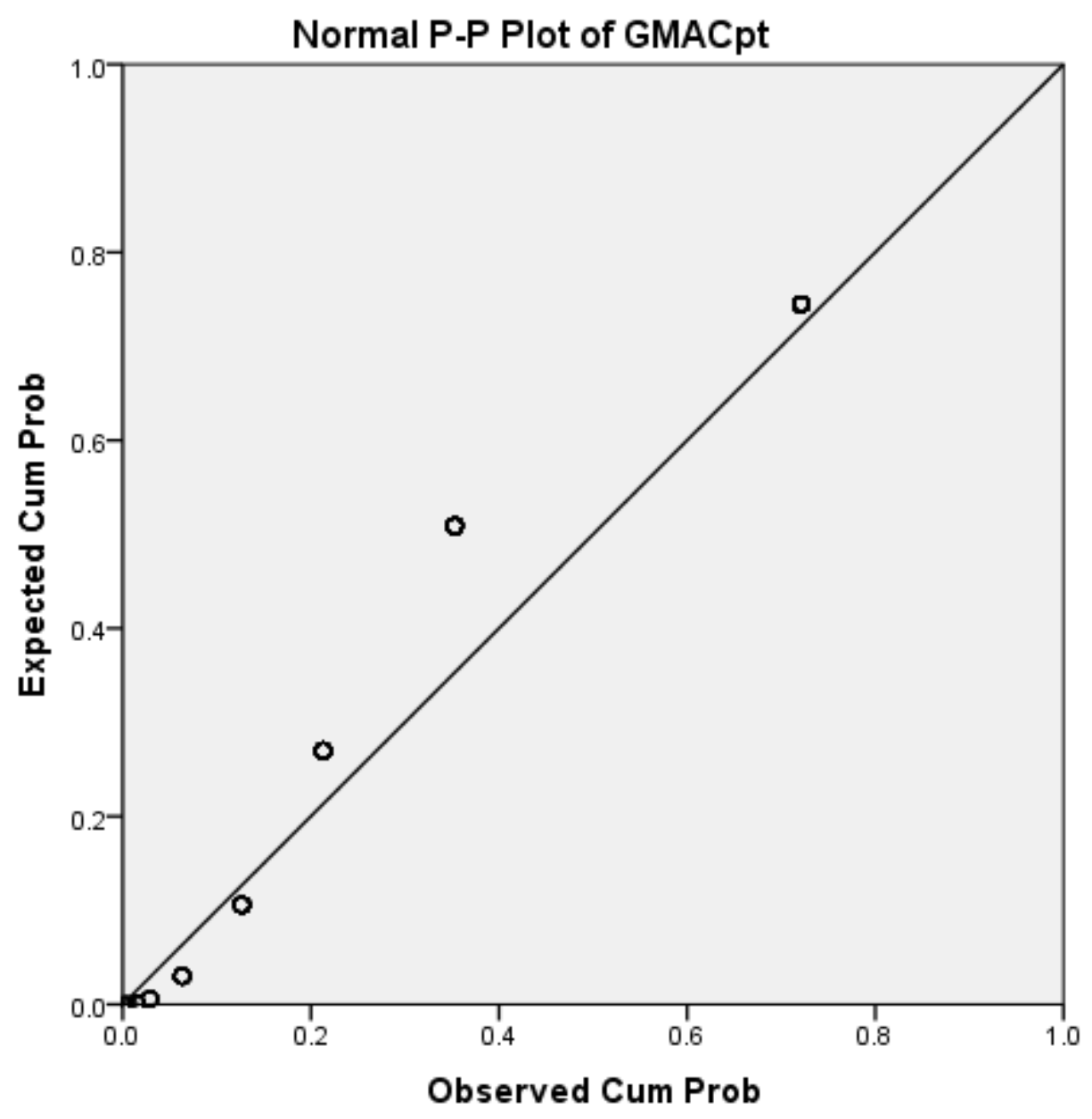




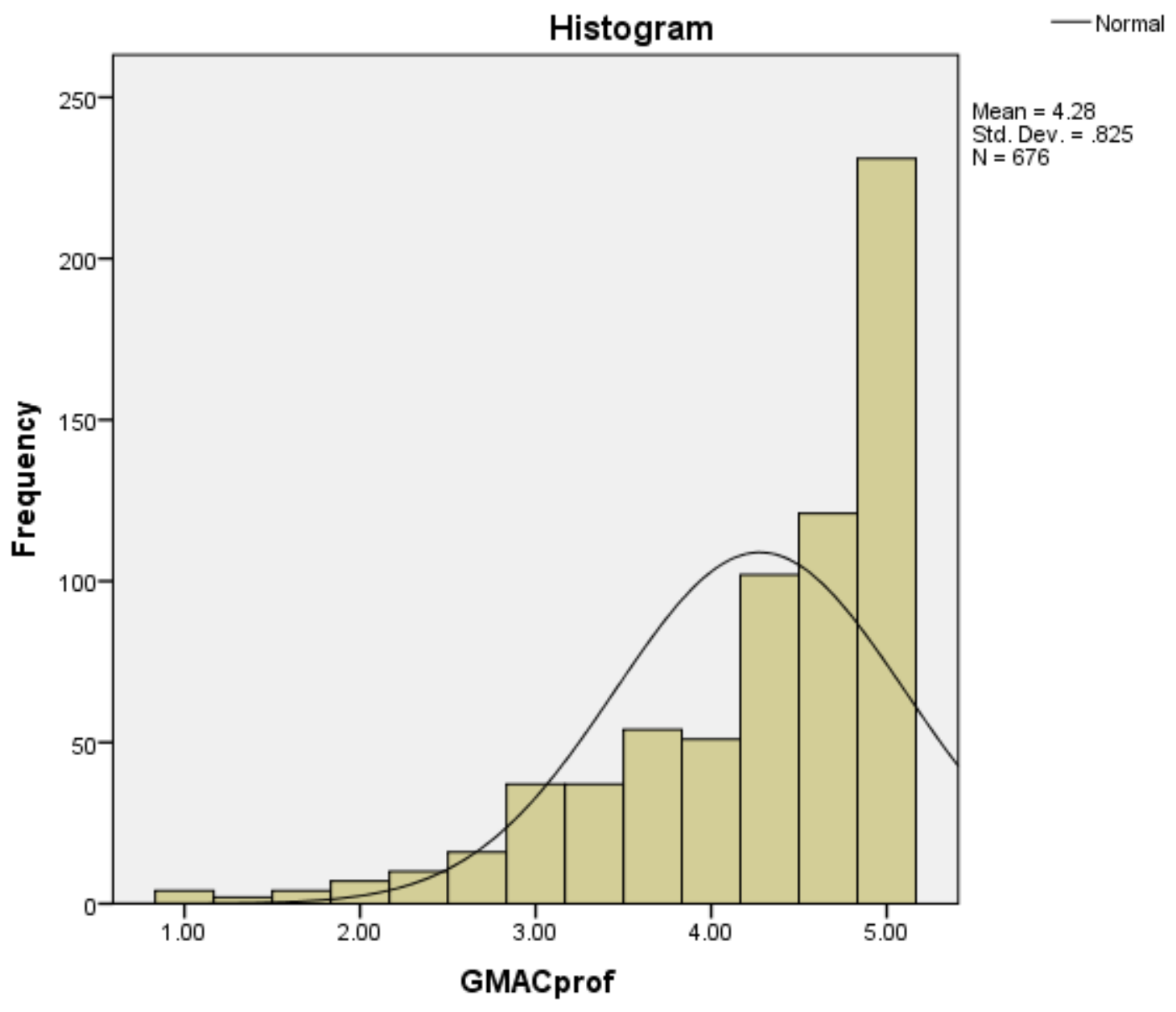




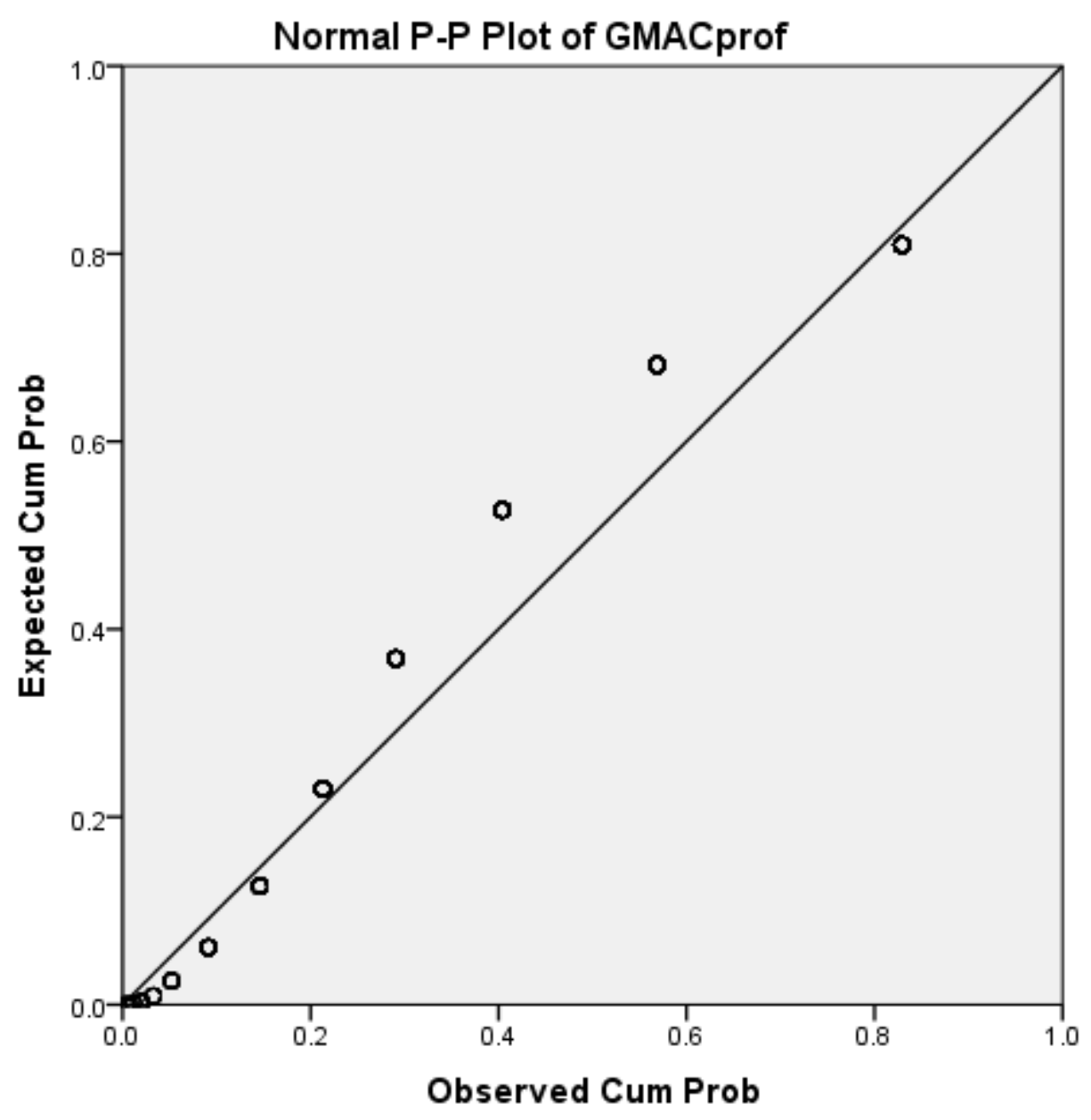




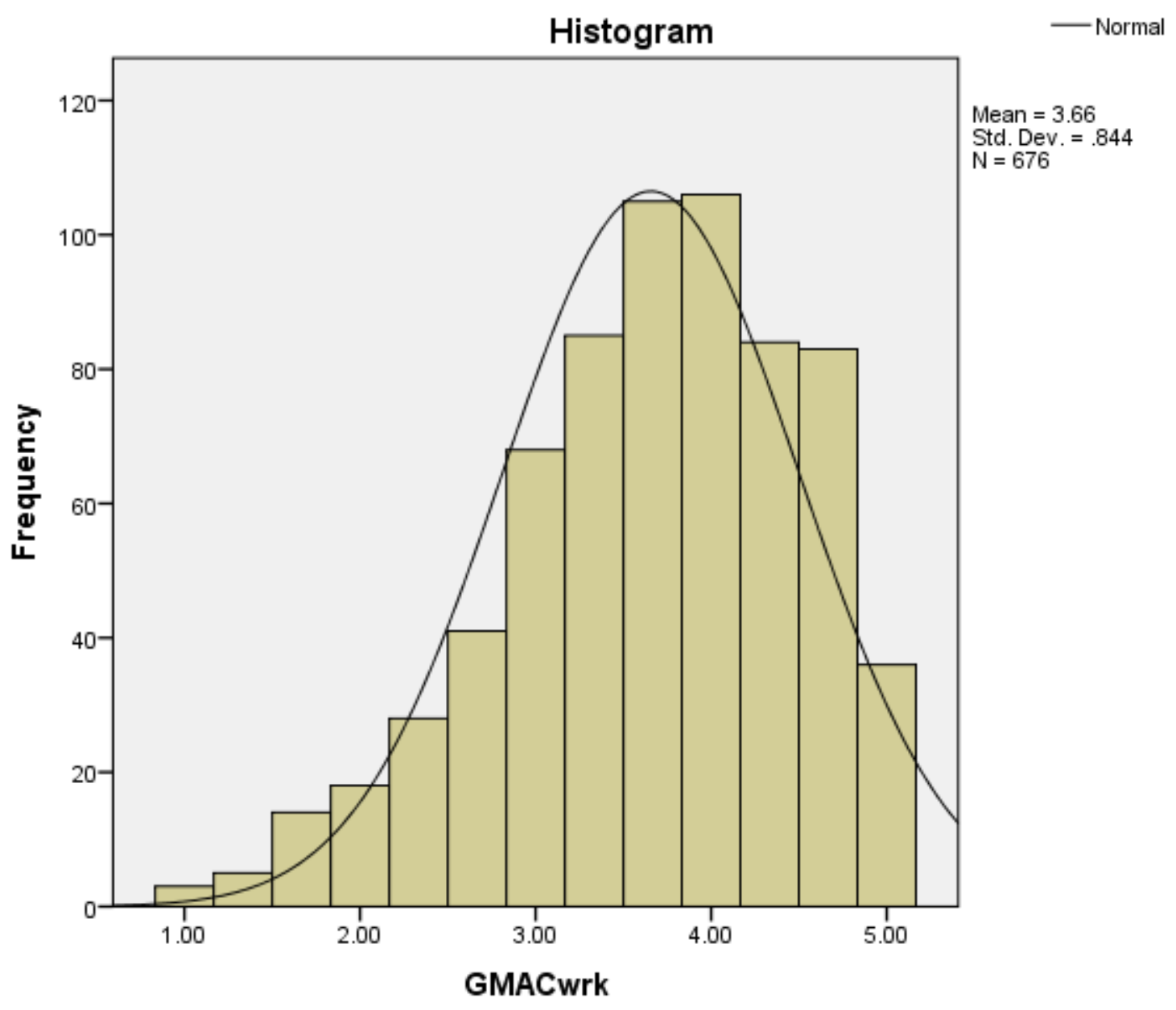




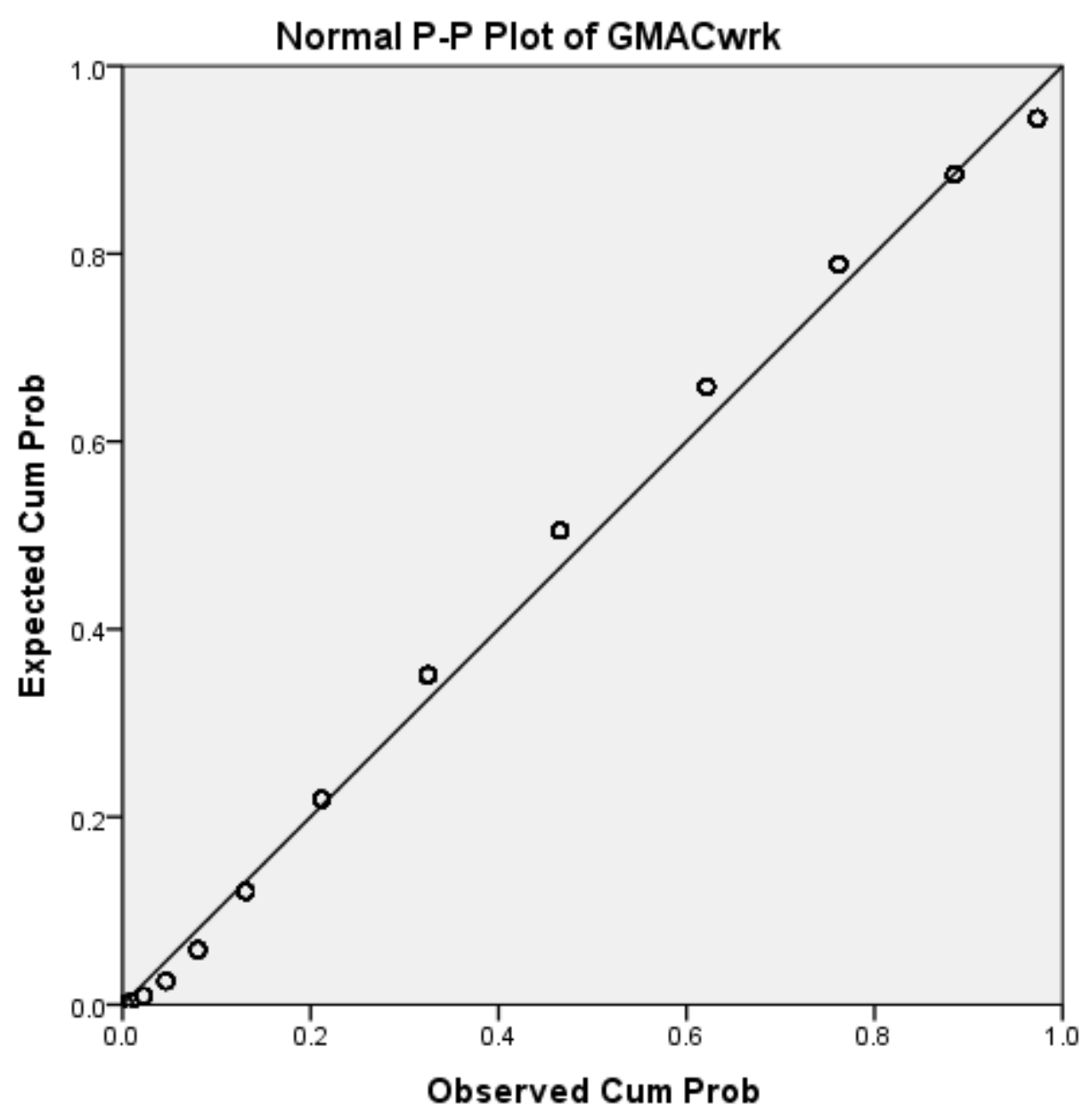




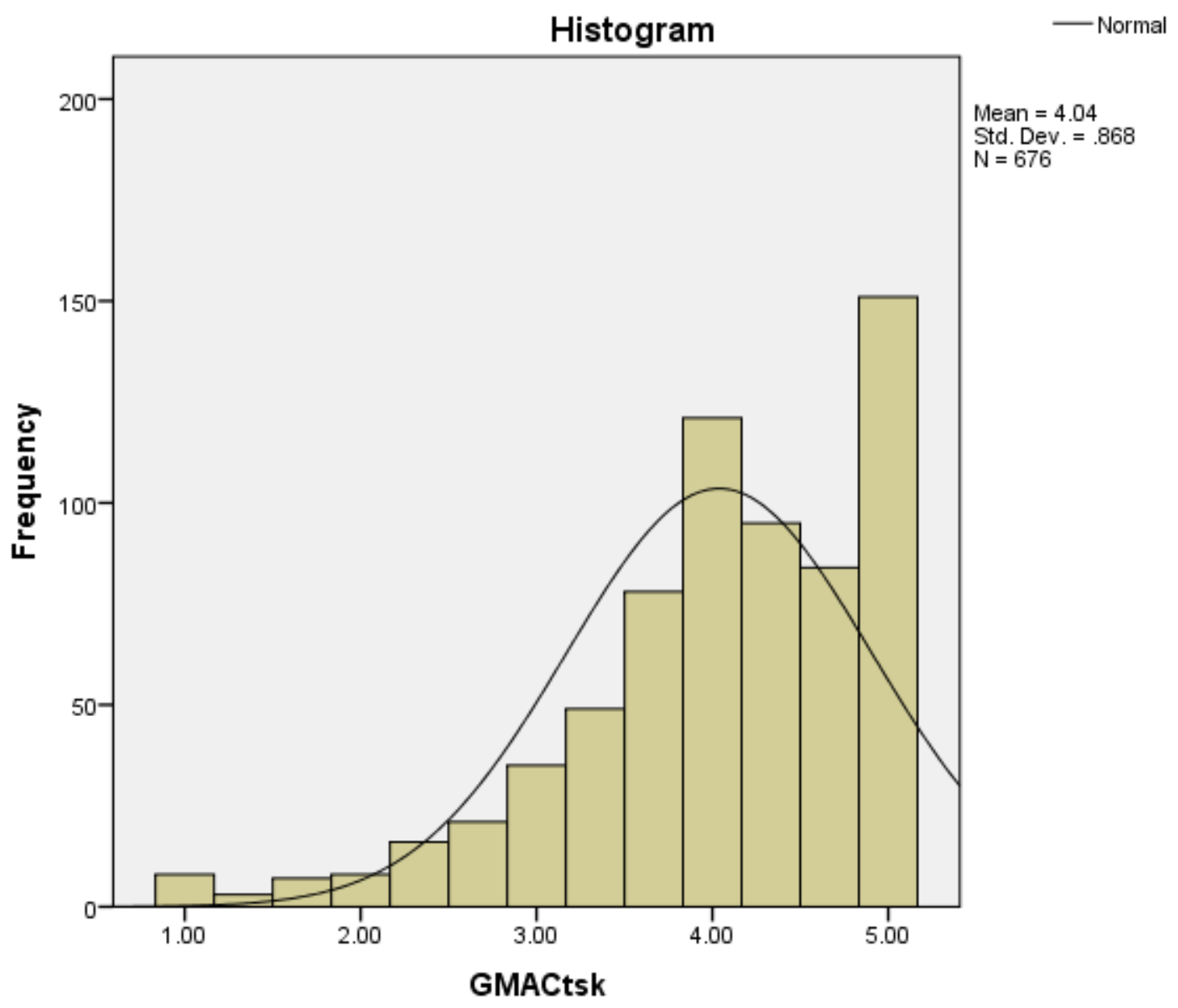




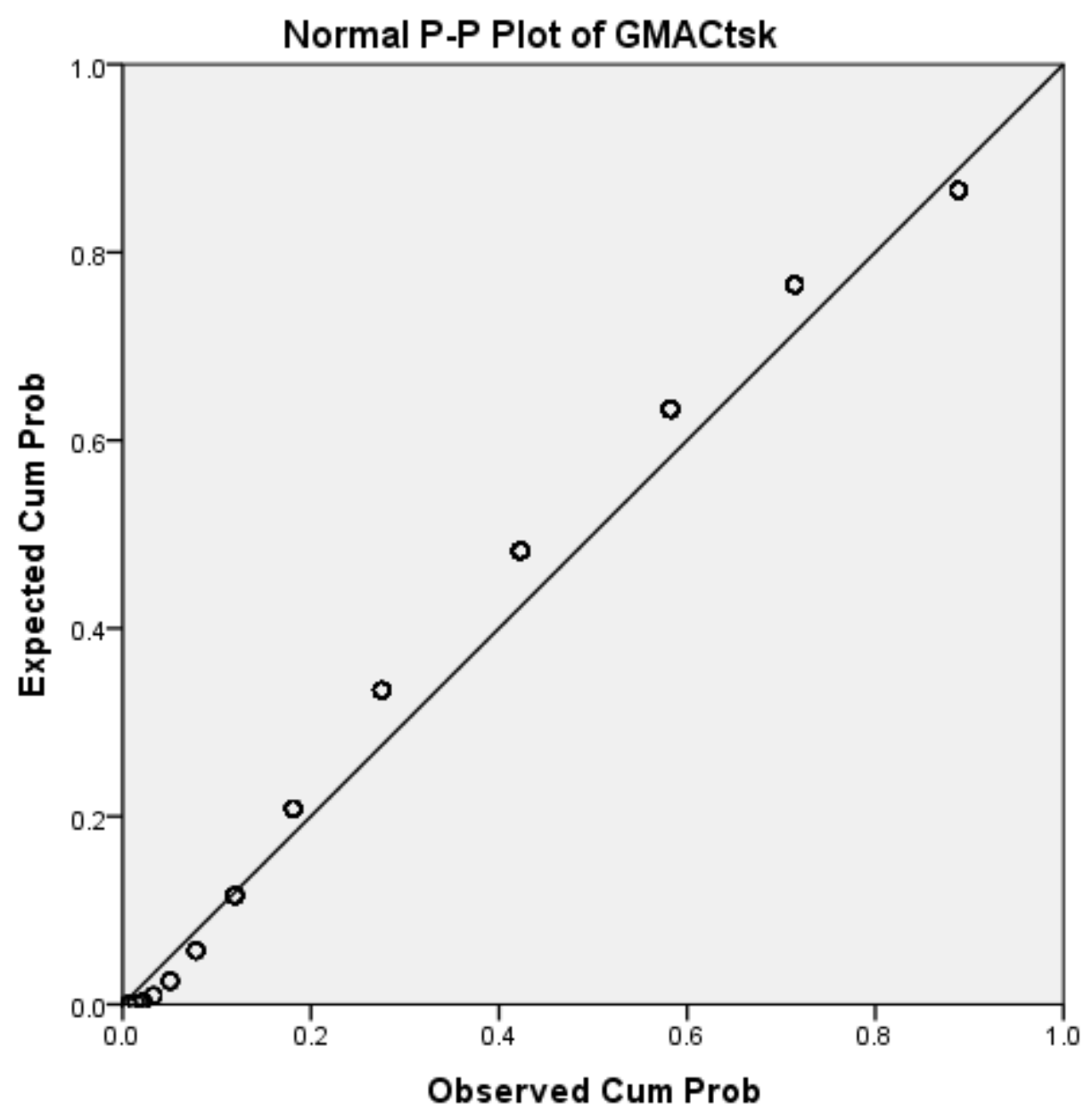




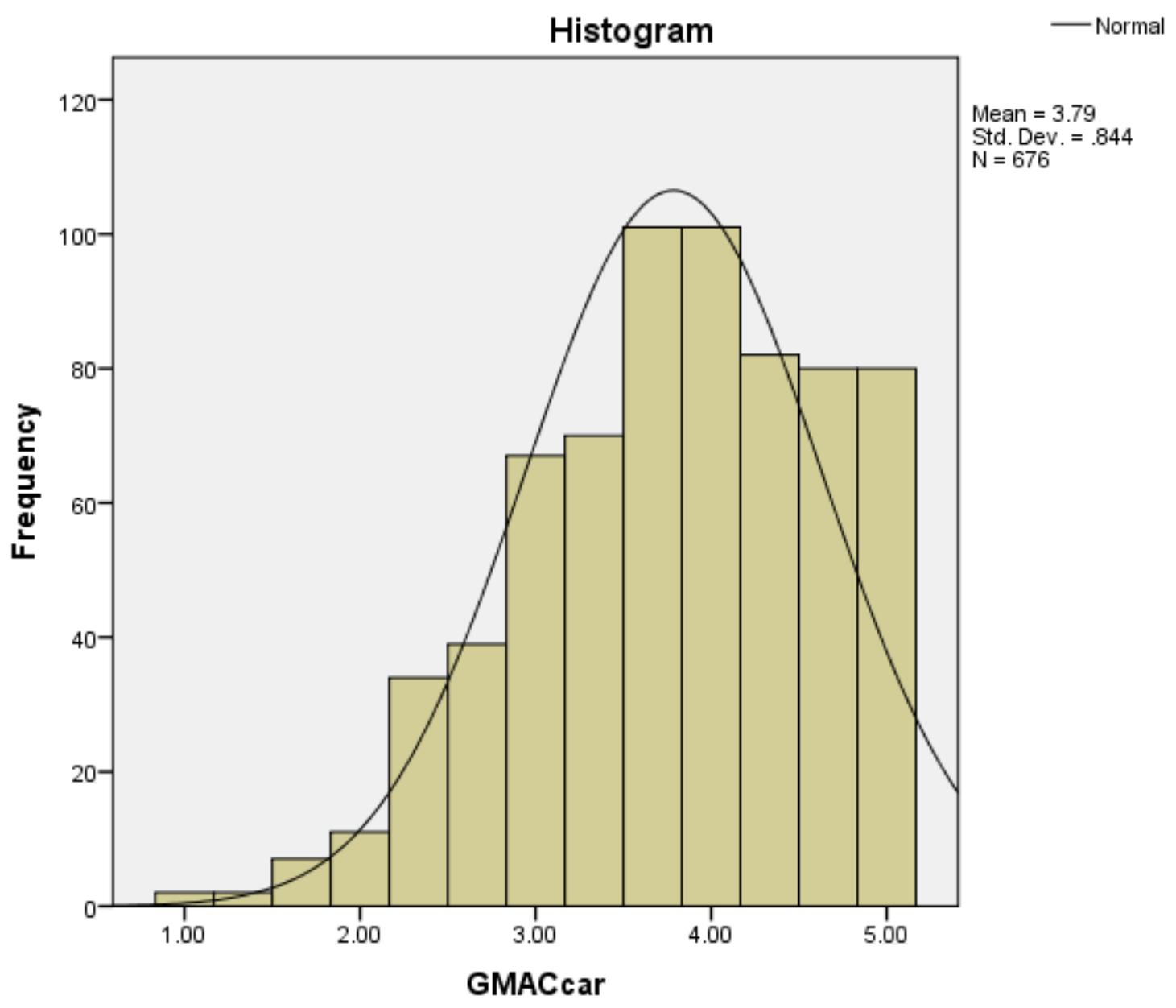




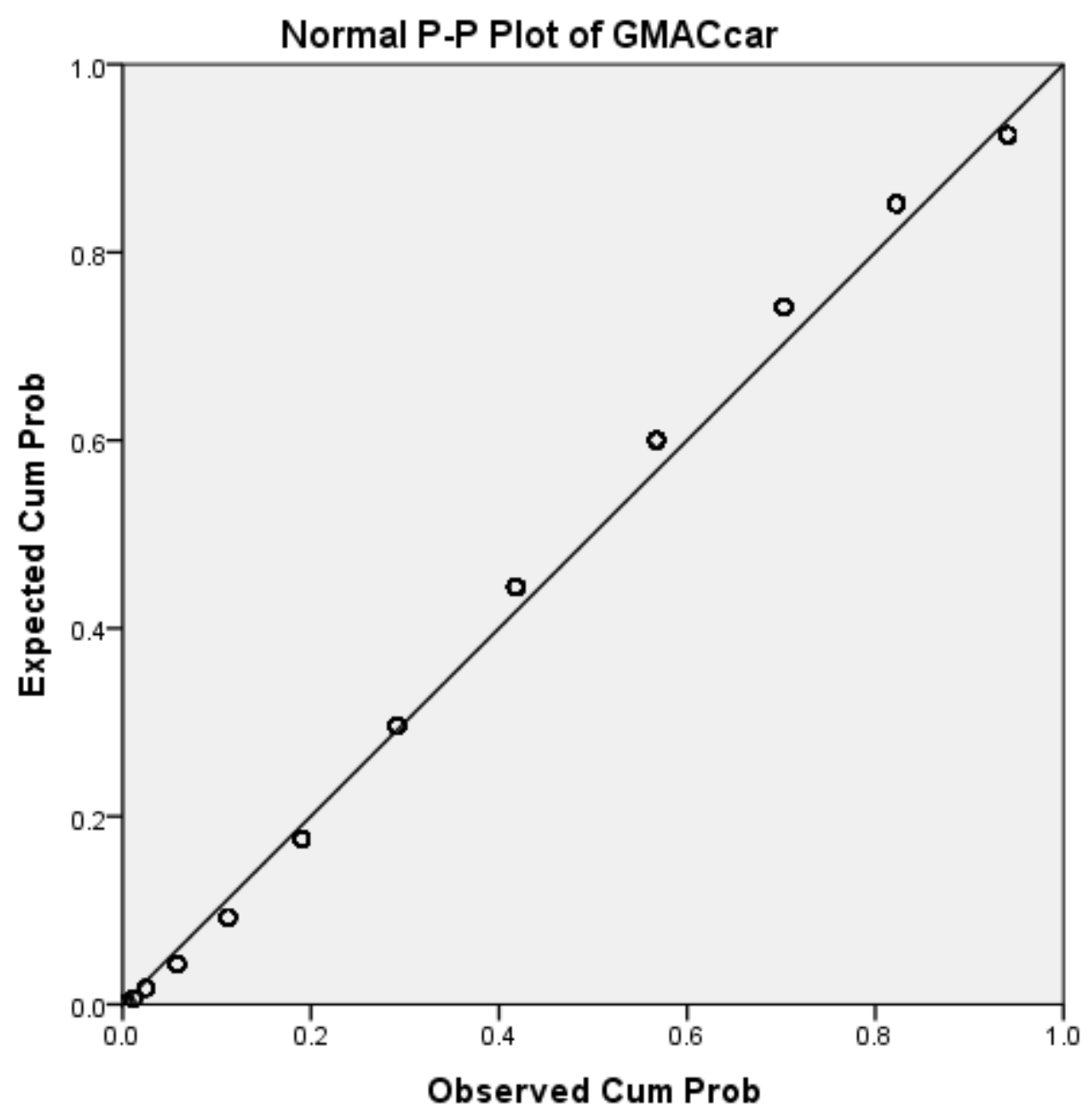




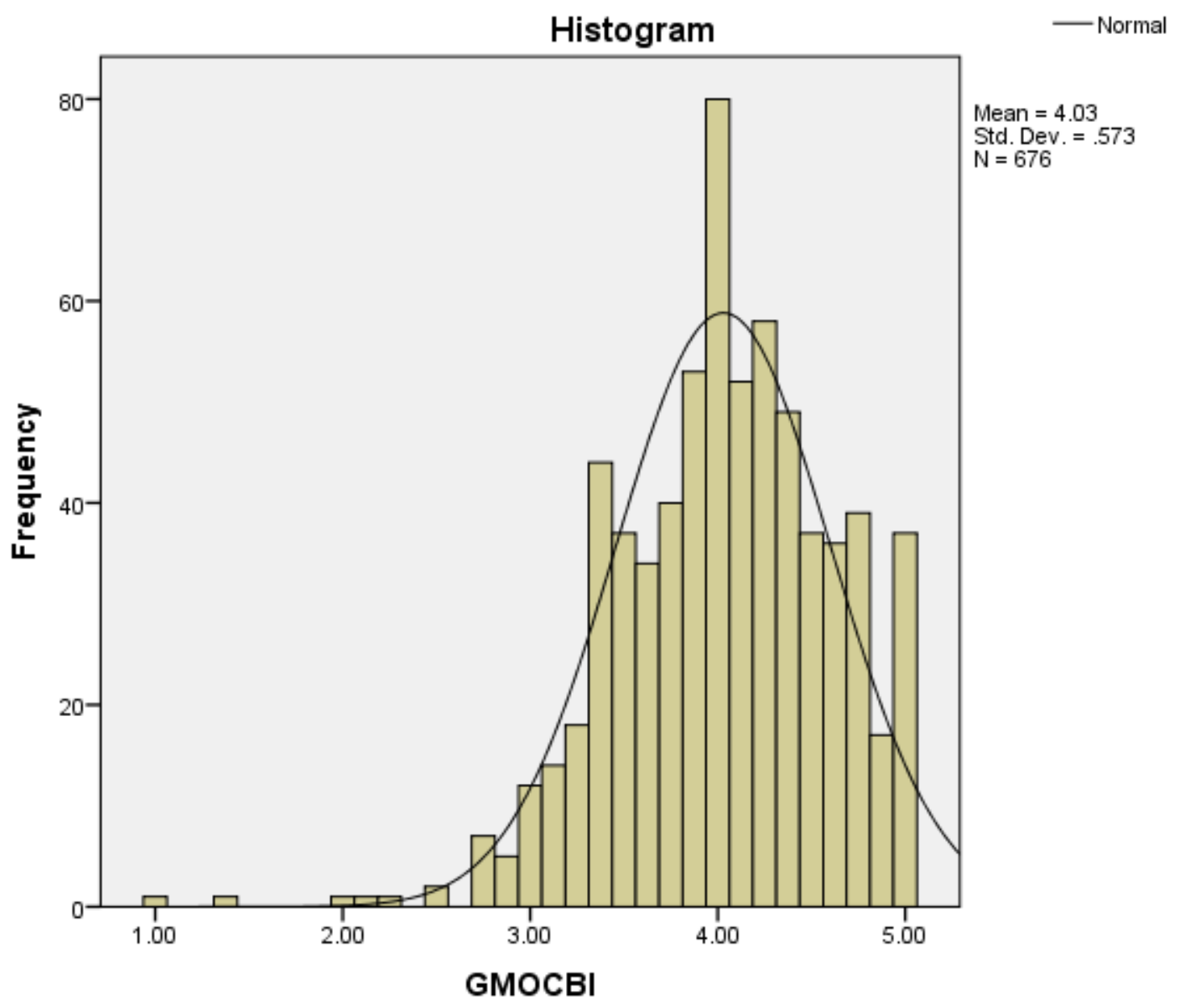




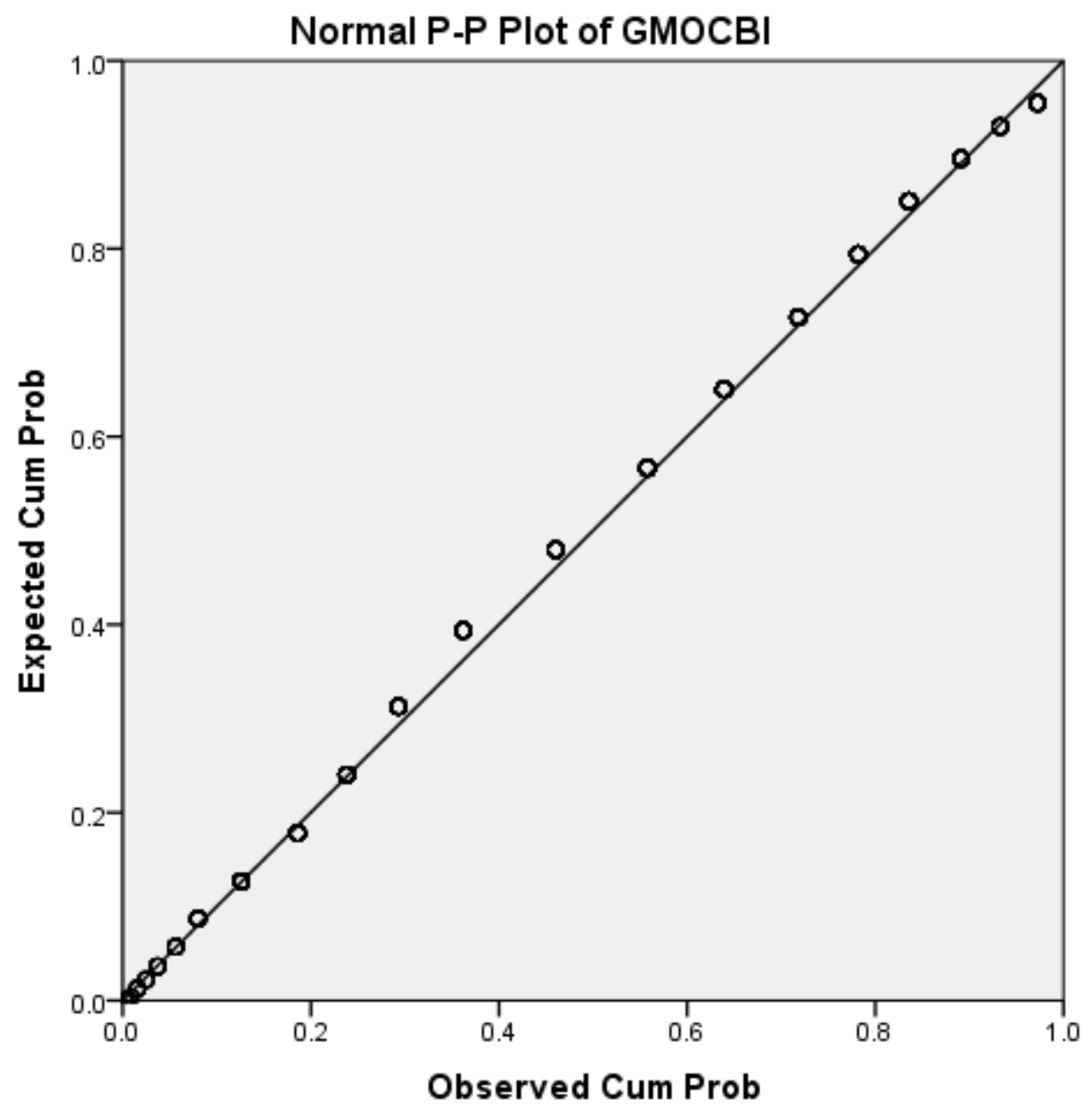




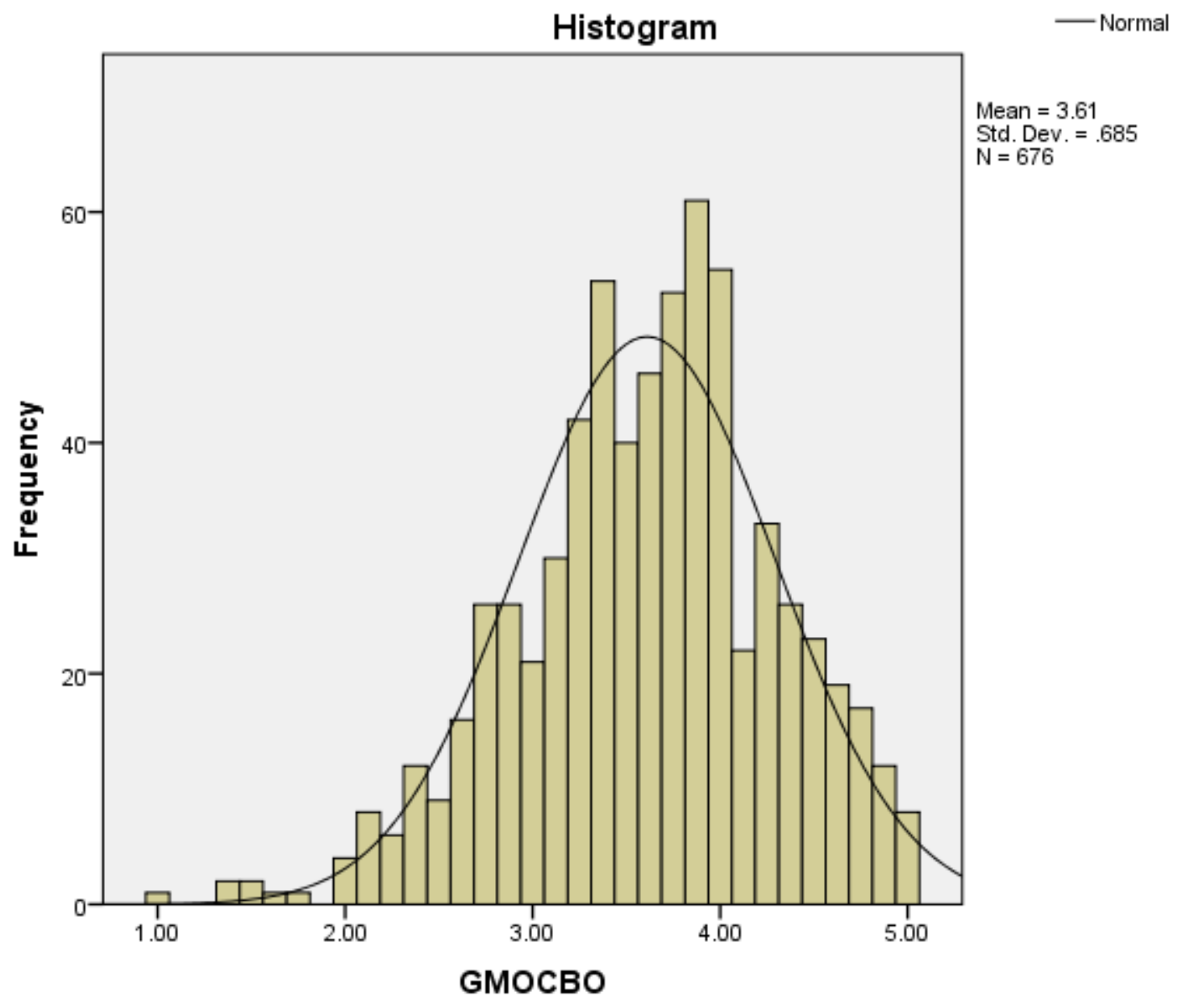




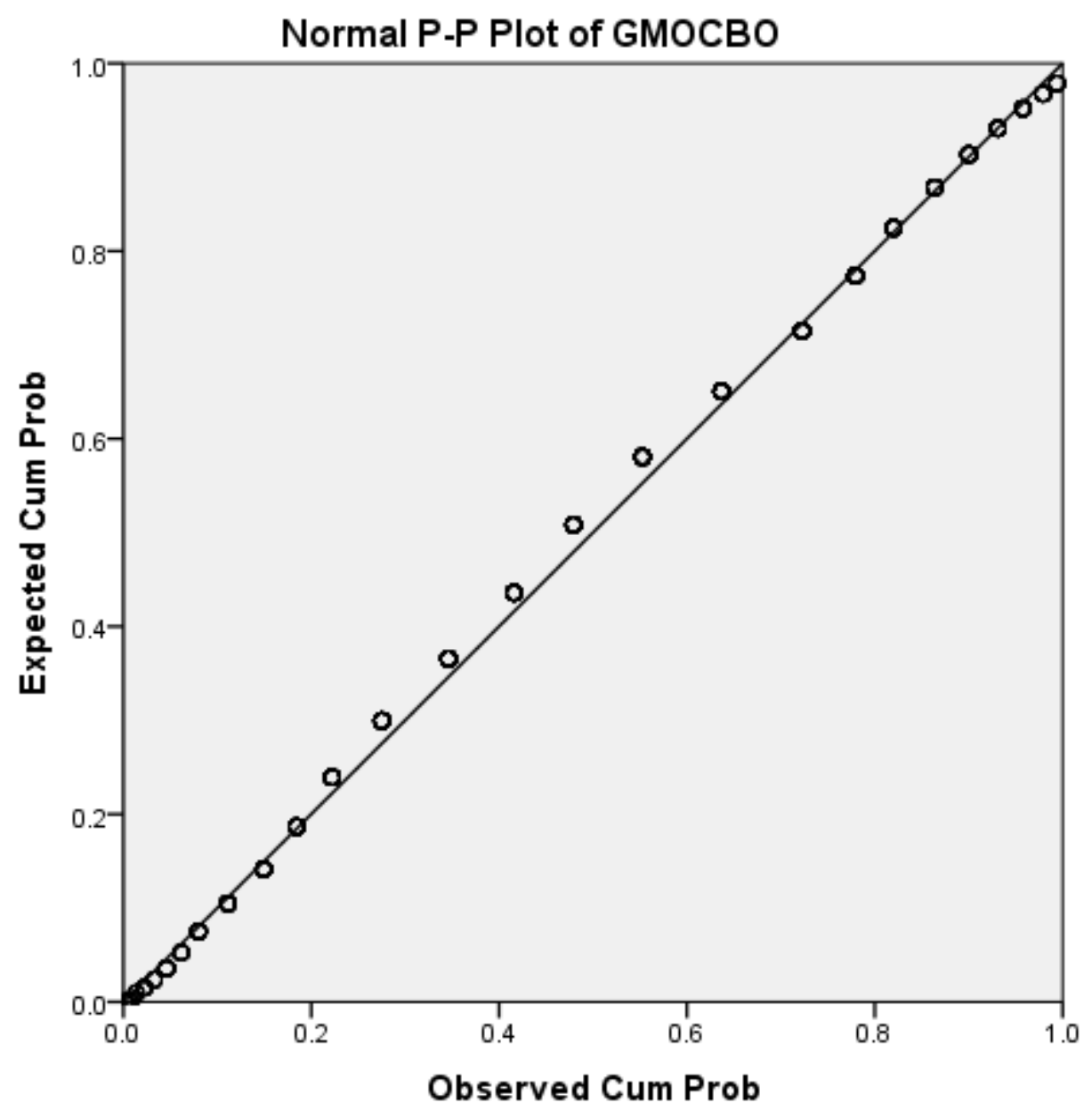


Tests of Normality

\begin{tabular}{|c|c|c|c|c|c|c|}
\hline & \multicolumn{3}{|c|}{ Kolmogorov-Smirnov ${ }^{a}$} & \multicolumn{3}{|c|}{ Shapiro-Wilk } \\
\hline & Statistic & df & Sig. & Statistic & df & Sig. \\
\hline GMJD & .116 & 676 & .000 & .955 & 676 & .000 \\
\hline GMJP & .075 & 676 & .000 & .974 & 676 & .000 \\
\hline GMJInper & .180 & 676 & .000 & .869 & 676 & .000 \\
\hline GMPOS & .043 & 676 & .005 & .981 & 676 & .000 \\
\hline GMJInfo & .120 & 676 & .000 & .949 & 676 & .000 \\
\hline GMACorg & .146 & 676 & .000 & .904 & 676 & .000 \\
\hline GMACsup & .102 & 676 & .000 & .929 & 676 & .000 \\
\hline GMACco & .181 & 676 & .000 & .840 & 676 & .000 \\
\hline GMACpt & .302 & 676 & .000 & .703 & 676 & .000 \\
\hline GMACprof & .202 & 676 & .000 & .826 & 676 & .000 \\
\hline GMACwrk & .118 & 676 & .000 & .957 & 676 & .000 \\
\hline GMACtsk & .149 & 676 & .000 & .892 & 676 & .000 \\
\hline GMACcar & .108 & 676 & .000 & .954 & 676 & .000 \\
\hline GMOCBI & .079 & 676 & .000 & .967 & 676 & .000 \\
\hline GMOCBO & .067 & 676 & .000 & .985 & 676 & .000 \\
\hline
\end{tabular}

a. Lilliefors Significance Correction 
Appendix U. Correlation Matrix for Justice Measures

\begin{tabular}{|c|c|c|c|c|c|c|c|c|c|c|}
\hline \multicolumn{11}{|c|}{ Correlation Matrix } \\
\hline & JD1 & JD2 & JD3 & JD4 & JP1 & JP2 & JP3 & JP4 & JP5 & JP6 \\
\hline JD1 & 1.000 & 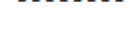 & 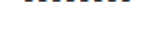 & 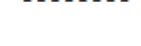 & - & & & & & \\
\hline JD2 & 0.855 & 1.000 & & & & & & & & \\
\hline JD3 & 0.818 & 0.893 & 1.000 & & & & & & & \\
\hline JD4 & 0.839 & 0.897 & 0.875 & 1.000 & & & & & & \\
\hline JP1 & 0.667 & 0.693 & 0.683 & 0.735 & 1.000 & & & & & \\
\hline JP2 & 0.642 & 0.683 & 0.671 & 0.747 & 0.823 & 1.000 & & & & \\
\hline JP3 & 0.603 & 0.659 & 0.632 & 0.681 & 0.741 & 0.763 & 1.000 & & & \\
\hline JP4 & 0.594 & 0.657 & 0.673 & 0.705 & 0.745 & 0.721 & 0.774 & 1.000 & & \\
\hline JP5 & 0.667 & 0.710 & 0.710 & 0.772 & 0.780 & 0.779 & 0.800 & 0.869 & 1.000 & \\
\hline JP6 & 0.555 & 0.572 & 0.608 & 0.610 & 0.700 & 0.710 & 0.655 & 0.674 & 0.690 & 1.000 \\
\hline JP7 & 0.579 & 0.664 & 0.666 & 0.699 & 0.721 & 0.684 & 0.697 & 0.794 & 0.797 & 0.759 \\
\hline JInper1 & 0.500 & 0.535 & 0.548 & 0.602 & 0.689 & 0.577 & 0.594 & 0.680 & 0.656 & 0.586 \\
\hline JInper2 & 0.520 & 0.553 & 0.576 & 0.621 & 0.708 & 0.598 & 0.604 & 0.700 & 0.690 & 0.593 \\
\hline JInper 3 & 0.512 & 0.540 & 0.572 & 0.606 & 0.702 & 0.587 & 0.599 & 0.703 & 0.679 & 0.595 \\
\hline JInper4 & 0.426 & 0.471 & 0.493 & 0.536 & 0.610 & 0.495 & 0.567 & 0.624 & 0.603 & 0.515 \\
\hline JInfo1 & 0.535 & 0.565 & 0.583 & 0.610 & 0.716 & 0.611 & 0.621 & 0.712 & 0.717 & 0.569 \\
\hline JInfo2 & 0.540 & 0.559 & 0.571 & 0.599 & 0.715 & 0.655 & 0.658 & 0.659 & 0.691 & 0.583 \\
\hline JInfo3 & 0.592 & 0.624 & 0.623 & 0.689 & 0.742 & 0.693 & 0.732 & 0.740 & 0.772 & 0.619 \\
\hline JInfo4 & 0.549 & 0.562 & 0.585 & 0.626 & 0.674 & 0.635 & 0.685 & 0.675 & 0.718 & 0.586 \\
\hline \multirow[t]{3}{*}{ JInfo5 } & 0.563 & 0.595 & 0.608 & 0.652 & 0.720 & 0.661 & 0.676 & 0.717 & 0.741 & 0.600 \\
\hline & JP7 & JInper1 & JInper2 & JInper3 & JInper4 & JInfo1 & JInfo2 & JInfo3 & JInfo4 & JInfo5 \\
\hline & 10ab & - & - & - & - & - n & - & - & - & \\
\hline JP7 & 1.000 & & & & & & & & & \\
\hline JInper1 & 0.661 & 1.000 & & & & & & & & \\
\hline JInper2 & 0.674 & 0.960 & 1.000 & & & & & & & \\
\hline JInper3 & 0.665 & 0.953 & 0.976 & 1.000 & & & & & & \\
\hline JInper4 & 0.591 & 0.896 & 0.893 & 0.890 & 1.000 & & & & & \\
\hline JInfo1 & 0.655 & 0.839 & 0.856 & 0.852 & 0.777 & 1.000 & & & & \\
\hline JInfo2 & 0.651 & 0.723 & 0.735 & 0.721 & 0.648 & 0.802 & 1.000 & & & \\
\hline JInfo3 & 0.706 & 0.774 & 0.779 & 0.770 & 0.702 & 0.825 & 0.894 & 1.000 & & \\
\hline JInfo4 & 0.641 & 0.745 & 0.740 & 0.741 & 0.668 & 0.798 & 0.799 & 0.849 & 1.000 & \\
\hline JInfo5 & 0.673 & 0.777 & 0.789 & 0.795 & 0.723 & 0.837 & 0.815 & 0.883 & 0.882 & 1.000 \\
\hline
\end{tabular}


Appendix V. Correlation Matrix of Justice Independent Variables

$\begin{array}{crrrr} & \text { JD } & \text { JP } & \text { JInper } & \text { JInfo } \\ \text { JD } & 1.000 & & & \\ \text { JP } & \begin{array}{r}0.829 \\ (0.014)\end{array} & 1.000 & & \\ & 60.793 & & & \\ \text { JInper } & 0.613 & 0.761 & 1.000 & \\ & (0.025) & (0.017) & & \\ & 24.660 & 44.114 & & \\ & & & & \\ \text { JInfo } & 0.699 & 0.858 & 0.854 & 1.000 \\ & (0.021) & (0.012) & (0.011) & \\ & 33.295 & 73.195 & 75.792 & \end{array}$




\section{Appendix W. Model Misspecification for Justice Measures}

To reiterate, model modification was not performed. However, if I wanted to adopt a more conservative approach, in addition to reviewing the goodness of fit indices to establish the extent to which the hypothesized model fits the sample data, areas of misfit in the model can be identified by reviewing the residuals and modification indices generated by LISREL. In Table W-1, one can conclude that there are numerous values greater than 3.29, indicative of possible misfit in the model. To address, additional paths within the model would need to be added and/or the potential deletion of observed variables.

Table W-1. Standardized Residuals for Justice Measures

\begin{tabular}{|c|c|c|c|c|c|c|c|c|c|c|}
\hline & JD1 & JD2 & JD3 & JD4 & JP1 & JP2 & JP3 & JP4 & JP5 & JP6 \\
\hline & - & . & 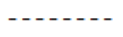 & $\ldots$ & 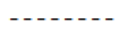 & 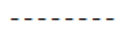 & 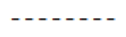 & 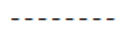 & 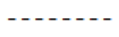 & - \\
\hline JD1 & 0.000 & & & & & & & & & \\
\hline JD2 & 2.385 & 0.000 & & & & & & & & \\
\hline JD3 & -1.159 & 2.556 & 0.000 & & & & & & & \\
\hline JD4 & -0.158 & -1.735 & -1.614 & 0.000 & & & & & & \\
\hline JP1 & 1.765 & 0.356 & 0.906 & 4.329 & 0.000 & & & & & \\
\hline JP2 & 0.898 & 0.608 & 0.895 & 6.117 & 8.766 & 0.000 & & & & \\
\hline JP3 & -1.731 & -1.333 & -2.021 & 0.829 & -0.569 & 3.357 & 0.000 & & & \\
\hline JP4 & -4.757 & -4.716 & -1.356 & 0.281 & -4.874 & -5.783 & 1.163 & 0.000 & & \\
\hline JP5 & -1.168 & -2.457 & -0.333 & 4.853 & -4.971 & -2.319 & 1.273 & 7.557 & 0.000 & \\
\hline JP6 & -1.147 & -3.133 & 0.375 & -0.240 & 1.663 & 3.610 & -1.147 & -2.645 & -4.421 & 0.000 \\
\hline JP7 & -3.344 & -0.908 & 0.607 & 2.290 & -2.867 & -5.169 & -3.611 & 3.791 & 0.798 & 7.910 \\
\hline JInper1 & -1.893 & -3.061 & -0.359 & 3.694 & 3.562 & -4.101 & -2.759 & 1.732 & -2.822 & 0.574 \\
\hline JInper2 & -1.344 & -3.032 & 1.128 & 5.265 & 4.422 & -3.836 & -3.220 & 2.546 & -0.997 & 0.294 \\
\hline JInper 3 & -1.735 & -3.976 & 1.022 & 3.688 & 4.145 & -4.326 & -3.291 & 3.136 & -1.697 & 0.603 \\
\hline JInper4 & -3.700 & -3.945 & -1.474 & 0.707 & 0.567 & -5.798 & -1.324 & 0.516 & -2.678 & -1.244 \\
\hline JInfo1 & -1.192 & -2.350 & 0.108 & 1.338 & 3.471 & -3.381 & -2.564 & 2.075 & 0.467 & -1.973 \\
\hline JInfo2 & -1.110 & -3.042 & -0.902 & 0.317 & 3.202 & -0.363 & -0.103 & -2.582 & -2.241 & -1.285 \\
\hline JInfo3 & 0.276 & -0.770 & 0.601 & 5.949 & 2.927 & -0.263 & 3.179 & 1.278 & 2.116 & -1.252 \\
\hline JInfo4 & -0.770 & -3.200 & -0.168 & 2.107 & -0.262 & -2.152 & 1.635 & -1.631 & -0.100 & -1.362 \\
\hline JInfo5 & -1.212 & -2.601 & 0.001 & 2.921 & 1.665 & -2.197 & -0.932 & -0.133 & -0.343 & -1.948 \\
\hline
\end{tabular}




\begin{tabular}{|c|c|c|c|c|c|c|c|c|c|c|}
\hline & JP7 & JInper1 & JInper2 & JInper 3 & JInper 4 & JInfol & JInfo2 & JInfo3 & JInfo4 & JInfo5 \\
\hline & - - & - & - & - & $\ldots$ & $-\ldots$ & $\ldots$ & - & - & $-\ldots$ \\
\hline JP7 & 0.000 & & & & & & & & & \\
\hline JInper1 & 2.267 & 0.000 & & & & & & & & \\
\hline JInper2 & 2.490 & -0.316 & 0.000 & & & & & & & \\
\hline JInper 3 & 1.938 & -1.002 & 0.450 & 0.000 & & & & & & \\
\hline JInper4 & 0.140 & 4.395 & -1.493 & -0.690 & 0.000 & & & & & \\
\hline JInfo1 & -0.089 & 10.094 & 11.759 & 11.273 & 6.726 & 0.000 & & & & \\
\hline JInfo2 & -0.626 & -2.298 & -3.049 & -4.052 & -3.805 & -0.275 & 0.000 & & & \\
\hline JInfo3 & 0.885 & -1.574 & -4.060 & -4.533 & -2.997 & -5.183 & 9.528 & 0.000 & & \\
\hline JInfo4 & -1.695 & -0.441 & -3.127 & -2.313 & -2.570 & -1.647 & -2.180 & -1.871 & 0.000 & \\
\hline JInfo5 & -1.163 & 0.161 & -0.357 & 1.179 & -0.134 & -0.037 & -5.370 & -1.197 & 7.452 & 0.000 \\
\hline
\end{tabular}

Summary Statistics for Standardized Residuals

Smallest Standardized Residual $=-5.798$

Median Standardized Residual $=-0.204$

Largest Standardized Residual $=11.759$ 


\section{Appendix X. Correlation Matrix for POS Measures}

\begin{tabular}{|c|c|c|c|c|c|c|c|c|}
\hline & POS1 & POS2_Rec & POS3_Rec & POS 4 & POS5_Rec & POS 6 & POS7_Rec & POS8 \\
\hline POS1 & 1.000 & ------- & -------- & -- & ------- & --- & & \\
\hline POS2_Rec & 0.855 & 1.000 & & & & & & \\
\hline Pos3_Rec & 0.818 & 0.893 & 1.000 & & & & & \\
\hline$\overline{\mathrm{POS}} 4$ & 0.839 & 0.897 & 0.875 & 1.000 & & & & \\
\hline POS5_Rec & 0.667 & 0.693 & 0.683 & 0.735 & 1.000 & & & \\
\hline POS 6 & 0.642 & 0.683 & 0.671 & 0.747 & 0.823 & 1.000 & & \\
\hline POS7_Rec & 0.603 & 0.659 & 0.632 & 0.681 & 0.741 & 0.763 & 1.000 & \\
\hline$\overline{\mathrm{P} O S 8}$ & 0.594 & 0.657 & 0.673 & 0.705 & 0.745 & 0.721 & 0.774 & 1.000 \\
\hline Total Var & $e=8$. & 0 Generali & ed Varianc & $=0.11182$ & $D-03$ & & & \\
\hline Largest & value = & $6.124 \mathrm{Sma}$ & est Eigenv & lue $=0.09$ & & & & \\
\hline
\end{tabular}




\section{Appendix Y. Model Misspecification for POS Measures}

In Table Y-1, examining the number of values greater than 3.29, one can conclude that there are numerous values indicative of possible misfit in the model. To address, additional paths within the model would need to be added and/or the potential deletion of observed variables.

Table Y-1. Standardized Residual for POS

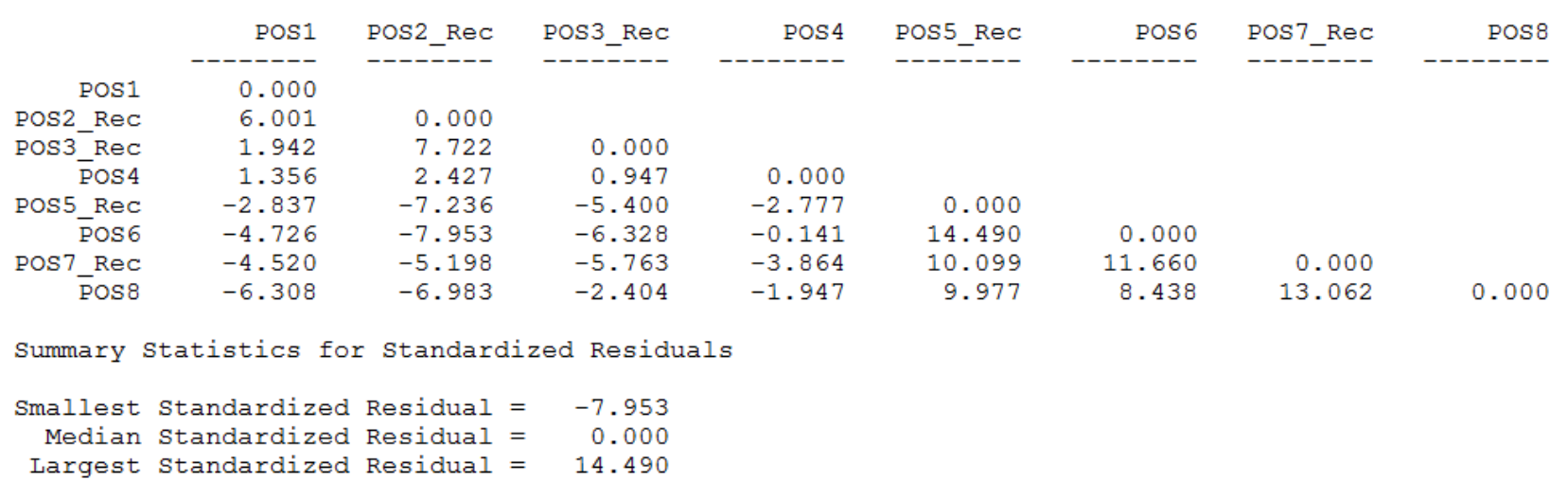




\section{Appendix Z. Correlation Matrix for Affective Commitment}

\begin{tabular}{|c|c|c|c|c|c|c|c|c|c|c|}
\hline & ACorg1 & ACsup1 & $\mathrm{ACc} 01$ & ACpt 1 & ACprof 1 & ACwrk1 & ACtsk1 & ACcar1 & ACorg2 & ACsup2 \\
\hline ACorg1 & $\begin{array}{r}------ \\
1.000\end{array}$ & -------- & -------- & ------ & -------- & & & & & \\
\hline ACsup1 & 0.569 & 1.000 & & & & & & & & \\
\hline $\mathrm{ACc} 01$ & 0.387 & 0.250 & 1.000 & & & & & & & \\
\hline ACpt 1 & 0.273 & 0.122 & 0.393 & 1.000 & & & & & & \\
\hline ACprof1 & 0.500 & 0.297 & 0.428 & 0.539 & 1.000 & & & & & \\
\hline ACwrk1 & 0.232 & 0.137 & 0.143 & 0.349 & 0.506 & 1.000 & & & & \\
\hline ACtsk1 & 0.441 & 0.266 & 0.460 & 0.396 & 0.549 & 0.362 & 1.000 & & & \\
\hline ACcar 1 & 0.118 & 0.053 & 0.065 & 0.081 & 0.176 & 0.248 & 0.127 & 1.000 & & \\
\hline ACorg2 & 0.788 & 0.472 & 0.359 & 0.316 & 0.532 & 0.413 & 0.517 & 0.243 & 1.000 & \\
\hline ACsup2 & 0.527 & 0.879 & 0.283 & 0.160 & 0.341 & 0.216 & 0.329 & 0.115 & 0.522 & 1.000 \\
\hline $\mathrm{ACc} 02$ & 0.437 & 0.318 & 0.853 & 0.362 & 0.382 & 0.216 & 0.479 & 0.112 & 0.442 & 0.390 \\
\hline ACpt2 & 0.362 & 0.146 & 0.425 & 0.689 & 0.551 & 0.414 & 0.441 & 0.123 & 0.391 & 0.207 \\
\hline ACprof2 & 0.481 & 0.304 & 0.383 & 0.457 & 0.660 & 0.359 & 0.525 & 0.027 & 0.506 & 0.309 \\
\hline ACtsk2 & 0.471 & 0.274 & 0.414 & 0.386 & 0.529 & 0.322 & 0.779 & 0.002 & 0.485 & 0.299 \\
\hline ACcar 2 & 0.105 & 0.099 & 0.000 & 0.010 & 0.110 & 0.230 & 0.074 & 0.756 & 0.179 & 0.144 \\
\hline \multirow[t]{3}{*}{ ACwrk2 } & 0.293 & 0.138 & 0.189 & 0.294 & 0.400 & 0.573 & 0.379 & 0.246 & 0.433 & 0.201 \\
\hline & ACprof3 & ACwrk3 & ACtsk3_R & ACcar 3 & 0.433 & 0.187 & 0.414 & 0.089 & 0.705 & 0.533 \\
\hline & $---0----$ & -------- & $-0-0-0$ & ------- & 0.288 & 0.134 & 0.253 & 0.100 & 0.419 & 0.894 \\
\hline ACprof3 & 1.000 & & & & 0.339 & 0.183 & 0.462 & 0.070 & 0.327 & 0.274 \\
\hline ACwrk3 & 0.437 & 1.000 & & & 0.461 & 0.288 & 0.298 & 0.121 & 0.440 & 0.291 \\
\hline ACtsk3 R & 0.389 & 0.151 & 1.000 & & 0.612 & 0.363 & 0.394 & 0.048 & 0.391 & 0.277 \\
\hline ACcar 3 & 0.123 & 0.240 & 0.049 & 1.000 & 0.317 & 0.523 & 0.205 & 0.277 & 0.257 & 0.157 \\
\hline \multirow{3}{*}{ ACcar 3} & & & & & 0.415 & 0.166 & 0.586 & -0.023 & 0.408 & 0.297 \\
\hline & 0.039 & -0.058 & 0.125 & 0.233 & 0.204 & 0.227 & 0.098 & 0.351 & 0.174 & -0.017 \\
\hline & $\mathrm{ACc} \circ 2$ & ACpt 2 & ACprof2 & ACtsk2 & ACcar2 & ACwrk2 & ACorg3_R & ACsup 3 & $\mathrm{ACCO} 3$ & ACpt 3 \\
\hline $\mathrm{ACco} 2$ & 1.000 & & & & & & & & & \\
\hline ACpt2 & 0.389 & 1.000 & & & & & & & & \\
\hline ACprof2 & 0.419 & 0.538 & 1.000 & & & & & & & \\
\hline ACtsk2 & 0.435 & 0.532 & 0.642 & 1.000 & & & & & & \\
\hline ACcar2 & 0.041 & 0.053 & -0.029 & 0.034 & 1.000 & & & & & \\
\hline ACwrk2 & 0.253 & 0.369 & 0.444 & 0.375 & 0.245 & 1.000 & & & & \\
\hline ACorg3_R & 0.420 & 0.209 & 0.488 & 0.478 & 0.073 & 0.280 & 1.000 & & & \\
\hline ACsup 3 & 0.321 & 0.140 & 0.293 & 0.256 & 0.124 & 0.172 & 0.470 & 1.000 & & \\
\hline $\mathrm{ACc} 03$ & 0.854 & 0.367 & 0.327 & 0.403 & -0.013 & 0.196 & 0.314 & 0.279 & 1.000 & \\
\hline ACpt3 & 0.288 & 0.579 & 0.458 & 0.437 & 0.113 & 0.270 & 0.378 & 0.242 & 0.243 & 1.000 \\
\hline ACprof3 & 0.351 & 0.432 & 0.739 & 0.493 & 0.008 & 0.403 & 0.373 & 0.230 & 0.304 & 0.401 \\
\hline ACwrk3 & 0.084 & 0.258 & 0.346 & 0.306 & 0.332 & 0.508 & 0.068 & 0.119 & 0.094 & 0.158 \\
\hline ACtsk3_R & 0.355 & 0.356 & 0.488 & 0.660 & -0.018 & 0.263 & 0.564 & 0.288 & 0.307 & 0.365 \\
\hline ACcā̌ 3 & 0.113 & 0.300 & 0.155 & 0.118 & 0.273 & 0.303 & 0.052 & 0.037 & 0.114 & 0.253 \\
\hline
\end{tabular}




\section{Appendix AA. Correlation Matrix of Affective Commitment Independent Variables}

\begin{tabular}{|c|c|c|c|c|c|c|c|c|}
\hline & ACorg & ACsup & $\mathrm{ACco}$ & ACpt & ACprof & ACwrk & ACtsk & ACcar \\
\hline ACorg & 1.000 & & & & & & & \\
\hline ACsup & $\begin{array}{c}0.612 \\
(0.027) \\
22.852\end{array}$ & 1.000 & & & & & & \\
\hline $\mathrm{ACco}$ & $\begin{array}{c}0.456 \\
(0.033) \\
13.638\end{array}$ & $\begin{array}{r}0.340 \\
(0.036) \\
9.481\end{array}$ & 1.000 & & & & & \\
\hline ACpt & $\begin{array}{r}0.463 \\
(0.036) \\
12.978\end{array}$ & $\begin{array}{r}0.244 \\
(0.040) \\
6.048\end{array}$ & $\begin{array}{r}0.482 \\
(0.034) \\
14.138\end{array}$ & 1.000 & & & & \\
\hline ACprof & $\begin{array}{c}0.628 \\
(0.028) \\
22.299\end{array}$ & $\begin{array}{r}0.375 \\
(0.037) \\
10.239\end{array}$ & $\begin{array}{r}0.472 \\
(0.034) \\
13.959\end{array}$ & $\begin{array}{r}0.707 \\
(0.026) \\
27.051\end{array}$ & 1.000 & & & \\
\hline $\mathrm{ACwrk}$ & $\begin{array}{c}0.401 \\
(0.040) \\
10.129\end{array}$ & $\begin{array}{r}0.240 \\
(0.042) \\
5.688\end{array}$ & $\begin{array}{r}0.241 \\
(0.043) \\
5.659\end{array}$ & $\begin{array}{c}0.516 \\
(0.038) \\
13.763\end{array}$ & $\begin{array}{c}0.644 \\
(0.031) \\
20.528\end{array}$ & 1.000 & & \\
\hline ACtsk & $\begin{array}{c}0.613 \\
(0.028) \\
21.714\end{array}$ & $\begin{array}{c}0.351 \\
(0.037) \\
9.604\end{array}$ & $\begin{array}{c}0.518 \\
(0.031) \\
16.514\end{array}$ & $\begin{array}{c}0.613 \\
(0.030) \\
20.461\end{array}$ & $\begin{array}{c}0.736 \\
(0.023) \\
31.810\end{array}$ & $\begin{array}{c}0.490 \\
(0.037) \\
13.263\end{array}$ & 1.000 & \\
\hline ACcar & $\begin{array}{r}0.177 \\
(0.042) \\
4.208\end{array}$ & $\begin{array}{r}0.130 \\
(0.041) \\
3.141\end{array}$ & $\begin{array}{r}0.072 \\
(0.042) \\
1.713\end{array}$ & $\begin{array}{c}0.141 \\
(0.044) \\
3.216\end{array}$ & $\begin{array}{r}0.077 \\
(0.044) \\
1.754\end{array}$ & $\begin{array}{c}0.414 \\
(0.040) \\
10.250\end{array}$ & $\begin{array}{c}0.051 \\
(0.043) \\
1.176\end{array}$ & 1.000 \\
\hline
\end{tabular}




\section{Appendix BB. Model Misspecification for Affective Commitment}

In Table BB-1, examining the number of values greater than 3.29, one can conclude that there are numerous values indicative of possible misfit in the model.

Table BB-1. Standardized Residuals for Affective Commitment

\begin{tabular}{|c|c|c|c|c|c|c|c|c|c|c|}
\hline & ACorg1 & ACsup1 & $\mathrm{ACc} \circ 1$ & ACpt 1 & ACprof1 & ACwrk1 & ACtsk1 & ACcar 1 & ACorg2 & ACsup2 \\
\hline ACorg1 & 0.000 & & & & & & & & & \\
\hline ACsup1 & 4.363 & 0.000 & & & & & & & & \\
\hline $\mathrm{ACCO} 1$ & -0.009 & -2.308 & 0.000 & & & & & & & \\
\hline ACpt 1 & -3.184 & -2.420 & 1.964 & 0.000 & & & & & & \\
\hline ACprof1 & 2.844 & 1.317 & 4.140 & 5.118 & 0.000 & & & & & \\
\hline ACwrk1 & -2.095 & -1.207 & -1.177 & 1.846 & 5.969 & 0.000 & & & & \\
\hline ACtsk1 & -1.694 & -0.136 & 3.209 & -0.617 & 3.600 & 2.415 & 0.000 & & & \\
\hline ACcar1 & -1.779 & -3.135 & 0.302 & -0.921 & 5.397 & -1.644 & 4.368 & 0.000 & & \\
\hline ACorg2 & 1.402 & -0.429 & -0.340 & 0.044 & 5.390 & 6.813 & 4.097 & 5.664 & 0.000 & \\
\hline ACsup2 & -1.226 & -1.631 & -1.937 & -1.401 & 2.863 & 2.046 & 2.515 & 0.170 & 0.933 & 0.000 \\
\hline $\mathrm{ACCO} 2$ & 3.690 & 1.891 & -2.485 & 0.530 & 1.998 & 2.239 & 4.434 & 3.279 & 4.508 & 6.764 \\
\hline ACpt 2 & -0.170 & -2.526 & 2.565 & 0.559 & 4.205 & 4.062 & -0.226 & 0.794 & 2.569 & 0.224 \\
\hline ACprof2 & -2.038 & 0.100 & -0.419 & -2.631 & -5.824 & -4.193 & -1.522 & -2.127 & 1.782 & -0.980 \\
\hline ACtsk2 & -4.122 & -1.411 & -2.708 & -4.062 & -0.296 & -1.013 & 1.188 & -2.968 & -0.142 & -1.539 \\
\hline Accar2 & -1.634 & -0.024 & -2.945 & -3.560 & 2.384 & -1.523 & 1.622 & 1.093 & 2.336 & 2.206 \\
\hline ACwrk2 & 0.863 & -1.203 & 0.925 & -0.675 & 0.838 & 0.701 & 3.125 & -1.805 & 7.687 & 1.276 \\
\hline ACorg3_R & 2.415 & 4.100 & -1.118 & -5.764 & 0.742 & -2.978 & -1.126 & -2.288 & -4.016 & 2.212 \\
\hline ACsup3 & -5.553 & 1.035 & -1.896 & -3.441 & 0.786 & -1.434 & -0.902 & -0.452 & -4.095 & 0.969 \\
\hline $\mathrm{ACc} 03$ & -4.926 & -3.198 & 1.964 & -1.279 & -0.140 & 0.715 & 3.435 & 0.628 & -2.007 & -2.395 \\
\hline ACpt3 & 7.258 & 5.267 & -0.989 & 2.602 & 3.317 & 0.717 & -2.535 & 1.237 & 6.491 & 5.127 \\
\hline ACprof 3 & -4.112 & -1.535 & -1.250 & -5.986 & -0.867 & -0.996 & -5.330 & -0.291 & -1.866 & -0.499 \\
\hline ACwrk3 & -5.130 & -3.461 & -3.547 & -5.924 & -1.358 & 0.429 & -3.204 & 0.947 & 0.757 & -0.143 \\
\hline ACtsk3_R & 2.907 & 3.182 & -0.404 & -1.457 & 0.091 & -3.661 & -1.333 & -2.102 & 1.378 & 2.240 \\
\hline \multirow[t]{2}{*}{ ACcar 3} & -0.610 & -2.906 & 2.811 & 5.342 & 5.009 & 3.233 & 2.269 & 1.769 & 3.304 & -1.833 \\
\hline & $\mathrm{ACCO} 2$ & ACpt2 & ACprof2 & ACtsk2 & ACcar2 & ACwrk2 & ACorg3_R & ACsup3 & $\mathrm{ACcO} 3$ & ACpt 3 \\
\hline $\mathrm{ACco} 2$ & 0.000 & & & & & & & & & \\
\hline ACpt2 & 0.324 & 0.000 & & & & & & & & \\
\hline ACprof2 & 2.304 & -0.304 & 0.000 & & & & & & & \\
\hline ACtsk2 & -0.452 & 3.716 & 4.275 & 0.000 & & & & & & \\
\hline ACcar2 & -0.748 & -2.476 & -4.341 & -0.312 & 0.000 & & & & & \\
\hline ACwrk2 & 3.935 & 1.629 & 0.782 & 1.812 & -0.877 & 0.000 & & & & \\
\hline ACorg3_R & 3.422 & -6.963 & 0.980 & -0.154 & -2.389 & 1.017 & 0.000 & & & \\
\hline ACsup 3 & 1.950 & -3.118 & -0.795 & -2.962 & 1.177 & 0.193 & -0.470 & 0.000 & & \\
\hline $\mathrm{ACCO} 3$ & 0.495 & -1.231 & -3.972 & -3.195 & -3.489 & 1.275 & -2.342 & -0.645 & 0.000 & \\
\hline ACpt 3 & -0.874 & -3.085 & 1.196 & 2.147 & 1.074 & -0.034 & 4.129 & 3.253 & -2.837 & 0.000 \\
\hline ACprof 3 & 0.346 & -3.176 & 6.622 & -3.160 & -1.770 & 0.861 & -2.423 & -1.989 & -2.055 & 0.518 \\
\hline ACwrk3 & -2.732 & -2.264 & -2.443 & -0.273 & 3.835 & -1.128 & -6.547 & -1.339 & -2.400 & -3.219 \\
\hline ACtsk3 R & 0.596 & -1.053 & 1.215 & -0.063 & -1.738 & -0.059 & 8.256 & 2.220 & -1.517 & 2.276 \\
\hline ACcar 3 & 2.489 & 7.192 & 3.636 & 2.836 & -3.632 & 5.476 & -0.124 & -0.229 & 2.500 & 5.922 \\
\hline
\end{tabular}




$\begin{array}{rrrrr} & \text { ACprof3 } & \text { ACwrk3 } & \text { ACtsk3_R } & \text { ACcar3 } \\ & ------ & ------ & ----- & ----- \\ \text { ACprof3 } & 0.000 & & & \\ \text { ACwrk3 } & 3.723 & 0.000 & & \\ \text { ACtsk3_R } & -1.259 & -3.240 & 0.000 & \\ \text { ACcar3 } & 2.763 & 3.832 & 0.959 & 0.000\end{array}$

Summary Statistics for Standardized Residuals

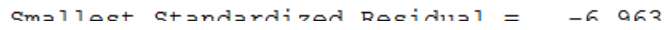

Correlation Matrix

\begin{tabular}{|c|c|c|c|c|c|c|c|c|c|c|}
\hline & OCBI1 & OCBI2 & OCBI3 & OCBI 4 & OCBI 5 & OCBI 6 & OCBI 7 & OCBI8 & OCBO 1 & $\mathrm{OCBO} 2$ \\
\hline OCBI1 & 1.000 & & & & & & & & & \\
\hline OCBI2 & 0.691 & 1.000 & & & & & & & & \\
\hline OCBI3 & 0.475 & 0.466 & 1.000 & & & & & & & \\
\hline OCBI5 & 0.456 & 0.621 & 0.318 & 0.703 & 1.000 & & & & & \\
\hline OCBI 6 & 0.496 & 0.705 & 0.477 & 0.543 & 0.619 & 1.000 & & & & \\
\hline OCBI 7 & 0.488 & 0.488 & 0.387 & 0.463 & 0.472 & 0.571 & 1.000 & & & \\
\hline OCBI 8 & 0.349 & 0.396 & 0.391 & 0.314 & 0.368 & 0.525 & 0.535 & 1.000 & & \\
\hline $\mathrm{OCBO} 2$ & 0.221 & 0.299 & 0.148 & 0.246 & 0.346 & 0.183 & 0.189 & 0.132 & 0.481 & 1.000 \\
\hline OCBO3 & 0.187 & 0.275 & 0.225 & 0.316 & 0.348 & 0.242 & 0.174 & 0.164 & 0.512 & 0.469 \\
\hline OCBO 4 & 0.235 & 0.322 & 0.198 & 0.350 & 0.350 & 0.231 & 0.191 & 0.152 & 0.470 & 0.481 \\
\hline OCBO5 & 0.225 & 0.290 & 0.136 & 0.313 & 0.258 & 0.225 & 0.227 & 0.233 & 0.370 & 0.431 \\
\hline OCBO 6 & 0.196 & 0.248 & 0.210 & 0.329 & 0.326 & 0.220 & 0.168 & 0.191 & 0.466 & 0.418 \\
\hline OCBO 7 & 0.255 & 0.298 & 0.250 & 0.356 & 0.329 & 0.281 & 0.236 & 0.195 & 0.345 & 0.453 \\
\hline OCBO8 & 0.267 & 0.332 & 0.265 & 0.387 & 0.328 & 0.293 & 0.249 & 0.220 & 0.439 & 0.527 \\
\hline
\end{tabular}

OCB

\begin{tabular}{|c|c|c|c|c|c|c|}
\hline & OCBO3 & OCBO 4 & OCBO5 & OCBO 6 & OCBO 7 & ОСВО8 \\
\hline $\mathrm{OCBO} 3$ & 1.000 & & & & & \\
\hline OCBO 4 & 0.734 & 1.000 & & & & \\
\hline OCBO 5 & 0.323 & 0.412 & 1.000 & & & \\
\hline OCBO 6 & 0.715 & 0.767 & 0.438 & 1.000 & & \\
\hline $\mathrm{OCBO} 7$ & 0.435 & 0.464 & 0.528 & 0.497 & 1.000 & \\
\hline OCBO & 0.569 & 0.604 & 0.524 & 0.606 & 0.788 & 1.000 \\
\hline
\end{tabular}


Appendix DD. Correlation Matrix for OCB Independent Variables

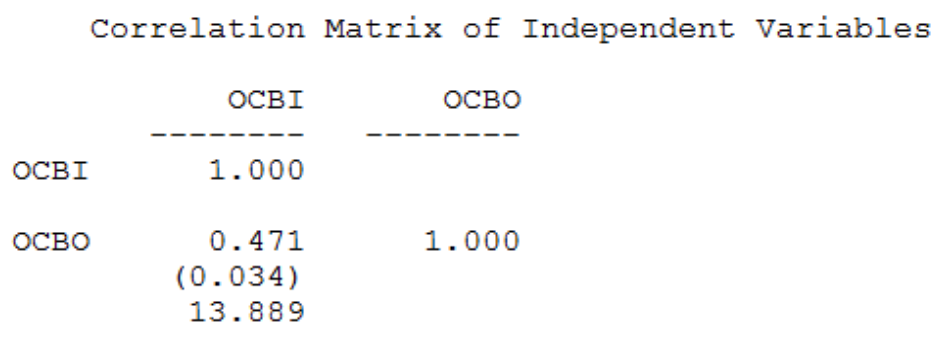




\section{Appendix EE. Model Misspecification for OCB}

In Table EE -1, examining the number of values greater than the absolute value of 3.29, one can conclude that there are numerous values indicative of possible misfit in the model.

Table EE-1. Standardized Residuals for OCB

\begin{tabular}{|c|c|c|c|c|c|c|c|c|c|c|}
\hline & OCBI 1 & OCBI2 & OCBI 3 & OCBI 4 & OCBI 5 & OCBI 6 & OCBI 7 & OCBI 8 & OCBO1 & $\mathrm{OCBO} 2$ \\
\hline OCBI1 & 0.000 & & & & & & & & & \\
\hline OCBI 2 & 9.121 & 0.000 & & & & & & & & \\
\hline OCBI3 & 3.844 & -0.225 & 0.000 & & & & & & & \\
\hline OCBI 4 & -1.465 & -4.076 & -1.330 & 0.000 & & & & & & \\
\hline OCBI 5 & -4.726 & -0.794 & -5.862 & 11.000 & 0.000 & & & & & \\
\hline OCBI 6 & -5.712 & 3.157 & 1.072 & -2.918 & 0.240 & 0.000 & & & & \\
\hline OCBI 7 & 1.366 & -4.866 & 0.613 & -0.380 & -1.737 & 2.349 & 0.000 & & & \\
\hline OCBI 8 & -1.807 & -4.395 & 3.134 & -3.874 & -2.697 & 4.617 & 7.528 & 0.000 & & \\
\hline OCBO1 & -0.273 & 0.794 & 2.856 & 1.290 & 1.516 & 0.117 & -1.983 & 3.010 & 0.000 & \\
\hline $\mathrm{OCBO} 2$ & 0.622 & 2.071 & -0.436 & 1.327 & 4.238 & -1.753 & -0.044 & -0.838 & 5.177 & 0.000 \\
\hline $\mathrm{OCBO} 3$ & -2.684 & -1.500 & 0.461 & 1.839 & 2.512 & -2.582 & -2.558 & -1.414 & 2.587 & -0.971 \\
\hline OCBO 4 & -1.479 & -0.204 & -0.804 & 2.687 & 2.161 & -3.873 & -2.473 & -2.171 & -1.537 & -2.011 \\
\hline OCBO5 & 1.202 & 2.287 & -0.425 & 3.880 & 1.810 & 0.259 & 1.555 & 2.511 & 1.486 & 3.622 \\
\hline OCBO 6 & -2.848 & -3.354 & -0.304 & 1.967 & 1.292 & -4.181 & -3.206 & -0.822 & -1.484 & -5.953 \\
\hline OCBO 7 & 1.035 & 1.155 & 2.151 & 4.281 & 3.013 & 0.720 & 0.773 & 0.551 & -2.713 & 1.806 \\
\hline ОСВО8 & 0.211 & 0.894 & 1.775 & 4.424 & 1.761 & -0.475 & 0.047 & 0.421 & -1.816 & 2.609 \\
\hline
\end{tabular}

$\begin{array}{lrrrrrr} & \text { OCBO3 } & \text { OCBO4 } & \text { OCBO5 } & \text { OCBO6 } & \text { OCBO7 } & \text { OCBO8 } \\ & ----- & ------ & ------ & ------ & ----- & ---- \\ \text { OCBO3 } & 0.000 & & & & & \\ \text { OCBO4 } & 7.563 & 0.000 & & & & \\ \text { OCB05 } & -7.311 & -3.918 & 0.000 & & & \\ \text { OCBO6 } & 5.996 & 9.282 & -1.831 & 0.000 & & \\ \text { OCB07 } & -7.095 & -8.049 & 6.640 & -4.890 & 0.000 & \\ \text { OCB08 } & -5.315 & -5.910 & 4.461 & -4.861 & 16.887 & 0.000\end{array}$

Summary Statistics for Standardized Residuals

Smallest Standardized Residual $=-8.049$

Median Standardized Residual $=0.000$

Largest Standardized Residual $=16.887$ 
Appendix FF. SEM Correlation Matrix

\begin{tabular}{|c|c|c|c|c|c|c|c|c|c|c|}
\hline & JD1 & JD2 & JD3 & JD4 & JInper 1 & JInper2 & JInper3 & JInper 4 & Pos1 & POS2_Rec \\
\hline JD1 & 1.000 & & & & & & & & & \\
\hline JD2 & 0.855 & 1.000 & & & & & & & & \\
\hline JD3 & 0.818 & 0.893 & 1.000 & & & & & & & \\
\hline JD4 & 0.839 & 0.897 & 0.875 & 1.000 & & & & & & \\
\hline JInper1 & 0.500 & 0.535 & 0.548 & 0.602 & 1.000 & & & & & \\
\hline JInper2 & 0.520 & 0.553 & 0.576 & 0.621 & 0.960 & 1.000 & & & & \\
\hline JInper3 & 0.512 & 0.540 & 0.572 & 0.606 & 0.953 & 0.976 & 1.000 & & & \\
\hline JInper4 & 0.426 & 0.471 & 0.493 & 0.536 & 0.896 & 0.893 & 0.890 & 1.000 & & \\
\hline POS1 & 0.435 & 0.468 & 0.556 & 0.451 & 0.445 & 0.478 & 0.471 & 0.389 & 1.000 & \\
\hline POS2_ReC & 0.342 & 0.362 & 0.404 & 0.342 & 0.283 & 0.310 & 0.320 & 0.281 & 0.546 & 1.000 \\
\hline POS3_Rec & 0.361 & 0.401 & 0.430 & 0.365 & 0.417 & 0.456 & 0.458 & 0.398 & 0.593 & 0.646 \\
\hline$\overline{\mathrm{P}} \mathrm{OS} 4$ & 0.420 & 0.448 & 0.483 & 0.418 & 0.420 & 0.448 & 0.437 & 0.376 & 0.771 & 0.541 \\
\hline POS5 ReC & 0.456 & 0.463 & 0.512 & 0.441 & 0.444 & 0.462 & 0.471 & 0.398 & 0.648 & 0.680 \\
\hline POS 6 & 0.416 & 0.447 & 0.505 & 0.443 & 0.445 & 0.468 & 0.458 & 0.404 & 0.764 & 0.547 \\
\hline POS7_ReC & 0.442 & 0.455 & 0.484 & 0.419 & 0.455 & 0.470 & 0.475 & 0.393 & 0.698 & 0.660 \\
\hline$\overline{\mathrm{P}} 0 \mathrm{~s} 8$ & 0.404 & 0.462 & 0.514 & 0.441 & 0.376 & 0.406 & 0.414 & 0.352 & 0.745 & 0.540 \\
\hline ACorg 1 & 0.345 & 0.398 & 0.441 & 0.343 & 0.384 & 0.412 & 0.386 & 0.364 & 0.682 & 0.429 \\
\hline ACsup1 & 0.510 & 0.537 & 0.573 & 0.568 & 0.719 & 0.747 & 0.756 & 0.697 & 0.577 & 0.418 \\
\hline $\mathrm{ACCO} 1$ & 0.198 & 0.207 & 0.231 & 0.188 & 0.227 & 0.224 & 0.210 & 0.232 & 0.249 & 0.172 \\
\hline ACpt 1 & 0.136 & 0.130 & 0.124 & 0.126 & 0.081 & 0.098 & 0.068 & 0.073 & 0.074 & 0.047 \\
\hline ACprof 1 & 0.232 & 0.257 & 0.232 & 0.222 & 0.244 & 0.226 & 0.200 & 0.211 & 0.280 & 0.170 \\
\hline ACtsk1 & 0.196 & 0.209 & 0.230 & 0.218 & 0.196 & 0.195 & 0.180 & 0.166 & 0.327 & 0.285 \\
\hline ACcar1 & 0.031 & 0.017 & -0.018 & -0.034 & 0.031 & 0.022 & 0.006 & 0.001 & 0.036 & -0.005 \\
\hline ACorg2 & 0.288 & 0.300 & 0.327 & 0.274 & 0.323 & 0.333 & 0.327 & 0.307 & 0.593 & 0.388 \\
\hline ACsup2 & 0.463 & 0.488 & 0.517 & 0.520 & 0.721 & 0.741 & 0.756 & 0.669 & 0.536 & 0.391 \\
\hline $\mathrm{ACco} 2$ & 0.205 & 0.218 & 0.239 & 0.228 & 0.250 & 0.238 & 0.233 & 0.229 & 0.279 & 0.189 \\
\hline ACpt2 & 0.082 & 0.069 & 0.078 & 0.081 & 0.119 & 0.114 & 0.088 & 0.093 & 0.183 & 0.054 \\
\hline ACprof2 & 0.196 & 0.216 & 0.212 & 0.216 & 0.212 & 0.206 & 0.210 & 0.208 & 0.296 & 0.222 \\
\hline ACtsk2 & 0.229 & 0.227 & 0.237 & 0.234 & 0.195 & 0.196 & 0.184 & 0.165 & 0.350 & 0.290 \\
\hline ACcar2 & 0.100 & 0.080 & 0.070 & 0.058 & 0.012 & 0.014 & 0.016 & -0.015 & 0.072 & 0.050 \\
\hline
\end{tabular}

\begin{tabular}{|c|c|c|c|c|c|c|c|c|c|c|}
\hline ACorg3_R & 0.353 & 0.392 & 0.440 & 0.357 & 0.419 & 0.440 & 0.437 & 0.399 & 0.648 & 0.454 \\
\hline ACsup̄3 & 0.472 & 0.486 & 0.494 & 0.505 & 0.711 & 0.731 & 0.738 & 0.688 & 0.464 & 0.348 \\
\hline $\mathrm{ACc} 03$ & 0.168 & 0.168 & 0.182 & 0.175 & 0.209 & 0.217 & 0.201 & 0.220 & 0.221 & 0.198 \\
\hline ACpt3 & 0.258 & 0.244 & 0.231 & 0.233 & 0.221 & 0.226 & 0.201 & 0.166 & 0.280 & 0.208 \\
\hline ACprof3 & 0.125 & 0.112 & 0.109 & 0.109 & 0.130 & 0.132 & 0.145 & 0.140 & 0.181 & 0.154 \\
\hline ACtsk3_R & 0.240 & 0.241 & 0.287 & 0.231 & 0.220 & 0.213 & 0.206 & 0.196 & 0.365 & 0.351 \\
\hline ACca $\bar{r} 3$ & 0.041 & 0.019 & 0.018 & -0.007 & -0.023 & -0.041 & -0.047 & -0.002 & -0.014 & 0.044 \\
\hline OCBI 1 & 0.059 & 0.069 & 0.061 & 0.070 & 0.053 & 0.058 & 0.023 & 0.028 & 0.075 & 0.047 \\
\hline OCBI2 & 0.121 & 0.118 & 0.100 & 0.108 & 0.113 & 0.114 & 0.092 & 0.103 & 0.115 & 0.019 \\
\hline OCBI3 & 0.064 & 0.056 & 0.081 & 0.041 & -0.074 & -0.061 & -0.086 & -0.071 & 0.147 & 0.042 \\
\hline OCBI 4 & 0.070 & 0.057 & 0.083 & 0.057 & 0.098 & 0.096 & 0.066 & 0.068 & 0.142 & 0.071 \\
\hline OCBI5 & 0.162 & 0.126 & 0.130 & 0.131 & 0.149 & 0.166 & 0.131 & 0.145 & 0.126 & 0.136 \\
\hline OCBI 6 & 0.087 & 0.063 & 0.077 & 0.062 & 0.045 & 0.059 & 0.034 & 0.034 & 0.064 & 0.067 \\
\hline OCBI 7 & 0.059 & 0.013 & 0.017 & 0.051 & 0.017 & 0.020 & -0.004 & 0.015 & 0.042 & -0.031 \\
\hline OCBI8 & 0.056 & -0.003 & 0.029 & 0.043 & -0.037 & -0.029 & -0.056 & -0.089 & 0.104 & -0.013 \\
\hline OCBO1 & 0.138 & 0.163 & 0.207 & 0.126 & 0.120 & 0.121 & 0.129 & 0.118 & 0.389 & 0.253 \\
\hline $\mathrm{OCBO} 2$ & 0.141 & 0.146 & 0.133 & 0.167 & 0.157 & 0.148 & 0.129 & 0.188 & 0.183 & 0.147 \\
\hline $\mathrm{OCBO} 3$ & 0.217 & 0.217 & 0.262 & 0.200 & 0.160 & 0.182 & 0.181 & 0.195 & 0.474 & 0.322 \\
\hline $\mathrm{OCBO} 4$ & 0.259 & 0.261 & 0.296 & 0.247 & 0.275 & 0.264 & 0.251 & 0.224 & 0.506 & 0.325 \\
\hline OCBO 5 & 0.047 & 0.014 & 0.007 & 0.022 & 0.039 & 0.033 & 0.030 & 0.013 & 0.168 & 0.085 \\
\hline OCBO 6 & 0.241 & 0.256 & 0.276 & 0.223 & 0.255 & 0.259 & 0.244 & 0.255 & 0.454 & 0.299 \\
\hline OCBO 7 & 0.044 & 0.040 & 0.033 & 0.053 & 0.016 & 0.012 & -0.022 & 0.038 & 0.192 & 0.080 \\
\hline ОСВО8 & 0.110 & 0.126 & 0.110 & 0.121 & 0.103 & 0.085 & 0.066 & 0.095 & 0.269 & 0.179 \\
\hline JP1 & 0.667 & 0.693 & 0.683 & 0.735 & 0.689 & 0.708 & 0.702 & 0.610 & 0.467 & 0.337 \\
\hline JP2 & 0.642 & 0.683 & 0.671 & 0.747 & 0.577 & 0.598 & 0.587 & 0.495 & 0.420 & 0.334 \\
\hline JP3 & 0.603 & 0.659 & 0.632 & 0.681 & 0.594 & 0.604 & 0.599 & 0.567 & 0.420 & 0.374 \\
\hline JP4 & 0.594 & 0.657 & 0.673 & 0.705 & 0.680 & 0.700 & 0.703 & 0.624 & 0.447 & 0.377 \\
\hline JP5 & 0.667 & 0.710 & 0.710 & 0.772 & 0.656 & 0.690 & 0.679 & 0.603 & 0.478 & 0.347 \\
\hline JP6 & 0.555 & 0.572 & 0.608 & 0.610 & 0.586 & 0.593 & 0.595 & 0.515 & 0.386 & 0.359 \\
\hline JP7 & 0.579 & 0.664 & 0.666 & 0.699 & 0.661 & 0.674 & 0.665 & 0.591 & 0.457 & 0.342 \\
\hline JInfo1 & 0.535 & 0.565 & 0.583 & 0.610 & 0.839 & 0.856 & 0.852 & 0.777 & 0.475 & 0.342 \\
\hline JInfo2 & 0.540 & 0.559 & 0.571 & 0.599 & 0.723 & 0.735 & 0.721 & 0.648 & 0.423 & 0.325 \\
\hline JInfo3 & 0.592 & 0.624 & 0.623 & 0.689 & 0.774 & 0.779 & 0.770 & 0.702 & 0.444 & 0.326 \\
\hline JInfo4 & 0.549 & 0.562 & 0.585 & 0.626 & 0.745 & 0.740 & 0.741 & 0.668 & 0.437 & 0.298 \\
\hline JInfo5 & 0.563 & 0.595 & 0.608 & 0.652 & 0.777 & 0.789 & 0.795 & 0.723 & 0.461 & 0.329 \\
\hline
\end{tabular}




\begin{tabular}{|c|c|c|c|c|c|c|c|c|c|c|}
\hline ACwrk1 & 0.030 & 0.021 & 0.020 & 0.056 & 0.075 & 0.071 & 0.071 & 0.040 & 0.116 & 0.037 \\
\hline ACwrk2 & 0.046 & 0.058 & 0.055 & 0.051 & -0.003 & 0.023 & 0.026 & -0.004 & 0.167 & 0.117 \\
\hline ACwrk3 & -0.016 & -0.036 & -0.046 & -0.032 & -0.035 & -0.036 & -0.048 & -0.055 & 0.008 & 0.030 \\
\hline \multicolumn{11}{|c|}{ Correlation Matrix } \\
\hline & POS3_Rec & POS 4 & POS5_Rec & POS 6 & POS7_Rec & POS8 & ACorg1 & ACsup1 & $\mathrm{ACCO} 1$ & ACpt 1 \\
\hline POS3 Rec & 1.000 & & & & & & & & & \\
\hline$\overline{\mathrm{P}} \mathrm{OS} 4$ & 0.600 & 1.000 & & & & & & & & \\
\hline POS5_Rec & 0.664 & 0.644 & 1.000 & & & & & & & \\
\hline Pos 6 & 0.594 & 0.825 & 0.634 & 1.000 & & & & & & \\
\hline POS7_Rec & 0.701 & 0.705 & 0.782 & 0.701 & 1.000 & & & & & \\
\hline POS8 & 0.571 & 0.749 & 0.638 & 0.767 & 0.662 & 1.000 & & & & \\
\hline ACorg1 & 0.508 & 0.659 & 0.562 & 0.633 & 0.585 & 0.611 & 1.000 & & & \\
\hline ACsup1 & 0.537 & 0.597 & 0.566 & 0.597 & 0.585 & 0.532 & 0.569 & 1.000 & & \\
\hline $\mathrm{ACCO} 1$ & 0.188 & 0.279 & 0.216 & 0.258 & 0.226 & 0.290 & 0.387 & 0.250 & 1.000 & \\
\hline ACpt1 & 0.100 & 0.172 & 0.087 & 0.066 & 0.068 & 0.130 & 0.273 & 0.122 & 0.393 & 1.000 \\
\hline ACprof1 & 0.334 & 0.305 & 0.261 & 0.249 & 0.273 & 0.279 & 0.500 & 0.297 & 0.428 & 0.539 \\
\hline ACtsk1 & 0.290 & 0.336 & 0.247 & 0.337 & 0.255 & 0.333 & 0.441 & 0.266 & 0.460 & 0.396 \\
\hline ACcar1 & 0.065 & 0.090 & 0.028 & 0.060 & 0.043 & 0.045 & 0.118 & 0.053 & 0.065 & 0.081 \\
\hline ACorg2 & 0.439 & 0.597 & 0.499 & 0.555 & 0.529 & 0.546 & 0.788 & 0.472 & 0.359 & 0.316 \\
\hline ACsup2 & 0.469 & 0.567 & 0.490 & 0.563 & 0.541 & 0.507 & 0.527 & 0.879 & 0.283 & 0.160 \\
\hline $\mathrm{ACcO} 2$ & 0.199 & 0.353 & 0.260 & 0.306 & 0.282 & 0.325 & 0.437 & 0.318 & 0.853 & 0.362 \\
\hline ACpt2 & 0.131 & 0.239 & 0.076 & 0.142 & 0.154 & 0.191 & 0.362 & 0.146 & 0.425 & 0.689 \\
\hline ACprof2 & 0.285 & 0.356 & 0.278 & 0.372 & 0.281 & 0.363 & 0.481 & 0.304 & 0.383 & 0.457 \\
\hline ACtsk2 & 0.307 & 0.340 & 0.268 & 0.364 & 0.301 & 0.323 & 0.471 & 0.274 & 0.414 & 0.386 \\
\hline ACcar2 & 0.047 & 0.077 & 0.067 & 0.080 & 0.067 & 0.083 & 0.105 & 0.099 & 0.000 & 0.010 \\
\hline ACorg3 R & 0.565 & 0.656 & 0.580 & 0.644 & 0.625 & 0.562 & 0.781 & 0.544 & 0.340 & 0.185 \\
\hline ACsup̄3 & 0.450 & 0.498 & 0.472 & 0.513 & 0.492 & 0.449 & 0.439 & 0.843 & 0.262 & 0.103 \\
\hline $\mathrm{ACCO} 3$ & 0.198 & 0.255 & 0.179 & 0.224 & 0.208 & 0.261 & 0.313 & 0.232 & 0.866 & 0.329 \\
\hline ACpt3 & 0.194 & 0.301 & 0.219 & 0.290 & 0.247 & 0.258 & 0.464 & 0.294 & 0.289 & 0.580 \\
\hline ACprof3 & 0.207 & 0.254 & 0.178 & 0.242 & 0.182 & 0.218 & 0.381 & 0.237 & 0.323 & 0.330 \\
\hline ACtsk3_R & 0.361 & 0.370 & 0.353 & 0.405 & 0.370 & 0.323 & 0.461 & 0.311 & 0.336 & 0.312 \\
\hline ACcar 3 & -0.044 & 0.051 & -0.008 & 0.032 & -0.010 & 0.058 & 0.039 & -0.058 & 0.125 & 0.233 \\
\hline OCBI1 & 0.057 & 0.055 & 0.011 & 0.022 & 0.022 & 0.029 & 0.105 & 0.030 & 0.163 & 0.319 \\
\hline OCBI2 & 0.048 & 0.081 & 0.049 & 0.067 & 0.063 & 0.103 & 0.198 & 0.095 & 0.281 & 0.345 \\
\hline OCBI3 & 0.010 & 0.114 & 0.037 & 0.094 & 0.067 & 0.111 & 0.159 & -0.011 & 0.172 & 0.278 \\
\hline OCBI 4 & 0.015 & 0.084 & 0.105 & 0.087 & 0.150 & 0.133 & 0.236 & 0.081 & 0.244 & 0.350 \\
\hline OCBI5 & 0.057 & 0.090 & 0.087 & 0.106 & 0.102 & 0.152 & 0.250 & 0.129 & 0.319 & 0.382 \\
\hline OCBI 6 & 0.017 & 0.050 & -0.003 & 0.031 & 0.036 & 0.053 & 0.147 & 0.042 & 0.192 & 0.248 \\
\hline OCBI 7 & -0.016 & -0.027 & -0.045 & -0.017 & -0.012 & 0.001 & 0.043 & -0.006 & 0.078 & 0.142 \\
\hline OCBI8 & -0.026 & 0.053 & -0.040 & 0.032 & 0.047 & 0.107 & 0.109 & 0.020 & 0.138 & 0.132 \\
\hline ОСВО1 & 0.247 & 0.341 & 0.280 & 0.315 & 0.300 & 0.378 & 0.399 & 0.204 & 0.201 & 0.160 \\
\hline $\mathrm{OCBO} 2$ & 0.149 & 0.211 & 0.157 & 0.189 & 0.177 & 0.257 & 0.291 & 0.173 & 0.148 & 0.300 \\
\hline OCBO3 & 0.360 & 0.460 & 0.377 & 0.455 & 0.454 & 0.437 & 0.631 & 0.353 & 0.226 & 0.203 \\
\hline OCBO4 & 0.395 & 0.485 & 0.424 & 0.465 & 0.443 & 0.461 & 0.690 & 0.352 & 0.240 & 0.292 \\
\hline OCBO5 & 0.076 & 0.134 & 0.106 & 0.107 & 0.127 & 0.182 & 0.177 & 0.045 & 0.172 & 0.130 \\
\hline осВо 6 & 0.361 & 0.439 & 0.399 & 0.437 & 0.440 & 0.429 & 0.663 & 0.373 & 0.220 & 0.243 \\
\hline OCBO 7 & 0.070 & 0.202 & 0.112 & 0.160 & 0.147 & 0.247 & 0.242 & 0.020 & 0.074 & 0.304 \\
\hline OCBO 8 & 0.160 & 0.299 & 0.211 & 0.265 & 0.231 & 0.295 & 0.370 & 0.126 & 0.121 & 0.337 \\
\hline JP1 & 0.444 & 0.440 & 0.480 & 0.473 & 0.487 & 0.467 & 0.392 & 0.631 & 0.270 & 0.101 \\
\hline JP2 & 0.423 & 0.407 & 0.444 & 0.443 & 0.430 & 0.457 & 0.360 & 0.559 & 0.259 & 0.154 \\
\hline JP3 & 0.437 & 0.420 & 0.436 & 0.463 & 0.477 & 0.439 & 0.384 & 0.589 & 0.219 & 0.107 \\
\hline JP4 & 0.445 & 0.451 & 0.465 & 0.492 & 0.467 & 0.430 & 0.397 & 0.636 & 0.246 & 0.098 \\
\hline JP5 & 0.450 & 0.489 & 0.503 & 0.514 & 0.487 & 0.485 & 0.419 & 0.642 & 0.278 & 0.094 \\
\hline JP6 & 0.395 & 0.377 & 0.433 & 0.400 & 0.444 & 0.402 & 0.342 & 0.544 & 0.267 & 0.019 \\
\hline JP7 & 0.429 & 0.453 & 0.455 & 0.482 & 0.463 & 0.457 & 0.463 & 0.618 & 0.234 & 0.112 \\
\hline JInfo1 & 0.453 & 0.475 & 0.466 & 0.479 & 0.494 & 0.439 & 0.442 & 0.751 & 0.267 & 0.086 \\
\hline JInfo2 & 0.403 & 0.430 & 0.412 & 0.448 & 0.433 & 0.413 & 0.382 & 0.656 & 0.262 & 0.024 \\
\hline JInfo3 & 0.410 & 0.448 & 0.432 & 0.473 & 0.452 & 0.421 & 0.368 & 0.714 & 0.252 & 0.090 \\
\hline JInfo4 & 0.396 & 0.418 & 0.419 & 0.450 & 0.462 & 0.413 & 0.369 & 0.674 & 0.222 & 0.061 \\
\hline JInfo5 & 0.451 & 0.431 & 0.462 & 0.466 & 0.477 & 0.432 & 0.398 & 0.715 & 0.223 & 0.041 \\
\hline ACwrk1 & 0.101 & 0.097 & 0.054 & 0.079 & 0.064 & 0.140 & 0.232 & 0.137 & 0.143 & 0.349 \\
\hline ACwrk2 & 0.157 & 0.140 & 0.100 & 0.177 & 0.114 & 0.198 & 0.293 & 0.138 & 0.189 & 0.294 \\
\hline ACwrk3 & 0.026 & 0.039 & -0.039 & 0.065 & -0.022 & 0.074 & 0.133 & 0.062 & 0.067 & 0.136 \\
\hline
\end{tabular}




\begin{tabular}{|c|c|c|c|c|c|c|c|c|c|c|}
\hline & ACprof1 & ACtsk1 & ACcar1 & ACorg2 & ACsup2 & $\mathrm{ACc} 02$ & ACpt2 & ACprof2 & ACtsk2 & ACcar2 \\
\hline ACprof1 & 1.000 & & & & & & & & & \\
\hline ACtsk1 & 0.549 & 1.000 & & & & & & & & \\
\hline ACcar 1 & 0.176 & 0.127 & 1.000 & & & & & & & \\
\hline ACorg 2 & 0.532 & 0.517 & 0.243 & 1.000 & & & & & & \\
\hline ACsup2 & 0.341 & 0.329 & 0.115 & 0.522 & 1.000 & & & & & \\
\hline $\mathrm{ACCO} 2$ & 0.382 & 0.479 & 0.112 & 0.442 & 0.390 & 1.000 & & & & \\
\hline ACpt2 & 0.551 & 0.441 & 0.123 & 0.391 & 0.207 & 0.389 & 1.000 & & & \\
\hline ACprof2 & 0.660 & 0.525 & 0.027 & 0.506 & 0.309 & 0.419 & 0.538 & 1.000 & & \\
\hline ACtsk2 & 0.529 & 0.779 & 0.002 & 0.485 & 0.299 & 0.435 & 0.532 & 0.642 & 1.000 & \\
\hline ACcar2 & 0.110 & 0.074 & 0.756 & 0.179 & 0.144 & 0.041 & 0.053 & -0.029 & 0.034 & 1.000 \\
\hline ACorg 3 R & 0.433 & 0.414 & 0.089 & 0.705 & 0.533 & 0.420 & 0.209 & 0.488 & 0.478 & 0.073 \\
\hline ACsup 3 & 0.288 & 0.253 & 0.100 & 0.419 & 0.894 & 0.321 & 0.140 & 0.293 & 0.256 & 0.124 \\
\hline $\mathrm{ACcO} 3$ & 0.339 & 0.462 & 0.070 & 0.327 & 0.274 & 0.854 & 0.367 & 0.327 & 0.403 & -0.013 \\
\hline ACpt3 & 0.461 & 0.298 & 0.121 & 0.440 & 0.291 & 0.288 & 0.579 & 0.458 & 0.437 & 0.113 \\
\hline ACprof3 & 0.612 & 0.394 & 0.048 & 0.391 & 0.277 & 0.351 & 0.432 & 0.739 & 0.493 & 0.008 \\
\hline ACtsk3_R & 0.415 & 0.586 & -0.023 & 0.408 & 0.297 & 0.355 & 0.356 & 0.488 & 0.660 & -0.018 \\
\hline ACcar 3 & 0.204 & 0.098 & 0.351 & 0.174 & -0.017 & 0.113 & 0.300 & 0.155 & 0.118 & 0.273 \\
\hline OCBI 1 & 0.175 & 0.101 & 0.095 & 0.142 & -0.005 & 0.179 & 0.300 & 0.180 & 0.177 & 0.051 \\
\hline OCBI2 & 0.214 & 0.147 & 0.156 & 0.218 & 0.075 & 0.284 & 0.317 & 0.204 & 0.200 & 0.029 \\
\hline OCBI3 & 0.081 & 0.108 & 0.078 & 0.170 & -0.006 & 0.200 & 0.244 & 0.102 & 0.148 & 0.060 \\
\hline OCBI 4 & 0.230 & 0.223 & 0.109 & 0.258 & 0.109 & 0.175 & 0.306 & 0.223 & 0.268 & 0.079 \\
\hline OCBI5 & 0.321 & 0.250 & 0.164 & 0.270 & 0.168 & 0.297 & 0.326 & 0.220 & 0.245 & 0.087 \\
\hline OCBI 6 & 0.105 & 0.071 & 0.216 & 0.193 & 0.058 & 0.202 & 0.168 & 0.106 & 0.102 & 0.173 \\
\hline OCBI 7 & -0.008 & 0.107 & 0.131 & 0.077 & -0.028 & 0.126 & 0.086 & 0.028 & 0.079 & 0.081 \\
\hline OCBI 8 & 0.023 & 0.134 & 0.087 & 0.143 & 0.016 & 0.171 & 0.126 & 0.110 & 0.171 & 0.087 \\
\hline OCBO1 & 0.266 & 0.262 & 0.175 & 0.438 & 0.199 & 0.230 & 0.184 & 0.310 & 0.274 & 0.234 \\
\hline ОСВО2 & 0.324 & 0.224 & 0.110 & 0.362 & 0.153 & 0.121 & 0.247 & 0.259 & 0.175 & 0.077 \\
\hline OCBO3 & 0.434 & 0.309 & 0.084 & 0.617 & 0.334 & 0.234 & 0.211 & 0.414 & 0.353 & 0.143 \\
\hline OCBO 4 & 0.490 & 0.314 & 0.137 & 0.659 & 0.347 & 0.282 & 0.368 & 0.431 & 0.351 & 0.109 \\
\hline OCBO5 & 0.213 & 0.158 & 0.259 & 0.217 & 0.063 & 0.176 & 0.319 & 0.169 & 0.174 & 0.192 \\
\hline
\end{tabular}

\begin{tabular}{|c|c|c|c|c|c|c|c|c|c|c|}
\hline ОСВО 6 & 0.503 & 0.333 & 0.151 & 0.682 & 0.387 & 0.295 & 0.309 & 0.428 & 0.386 & 0.142 \\
\hline OCBO 7 & 0.246 & 0.175 & 0.121 & 0.307 & 0.026 & 0.071 & 0.317 & 0.186 & 0.199 & 0.104 \\
\hline ОСВО8 & 0.317 & 0.241 & 0.076 & 0.448 & 0.126 & 0.169 & 0.305 & 0.288 & 0.261 & 0.086 \\
\hline JP1 & 0.277 & 0.233 & 0.016 & 0.344 & 0.584 & 0.288 & 0.110 & 0.256 & 0.271 & 0.022 \\
\hline JP2 & 0.311 & 0.267 & 0.051 & 0.319 & 0.494 & 0.276 & 0.090 & 0.251 & 0.251 & 0.103 \\
\hline JP3 & 0.244 & 0.220 & 0.049 & 0.325 & 0.540 & 0.255 & 0.064 & 0.254 & 0.207 & 0.069 \\
\hline JP4 & 0.266 & 0.228 & 0.034 & 0.334 & 0.564 & 0.260 & 0.073 & 0.263 & 0.243 & 0.014 \\
\hline JP5 & 0.257 & 0.246 & 0.056 & 0.350 & 0.590 & 0.300 & 0.100 & 0.258 & 0.227 & 0.040 \\
\hline JP6 & 0.195 & 0.230 & -0.028 & 0.270 & 0.496 & 0.300 & 0.095 & 0.203 & 0.232 & 0.040 \\
\hline JP7 & 0.269 & 0.212 & 0.021 & 0.369 & 0.577 & 0.249 & 0.132 & 0.231 & 0.229 & 0.025 \\
\hline JInfo1 & 0.228 & 0.244 & 0.030 & 0.367 & 0.747 & 0.297 & 0.141 & 0.226 & 0.225 & 0.015 \\
\hline JInfo2 & 0.208 & 0.237 & 0.026 & 0.317 & 0.636 & 0.272 & 0.135 & 0.176 & 0.227 & 0.044 \\
\hline JInfo3 & 0.221 & 0.236 & 0.064 & 0.340 & 0.693 & 0.311 & 0.119 & 0.215 & 0.218 & 0.069 \\
\hline JInfo 4 & 0.195 & 0.211 & 0.041 & 0.310 & 0.671 & 0.266 & 0.091 & 0.202 & 0.214 & 0.078 \\
\hline JInfo5 & 0.208 & 0.213 & 0.067 & 0.339 & 0.719 & 0.300 & 0.085 & 0.191 & 0.200 & 0.089 \\
\hline ACwrk1 & 0.506 & 0.362 & 0.248 & 0.413 & 0.216 & 0.216 & 0.414 & 0.359 & 0.322 & 0.230 \\
\hline ACwrk2 & 0.400 & 0.379 & 0.246 & 0.433 & 0.201 & 0.253 & 0.369 & 0.444 & 0.375 & 0.245 \\
\hline ACwrk3 & 0.317 & 0.205 & 0.277 & 0.257 & 0.157 & 0.084 & 0.258 & 0.346 & 0.306 & 0.332 \\
\hline & crelation & atrix & & & & & & & & \\
\hline & ACorg3_R & ACsup 3 & $\mathrm{ACco} 3$ & ACpt3 & ACprof3 & ACtsk3_R & ACcar 3 & OCBI1 & OCBI2 & OCBI3 \\
\hline ACorg $3 \mathrm{R}$ & 1.000 & -1 & & & & & & & & \\
\hline ACsup 3 & 0.470 & 1.000 & & & & & & & & \\
\hline $\mathrm{ACcO} 3$ & 0.314 & 0.279 & 1.000 & & & & & & & \\
\hline ACpt 3 & 0.378 & 0.242 & 0.243 & 1.000 & & & & & & \\
\hline ACprof3 & 0.373 & 0.230 & 0.304 & 0.401 & 1.000 & & & & & \\
\hline ACtsk3 R & 0.564 & 0.288 & 0.307 & 0.365 & 0.389 & 1.000 & & & & \\
\hline ACcar 3 & 0.052 & 0.037 & 0.114 & 0.253 & 0.123 & 0.049 & 1.000 & & & \\
\hline OCBI1 & 0.078 & -0.002 & 0.189 & 0.221 & 0.146 & 0.121 & 0.163 & 1.000 & & \\
\hline OCBI2 & 0.138 & 0.066 & 0.250 & 0.264 & 0.204 & 0.166 & 0.185 & 0.691 & 1.000 & \\
\hline OCBI3 & 0.096 & -0.035 & 0.153 & 0.155 & 0.062 & 0.099 & 0.112 & 0.475 & 0.466 & 1.000 \\
\hline OCBI 4 & 0.172 & 0.122 & 0.229 & 0.327 & 0.217 & 0.188 & 0.244 & 0.472 & 0.544 & 0.374 \\
\hline OCBI5 & 0.208 & 0.142 & 0.337 & 0.272 & 0.244 & 0.160 & 0.156 & 0.456 & 0.621 & 0.318 \\
\hline
\end{tabular}




\begin{tabular}{|c|c|c|c|c|c|c|c|c|c|c|}
\hline OCBI 6 & 0.043 & 0.054 & 0.231 & 0.192 & 0.117 & 0.028 & 0.118 & 0.496 & 0.705 & 0.477 \\
\hline OCBI 7 & 0.021 & -0.011 & 0.150 & 0.094 & 0.003 & 0.005 & 0.136 & 0.488 & 0.488 & 0.387 \\
\hline OCBI8 & 0.041 & 0.017 & 0.131 & 0.090 & 0.131 & 0.047 & 0.037 & 0.349 & 0.396 & 0.391 \\
\hline ОСВ01 & 0.377 & 0.130 & 0.189 & 0.256 & 0.242 & 0.243 & 0.166 & 0.186 & 0.255 & 0.253 \\
\hline $\mathrm{OCBO} 2$ & 0.223 & 0.152 & 0.106 & 0.263 & 0.206 & 0.178 & 0.228 & 0.221 & 0.299 & 0.148 \\
\hline OCBO3 & 0.571 & 0.311 & 0.222 & 0.398 & 0.348 & 0.346 & 0.085 & 0.187 & 0.275 & 0.225 \\
\hline OCBO 4 & 0.633 & 0.298 & 0.226 & 0.430 & 0.345 & 0.356 & 0.092 & 0.235 & 0.322 & 0.198 \\
\hline OCBO5 & 0.135 & 0.079 & 0.159 & 0.196 & 0.148 & 0.162 & 0.238 & 0.225 & 0.290 & 0.136 \\
\hline OCBO6 & 0.612 & 0.358 & 0.221 & 0.370 & 0.399 & 0.373 & 0.132 & 0.196 & 0.248 & 0.210 \\
\hline OCBO 7 & 0.160 & 0.048 & 0.075 & 0.270 & 0.151 & 0.152 & 0.217 & 0.255 & 0.298 & 0.250 \\
\hline OCBO8 & 0.303 & 0.131 & 0.135 & 0.320 & 0.201 & 0.217 & 0.188 & 0.267 & 0.332 & 0.265 \\
\hline JP1 & 0.420 & 0.562 & 0.231 & 0.245 & 0.165 & 0.290 & 0.006 & 0.059 & 0.110 & 0.013 \\
\hline JP2 & 0.403 & 0.506 & 0.203 & 0.229 & 0.159 & 0.276 & 0.038 & 0.055 & 0.120 & 0.032 \\
\hline JP3 & 0.392 & 0.538 & 0.184 & 0.199 & 0.119 & 0.232 & 0.006 & 0.012 & 0.095 & -0.016 \\
\hline JP4 & 0.411 & 0.560 & 0.230 & 0.247 & 0.147 & 0.275 & -0.002 & 0.025 & 0.084 & -0.025 \\
\hline JP5 & 0.444 & 0.581 & 0.255 & 0.219 & 0.145 & 0.269 & 0.013 & 0.044 & 0.065 & -0.009 \\
\hline JP6 & 0.363 & 0.496 & 0.220 & 0.139 & 0.134 & 0.221 & -0.040 & 0.045 & 0.113 & 0.041 \\
\hline JP7 & 0.447 & 0.548 & 0.200 & 0.219 & 0.150 & 0.221 & 0.013 & 0.062 & 0.127 & 0.041 \\
\hline JInfo1 & 0.431 & 0.718 & 0.238 & 0.218 & 0.162 & 0.273 & -0.040 & 0.064 & 0.112 & -0.067 \\
\hline JInfo2 & 0.371 & 0.612 & 0.264 & 0.124 & 0.137 & 0.219 & -0.061 & 0.074 & 0.130 & 0.046 \\
\hline JInfo3 & 0.382 & 0.662 & 0.256 & 0.188 & 0.133 & 0.236 & -0.029 & 0.076 & 0.116 & 0.021 \\
\hline JInfo4 & 0.383 & 0.677 & 0.180 & 0.174 & 0.099 & 0.229 & -0.086 & 0.028 & 0.029 & -0.020 \\
\hline JInfo5 & 0.396 & 0.697 & 0.202 & 0.149 & 0.130 & 0.209 & -0.038 & 0.050 & 0.044 & -0.034 \\
\hline ACwrk1 & 0.187 & 0.134 & 0.183 & 0.288 & 0.363 & 0.166 & 0.227 & 0.117 & 0.129 & 0.102 \\
\hline ACwrk2 & 0.280 & 0.172 & 0.196 & 0.270 & 0.403 & 0.263 & 0.303 & 0.121 & 0.096 & 0.102 \\
\hline ACwrk3 & 0.068 & 0.119 & 0.094 & 0.158 & 0.437 & 0.151 & 0.240 & 0.128 & 0.169 & 0.171 \\
\hline \multicolumn{11}{|c|}{ Correlation Matrix } \\
\hline & OCBI 4 & OCBI5 & OCBI 6 & OCBI 7 & OCBI8 & OCBO1 & $\mathrm{OCBO} 2$ & ОСВО3 & OCBO 4 & OCBO5 \\
\hline OCBI 4 & 1.000 & & & & & & & & & \\
\hline OCBI5 & 0.703 & 1.000 & & & & & & & & \\
\hline OCBI 6 & 0.543 & 0.619 & 1.000 & & & & & & & \\
\hline OCBI 7 & 0.463 & 0.472 & 0.571 & 1.000 & & & & & & \\
\hline
\end{tabular}

\begin{tabular}{|c|c|c|c|c|c|c|c|c|c|c|}
\hline OCBI8 & 0.314 & 0.368 & 0.525 & 0.535 & 1.000 & & & & & \\
\hline OCBO1 & 0.239 & 0.257 & 0.230 & 0.120 & 0.256 & 1.000 & & & & \\
\hline OCBO2 & 0.246 & 0.346 & 0.183 & 0.189 & 0.132 & 0.481 & 1.000 & & & \\
\hline OCBO3 & 0.316 & 0.348 & 0.242 & 0.174 & 0.164 & 0.512 & 0.469 & 1.000 & & \\
\hline OCBO 4 & 0.350 & 0.350 & 0.231 & 0.191 & 0.152 & 0.470 & 0.481 & 0.734 & 1.000 & \\
\hline OCBO5 & 0.313 & 0.258 & 0.225 & 0.227 & 0.233 & 0.370 & 0.431 & 0.323 & 0.412 & 1.000 \\
\hline OCBO6 & 0.329 & 0.326 & 0.220 & 0.168 & 0.191 & 0.466 & 0.418 & 0.715 & 0.767 & 0.438 \\
\hline OCBO 7 & 0.356 & 0.329 & 0.281 & 0.236 & 0.195 & 0.345 & 0.453 & 0.435 & 0.464 & 0.528 \\
\hline ОСВО8 & 0.387 & 0.328 & 0.293 & 0.249 & 0.220 & 0.439 & 0.527 & 0.569 & 0.604 & 0.524 \\
\hline JP1 & 0.092 & 0.163 & 0.082 & 0.075 & 0.036 & 0.151 & 0.223 & 0.262 & 0.318 & 0.124 \\
\hline JP2 & 0.060 & 0.143 & 0.052 & 0.050 & 0.054 & 0.170 & 0.195 & 0.245 & 0.274 & 0.122 \\
\hline JP3 & 0.050 & 0.142 & 0.078 & 0.073 & 0.038 & 0.154 & 0.182 & 0.230 & 0.250 & 0.050 \\
\hline JP4 & 0.041 & 0.135 & 0.064 & 0.057 & -0.018 & 0.150 & 0.119 & 0.243 & 0.273 & -0.003 \\
\hline JP5 & 0.071 & 0.166 & 0.042 & 0.071 & 0.023 & 0.125 & 0.167 & 0.265 & 0.283 & 0.050 \\
\hline JP6 & 0.086 & 0.181 & 0.075 & 0.018 & 0.033 & 0.122 & 0.121 & 0.188 & 0.235 & 0.067 \\
\hline JP7 & 0.077 & 0.205 & 0.082 & 0.052 & 0.001 & 0.169 & 0.182 & 0.278 & 0.331 & 0.048 \\
\hline JInfo1 & 0.130 & 0.199 & 0.052 & 0.031 & -0.029 & 0.153 & 0.168 & 0.245 & 0.272 & 0.071 \\
\hline JInfo2 & 0.090 & 0.199 & 0.112 & 0.067 & 0.073 & 0.116 & 0.113 & 0.227 & 0.215 & 0.072 \\
\hline JInfo3 & 0.071 & 0.191 & 0.083 & 0.067 & 0.020 & 0.121 & 0.129 & 0.220 & 0.234 & 0.057 \\
\hline JInfo4 & 0.071 & 0.142 & 0.024 & 0.042 & 0.018 & 0.119 & 0.132 & 0.211 & 0.236 & 0.043 \\
\hline JInfo5 & 0.062 & 0.148 & 0.063 & 0.090 & 0.030 & 0.134 & 0.116 & 0.209 & 0.252 & 0.063 \\
\hline ACwrk1 & 0.125 & 0.197 & 0.181 & 0.083 & 0.126 & 0.212 & 0.200 & 0.174 & 0.255 & 0.144 \\
\hline ACwrk2 & 0.126 & 0.132 & 0.069 & 0.026 & 0.070 & 0.179 & 0.132 & 0.217 & 0.266 & 0.149 \\
\hline ACwrk3 & 0.160 & 0.149 & 0.178 & 0.054 & 0.214 & 0.182 & 0.081 & 0.193 & 0.139 & 0.115 \\
\hline
\end{tabular}

Correlation Matrix

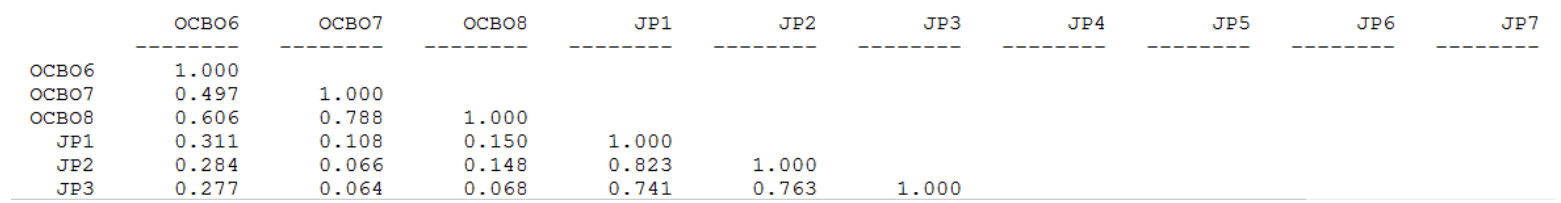




\begin{tabular}{|c|c|c|c|c|c|c|c|c|c|c|}
\hline JP4 & 0.276 & -0.001 & 0.073 & 0.745 & 0.721 & 0.774 & 1.000 & & & \\
\hline JP5 & 0.291 & 0.050 & 0.091 & 0.780 & 0.779 & 0.800 & 0.869 & 1.000 & & \\
\hline JP 6 & 0.237 & 0.034 & 0.057 & 0.700 & 0.710 & 0.655 & 0.674 & 0.690 & 1.000 & \\
\hline JP7 & 0.337 & 0.075 & 0.083 & 0.721 & 0.684 & 0.697 & 0.794 & 0.797 & 0.759 & 1.000 \\
\hline JInfo1 & 0.270 & 0.045 & 0.107 & 0.716 & 0.611 & 0.621 & 0.712 & 0.717 & 0.569 & 0.655 \\
\hline JInfo2 & 0.239 & 0.024 & 0.091 & 0.715 & 0.655 & 0.658 & 0.659 & 0.691 & 0.583 & 0.651 \\
\hline JInfo3 & 0.246 & 0.019 & 0.073 & 0.742 & 0.693 & 0.732 & 0.740 & 0.772 & 0.619 & 0.706 \\
\hline JInfo 4 & 0.254 & 0.016 & 0.054 & 0.674 & 0.635 & 0.685 & 0.675 & 0.718 & 0.586 & 0.641 \\
\hline JInfo5 & 0.275 & 0.034 & 0.083 & 0.720 & 0.661 & 0.676 & 0.717 & 0.741 & 0.600 & 0.673 \\
\hline ACwrk1 & 0.249 & 0.194 & 0.264 & 0.046 & 0.095 & 0.040 & 0.042 & 0.031 & -0.001 & 0.036 \\
\hline ACwrk2 & 0.303 & 0.112 & 0.206 & 0.076 & 0.142 & 0.112 & 0.044 & 0.074 & 0.037 & 0.077 \\
\hline ACwrk3 & 0.233 & 0.124 & 0.147 & -0.037 & -0.003 & -0.003 & -0.024 & -0.031 & -0.047 & -0.016 \\
\hline \multicolumn{11}{|c|}{ Correlation Matrix } \\
\hline & JInfo1 & JInfo2 & JInfo3 & JInfo4 & JInfo5 & ACwrk1 & ACwrk2 & ACwrk3 & & \\
\hline JInfo1 & 1.000 & & & & & & & & & \\
\hline JInfo2 & 0.802 & 1.000 & & & & & & & & \\
\hline JInfo3 & 0.825 & 0.894 & 1.000 & & & & & & & \\
\hline JInfo 4 & 0.798 & 0.799 & 0.849 & 1.000 & & & & & & \\
\hline JInfo5 & 0.837 & 0.815 & 0.883 & 0.882 & 1.000 & & & & & \\
\hline ACwrk1 & 0.087 & 0.054 & 0.087 & 0.048 & 0.074 & 1.000 & & & & \\
\hline ACwrk2 & 0.066 & 0.062 & 0.065 & 0.047 & 0.058 & 0.573 & 1.000 & & & \\
\hline ACwrk3 & 0.012 & 0.035 & 0.021 & -0.013 & -0.014 & 0.523 & 0.508 & 1.000 & & \\
\hline
\end{tabular}

Total Variance $=68.000$ Generalized Variance $=0.285900 \mathrm{D}-33$

Largest Eigenvalue $=22.563$ Smallest Eigenvalue $=0.016$

Condition Number $=37.522$

WARNING: The Condition Number indicates severe multicollinearity.

one or more variables may be redundant. 


\section{Appendix GG. SEM Measurement Equations}

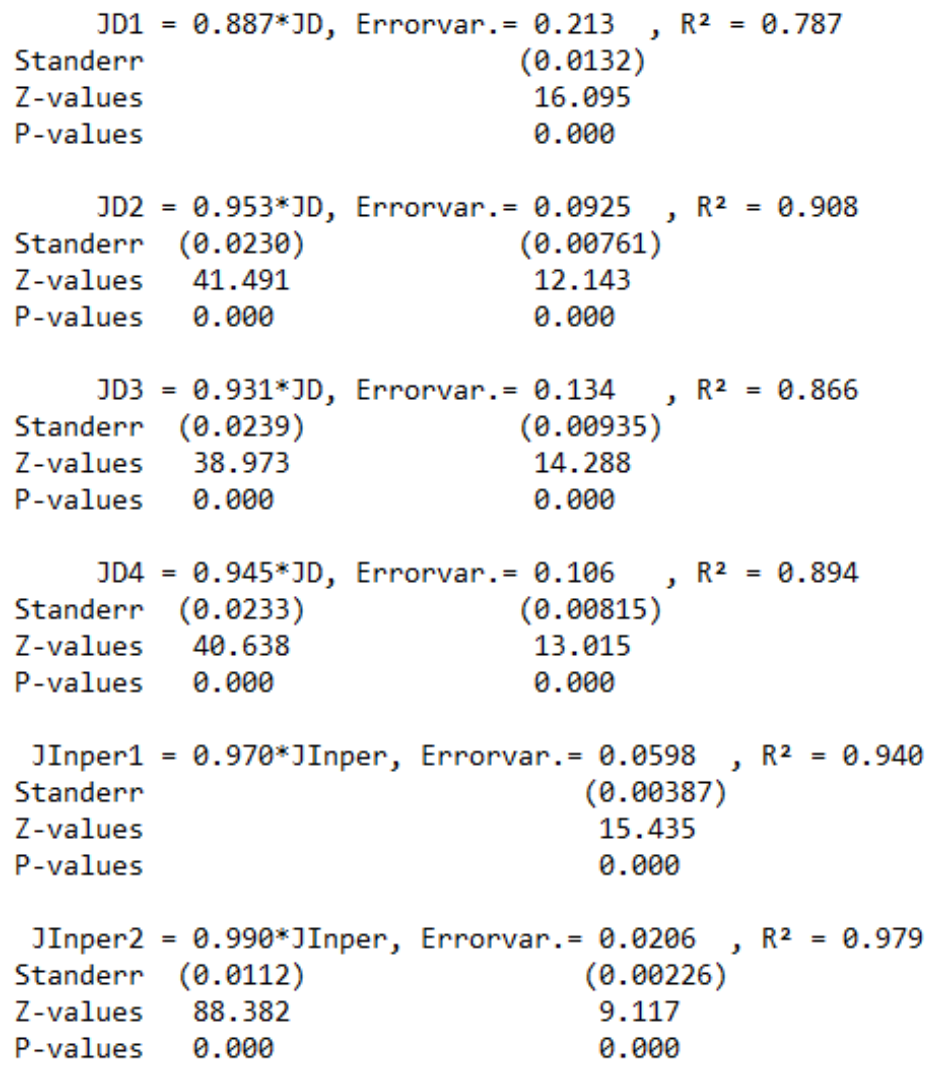




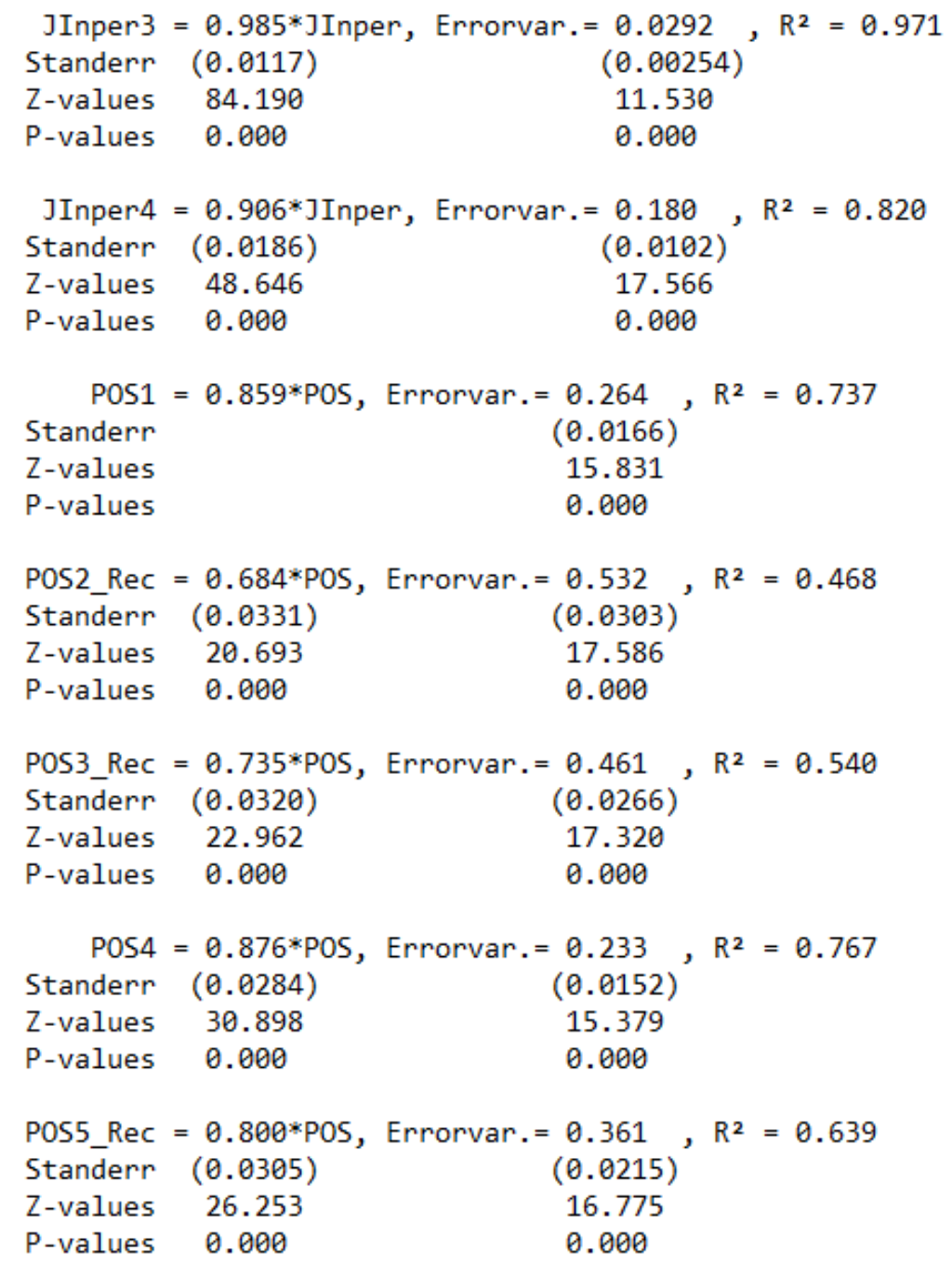




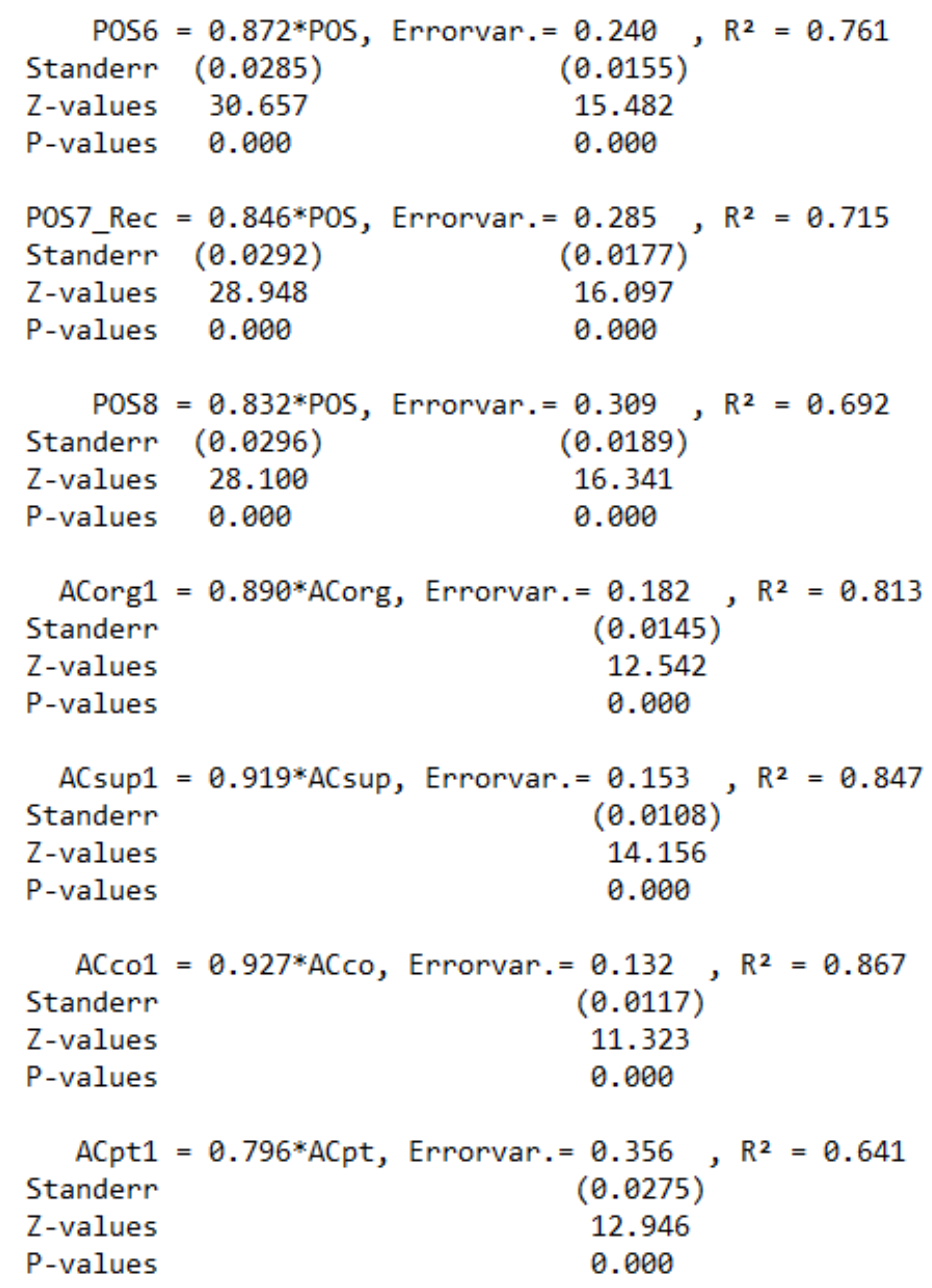




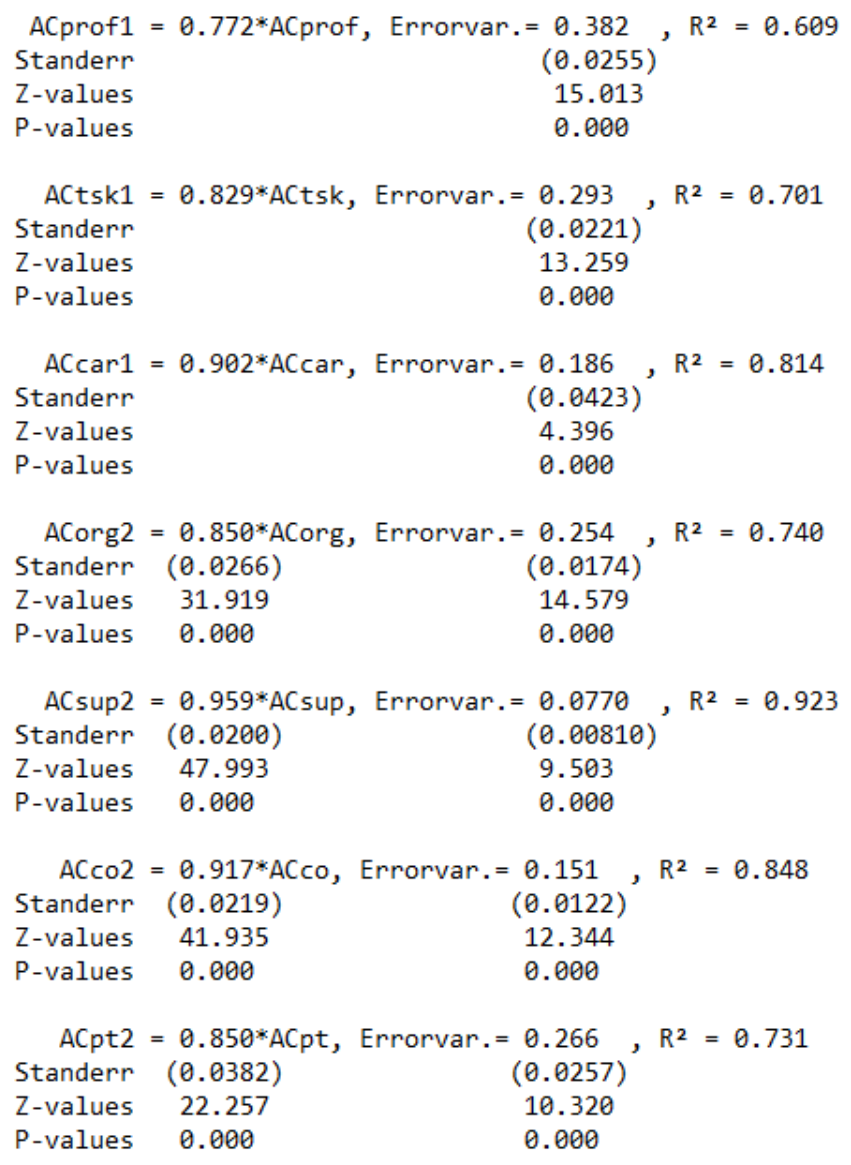




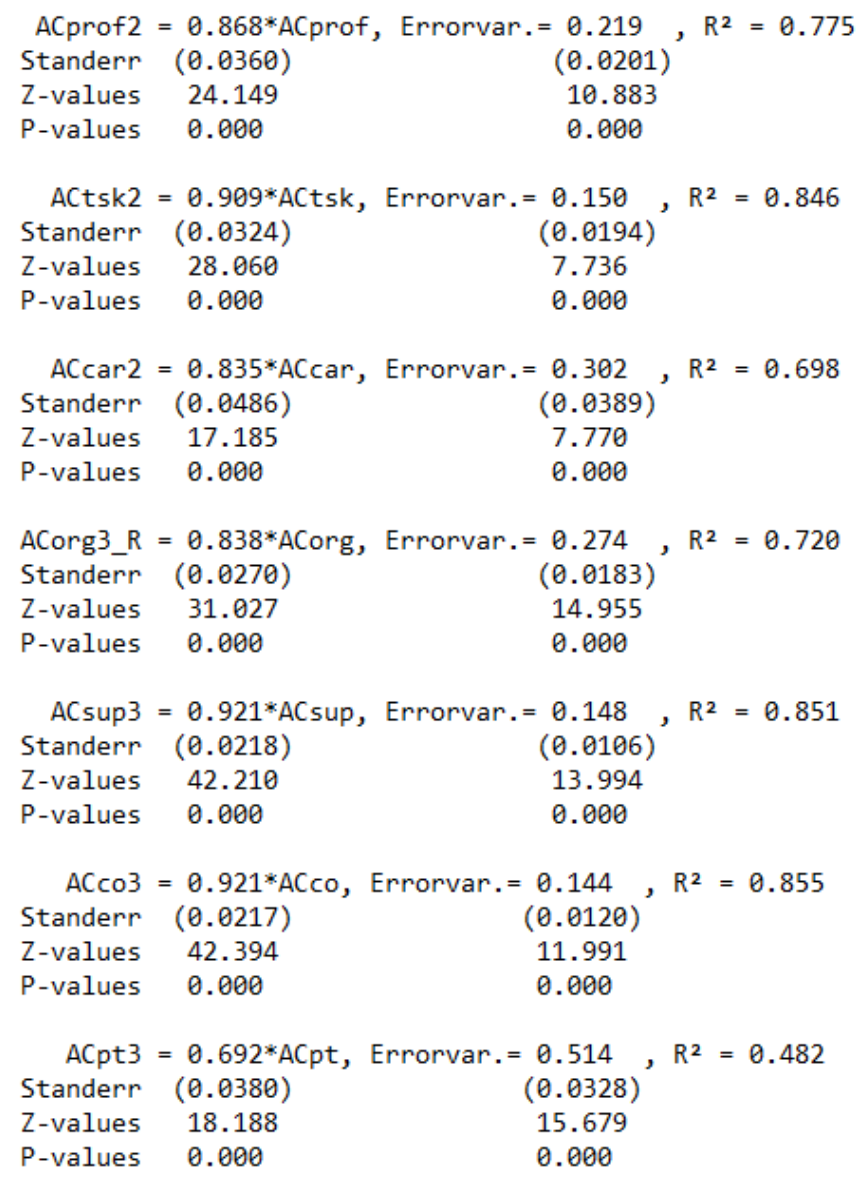




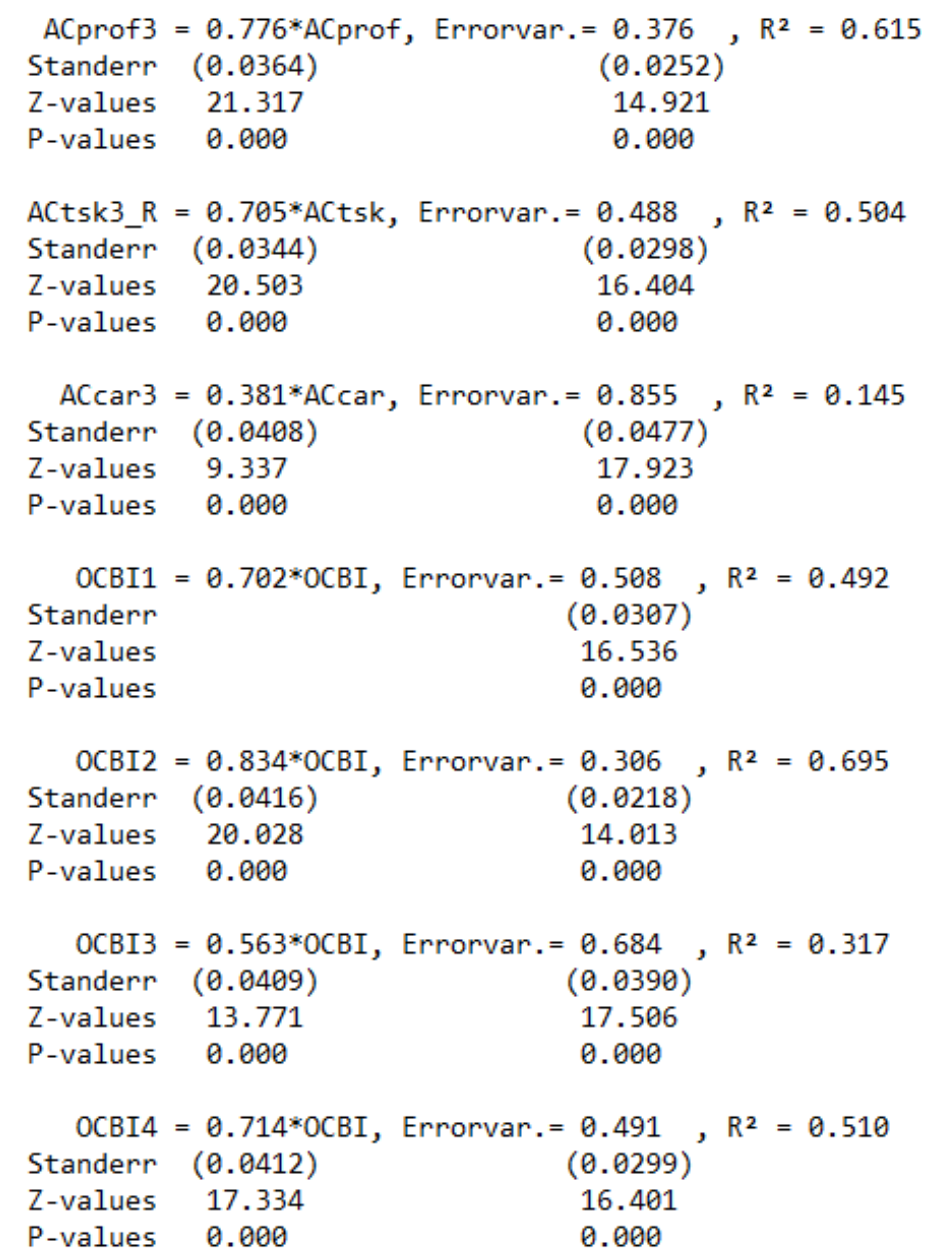




\begin{tabular}{|c|c|c|c|}
\hline OCBI5 & $=0.763 * O C B I$, & Errorvar. $=0.419$, & $R^{2}=0.581$ \\
\hline Stander $r$ & $(0.0413)$ & $(0.0266)$ & \\
\hline Z-values & 18.447 & 15.728 & \\
\hline P-values & 0.000 & 0.000 & \\
\hline OCBI6 & $=0.810 * 0 C B I$, & Errorvar. $=0.345$, & $R^{2}=0.656$ \\
\hline Standerr & $(0.0415)$ & $(0.0234)$ & \\
\hline Z-values & 19.511 & 14.726 & \\
\hline P-values & 0.000 & 0.000 & \\
\hline OCBI7 & $=0.657 * 0 C B I$, & Errorvar. $=0.569$, & $R^{2}=0.431$ \\
\hline Standerr & $(0.0411)$ & $(0.0336)$ & \\
\hline Z-values & 15.996 & 16.943 & \\
\hline P-values & 0.000 & 0.000 & \\
\hline OCBI8 & $=0.549 * 0 C B I$, & Errorvar. $=0.699$, & $R^{2}=0.301$ \\
\hline Stander $r$ & $(0.0409)$ & $(0.0398)$ & \\
\hline Z-values & 13.431 & 17.569 & \\
\hline P-values & 0.000 & 0.000 & \\
\hline OCB01 & $=0.584 * 0 C B 0$, & Errorvar. $=0.653$, & $R^{2}=0.343$ \\
\hline Standerr & & $(0.0370)$ & \\
\hline Z-values & & 17.636 & \\
\hline P-values & & 0.000 & \\
\hline OCBO2 & $=0.568 * 0 C B O$, & Errorvar. $=0.671$, & $R^{2}=0.325$ \\
\hline Standerr & $(0.0455)$ & $(0.0379)$ & \\
\hline Z-values & 12.496 & 17.693 & \\
\hline P-values & 0.000 & 0.000 & \\
\hline OCBO3 & $=0.815 * 0 C B O$, & Errorvar. $=0.324$, & $\mathrm{R}^{2}=0.672$ \\
\hline Stander $r$ & $(0.0507)$ & $(0.0210)$ & \\
\hline Z-values & 16.054 & 15.404 & \\
\hline P-values & 0.000 & 0.000 & \\
\hline
\end{tabular}




\begin{tabular}{|c|c|c|c|}
\hline OCBO4 & $=0.865 * 0 C B O$, & Errorvar. $=0.238$, &,$R^{2}=0.759$ \\
\hline Standerr & $(0.0520)$ & $(0.0173)$ & \\
\hline Z-values & 16.631 & 13.793 & \\
\hline P-values & 0.000 & 0.000 & \\
\hline OCB05 & $=0.503 * 0 C B 0$, & Errorvar. $=0.742$, &,$R^{2}=0.254$ \\
\hline Standerr & $(0.0443)$ & $(0.0415)$ & \\
\hline Z-values & 11.347 & 17.896 & \\
\hline P-values & 0.000 & 0.000 & \\
\hline OCB06 & $=0.850 * 0 C B O$, & Errorvar. $=0.264$, &,$R^{2}=0.732$ \\
\hline Standerr & $(0.0516)$ & $(0.0183)$ & \\
\hline Z-values & 16.467 & 14.384 & \\
\hline P-values & 0.000 & 0.000 & \\
\hline OCB07 & $=0.605 * 0 C B 0$, & Errorvar.$=0.627$, &,$R^{2}=0.369$ \\
\hline Standerr & $(0.0462)$ & $(0.0357)$ & \\
\hline Z-values & 13.101 & 17.546 & \\
\hline P-values & 0.000 & 0.000 & \\
\hline OCB08 & $=0.731 * O C B O$, & Errorvar $=0.456$, & , $R^{2}=0.539$ \\
\hline Standerr & $(0.0488)$ & $(0.0273)$ & \\
\hline Z-values & 14.974 & 16.695 & \\
\hline P-values & 0.000 & 0.000 & \\
\hline JP1 & $=0.873 * J \mathrm{P}, \mathrm{E}$ & Errorvar. $=0.239, R$ & $R^{2}=0.761$ \\
\hline Standerr & $(0.0305)$ & $(0.0147)$ & \\
\hline Z-values & 28.585 & 16.259 & \\
\hline P-values & 0.000 & 0.000 & \\
\hline JP2 & $=0.856 * \mathrm{JP}, \mathrm{E}$ & Errorvar. $=0.267$, & $R^{2}=0.733$ \\
\hline Standerr & $(0.0309)$ & $(0.0161)$ & \\
\hline Z-values & 27.707 & 16.561 & \\
\hline P-values & 0.000 & 0.000 & \\
\hline
\end{tabular}




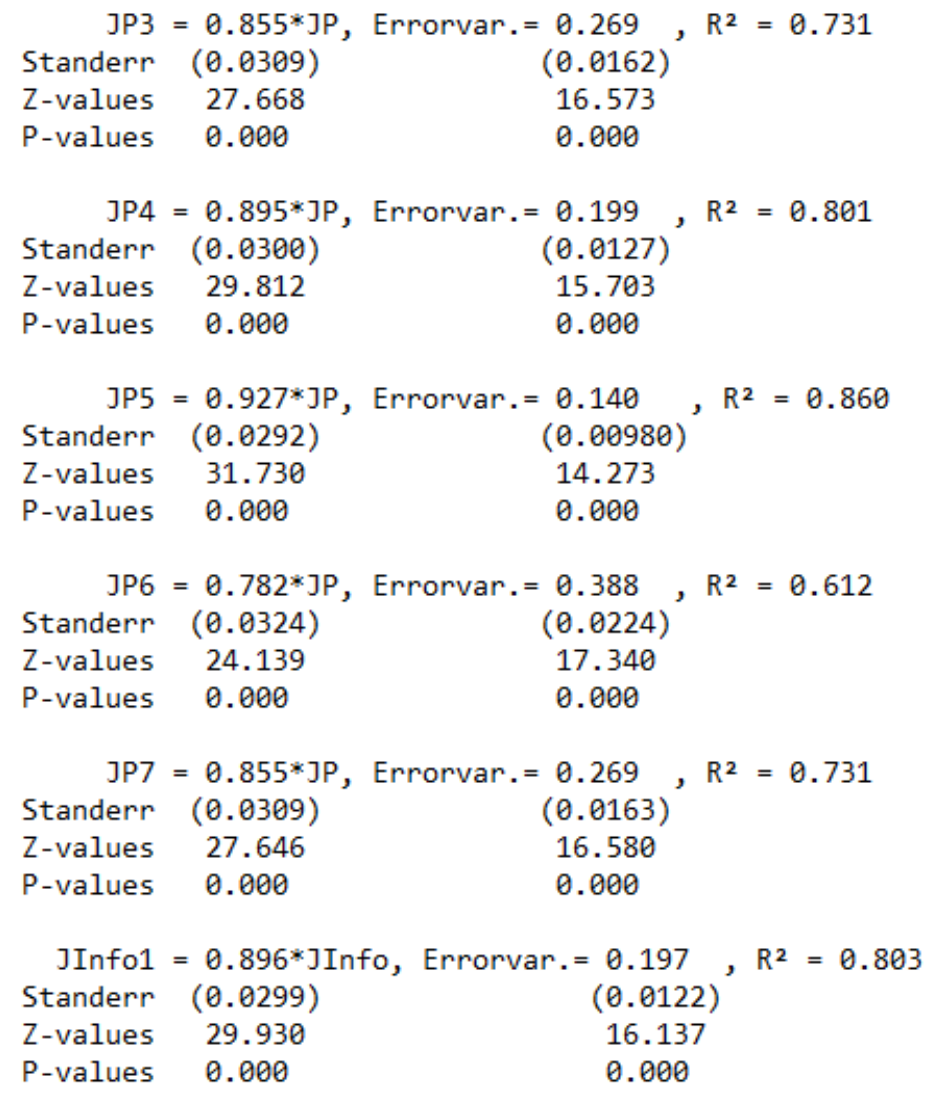




\begin{tabular}{|c|c|c|c|}
\hline $\begin{array}{r}\text { JInfo2 } \\
\text { Standerr }\end{array}$ & $\begin{array}{c}=0.897 * \text { JInfo, } \\
(0.0299)\end{array}$ & $\begin{aligned} \text { Errorvar. }= & 0.196 \\
& (0.0121)\end{aligned}$, & $\mathrm{R}^{2}=0.804$ \\
\hline Z-values & 29.980 & 16.114 & \\
\hline P-values & 0.000 & 0.000 & \\
\hline JInfo3 & $=0.947 *$ JInfo, & Errorvar. $=0.103$ &,$R^{2}=0.897$ \\
\hline Stander $r$ & $(0.0287)$ & $(0.00762)$ & \\
\hline Z-values & 33.001 & 13.539 & \\
\hline P-values & 0.000 & 0.000 & \\
\hline JInfo4 & $=0.905^{*} \mathrm{JInfo}$, & Errorvar. $=0.181$, & $\mathrm{R}^{2}=0.819$ \\
\hline Stander $r$ & $(0.0297)$ & $(0.0114)$ & \\
\hline Z-values & 30.432 & 15.889 & \\
\hline P-values & 0.000 & 0.000 & \\
\hline JInfo5 & $=0.937 * J \operatorname{Info}$, & Errorvar. $=0.122$ &,$R^{2}=0.878$ \\
\hline Standerr & $(0.0289)$ & $(0.00850)$ & \\
\hline Z-values & 32.366 & 14.378 & \\
\hline P-values & 0.000 & 0.000 & \\
\hline ACwrk1 & $=0.750 * A C w r k$, & Errorvar. $=0.438$, & $R^{2}=0.562$ \\
\hline Standerr & $(0.0362)$ & $(0.0335)$ & \\
\hline Z-values & 20.712 & 13.069 & \\
\hline P-values & 0.000 & 0.000 & \\
\hline ACwrk2 & $=0.750 * A C w r k$, & Errorvar. $=0.438$, & $R^{2}=0.562$ \\
\hline Standerr & $(0.0362)$ & $(0.0335)$ & \\
\hline Z-values & 20.704 & 13.076 & \\
\hline P-values & 0.000 & 0.000 & \\
\hline ACwrk3 & $=0.694 * A C w r k$, & Errorvar. $=0.518$, & $R^{2}=0.482$ \\
\hline Standerr & $(0.0370)$ & $(0.0356)$ & \\
\hline Z-values & 18.766 & 14.568 & \\
\hline P-values & 0.000 & 0.000 & \\
\hline
\end{tabular}




\section{Appendix HH. SEM Structural Equations}
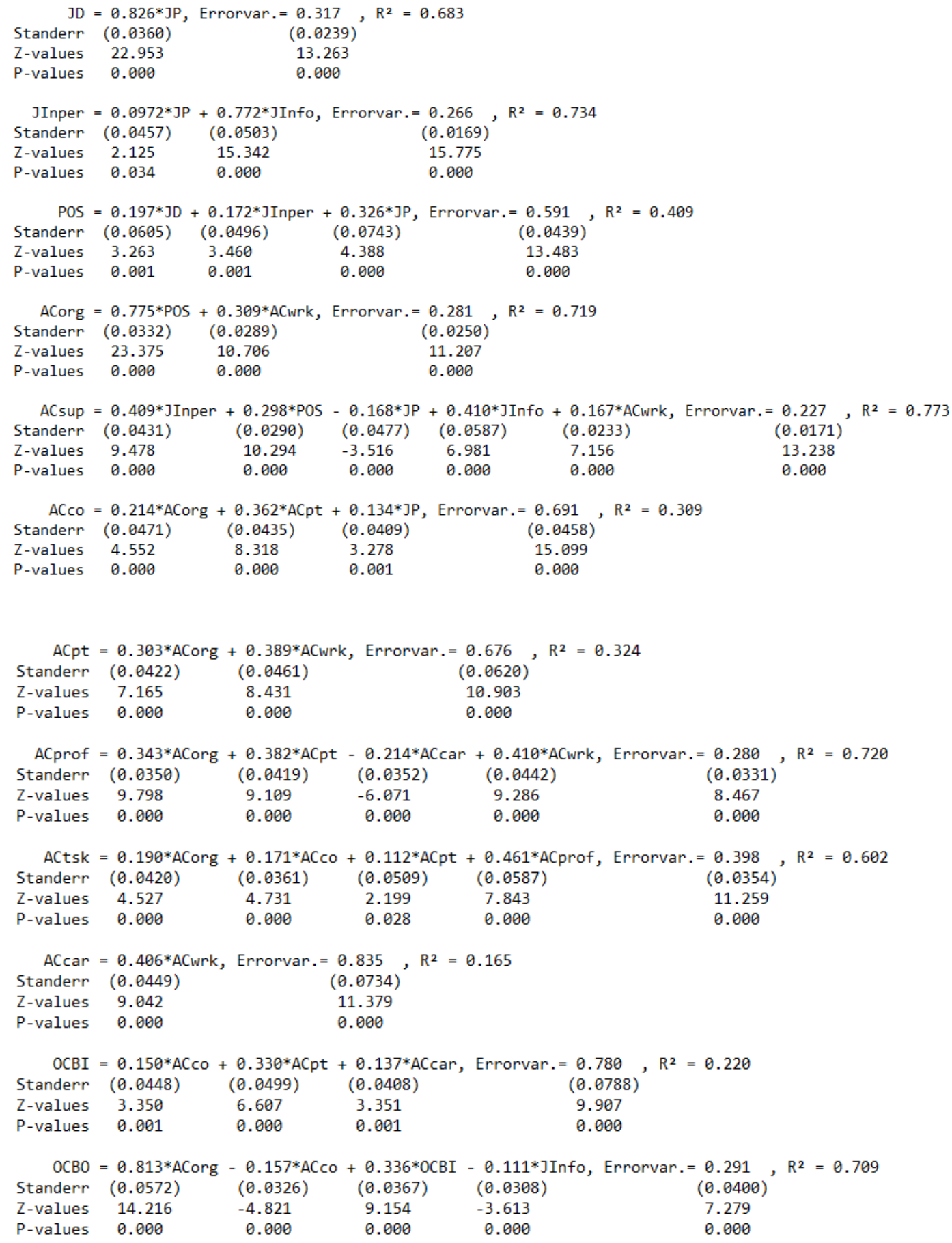


\section{Appendix II. Path Analysis Correlation Matrix}

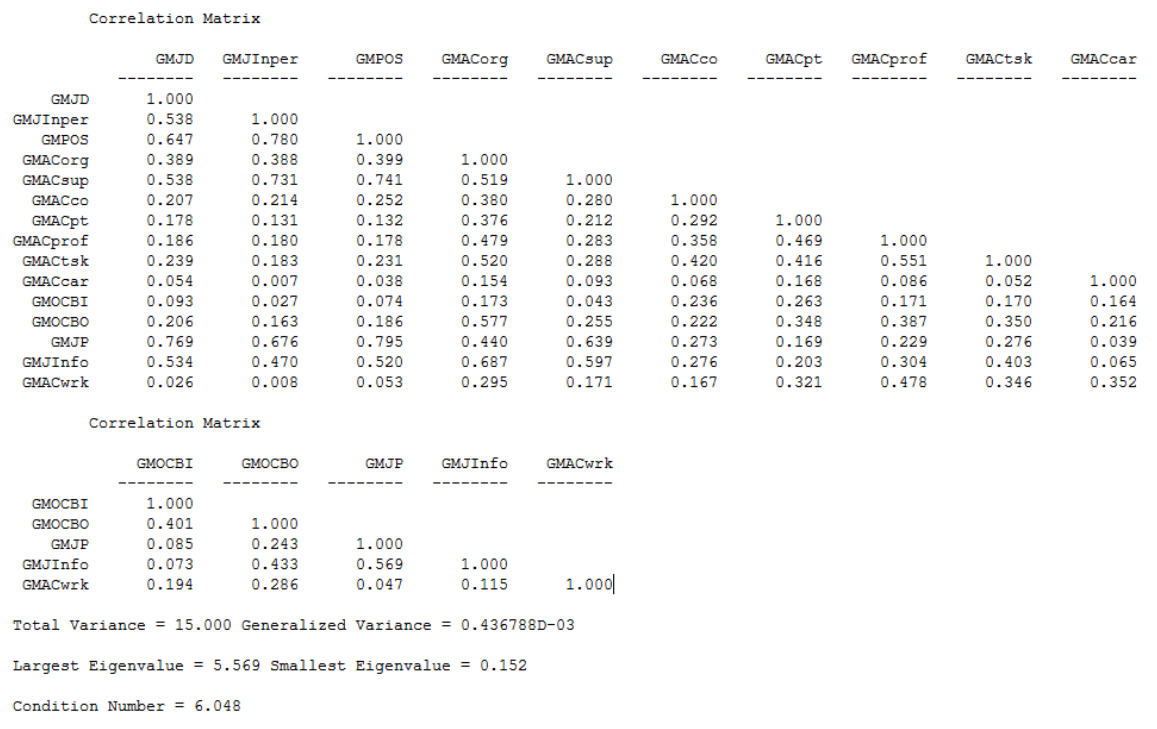




\section{Appendix JJ. Path Analysis Structural Equations}

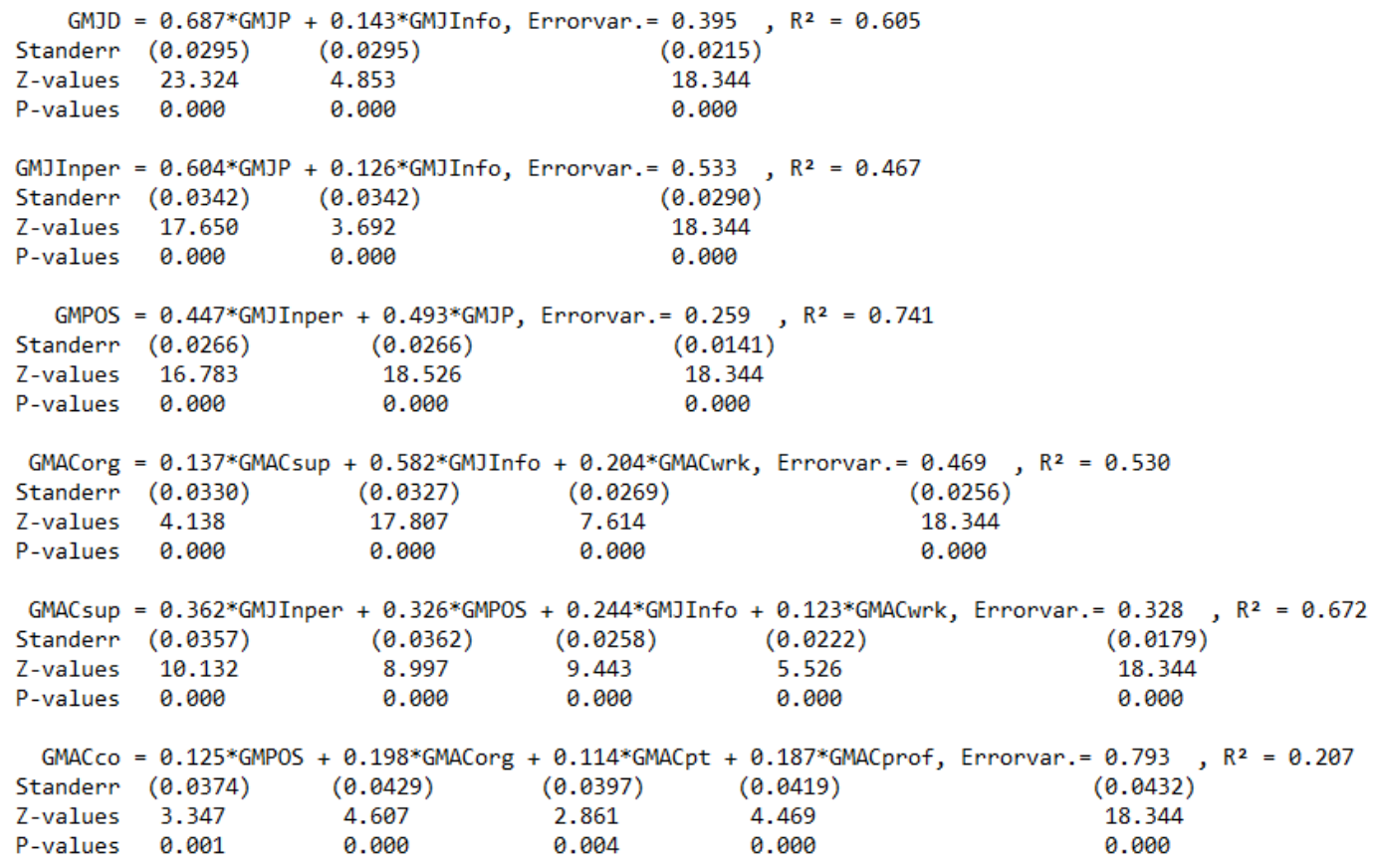




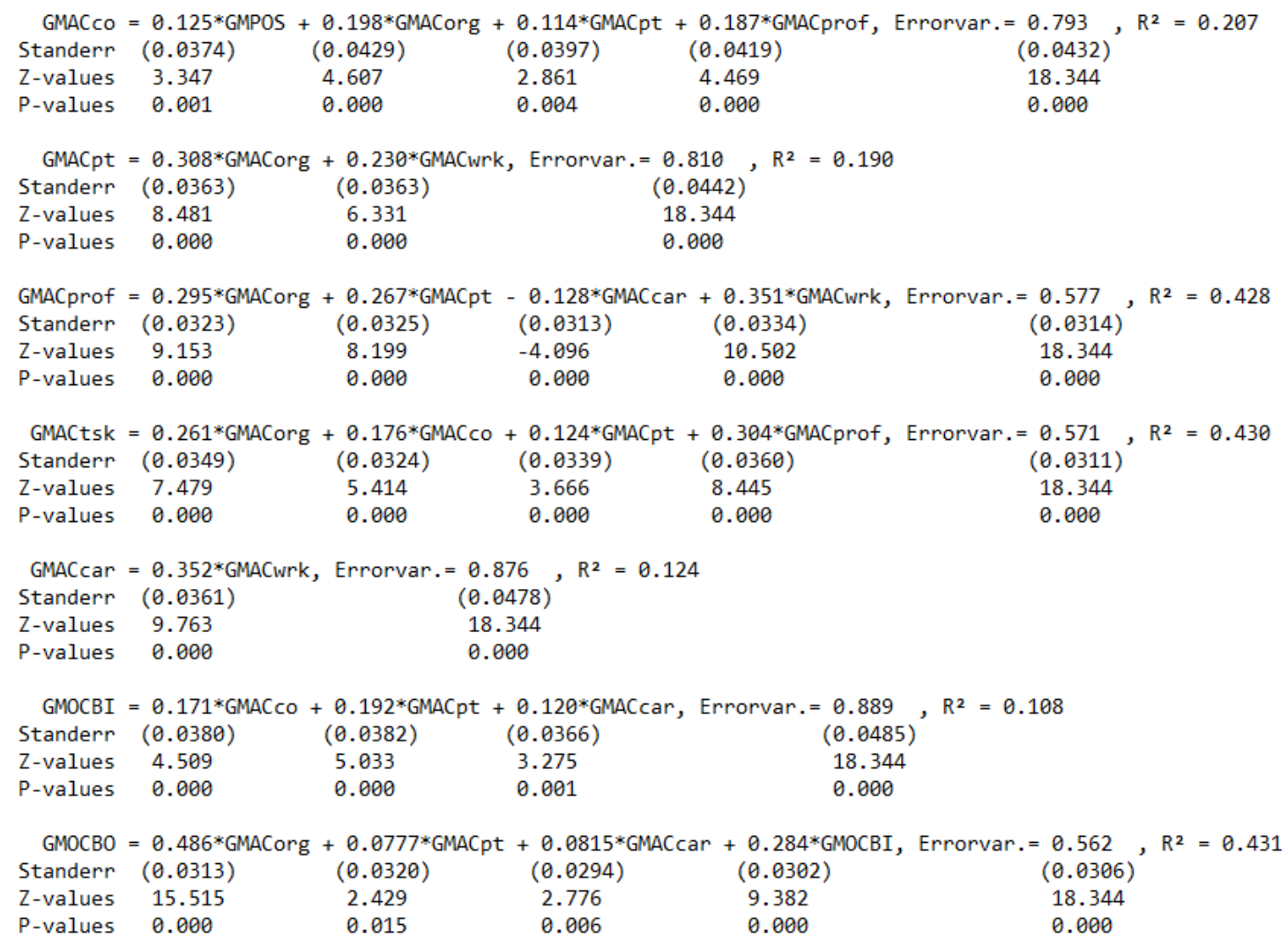




\section{Copyright Acknowledgements}

None Required 